Pacific Northwest

National Laboratory

Operated by Battelle for the

U.S. Department of Energy

\title{
Vadose Zone Hydrogeology Data Package for the 2004 Composite Analysis
}

\author{
G. V. Last \\ E. J. Freeman \\ K. J. Cantrell \\ M. J. Fayer
}

\author{
G. W. Gee \\ W. E. Nichols \\ B. N. Bjornstad \\ D. G. Horton
}

July 2004

Prepared for the U.S. Department of Energy under Contract DE-AC06-76RL01830 


\title{
DISCLAIMER
}

This report was prepared as an account of work sponsored by an agency of the United States Government. Neither the United States Government nor any agency thereof, nor Battelle Memorial Institute, nor any of their employees, makes any warranty, express or implied, or assumes any legal liability or responsibility for the accuracy, completeness, or usefulness of any information, apparatus, product, or process disclosed, or represents that its use would not infringe privately owned rights. Reference herein to any specific commercial product, process, or service by trade name, trademark, manufacturer, or otherwise does not necessarily constitute or imply its endorsement, recommendation, or favoring by the United States Government or any agency thereof, or Battelle Memorial Institute. The views and opinions of authors expressed herein do not necessarily state or reflect those of the United States Government or any agency thereof.

\author{
PACIFIC NORTHWEST NATIONAL LABORATORY \\ operated by \\ BATTELLE \\ for the \\ UNITED STATES DEPARTMENT OF ENERGY \\ under Contract DE-AC06-76RL01830
}

Printed in the United States of America

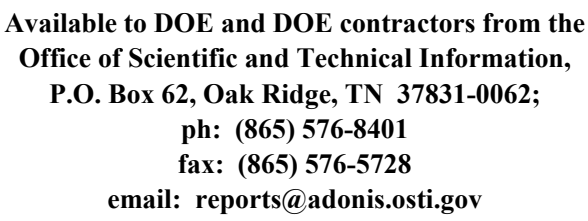

Available to the public from the National Technical Information Service, U.S. Department of Commerce, 5285 Port Royal Rd., Springfield, VA 22161

ph: (800) 553-6847

fax: (703) 605-6900

email: orders@ntis.fedworld.gov

online ordering: http://www.ntis.gov/ordering.htm 


\section{Vadose Zone Hydrogeology Data Package for the 2004 Composite Analysis}
G. V. Last
G. W. Gee
E. J. Freeman
W. E. Nichols
K. J. Cantrell
B. N. Bjornstad
M. J. Fayer
D. G. Horton

July 2004

Prepared for

the U.S. Department of Energy

under Contract DE-AC06-76RL01830

Pacific Northwest National Laboratory

Richland, Washington 99352 


\section{Executive Summary}

The U.S. Department of Energy is required to conduct a composite analysis of active and planned low-level radioactive waste disposal facilities associated with the Hanford Site. The original composite analysis was completed in 1998; however, it must be revised in 2004 to address a number of revisions to waste site information, updated performance assessments and environmental impact statements (EIS), changes in inventory estimates, and changes in the definition of offsite receptors.

This data package documents the technical basis for selecting physical and geochemical parameters and input values that will be used in vadose zone modeling for the 2004 Composite Analysis. This work was conducted as part of the Characterization of Systems Task of the Groundwater Remediation Project (formerly the Groundwater Protection Program) managed by Fluor Hanford, Inc., Richland, Washington.

This data package describes the geologic framework, the physical, hydrologic, and contaminant transport properties of the geologic materials, and deep drainage (i.e., recharge) estimates, building on the general framework developed for the initial assessment conducted using the System Assessment Capability (SAC). The general approach for this work was to update and provide incremental improvements over the previous SAC data package completed in 2001. As with the previous SAC data package, much of the data and interpreted information were extracted from existing documents and databases. Every attempt was made to provide traceability back to the original source(s) of the data or interpretations.

Kincaid et al. (2004) identified 1,046 waste sites from the Waste Information Data System (WIDS) sites and several existing and future storage sites for inclusion in the 2004 Composite Analysis, with analyses to be conducted on a site-by-site basis whenever inventory and release data permit. ${ }^{\text {(a) }}$ The complexity of this assessment, together with the lack of detailed characterization data and/or understanding of some of the less dominant fine-scale fate and transport processes necessitates simplification of the site features, release events, and the contaminant fate and transport processes to those factors considered most dominant. The dominant factors affecting transport of contaminants through the vadose zone include: 1) waste inventory and release estimates, 2) estimates of deep drainage (recharge), 3) the hydrogeologic profiles and properties of the vadose zone affecting aqueous phase advection and dispersion, and 4) estimates of geochemical reactions (e.g., sorption) affecting the retardation of contaminants. The last three of these data types are addressed by this data package. The first one, waste inventory and release estimates, is addressed in the inventory and release model data packages.

The 2004 Composite Analysis will, in general, use a one-dimensional vadose zone model, configured to account for lateral spreading, and in selected cases, conditioned against multi-dimensional model results (Kincaid et al. 2004). Waste sites were grouped into a number of geographic areas assumed to

(a) Originally 974 of 2,730 Waste Information Data System (WIDS) sites were identified for inclusion in the 2004 Composite Analysis. Further work identified 48 more waste sites bringing the total to 1,022. Subsequent reviews identified an additional 24 sites that have been included, many of which account for offsite transfers of waste and nuclear material. This brings the total to 1,046 . 
have similar hydrogeologic structure and properties. Hydrogeologic units were identified and their thickness ranges specified for each of these hydrogeologic provinces. To account for uncertainty in the model parameters, a stochastic distribution was developed for each process model parameter for each hydrogeologic unit.

The vadose zone hydrostratigraphic profiles and hydrogeochemical property distributions for the 2004 Composite Analysis are represented by 26 generalized one-dimensional vertical columns representing 17 general geographic areas and 9 site-specific locations. Each hydrostratigraphic profile (template) was configured with the hydraulic and geochemical parameters necessary to simulate the flow and transport through the vadose zone using the Subsurface Transport Over Multiple Phases (STOMP) code. As many as five variations of a single hydrostratigraphic template were incorporated to more accurately represent the depth of waste release, the thickness of the vadose zone beneath the point of release, and variations in contaminant distribution coefficients ( $K_{d}$ values) associated with different waste chemistry designations. Each template consists of a few major hydrostratigraphic units that are horizontally layered with constant thicknesses, and are homogeneous and isotropic. Hydraulic and geochemical parameters for each hydrostratigraphic unit are represented by stochastic distributions to facilitate sensitivity and uncertainty analyses.

This data package is a compilation of the available data to support a composite analysis of Hanford's impact. As site characterization is completed at waste sites and as investigations into contaminant behavior are completed, the uncertainty in this information will be reduced and, as a result, the uncertainty in future estimates of impact will be reduced. 


\section{Acknowledgments}

The authors would like to acknowledge Thomas W. Fogwell and the Groundwater Remediation Project managed by Fluor Hanford, Inc. for supporting this work. We would like to thank Raziuddin Khaleel (Fluor Federal Services), and Charles T. Kincaid, Christopher J. Murray, Stephen P. Reidel, and Robert W. Bryce for their technical reviews. The authors would also like to thank Anderson L. Ward for his technical support throughout the completion of this work, and Christopher A. Newbill for preparation of the site location map. We would also like to thank Launa F. Morasch for her technical editorial support, and Lila M. Andor and the rest of the Publication Design team for their support in producing this document. 


\section{Contents}

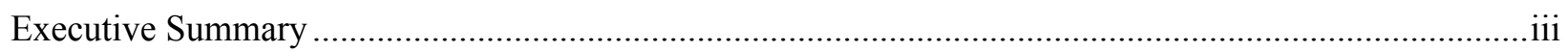

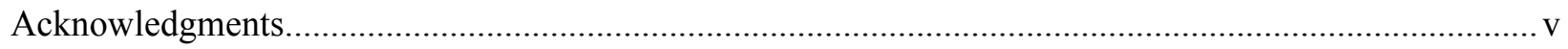

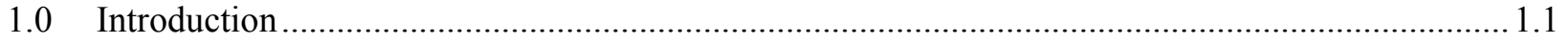

1.1 Purpose 1.1

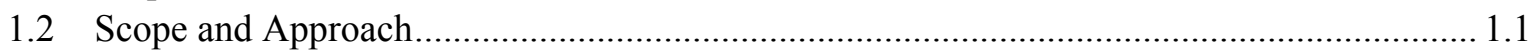

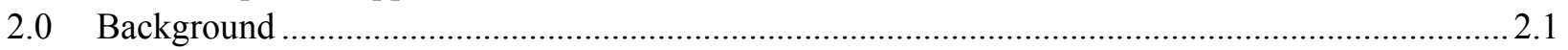

2.1 Conceptual Model of the Hanford Site Vadose Zone......................................................... 2.1

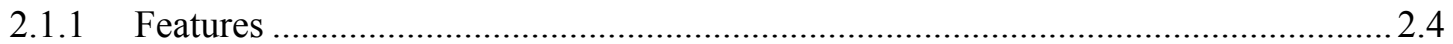

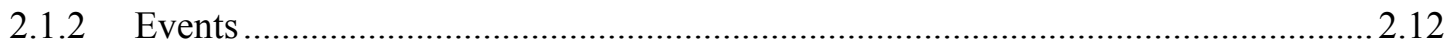

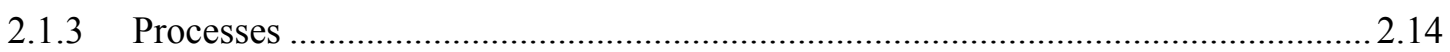

2.2 Uncertainty and Unresolved Technical Issues ………………………………………. 2.18

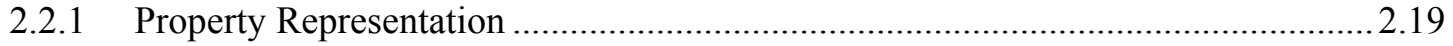

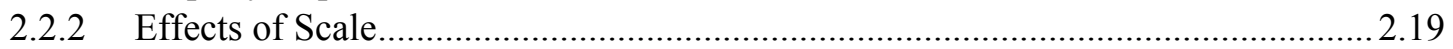

2.2.3 Spatial and Temporal Resolution of Site Data ………………………………........2.20

2.2.4 Preferential Flow ........................................................................................ 2.2.

2.2.5 Temperature and Density Effects ..................................................................2.2.22

2.2.6 Geochemical Processes ....................................................................................2.2.23

2.3 Technical Basis and Approach for Vadose Zone Modeling ............................................. 2.24

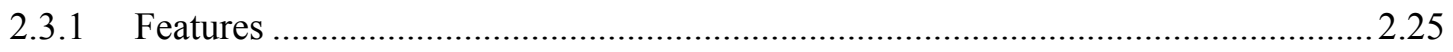

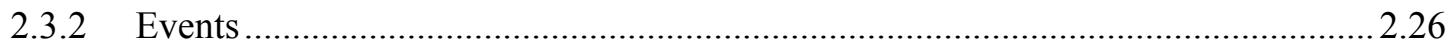

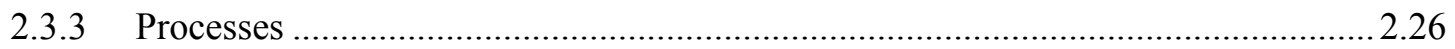

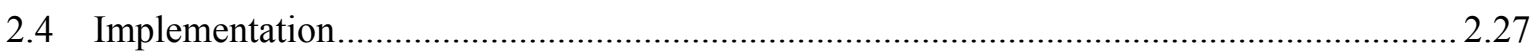

2.4.1 Hydrogeologic Profiles.....................................................................................2.2.

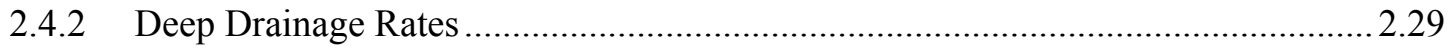

2.4.3 Geochemical Reactions .................................................................................... 2.2.30

2.4.4 Interaction with the Inventory, Release, and Groundwater Modules .......................2.30

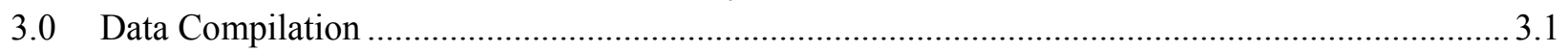

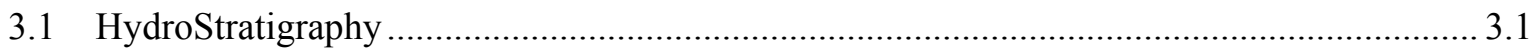

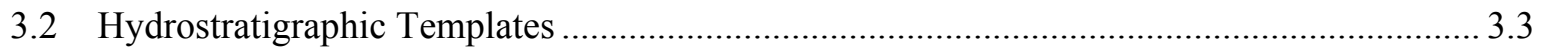

3.2.1 Waste Site Type (reflecting the depth of waste injection)..........................................3.3

3.2.2 Geographic and Site-Specific Areas Designations..................................................... 3.4

3.2.3 Waste Chemistry Groupings (for assigning $K_{d}$ ranges) ............................................. 3.4

3.2.4 Hydrostratigraphic Template Designations............................................................. 3.8

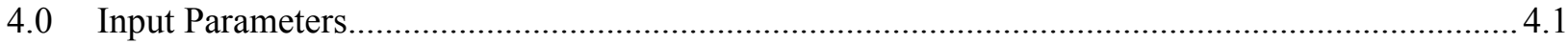

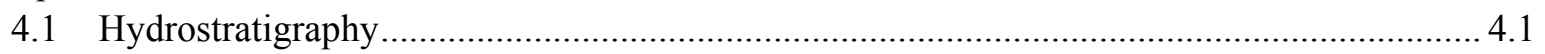

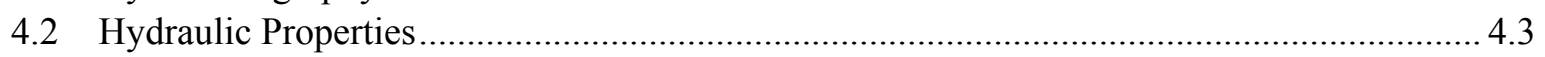

4.2.1 Site-Wide Hydraulic Property Distributions …………………………………....... 4.7

4.2.2 Site-Specific Hydraulic Property Distributions......................................................... 4.9

4.2.3 Application to Vadose Zone Simulations.................................................................. 4.9

4.2.4 Transport Parameters.......................................................................................... 4.11 


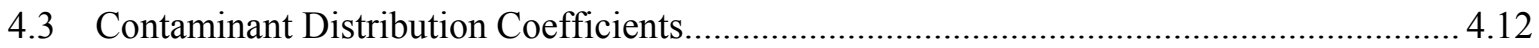

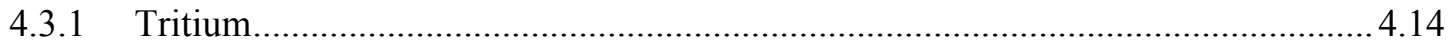

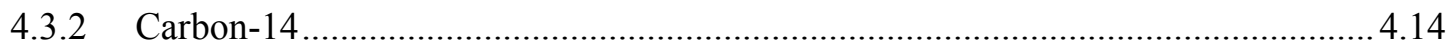

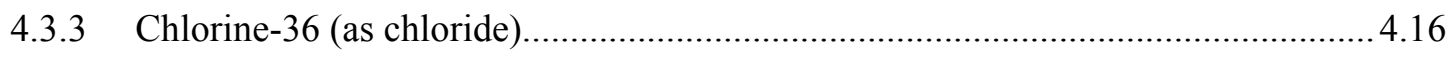

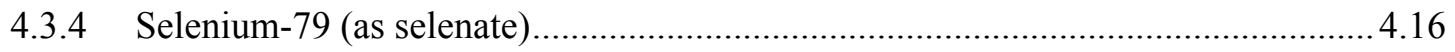

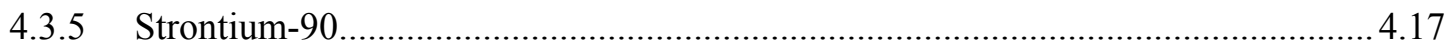

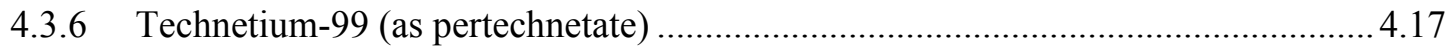

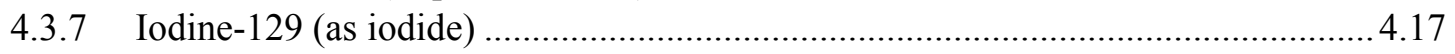

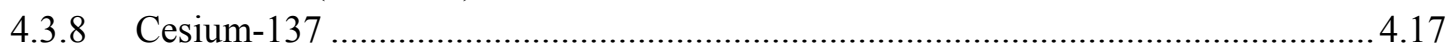

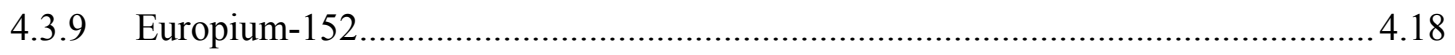

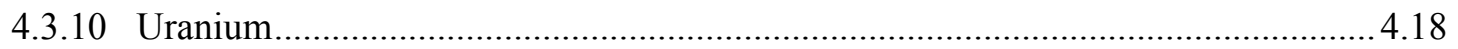

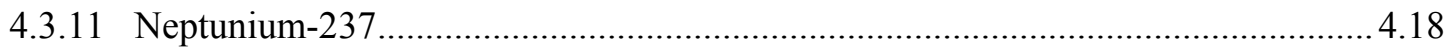

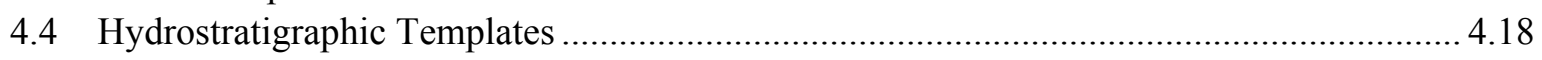

4.4.1 Assignment of Waste Chemistry Types ............................................................... 4.19

4.4.2 Facility Location, Dimensions, and Wetted Area ……....................................... 4.19

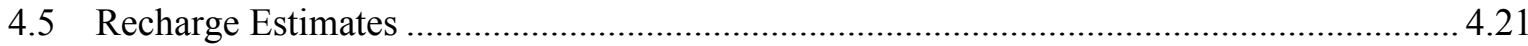

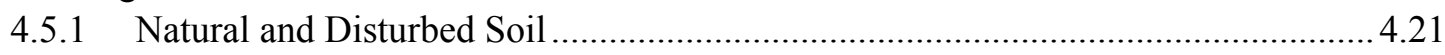

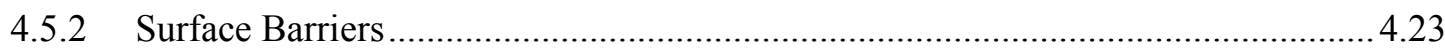

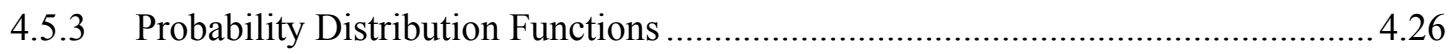

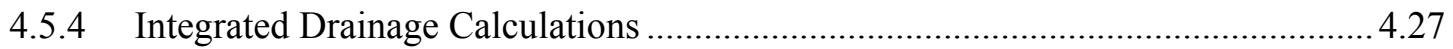

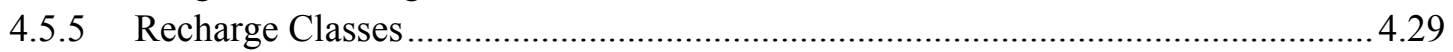

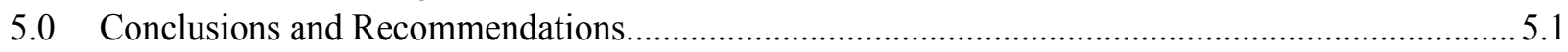

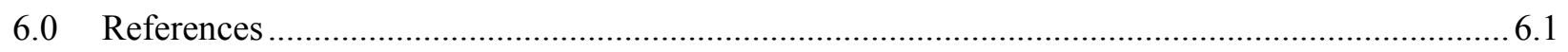

Appendix A - Hydrostratigraphic Templates …................................................................... A.1

Appendix B - Hydraulic Property Distributions....................................................................... B. 1

Appendix C - Resolution of Discrepancies in the System Assessment Capability Vadose Zone Model for the BC Cribs and Trenches.................................................................... C.1

Appendix D - Surface Barrier Degradation....................................................................... D. 1 


\section{Figures}

2.1 General Vadose Zone Conceptual Model Concepts after Caggiano (1996).

Note that the geologic nomenclature varies from that used today. ............................................. 2.2

2.2 Process Relationship Diagram of Vadose Zone Flow and Transport........................................... 2.3

2.3 Generalized West-to-East Geologic Cross Section Through the Hanford Site

(after Hartman 2000) ....................................................................................................... 2.7

2.4 Photograph of a Typical Clastic Dike as Found at the U.S. Ecology

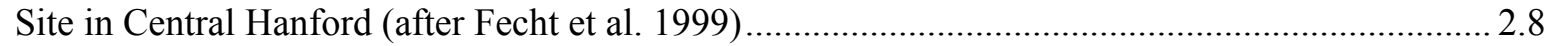

2.5 Schematic of Vadose Zone Implementation Model for the Composite Analysis ......................... 2.28

3.1 Location of Geographic Areas Represented by a Single Generalized

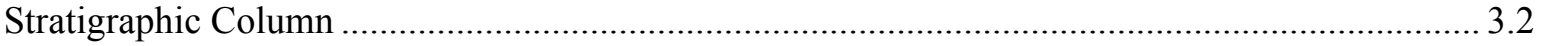

3.2 Schematic of One-Dimensional Vadose Zone Simulation........................................................... 3.3

4.1 Formation Specific Water Retention Curves for the Site-Wide Distribution.................................. 4.7

4.2 Formation Specific Hydraulic Conductivity Curves for the Site-Wide Distribution ....................... 4.8

4.3 Formation Specific Hydraulic Conductivity Curves Versus Saturation for the .............................. 4.8 


\section{Tables}

2.1 Options for the Composite Analysis (after the Preliminary Concepts Document) ${ }^{(a)}$................... 2.25

3.1 Waste Site Type Designations Used in the Hydrostratigraphic Template Codes ........................... 3.4

3.2 Geographic Area Designations Used in the Hydrostratigraphic Template Codes ......................... 3.5

3.3 Site-Specific Area Designations Used in the Hydrostratigraphic Template Codes ....................... 3.5

3.4 Waste Stream Designation and Assumed Compositions for Determination of

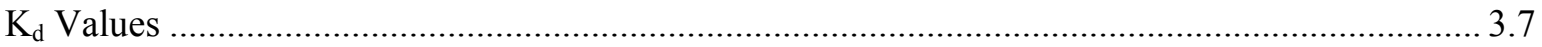

3.5 Waste Chemistry Designations Used in the Base Template Codes ............................................ 3.8

3.6 General Hydrostratigraphic Templates for Each Geographic Area ............................................... 3.9

3.7 Site-Specific Templates Established for a Few Key Facilities.................................................... 3.11

4.1 Sources of Hydrogeologic Data for the Seventeen Geographic

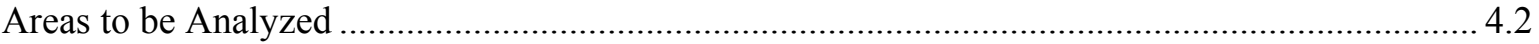

4.2 Hydrostratigraphic Units Used in this Study

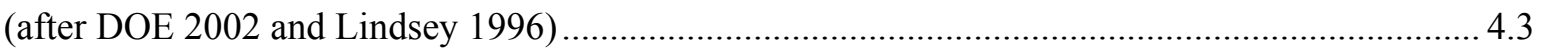

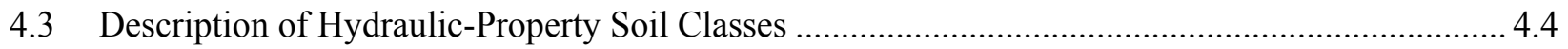

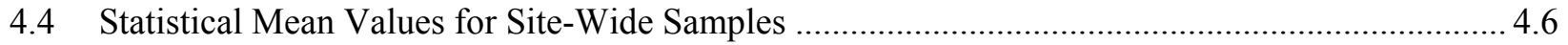

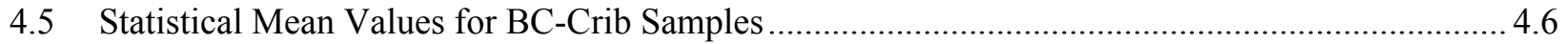

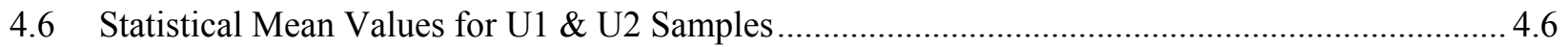

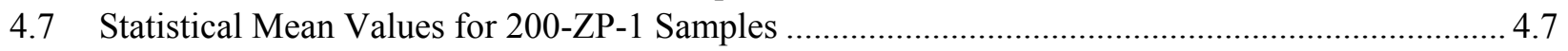

4.8 Statistical Mean Values for 200 West Area Samples.................................................................... 4.10

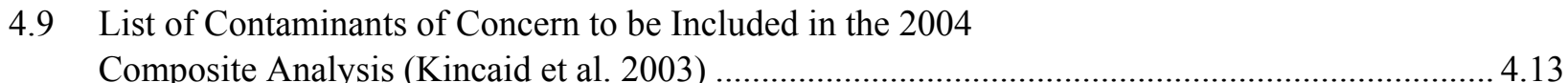

$4.10 \mathrm{~K}_{\mathrm{d}}$ Ranges by Waste Chemistry/Source Category .................................................................... 4.15

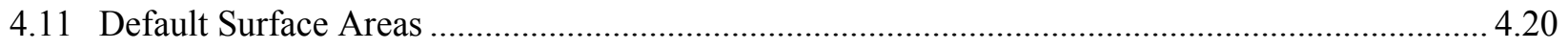

4.12 Estimated Recharge Rates for Predominant Soil Types and Sediment

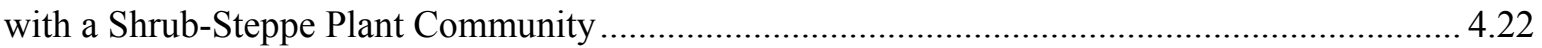

4.13 Estimated Recharge Rates for Soil Types and Sediment Without Vegetation.............................. 4.22

4.14 Estimated Recharge Rates by Soil Type/Sediment and Vegetation Condition in Each Hanford Area. Significant secondary soil types and their associated recharge estimates are shown in parentheses.............................................24

4.15 Barrier Design Life and Estimated Recharge Rates for Barrier Tops .......................................... 4.25

4.16 Initial Side Slope Recharge Rates for Hanford Site Climate Conditions .................................... 4.25

4.17 Estimated Recharge Rates for Baseline Soil Conditions.......................................................... 4.29

4.18 Estimated Recharge Rates for Disturbed Conditions and Sensitivity Tests................................ 4.30

4.19 Estimated Recharge Rates for Surface Barrier Components........................................................ 4.31

4.20 Estimated Recharge Rates for Surface Barriers with Side Slopes

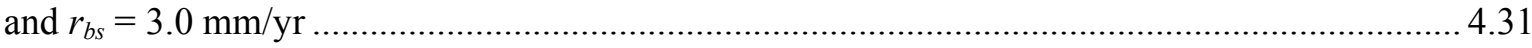

4.21 Estimated Recharge Rates for Surface Barriers with Side Slopes and $r_{b s}=42.0 \mathrm{~mm} / \mathrm{yr}$ 


\subsection{Introduction}

A composite analysis is required by U.S. Department of Energy (DOE) Order 435.1 to ensure public safety through the management of active and planned low-level radioactive waste disposal facilities associated with the Hanford Site (DOE M 435.1-1). The original composite analysis (Kincaid et al. 1998) must be revised and submitted to DOE Headquarters (DOE-HQ) in 2004 because of revisions to waste site information in the 100, 200, and 300 Areas, updated performance assessments and environmental impact statements (EIS), changes in inventory estimates for key sites and constituents, and a change in the definition of offsite receptors.

Kincaid et al. (2004) describe the technical scope of the 2004 Composite Analysis for the Hanford Site and the approach to perform this analysis. It will be a site-wide analysis, considering final remedial actions for the Columbia River corridor and the Central Plateau and will be a companion to waste-specific and site-specific assessments. The 2004 Composite Analysis also will provide supporting information on a regional or site-wide basis for use in important Hanford assessments and decisions such as the Comprehensive Environmental Response, Compensation, and Liability Act (CERCLA) 5-year review in 2005, tank closure decisions, decisions on final groundwater remedies for the 200 Areas, decisions on final groundwater remedies for the 100 Areas, and the Columbia River corridor final record of decision.

Beginning in fiscal year (FY) 2003, the DOE Richland Operations Office (DOE-RL) initiated activities, including the development of data packages, to support the 2004 Composite Analysis. This report describes the data compiled in FY 2003 to support vadose zone modeling for the 2004 Composite Analysis. This work was conducted as part of the Characterization of Systems Task of the Groundwater Remediation Project (formerly the Groundwater Protection Program) managed by Fluor Hanford, Inc., Richland, Washington.

\subsection{Purpose}

The purpose of this data package is to summarize the conceptual understanding of flow and transport through the vadose zone (i.e., the conceptual model), describe how this understanding will be simplified for numerical simulation as part of the 2004 Composite Analysis (i.e., implementation model), and finally to provide the input parameters needed for the vadose zone simulations.

\subsection{Scope and Approach}

The scope of this data package covers the geologic framework, the physical, hydrologic, and contaminant transport properties of the geologic materials in the vadose zone, and estimates of deep drainage (i.e., recharge). This data package builds on the general framework developed for the initial assessment conducted using the System Assessment Capability (SAC) as presented in:

- Preliminary System Assessment Capability Concepts for Architecture, Platform, and Data Management - Appendix C, Vadose Zone Conceptual Model (http://www.hanford.gov/cp/gpp/modeling/sacarchive/App\%20C.pdf) 
- Draft 2001 SAC Data Package, Appendix C - Vadose Zone Data for Initial Assessment Performed with System Assessment Capability (Revision 0)

(http://www.hanford.gov/cp/gpp/modeling/sacarchive/dp_vadose.pdf).

The general approach for this work was to update and provide incremental improvements over the previous 2001 data package. As with the previous SAC data package, much of the data and interpreted information were extracted from existing documents and databases. Every attempt was made to provide traceability back to the original source(s) of the data or interpretations. 


\subsection{Background}

The vadose zone is the hydrogeologic region that extends from the soil surface to the water table (DOE 1998). At the Hanford Site, the vadose zone ranges in thickness from less than 1 meter along the river in the 100 and 300 Areas to more than 100 meters on the Central Plateau in the center of the Hanford Site. At discrete locations, the vadose zone contains waste inventories from past waste disposal practices (e.g., direct liquid waste disposal to the ground via engineered facilities) and from unplanned releases (e.g., spills and tank leaks).

The geologic framework of the vadose zone is very complex with a high degree of heterogeneity and anisotropy in its physical, hydrologic, and geochemical properties. This complex hydrogeochemical framework, together with waste water and meteoric water fluxes lead to highly complex threedimensional movement of moisture and contaminants through the vadose zone. Wilson et al. (1995) describe flow within the vadose zone as dynamic and characterized by periods of unsaturated flow at varying degrees of partial saturation punctuated by episodes of preferential, saturated flow in response to hydrologic events or releases of liquids.

This section summarizes our conceptual understanding of flow and transport through the Vadose Zone and the technical basis and approach for modeling the Vadose Zone for the Composite Analysis. Conceptual models are evolving hypotheses that identify the important features, events, and processes controlling fluid flow and contaminant transport at a specific field site and in the context of a specific problem. Looney and Falta (2000) further describe a conceptual model as answering the question "How do we believe the system actually operates?" The conceptual model is one of the key initial elements in the overall modeling process. Once the site-specific problem has been defined and the important features, events, and processes conceptualized, quantitative descriptions can be prepared and implemented. Field and laboratory data are used to provide the input data, as well as to calibrate and independently test the predictive capabilities of the model. Of particular interest to this data package are the subsurface geologic, hydraulic, and geochemical parameters and the deep drainage estimates that control flow and transport through the vadose zone.

\subsection{Conceptual Model of the Hanford Site Vadose Zone}

Conceptual models of the vadose zone at the Hanford Site have been developed from information on the geology, geochemistry, and hydrologic regime as well as the distribution and movement of waste in the subsurface. Most of the information has been obtained from borehole drilling through sediment sampling and analysis and geophysical logging. This has provided a considerable amount of information about the lithology and stratigraphy, but a more limited amount of hydrologic and geochemical information has been obtained. These investigations into the vadose zone have traditionally been at or near the waste disposal sites; however, a few areas that represent background conditions or provide representative test sites have also been studied. The integrated knowledge from these previous studies and ongoing work provides a reasonable conceptual understanding of the geologic, hydraulic, and geochemical controls on contaminant movement and distribution within the vadose zone of the Hanford Site (DOE 1999). Figure 2.1 illustrates some of these controls. However, there are still many outstanding issues, some of which require additional study and some of which may never be completely resolved. 


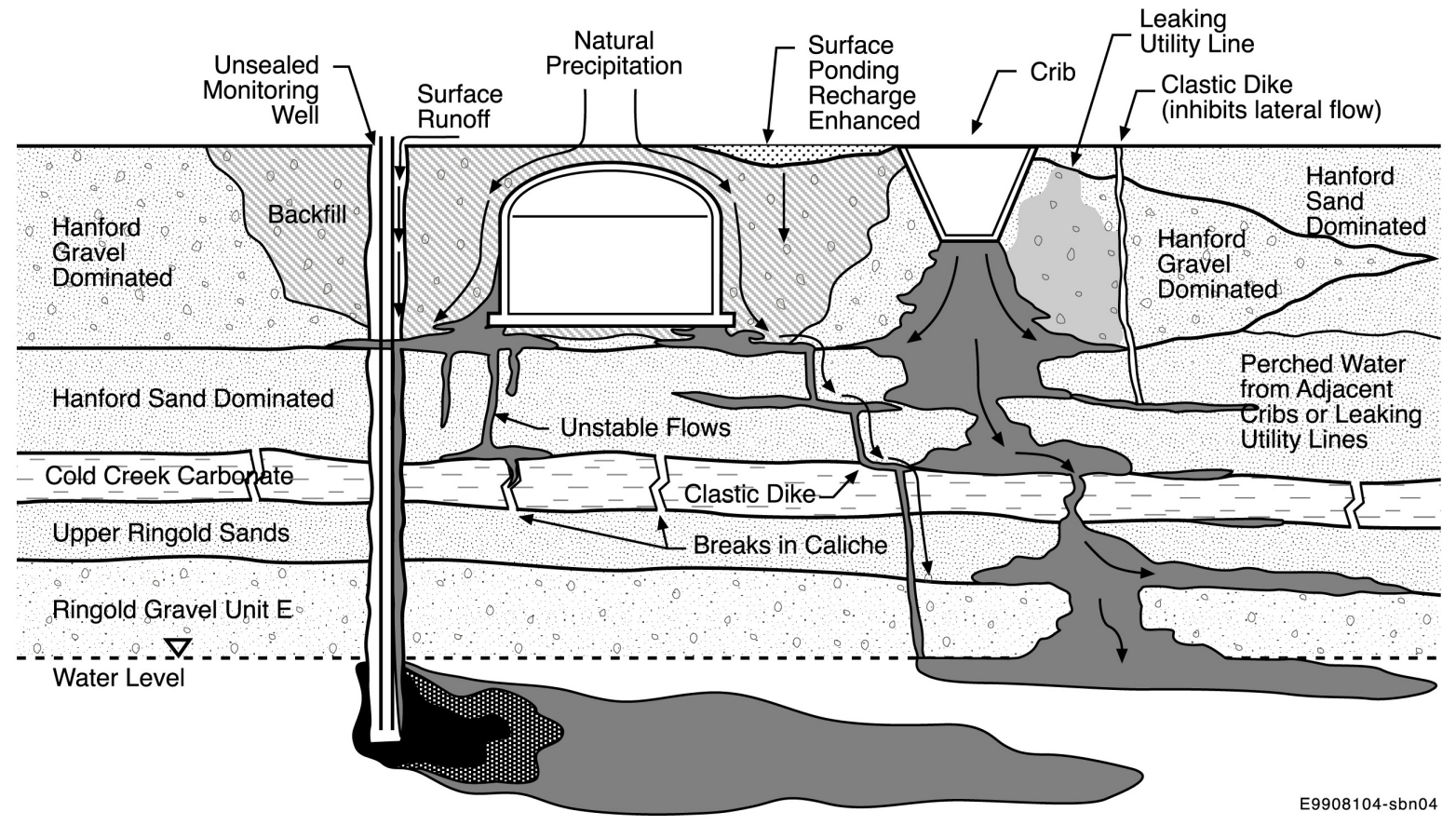

Figure 2.1. General Vadose Zone Conceptual Model Concepts after Caggiano (1996). Note that the geologic nomenclature varies from that used today.

The Preliminary System Assessment Capability Concepts for Architecture, Platform and Data Management, Appendix $C^{(a)}$ describes the conceptual models of vadose zone flow and transport and the preferred approach (and the rationale behind it) used for representing vadose zone transport in the initial assessments conducted using SAC. A common process to define the modeling requirements for a particular assessment is to break the conceptual model down into potentially relevant factors (i.e., features, events, and processes [FEPs]) and to logically screen and select the factors that should be included in the assessment (Last et al. 2004b). The process of identifying, classifying, and screening these factors is often called FEP analysis (NEA 2000) or FEP analysis methodology (Bailey and Billington 1998).

Kincaid's Candidate Sets Report ${ }^{(b)}$ and Soler et al. (2001) provide comprehensive compilations of the 1) features (the structure and transport properties of the various pathways), 2) events (e.g., recharge, source releases, etc.), and 3) processes (the fate and transport processes/mechanisms, including driving forces) considered potentially relevant to contaminant flow and transport within the vadose zone beneath the Hanford Site. Last et al. (2001) developed the process relationship diagram as a tool to illustrate the interrelationships between factors and to facilitate analysis/screening of the dominant versus subordinate

(a) Groundwater/Vadose Zone Integration Project Preliminary System Assessment Capability Concepts for Architecture, Platform, and Data Management. September 30, 1999. http://www.hanford.gov/cp/gpp/modeling/sacarchive/9-30rpt.pdf

(b) Kincaid CT et al. June 25 1999. Candidate Sets Report.

http://www.hanford.gov/cp/gpp/modeling/sacarchive/candsets.pdf 
factors of a given conceptual model. Figure 2.2 illustrates the main features and processes potentially effecting flow and transport within the vadose zone.

The following sections (taken from Preliminary System Assessment Capability Concepts for Architecture, Platform, and Data Management - Appendix C, Vadose Zone Conceptual Model $)^{(\mathrm{a})}$ describe
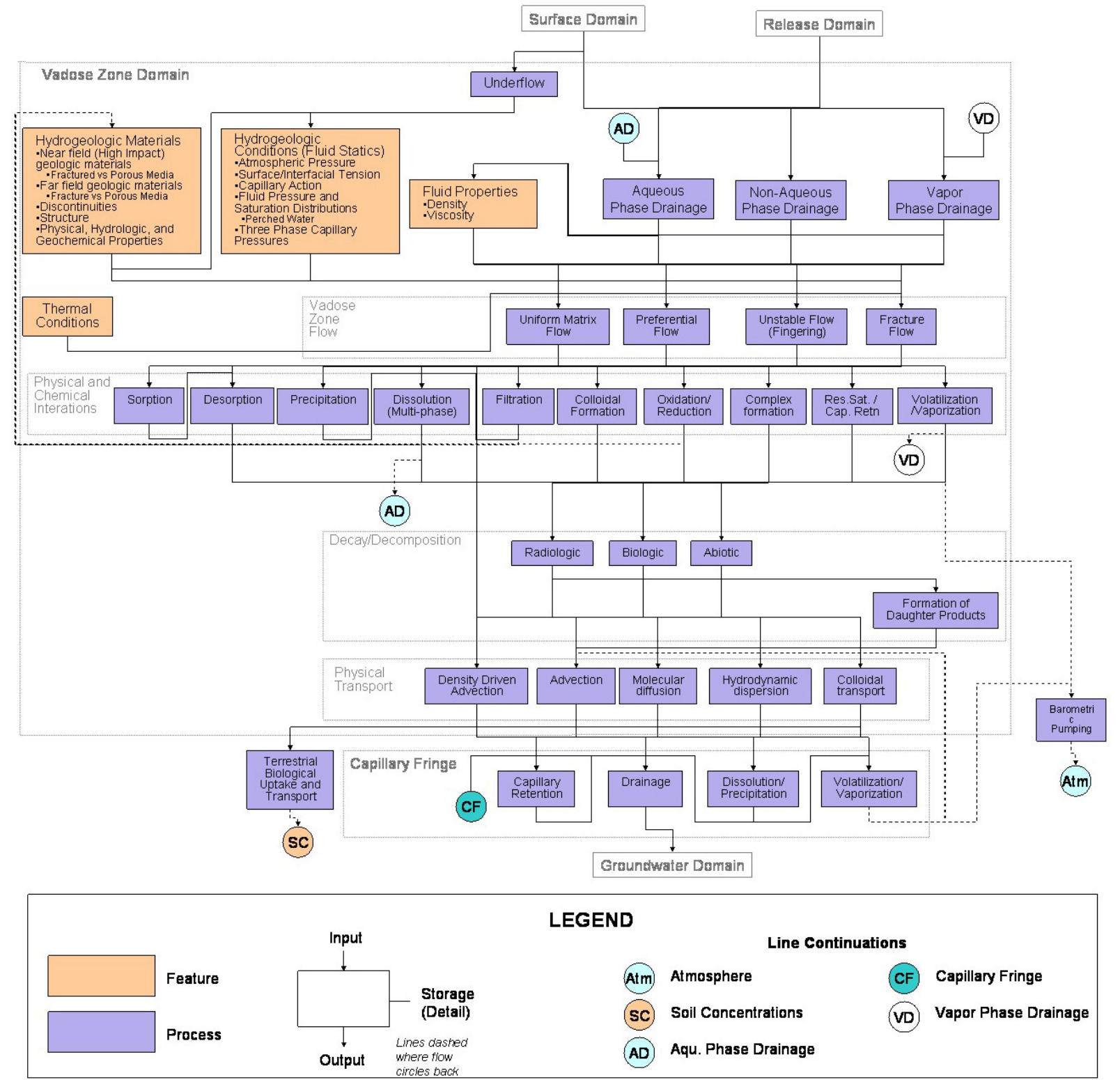

Figure 2.2. Process Relationship Diagram of Vadose Zone Flow and Transport

(a) Preliminary System Assessment Capability Concepts for Architecture, Platform, and Data Management Appendix C, Vadose Zone Conceptual Model

(http://www.hanford.gov/cp/gpp/modeling/sacarchive/App\%20C.pdf) 
these important features, events, and processes, and identifies those factors that are considered most dominant and have been selected as study sets for numerical representation (modeling) in the 2004 Composite Analysis.

\subsubsection{Features}

The primary features relevant to the vadose zone flow and transport include the hydrogeologic materials (and their physical, hydraulic, and geochemical properties); subsurface conditions (e.g., fluid statics and thermal conditions); and fluid properties. Other features relevant to the vadose zone conceptual model such as climate and weather statistics, terrestrial ecology, and projected land use are not specifically discussed here. Instead, the reader is referred to (Neitzel et al. 2003) for general discussions of these specific features. Some aspects of the climate and weather phenomena are discussed later as they relate to precipitation, run-off, and infiltration events.

There is a significant amount of hydrogeologic data available for the Hanford Site, primarily from borehole drilling in the vicinity of waste disposal operations. Interpretation of the geologic data are presented in numerous reports, including Delaney et al. (1991); Lindsey (1992, 1995); Lindsey et al. 1992a, b; Lindsey and Jager 1993; Hartman and Peterson (1992); Peterson et al. (1996); DOE (1993a, 1994); Thorne et al. (1993, 1994); Hartman (2000); Williams et al. (2000); Williams et al. (2002); and DOE (2002).

The thickness of the vadose zone varies from less than 1 meter along the river in the 100 and 300 Areas to more than 100 meters beneath the Central Plateau. The vadose zone lies mostly within cataclysmic flood deposits of the Hanford formation, but in places such as 200 West Area and portions of the 100 Areas it extends into the underlying Cold Creek unit, and/or the upper portions of the Ringold Formation. The physical structure (e.g., geology, hydrologic properties, and geochemical properties) of the geologic framework and its principal transport pathways is complex with a high degree of heterogeneity and anisotropy. To capture some of the site-wide variability in these features, this discussion is broken into three general physiographic areas (the 100, 200, and 300 Areas). While other selected areas away from these focus areas, such as areas representative of background conditions and areas that have the potential to become contaminated in the future, are also important to the general vadose zone technical element, they are not specifically discussed here.

\subsubsection{100 Areas}

The average thickness of the vadose zone in the reactor areas ranges from 6 meters (100-F Area) to over 30 meters (100-B/C Area) with each reactor area being slightly different. During operations, groundwater mounding reduced the thickness of the vadose zone by 6 to 9 meters directly under the retention basins or other liquid-waste disposal facilities.

Hydrogeologic Materials. The hydrogeologic framework of the vadose zone is complex; however, locally within the 100 Areas, it can be divided into two primary hydrostratigraphic units: 1) the graveldominated facies association of the Hanford formation and 2) the conglomeratic member of Wooded Island, Unit E, of the Ringold Formation (DOE 2002; Peterson et al. 1996; Hartman and Lindsey 1993; Lindberg 1993a, b; Lindsey and Jaeger 1993). The Ringold Formation makes up the lower portion of the 
vadose zone at the $100-\mathrm{K}, 100-\mathrm{N}$, and the $100-\mathrm{D}$ Areas. It is only partially present in the $100-\mathrm{B} / \mathrm{C}$ Area and not present in the 100-H and 100-F Areas. The Hanford formation extends from the surface to just above the water table when the Ringold Formation is present. The Hanford formation extends beneath the water table and makes up the unconfined aquifer in the 100-H and 100-F Areas.

The Ringold Formation Unit E is a fluvially deposited pebble-to-cobble conglomerate with a sandy matrix. It is characterized by complex interstratified beds and lenses of sand and gravel with variable degrees of cementation.

The gravel-dominated facies of the Hanford formation occasionally exhibits an open framework texture composed of uncemented, clast-supported pebble, cobble, and boulder gravel with a coarsegrained sandy matrix and minor sand and silt interbeds or stringers. The clast size decreases in the lower portion of the Hanford formation. The Hanford formation is generally less cemented and more poorly sorted than the Ringold Formation and typically contains a higher percentage of angular basaltic detritus.

Although clastic dikes have been observed in the vadose zone beneath the 100 Areas (Fecht et al. 1999), because of their limited areal distribution and lack of vertical continuity, they may not represent significant preferential pathways. However, these vertical features could represent natural cutoff walls that confine or limit plumes from spreading horizontally during wetting from a waste site; then later, under unsaturated conditions, be more conductive than the surrounding sediments (Murray et al. 2002). The contact between Ringold Unit $\mathrm{E}$ and the Hanford formation is important because the saturated hydraulic conductivity for the gravel-dominated sequence of the Hanford formation is one to two orders of magnitude higher than the denser and locally cemented Ringold Unit E. Since hydraulic conductivity varies with the formation, different groundwater level responses could occur where channels now filled with the Hanford formation had been scoured into the Ringold Unit E. These buried channels could become preferential pathways for contaminated groundwater during high river stages.

Hydraulic Properties and Conditions. The physical properties of the vadose zone in the 100 Areas are not well characterized. Peterson et al. (1996) reported saturated hydraulic conductivity, moisture content, specific gravity, and bulk density for samples taken from the single-pass reactor areas. No scaling of hydraulic conductivity based on particle-size distribution was done for that report. Khaleel and Relyea (1997) published moisture retention data for the 100-D, 100-F, and 100-H Areas. In the $100 \mathrm{~N}$ Area, Connelly et al. (1991) collected 10 surface samples for moisture retention data and DOE (1996a) collected four samples each from boreholes 199-N-108A and 199-N-109A. The measured physical properties for these samples vary widely reflecting the heterogeneity of the vadose zone. These data are recorded on the catalog of vadose zone flow parameters for the Hanford Site (Freeman et al. 2002).

The large volume of liquid discharges during operations created water table mounds 6 to 9 meters above the nominal water table under the retention basins and other liquid disposal facilities. Volumetric moisture content found in sediment under the 100-N Area liquid waste disposal facilities (DOE 1996a) appear to be high for the given sediment type and natural recharge rate. This suggests these soils are still draining. 
Geochemical Properties and Conditions. Results from the geochemical characterization studies in the 100 Areas show a contaminant zoning (chromatographic) effect in the vadose zone. For radionuclides and inorganic contaminants that are not adsorbed (i.e., tritium, nitrate), the large releases of water to the vadose zone at the retention basin and liquid waste disposal facilities quickly pushed these contaminants through the vadose zone, into the unconfined aquifer, and subsequently out to the Columbia River. Crews and Tillson (1969), using iodine-131 isotopic analysis, estimated the travel time to the Columbia River from 1301-N liquid waste disposal facility to be approximately 10 days during active disposal.

Contaminants that show moderate adsorption such as strontium-90 show differential distribution (i.e., chromatographic zoning) within the vadose zone. Serne and LeGore (1996) examined characterization

data from 12 boreholes within the 100-N Area and found that strontium-90 in the vadose zone is bound to sediment directly underneath the liquid waste disposal facilities in a relatively thin layer at depths that correspond to the elevated water table formed during operations. Serne and LeGore (1996) also reported the average bulk distribution coefficient $\left(\mathrm{K}_{\mathrm{d}}\right)$ for strontium- 90 to be $15 \mathrm{~mL} / \mathrm{g}$ for these sediments. Contaminants with strong adsorption such as cobalt-60, cesium-137, and plutonium-239/240 remained within 1 meter of the bottom of the disposal facility. Contaminated sediment that is now part of the vadose zone should be considered a source term for further downward migration to the water table.

Further complicating the release of contaminants from the vadose zone in the 100 Areas is the seasonal and diurnal fluctuations of the Columbia River. A high river stage can cause the water table to rise into sediment containing higher concentrations of contaminants. Additionally, the chemistry changes caused by the constant re-wetting of the soil due to diurnal fluctuations could affect how the contaminants are released from the vadose zone (Petersen and Connelly 2001).

\subsubsection{200 Areas}

The 200 East and 200 West Areas are located on the Central Plateau of the Hanford Site. The vadose zone beneath the 200 Areas ranges in thickness from about 50 meters in the western portion of the 200 West Area (beneath the former U Pond) to 104 meters in the southern part of 200 East Area. The stratigraphy of the vadose zone varies significantly across the Cold Creek floodbar making up the Central Plateau. A generalized geologic cross section showing the general stratigraphy through the 200 Areas is shown in Figure 2.3.

Hydrostratigraphy. The geology and hydrology of the 200 Areas have been extensively studied because they contain major sources of groundwater contamination (Hartman 2000). The major stratigraphic units making up the vadose zone include 1) glaciofluvial deposits of the Pleistocene-Age Hanford formation, 2) fluvial and/or eolian deposits and paleosols of the Pliocene/Pleistocene-Age Cold Creek unit, and 3) the fluvial/lacustrine deposits of the Miocene/Pliocene-Age Ringold Formation.

200 West Area. The vadose zone beneath 200 West Area ranges from 50 to 80 meters thick and can be subdivided into six principal hydrostratigraphic units (Lindsey et al. 1992a; Connelly et al. 1992a; Thorne et al. 1993; Williams et al. 2002; DOE 2002). These units include two facies associations of the Hanford formation (gravel-dominated and the sand-dominated), two lithofacies of the Cold Creek unit (the fine-grained, laminated to massive facies, and the coarse to fine-grained carbonate-cemented facies) 


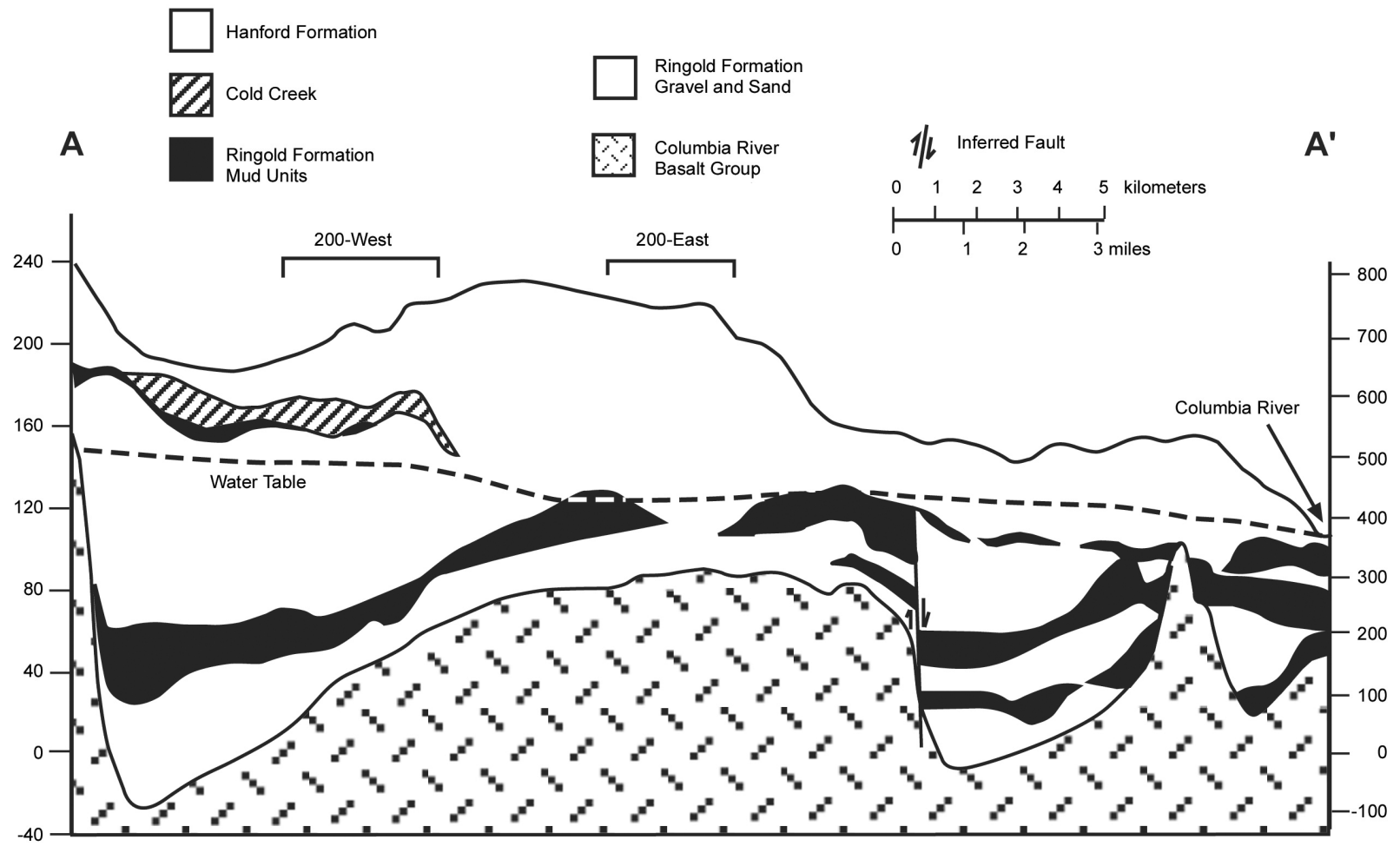

Figure 2.3. Generalized West-to-East Geologic Cross Section Through the Hanford Site (after Hartman 2000)

and two members of the Ringold Formation (the member of Taylor Flat and the member of Wooded Island, Unit E). Not all of these units are present everywhere within the 200 West Area, and as in any depositional system, the thickness, distribution, and continuity of these units can vary significantly from site to site.

Clastic dikes (Figure 2.4) occur as near-vertical sediment-filled structures that cut across bedding planes. Clastic dikes have been observed to form multisided polygonal cells enclosing the host sediment. Individual polygonal cells are bounded by other polygons to form what is described as a honeycomb pattern when viewed from the air (Fecht et al. 1999). Vertically oriented clay skins within clastic dikes could locally act to form an impediment to lateral flow.

Perhaps the most significant feature in the 200 West Area affecting vadose-zone transport is the finegrained and carbonate-cemented facies of the Cold Creek unit (Rohay et al. 1994), which represents an ancient buried calcic paleosol sequence (Slate 1996, 2000). Because of the cemented nature the Cold Creek unit, it is often considered impervious; however, it is also structurally brittle and, therefore, may contain many fractures that have developed during or since soil development. The degree of cementation varies considerably within the Cold Creek unit so that contaminants could breach the unit through discontinuities in cementation or structure. The Cold Creek unit which contains many weathering products (e.g., oxides and carbonates) may also chemically react with transported wastes with which it comes in contact. Immediately overlying the carbonate-cemented facies of the Cold Creek unit is the 


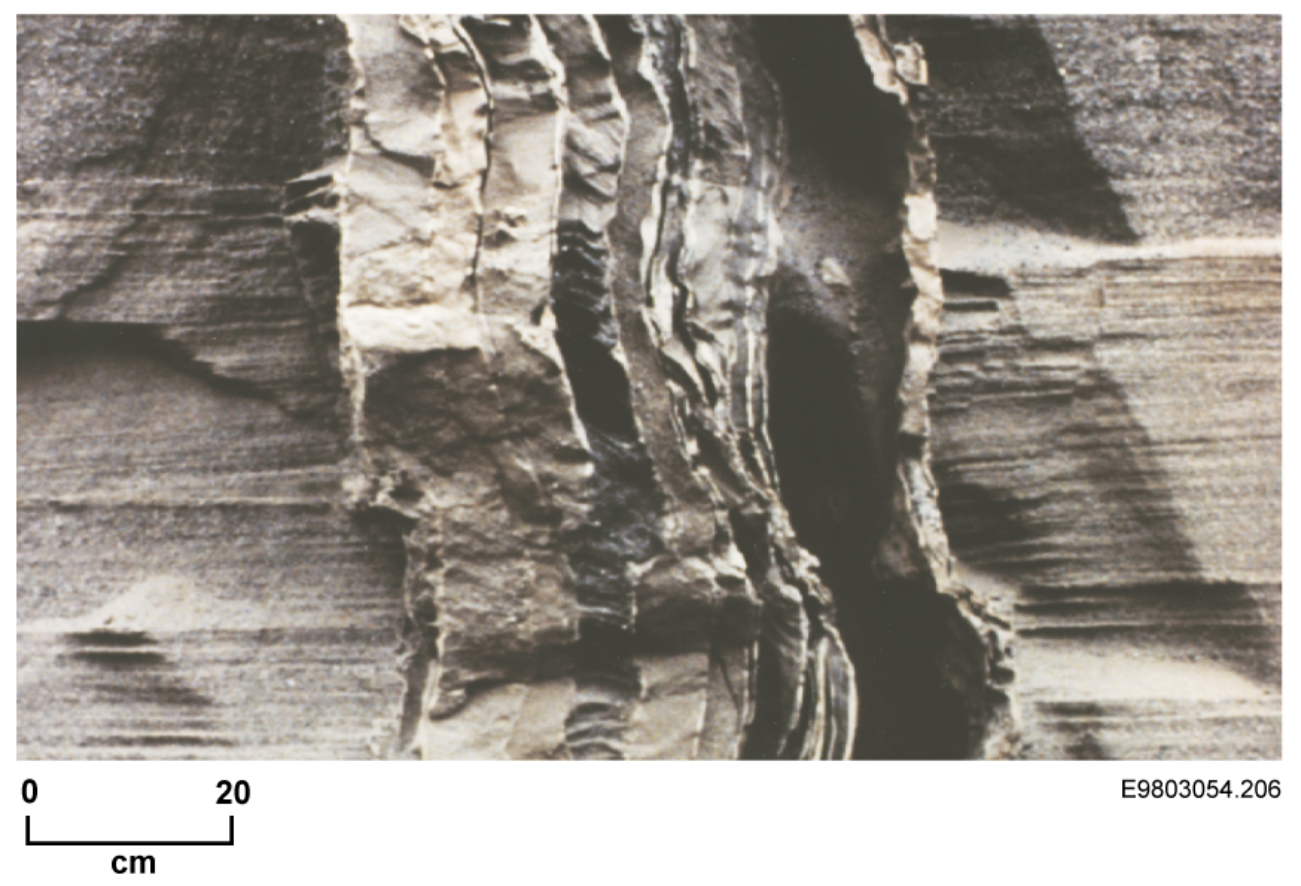

\section{Figure 2.4. Photograph of a Typical Clastic Dike as Found at the U.S. Ecology Site in Central Hanford (after Fecht et al. 1999)}

fine-grained, laminated to massive facies (formerly referred to as the "early Palouse soil") which has a relatively high moisture-retention capacity with a corresponding low permeability and would tend to retard the downward movement of moisture and contaminants.

200 East Area. The vadose zone beneath 200 East Area can be subdivided into six principal hydrostratigraphic units, including three units with in the Hanford formation, a fluvial gravel facies of the Cold Creek unit (equivalent to the Pre-Missoula Gravels), and two units belonging to the Ringold Formation (Lindsey et al. 1992b; Connelly et al. 1992b; Thorne et al. 1993; Williams et al. 2000; DOE 2002). The Hanford formation units include 1) an upper gravel-dominated facies, 2) a sand-dominated facies, and 3) a lower gravel-dominated facies. Over most of the 200 East Area the Hanford sand facies lies between the upper and lower gravel-dominated facies (Lindsey et al 1992b; Connelly et al. 1992b). Based on borehole samples, the upper and lower gravel-dominated facies appear to have similar physical and chemical properties. The Ringold Formation in the 200 East Area is, for the most part, eroded away in the northern half of 200 East Area. Here, the Hanford formation lies directly on top of basalt bedrock. With the dropping water table, basalt outcrops above the water table and, thus, is unsaturated beneath the northeastern portion of 200 East Area. Just south of 200 East Area, the water table lies within the Ringold Formation. Because the physical and chemical characteristics of the Ringold Formation, Member of Wooded Island, Unit A and Unit E gravels are similar, and because only a small portion of the vadose zone lies within Unit A, these units can be combined into a single hydrostratigraphic unit.

Clastic dikes have also been observed in the Hanford formation beneath 200 East Area. The vertically oriented clay skins within clastic dikes could locally act to form an impediment to lateral flow. This could then cause ponding (perching) of the water and eventual breakthrough to underlying strata. 
Sublinear to anastamosing (braid-stream like) channel-cut scour and fill features occur within the Hanford formation and could act as preferential pathways in the horizontal direction. Other types of heterogeneity are associated with stratigraphic pinch out or offlapping/onlapping of facies.

Both the Ringold and the Hanford formations often contain relatively thin fine-grained stringers that can result in lateral spreading of moisture and slow down the vertical movement of contaminants within the vadose zone. Low-permeability layers, where they exist, often occur as single, relatively thick (meters or more) and continuous layers within the Ringold Formation. Low-permeability layers within the Hanford formation, on the other hand, occur more frequently, yet are relatively thin ( 0.5 meter or less) and laterally discontinuous. Low-permeability layers within the sand-dominated facies of the Hanford formation are generally thicker and more continuous than those in the gravel-dominated facies. Paleosols and some facies changes (i.e., the contact between fine grained and coarser grained facies) have been observed to be fairly continuous over the range of at least 100 meters and have been found to promote lateral spreading of crib effluent on that same scale.

Hydraulic Properties and Conditions. Accurate predictions of flow and transport in the vadose zone require a detailed characterization of the hydrologic properties and their variability, and estimates of transport parameters such as dispersivity. In particular, data that are essential for quantifying the water storage and flow properties of unsaturated soil include the soil moisture characteristics (i.e., soil moisture content versus pressure head and unsaturated hydraulic conductivity versus pressure head relationships) for sediment in various geologic units.

Data on particle-size distribution, moisture retention, and saturated hydraulic conductivity $\left(K_{s}\right)$ have been cataloged for over 248 samples from throughout the Hanford Site, including 12 locations in 200 East and West Areas (Khaleel and Freeman 1995; Khaleel et al. 1995; Khaleel and Relyea 1997; and Khaleel and Heller 2003). The soil retention data were corrected for gravel content and the main drying curve. The saturated hydraulic conductivity was measured on intact, undisturbed splitspoon sleeve samples. After the data were corrected and cataloged, hydraulic parameters were determined by fitting the van Genuchten soil-moisture retention model to the data.

Macrodispersivity estimates for non-reactive species have been estimated using the Gelhar and Axness (1983) equation where the longitudinal macrodispersivity depends on the mean pressure head. Khaleel (1999) estimated a longitudinal macrodispersivity of about 100 centimeters for the sanddominated facies of the Hanford formation in 200 East Area. The transverse dispersivities have been estimated as one-tenth of the longitudinal values (Gelhar et al. 1992).

Ward et al. ${ }^{(a)}$ obtained dispersivity estimates via field measurements at a location close to the immobilized low-activity waste site, using potassium chloride $\left(K_{C l}\right)$ as a tracer. Analysis of the data provided dispersivities that ranged from 1.3 to 7.8 centimeters for travel distances ranging from 25 to 125 centimeters. Dispersivity increased with depth to about 0.75 meter, after which it essentially became constant. These estimates are for the Hanford formation, but the transport distance within the vadose

(a) Ward AL, RE Clayton and JS Ritter. 31 December 1998. "Hanford Low-Activity Tank Waste Performance Assessment Activity: Determination of In Situ Hydraulic Parameters of the Upper Hanford Formation." In Letter to Dr. Fredrick M Mann from AL Ward dated 31 March, 1999. 
zone is indeed of limited extent. Nevertheless, results based on the limited data are consistent with the concept of a scale-dependent dispersivity. Thus, although no data exist on large-scale dispersivities for the vadose zone, it is expected that they will be larger (as is suggested by the longitudinal dispersivity estimate of 100 centimeters) than those based on the small-scale tracer experiment of Ward et al. ${ }^{\text {(a) }}$

Based on a survey of literature, Gelhar (1993) examined the longitudinal vadose zone dispersivities as a function of the scale of the experiment, and found an increase of dispersivity with an increase in scale.

Geochemical Properties and Conditions. The Hanford formation sediment consists of glaciofluvial materials. The mineralogy of this sediment is highly variable depending on grain size. Gravel-dominated sediment tends to have a high degree of rock fragments (mostly basaltic, with some plutonic, metamorphic, and detrital caliche fragments) (DOE 2002). Microprobe analysis of the sand and finer-grained fraction has found it to be dominated by quartz ( 18 to $67.1 \%$ by weight), plagioclase ( 5.1 to $41.5 \%$ ) and Microcline (1.8 to 30.1\%) (Tallman et al. 1979; Serne et al. 1993; Xie et al. 2003). Other dominant minerals include amphiboles up to $36.6 \%$, pyroxenes up to $27.5 \%$, Mica (Biotite/Illite) up to $13.1 \%$, and calcite up to $6.5 \%$ by weight. Smectite clays represent a few weight percent of the bulk sand fraction (3.3 to 5\% [Serne et al. 1993]) and generally dominates in the clay fraction (Tallman et al. 1979).

Hanford formation sediment is typified as having low organic carbon content generally $<0.1 \%$ by weight (Serne et al. 1993) and low-to-moderate cation exchange capacity (2.6 to 7.8 milliequivalents per 100 grams, Serne et al. 1993). The sediment has a slightly basic pH when wetted (Serne et al. 1993 found that the $\mathrm{pH}$ of saturation extract ranging from 7.66 to 8.17). Small amounts of detrital calcium carbonate (calcite) are common and can act as a weak buffer.

Much less mineralogy data are available for the Cold Creek unit. Tallman et al. (1979) found that the sediment they referred to as Early "Palouse" Soil are fairly similar in mineralogy (25.3 to 29.4\% quartz, 15.1 to $18.2 \%$ plagioclase, 15 to $17.8 \%$ microcline, 7.9 to $10 \%$ amphiboles, 1.3 to $12.5 \%$ micas), but generally have higher in calcite (8 to 8.8\%), and lack pyroxenes. Bjornstad (1990) found similar results for these fine-grained sediment, but found that the carbonate-rich facies (referred to as the PlioPleistocene unit) consisted predominantly of calcium carbonate and/or sedimentary rock fragments, with lesser amounts of quartz and feldspars.

Thin beds of caliche with calcite predominate and variable amounts of ferric oxide exist in the 200 West Area in the Cold Creek unit just above the Ringold Formation.

Xie et al. (2003) found significant differences in electron microprobe and petrographic results between the Hanford and Ringold Formations. The Ringold Formation sediment is generally higher in quartz but lower in plagoclase and pyroxene. Deeper within the Ringold Formation, calcic/ferric oxide cements are often present. The cementing can alter significantly the permeability of the otherwise coarsegrained Ringold sediment.

(a) Ward AL, RE Clayton and JS Ritter. 31 December 1998. "Hanford Low-Activity Tank Waste Performance Assessment Activity: Determination of In Situ Hydraulic Parameters of the Upper Hanford Formation." In Letter to Dr. Fredrick M Mann from AL Ward dated 31 March, 1999. 
Empirical $K_{d}$ data describing contaminant adsorption for Hanford formation, Cold Creek unit, and Ringold Formation sediments are fairly well characterized for dilute waste solutions and groundwater (Cantrell et al. 2002, 2003a). Fewer $K_{d}$ data are available for high ionic strength waste solutions with slightly acidic to slightly basic $\mathrm{pH}$ values. A relatively small amount of $K_{d}$ data exists for the combined high ionic-strength/highly-basic tank liquors for many common radionuclides. These distribution coefficient $\left(K_{d}\right)$ data have been well tabulated by Cantrell et al. (2003a), Kincaid et al. (1998), Serne and Wood (1990), Kaplan and Serne (1995), and Kaplan et al. (1996, 1998). In most instances, adsorption is assumed to be the controlling geochemical process but neutralization of acid waste by the alkaline sediment and neutralization of basic tank waste can cause precipitation of some macro and many minor contaminant species within the sediment pores. Outside the zone of $\mathrm{pH}$ neutralization, adsorption is considered to be the dominant contaminant retardation process in the vadose zone.

The geochemical processes that affect contaminant migration and mineral alteration within the vadose zone sediment for both 200 East and 200 West Areas are quite similar. Some subtle changes should be considered as the fine-grained sediment and caliche zone above the Ringold are less prevalent in 200 East Area.

\subsubsection{300 Area}

The vadose zone beneath the 300 Area ranges in thickness from about 15 meters to less than 1 meter along the Columbia River.

Hydrostratigraphy. The geology of the vadose zone consists almost entirely of the Pleistocene Hanford formation with a thin veneer of Holocene eolian sand. Thin portions of the Ringold Formation may also extend above the water table in portions of the site. Schalla et al. (1988) described the eolian sand deposits as ranging from 0 to nearly 4.6 meters thick. Where missing, these deposits are thought to have been removed by construction activities and often replaced by or covered with construction gravel. The geologic contact with the underlying Hanford formation is quite distinct.

Schalla et al. (1988) described the Hanford formation as poorly sorted sandy gravel with some silt and local sand stringers. The upper portion was described as containing pebble to boulder gravel that grows finer with depth. The gravel fraction is described as mainly basaltic in nature with some quartz-rich and metamorphic clasts. The thickness of the Hanford formation varies from 6.4 to 24.7 meters.

Gaylord and Poeter (1991) describe the Hanford formation beneath the 300 Area as consisting predominantly of three lithofacies: gravelly sand, sandy granule to pebble-size gravel, and sandy cobble to boulder-size gravel. They further indicate that finer grained sand facies, comprising only a minor percentage of the 300 Area Hanford formation deposits, are concentrated in the southern part of the area intermixed with the coarse-grained gravel dominated deposits.

In an attempt to define the spatial distribution of hydrologic properties (primarily aimed at the unconfined aquifer) Gaylord and Poeter (1991) broke the 300 Area sediment into four general hydrofacies. These hydrofacies were defined based on grain size and sorting, recognizing the importance of the fine-grained component to hydraulic behavior. 
Based on the available geologic information for the 300 Area, the hydrostratigraphy of vadose sediment can be broken into five different units: 1) backfill (or surface cover); 2) eolian sands (if still present at the waste site); 3) sand-dominated Hanford sediment; 4) gravel-dominated Hanford sediment; and 5) gravel-dominated Ringold sediment (if present above the water table). Although these sediments are primarily coarse, it must be recognized that some silt stringers and fine-grained rip up clasts (some over 1 meter in diameter) are present, particularly in the Hanford formation. The location and extent of these stringers is uncertain. It must also be recognized that sedimentary structures (e.g., stratification, grading bedding, forset bedding) impart some degree of heterogeneity and anisotropy in each of the units; however, again there is insufficient data to adequately portray these characteristics.

Hydraulic Properties and Conditions. Schalla et al. (1988) presented the results of physical (e.g., field moisture content, water retention, particle-size analysis) and bulk geochemical analyses of selected samples. The field water content ranged from $<2$ to nearly $5 \%$ by weight.

Geochemical Properties and Conditions. Gaylord and Poeter (1991) also provided whole rock geochemical (via x-ray fluorescence) and rare earth/trace element (inductively coupled plasma/mass spectroscopy [ICP/MS]) analyses for the Hanford and Ringold Formations. These data are similar to those for Central Plateau sediment (Xie et al. 2003). Existing sorption data are rather limited for the 300 Area (Cantrell et al. 2003b), therefore sorption parameters must be derived from an assessment of the waste chemistry and existing sorption values from other Hanford site sediments (similar to the selection process used in the Hanford composite analysis [Kincaid et al. 1998]). Without site-specific geochemical data, values for the geochemical properties (i.e., $K_{d}$ values) will have to be estimated from the sediment type (e.g., grain-size data and the presence of secondary mineralization like the Fe oxide coatings often found in the Ringold Formation) and waste type. The mineralogy and contaminant adsorption properties of the Hanford formation sediment in the 300 Area are thought to be quite similar to those in the 200 Areas such that the extensive $K_{d}$ data base (Cantrell et al. 2003b) should be adequate for the 2004 Composite Analysis.

\subsubsection{Events}

Various events to be considered in the conceptual model include those that are naturally occurring (e.g., meteoric recharge), those that are manmade (e.g., intentional or unintentional contaminant and water releases), those that occur slowly over a long period of time, and those that represent extreme or unusual occurrences (e.g., 500 year storms, volcanism). A brief synopsis of some of the important types of events that should be considered are presented in the following sections.

\subsubsection{Recharge Events}

The long-term natural driving force for flow and transport through the vadose zone is precipitation that has infiltrated below the zone of evaporation and the influence of plant roots. Such water eventually flows to the water table, carrying with it whatever dissolved species may be present. Gee et al. (1992) presented evidence from multiple experiments showing that measurable diffuse natural recharge occurs across the lower elevations of the Hanford Site, with rates ranging from near zero in undisturbed shrubsteppe plant communities to more than $100 \mathrm{~mm}$ per year beneath the unvegetated graveled surfaces of tank farms. 
The arid climate setting, with cool wet winters and dry hot summers at the Hanford Site dictates that recharge potential is greatest in winter (Gee et al. 1992). During winter months at Hanford, precipitation is greatest and evaporation potential lowest; therefore, precipitation has the greatest chance to infiltrate into the ground. This type of recharge can occur as either diffuse or focused recharge. How much each event contributes is site- and event-dependent. Water runoff from the higher elevations occurs intermittently because of frozen ground and, while infrequent, can be extensive (e.g., Pearce et al. 1969). Cushing and Vaughan (1988) indicate runoff from higher elevations has a 3.8-year return period. Extensive water runoff does not appear prevalent at the Hanford Site between Highway 240 and the Columbia River based on the absence of geomorphic features such as erosion rills and gullies. For undisturbed (natural) sites in the 100 and 200 Areas at Hanford, there is typically gentle terrain and coarse soil that foster diffuse recharge. In contrast, at disturbed waste sites there can, at times, be localized ponding that gives rise to focused flow particularly under conditions of rapid snowmelt. Observations have revealed that local runoff does occur at waste sites when there is a heavy rain, quick snowmelt, or the ground is frozen (e.g., Gee and Hillel 1988; Jones 1989; Ward et al. 1997).

\subsubsection{Source/Release Events}

Another source of water that transports contaminants originates from industrial activities. Historically, millions of gallons of contaminated water were disposed to subsurface infiltration structures and surface ditches and ponds. Such unregulated disposal ceased several years ago. Currently, two facilities are permitted to discharge to the vadose zone: the State-Approved Liquid Disposal (SALD) Facility and the Treated Effluent Disposal Facility (TEDF). Discharges from these facilities are closely monitored and regulated. Numerous discharges of water, collectively called miscellaneous streams, are also permitted but do not need to be monitored unless they exceed certain discharge rates and annual amounts (DOE 1998). These streams include hydrotesting, maintenance, construction, cooling water and steam condensate, sanitary wastes, and storm water control. Also unregulated but possible sources of additional recharge water are roads, road shoulders, parking lots, power and fire lines, and all structures that do not have precipitation controls that fall under the miscellaneous streams permit.

Source events include accidental or intentional discharges of fluids, gases, and contaminants to the environment. Unintentional releases include spills, tank leaks, and distribution pipe leaks. The quantity, quality, duration, and phases of waste or fluid released are generally unknown. These events also include remediation activities that involve the injection of liquid, chemicals, gases, and heat.

\subsubsection{Discharge/Exit Events}

Discharge or withdrawal events include all actions to remove fluids, gases, and contaminants from the environment. These events must be characterized for quantity, quality, duration, and phases of waste or fluid removed. These events include remediation activities such as groundwater pumping, vapor extraction, and heat removal (e.g., cryogenic barriers). 


\subsubsection{Climate Events}

A change to a drier and/or warmer climate could result in a sparser plant community, a change in the mix of plant and animal species, increased wind erosion and deposition (e.g., re-activated sand dunes), and changes in natural recharge. The stress of this change could allow non-native plant and animal species to supplant native species.

\subsubsection{Volcanism}

Volcanic activity has the potential to deposit significant quantities of ash. Such deposition could reduce evaporation and plant activity for years, which could increase the natural recharge rate.

\subsubsection{Seismicity}

Earthquakes and other related events, such as fault rupture, landslides, or differential settlement could potential effect the integrity of surface or subsurface structures, potentially impacting recharge and vadose zone transport.

\subsubsection{Flooding Events}

Natural flooding in the Columbia River is predicted to affect low-lying areas along the river but not the 200 Areas. Failure of the upriver dams has the potential to affect the entire Hanford Site. The probable maximum flood in the Cold Creek drainage basin could affect the southwestern portion of the 200 West Area (Skaggs and Walter 1981). Under this scenario, water from the flood would reach the Yakima River.

\subsubsection{Human Disturbance Events}

Human activities are capable of degrading surface covers over waste sites and exposing the waste to increased recharge and more direct contract with the biosphere.

\subsubsection{Processes}

The primary processes governing flow and transport through the vadose zone are complex and interrelated. These processes depend on the physical and chemical nature of the geologic materials that make up the vadose zone (described above) as well as the types, amounts, and compositions of the fluids that occupy the pore spaces (Looney and Falta 2000, p. 13). At a high level, one can discuss these processes in terms of the mechanisms, rates, and routes by which contaminants move (or are moved) through the vadose zone to the water table (i.e., fluid flow, physical transport, and the capillary fringe) and the fate of the contaminants (i.e., physical and chemical interactions, decay and decomposition).

\subsubsection{Transport Mechanisms}

For the majority of contaminants, movement through the vadose zone is contingent on being dissolved within flowing water (i.e., aqueous phase drainage). The flow of water through the unsaturated soils depends in complex ways on the rate of water infiltration, moisture content of the soil, textural 
heterogeneity, and soil hydraulic properties. Infiltrating water provides the primary driving force for downward migration of contaminants. Perched water zones and lateral spreading may develop when water moving downward through the vadose zone accumulates on top of low-permeability soil lenses, highly cemented horizons, or above the contact between a fine-grained horizon and an underlying coarsegrained horizon. Unsaturated hydraulic conductivities may vary by several orders of magnitude depending on the water content of the soils.

Some contaminants (as well as water) are volatile and move in the gas phase. The bulk of this movement is diffusional, but convective flow can occur near the soil surface and near open boreholes in response to barometric changes. Remediation activities (e.g., vapor extraction, thermal treatment) can also affect local convective gas flow.

The geothermal gradient has a small but steady impact on the movement of water upward through the vadose zone. Enfield et al. (1973) used field measurements of temperature and matric potential at a site about $1 \mathrm{~km}$ to the south of the 200 East Area to calculate an upward water flux of $0.04 \mathrm{~mm}$ per year.

\subsubsection{Transport Rates}

Fluids such as water move through the vadose zone at rates determined by the hydraulic, thermal, and vapor gradients and the relevant properties of the sediment. For many applications, common assumptions include a static air phase, isothermal conditions, and no density effects. With these assumptions, flow rates are calculated using Richards equation with gravity and capillary potential gradients. When these assumptions are not appropriate (e.g., organic liquids, vapor flow, hot saline tank waste), more sophisticated equations must be used to calculate rates.

The rate of recharge at a particular location is influenced by five main factors: climate, soil, vegetation, topography, and springs or streams. Other factors can significantly impact recharge by affecting one or more of the main factors. These other factors include soil development, animal activity, fire, water and wind erosion and deposition, plant community changes, disturbance, and human structures (e.g., roads, buildings). The rate of recharge at each waste site will depend on the design of the surface cover. Plants and animals live within the upper 1 to 2 meters of soil, and some plant roots can reach depths of 3 meters. Surface covers can be designed to protect against such intrusion by including biobarriers, which are layers that resist biotic intrusion. Coarse gravel layers have been shown to be ineffective at preventing root and insect intrusion, but they appear to deter animal intrusion. For thinner cover designs, the biobarrier may be closer to the surface and more susceptible to degradation. Intrusion of surface covers by plants and animals can create macropores that could become conduits for surface water to flow into the soil much deeper than expected. Inadvertent intrusion by humans can result in surface depressions that could become areas of focused recharge when surface runoff occurs.

Some of the liquids that were disposed or leaked to the vadose zone had properties that differed significantly from the properties of pure water. Because their properties differed from those of water, their rate and route of movement through the vadose zone may differ from those of water. The specific gravity of waste that has leaked from single-shell tanks ranged from 1.1 to 1.65 , which could enhance the transport of contaminants. Increased density has been demonstrated to elongate contaminant plumes 
vertically and reduce lateral spreading caused by stratigraphic variations in hydraulic properties (Ward et al. 1997). The properties of these fluids will change as contaminants are diluted, sorbed, or the fluid evaporates into the sediment air space.

Organic fluids were also disposed at Hanford. The movement of these fluids through the vadose zone and groundwater aquifer is complex because it involves flow in multiple phases: the organic liquid phase, the dissolved phase in water, and the vapor phase in the vadose zone air space. The movement of organic fluids can be enhanced if their density is much higher than the density of water. That is the case for the primary organic fluid contaminant at Hanford - the dense nonaqueous phase liquid, carbon tetrachloride. Between 1955 and 1973, roughly 577 to 922 metric tons of carbon tetrachloride was disposed to three subsurface infiltration facilities at the Hanford Site (Rohay et al. 1994). The current groundwater plume containing concentrations above $0.5 \mathrm{mg} / \mathrm{L}$ covers an area of about 11 square kilometers. Soil-vapor extraction and pump-and-treat activities have been employed to prevent further movement of the plume and reduce contaminant mass. Efficiencies of the vapor extraction activities have decreased. The pumpand-treat activities may be having an impact, because the extent of the plume has not increased. The behavior of carbon tetrachloride in the subsurface and in the vadose zone is poorly understood and requires additional characterization and assessment to determine the important processes governing its fate and transport.

The rate of gas movement in the vadose zone will be affected by the magnitude of any temperature gradients. The vadose zone across the entire Hanford Site experiences temperature changes that arise from the diurnal and seasonal temperature changes at the soil surface. The magnitude of the temperature changes diminishes with depth; at 10 meters, the seasonal change appears to be less than $1^{\circ} \mathrm{C}$. Nearsurface temperatures appear to have a minimal effect on recharge rates if the rates exceed 10 millimeters per year, but they could be important when rates are less. In addition to the near-surface temperature changes, a steady upward geothermal gradient exists that drives gas (and water vapor) upward. The elevated temperatures of the leaked waste from the single-shell tanks and previous operational discharges could have induced local movement of both liquids and vapor.

The formation of colloids and occurrence of colloid-facilitated transport of contaminants were identified by the Expert Panel as a potentially important process for the vadose zone (DOE 1997). For most waste sites at Hanford, the low water contents and simple geochemistry are not conducive to colloid formation or colloid-facilitated transport. However, for the large-volume discharges and waste from leaking tanks, the conditions existed for both colloid formation and colloid-facilitated transport. However, insufficient data exist at the Hanford Site to adequately characterize the potential for colloidal transport under these conditions.

\subsubsection{Transport Pathways}

Because gravity is the dominant force that moves liquid downward, the predominant direction for contaminant movement is downward. Variations in the hydraulic properties and the presence of impeding features such as bedding interfaces, caliche layers and disposal facilities can locally alter and redirect the movement laterally. Various preferential pathways such as clastic dikes and fractures are capable of concentrating or contributing to phenomena such as fingering and funnel flow. Preferential flow has been documented along poorly sealed well casings at the Hanford Site (Baker et al. 1988) and transport along 
clastic dikes has been postulated to be potentially important (DOE 1997). Relatively simple stratigraphic layering can give rise to complex water content distributions and enhanced lateral spreading that impedes vertical migration of contaminants.

Because of the nature of some waste, local routes of contaminant movement will vary. The Vadose Zone Expert Panel (DOE 1997) stated that the likely mode of transport for leaked or disposed tank waste in the Hanford geology is along preferential, vertical, and possibly tortuous pathways. They identified possible preferential flow caused by:

- Hot $\left(177^{\circ} \mathrm{C}\right)$ caustic tank waste leaking into the vadose zone, flashing to steam, fracturing the matrix, and enlarging pores

- Hot $\left(177^{\circ} \mathrm{C}\right)$ caustic tank waste leaking into the vadose zone with a self-healing nature, creating geothermal convection systems that could move contaminants upward and the hot alkaline slurry reacts with Hanford sediment

- Dissolution of siliceous sediment by the hot and alkaline tank waste, which could increase porosity in some places (by dissolution) and lower porosity in others (by precipitation)

\subsubsection{Contaminant Behavior}

The fate of contaminants in the vadose zone depends on geochemical conditions, the speciation of the contaminant, residence time, and microbial activity.

Sediment has the capacity to sorb most contaminants from solution. The amount of sorption is a function of many factors, including mineral surface area and type, contaminant type (speciation) and concentration, overall solution concentration, $\mathrm{pH}$, Eh, and reaction rates for the controlling adsorption or precipitation, dissolution, and hydrolysis reactions.

Some contaminants do not sorb at all (i.e., soluble anions such as nitrate, chromate, and protectonate) and are moved along with the bulk solution. The movement of contaminants through the vadose zone is affected by their sorption in the far-field and sometimes by complex dissolution/precipitation reactions between waste liquids of extreme $\mathrm{pH}$ and the slightly alkaline sediment in the near field. The significance of sorption is that it delays downward movement of the contaminant and allows degradation processes to occur (e.g., radioactive decay) and, for some, irreversible incorporation into the sediment. Sorption can be described using a simple linear relationship (i.e., a distribution coefficient or $K_{d}$ ) that is determined empirically. Values of $K_{d}$ have been measured for a wide range of contaminants and waste types at the Hanford Site (Kincaid et al. 1998). The $K_{d}$ approach is applicable for conditions at Hanford where the contaminant concentrations are low and the chemistry is relatively constant. However, conditions near some waste sources are so variable due to the strong influence of the waste that the $K_{d}$ approach may not be applicable. Such is the case for the hot, highly concentrated tank waste in contact with Hanford sediment. The general consensus is that the presence of this waste will likely decrease the sorption of contaminants (e.g., cesium-137). The net effect will be an increase in their mobility until conditions in the sediment (e.g., lower concentrations via waste dilution) become more appropriate for the $K_{d}$ approach. The complex reactions that occur between the sediment and the highly acidic and (more importantly for 
Hanford) highly basic wastes are currently under study. Future SAC revisions will determine whether more complex chemical reaction processes should be considered to increase the accuracy of transport models used to estimate migration rates of key contaminants of concern.

Contaminants that exist in the gas phase (e.g., radon, carbon-14, carbon tetrachloride) are subject to atmospheric venting and remediation activities such as vapor extraction. Carbon-14 as carbon dioxide also reacts strongly with alkaline earth cations to form insoluble carbonates at neutral to basic $\mathrm{pH}$ values. Further it reacts with cement, a common constituent of waste form containers and structures used in many solid waste burial grounds, to form carbonate precipitates (Krupka and Serne 1996; Serne et al. 1992).

Contaminants near the soil surface are subject to animal and plant uptake. Plants and animals live within the upper 1 to 2 meters of soil, and some plant roots reach depths of 3 meters or more. Waste present within this zone is subject to ecological uptake and dispersal above ground.

Contaminants that are consumed by microbes are subject to degradation into other compounds that may or may not be considered contaminants. This degradation process depends on the presence of a microbial population that is capable of degrading the contaminant(s) in question and the availability of any additional nutrients that may be required for the microbes to be effective.

Sometimes it is the water that is consumed rather than the waste. Waste forms such as the immobilized low-activity waste undergo a corrosion process that consumes water. In a dry disposal, this consumption process will create a water vapor gradient that draws vapor toward the waste form.

\subsection{Uncertainty and Unresolved Technical Issues}

Unresolved technical issues and sources of uncertainty affect the ability to predict the behavior of contaminants in the vadose zone. These include property representation, scale effects, spatial and temporal resolution of data, preferential flow, funneled flow, colloid transport, density effects, and thermal effects. Many of these issues are not addressed in this data package but may be addressed in later revisions of the composite analysis after resolution of key issues by the science and technology program.

Discussions of outstanding issues are generally focused on performance/risk assessment under future conditions and future releases. However, there are also site characterization and laboratory study needs related to interpreting observations from past tank leaks, spills, and nearby intentional discharges. This information, i.e., interpretation of site characterization data, is important to estimate existing inventories for use as initial conditions and also to demonstrate the validity of our understanding and the predictive ability of the models used for flow and transport of contaminants. Interpreting the mass and distribution of contaminants is difficult because there is much about the history and character of the leaks, spills, and water losses that is difficult to characterize. The resulting uncertainty will always hamper the ability of models to predict observed distributions of contaminants in the vadose zone, even if the distributions are well known. 


\subsubsection{Property Representation}

The physical, chemical, and hydraulic properties of the various solids, liquids, and gases in the subsurface are typically represented within numerical simulators using mathematical functions. The form of these functions, and their resulting suite of parameters, change as more process knowledge and characterization information becomes available. Good examples are the water retention and hydraulic conductivity properties of the sediments. The parameters for these functions are determined by fitting them directly to data or by inferring them from physical properties. Many functions have been proposed to represent hydraulic properties. One of the most commonly used hydraulic models is the van Genuchten-Mualem model (Kosugi et al. 2002). A standard practice is to fit the van Genuchten retention model to retention data and the saturated conductivity value and use the resulting parameters with the Mualem conductivity model to predict unsaturated conductivity values. In this standard approach, the " $m$ " parameter is fixed equal to $1-1 / n$ and the pore interaction term is fixed at 0.5 . This approach has been shown to work for a number of soils, but examples exist to show that it is not universally applicable and that, for many soils, it becomes increasingly less applicable as the soil dries out (e.g., Stephens 1992; Khaleel et al. 1995). Predictions of dry-end conductivity can be improved by including one or more measured values of unsaturated conductivity in the fitting process and excluding the saturated conductivity value. Improvements can also be obtained by treating the " $m$ " parameter as independent and fitting both " $m$ " and the pore interaction term. The drawback to increasing the number of fitting parameters is the possibility of obtaining a non-unique set of parameter values during the fitting process. Some soils have unique structural features such as fractures and macropores that make them less amenable to characterization using a single function like the van Genuchten function. For such cases, Durner (1992) and others have proposed multiple functions, either linked or combined. The resulting fits to the data are better, but the number of parameters is so large that these techniques are not often used. To date, nearly all analyses at Hanford have used a single van Genuchten-Mualem function to represent hydraulic properties. Many have used the standard approach of fitting to retention and saturated conductivity data, but a portion have included an unsaturated conductivity value in the fitting process (Khaleel et al. 1995). As more knowledge is gained and the original data evaluated more fully, the parameter values can be revised such that uncertainty in the conductivity predictions can be reduced.

\subsubsection{Effects of Scale}

One of the greatest challenges facing the composite analysis and similar efforts is adequately understanding the effects of spatial and temporal scale related to processes, observation, modeling, and assessments. Not a lot is known about how vadose zone processes, at various spatial and temporal scales, interact, which ones are dominant, and how these interactions can be related to and interpreted from existing field and/or laboratory observations. It is also difficult to determine what must be measured and modeled to assess both risk and the ability of the models to assess the risk within useful uncertainty bounds (i.e., to determine the validity of the models).

In past assessments, the hydrogeologic units were generally assumed to be homogeneous and isotropic in character. In reality, these units display complex inter- and intra-sedimentary structures at various scales. The effects of these complex structures are generally thought to enhance lateral spreading and impede downward migration. However, some of these structures might also promote "funneled flow" 
and/or the development of "fingered flow." Thus, the effect of these small-scale structures needs to be more thoroughly understood and properly accounted for in the assignment of physical properties (e.g., effective permeability, porosity, moisture retention characteristics, anisotropy, dispersivity) to the larger modeled units. The effects of small-scale structures on large scale flow and transport parameters also needs to be assessed to understand the degree of uncertainty, to make appropriate choices for bounding calculations and to determine the effects of simplification on assessment predictions.

Scaling and volume averaging tools are needed that can be used to determine effective values of parameters from small scale (often disturbed) borehole samples in conjunction with soft information on the fine-scale structure of these sediments. Data are lacking for much of the vadose zone where the analysis will be focused, so scale-up and volume averaging will be required. The justification of upscaling and averaging will need to be evaluated either deterministically or by a probabilistic assessment that clearly reflects the uncertainties involved in the analysis.

\subsubsection{Spatial and Temporal Resolution of Site Data}

The resolution of the nature and extent of various hydrogeologic units beneath a given waste site, based on borehole samples, is generally on the order of 1.5 meters vertically and tens of meters or more horizontally, and the minimum discernable thickness of fine-grained units is thought to be about 15 centimeters. Also, the internal structure of these sedimentary units may have been lost in the drilling and sampling process. Vertical borehole data alone cannot provide the quality and quantity of data needed for accurate analysis of vadose zone transport. Thus, much of our knowledge on the internal structure and heterogeneities of these units comes from extrapolation of qualitative examination of "representative" outcrops. At the Hanford Site, only a few limited geostatistical studies have been conducted to quantitatively describe the internal structure and heterogeneities in outcrop and core samples. Thus, in many cases there is currently a lack of site specific data to support the development of detailed three dimensional geologic models for a given waste site.

\subsubsection{Preferential Flow}

Preferential pathways are important for contaminant transport associated with tank-farm releases and/or other low-volume discharges where mobile constituents have not yet been flushed through the vadose zone. However, it is important to differentiate between structurally controlled flow and unstable flow. Structurally controlled flow occurs when the structure of the porous medium or the presence of a buried structure (e.g., tank) routes the water along a "preferential path." Unstable flow or wetting-front instability occurs during infiltration when an instability develops at the fluid-fluid interface (e.g., waterair, dense nonaqueous phase liquid water).

\subsubsection{Structure Controlled Flow}

Preferential flow is greatest when the preferred flow path consists of a series of connected large pore spaces. Because flux is proportional to the fourth power of the pore radius, large pores transmit very large quantities of fluid, but only when the pores are filled. Thus, water content determines the effectiveness of preferred pathways to conduct water. When water contents are high (at or near saturation), 
preferred pathways can conduct copious quantities of water. When water contents are low (dry vadose zone), preferred pathways with large pores do not conduct water because they cannot fill with water.

Whenever there are variations in sediment properties, the potential exists for water flow to be affected. The capillary barrier effect is a good example. The arrangement of fine textured material over coarsetextured material temporarily delays the downward migration of water and allows it to be evaporated and transpired back into the atmosphere. The net effect is that deep drainage is reduced. Such textural breaks are used for surface covers, but they also occur naturally throughout the vadose zone. When such "capillary breaks" are sloped, the water that is retained above the break can move laterally. In fact, this feature has been used to improve the performance of waste disposal facilities in the vadose zone (Frind et al. 1977).

Clastic dikes and unsealed boreholes may potentially act as preferential flow paths for saturated flow by providing large connected pore spaces. These features are especially effective as preferred pathways when they cross-cut the normally horizontally layered sedimentary sequences. The actual influence of clastic dikes on flow is somewhat uncertain; whereas some portions of clastic dikes have large connected pore spaces, other portions have fine-grained clay skins that may actually limit high rates of lateral flow (Murray et al. 2002). Wood et al. (1995, 1996) and Jacobs (1999) suggested that both clastic dikes and unsealed boreholes are insufficiently large and continuous to be significant with respect to the overall contaminant mass transport through the vadose zone. A recent field study of clastic dikes suggested that dikes are not important preferential flow and transport pathways when the drainage flux was less than $100 \mathrm{~mm} / \mathrm{yr}$ (Murray et al. 2003). Thus, these potential pathways are not considered dominant enough features to be incorporated into an assessment on the scale of the 2004 Composite Analysis.

\subsubsection{Unstable Flow}

Unstable flow fingering seems to develop when a saturated fine-grained textured soil overlies a coarse-grained soil. Water accumulates in and over the fine-grained unit until the thickness of the perched water provides sufficient driving force to allow the water to "drip" into the large pore spaces of the underlying coarse-grained sediment. This situation results in fingers with inner cores that are saturated surrounded by an unsaturated layer. However, fingers that are clearly caused only by the instability of a wetting front have been primarily observed in the laboratory. There is a commonly held belief that unstable flow or fingering may be an artifact of the uniform, horizontal, and homogeneous layers (e.g., glass beads) used in the laboratory experiments. The phenomena may or may not occur in natural structured geologic media. If it does, the following questions need to be addressed:

- What effect does the fine-scaled structure that typically involves alternating coarse-grained and finegrained layers do to enhance or deter the formation of unstable flow fingers?

- How does this fine structure change the scale of fingers and relative speed up of the transport process (i.e., the effect of bypassing)?

Experiments by Yao and Hendricks (1996) found that at low infiltration rates wetting fronts stabilize because under these conditions capillarity dominates over gravity; thus, there is no mechanism to cause instability and no fingers form. They further found an increase in the number and a decrease in the size of 
fingers as the infiltration rate increased. Similar studies are needed to address finger formation and its scale when the fluid properties differ from these of water at ambient temperatures (e.g., high density fluids, hot liquids).

\subsubsection{Temporal Effects}

In dry environments, deep vadose zone flow (i.e., recharge to the aquifer) can be dominated by the extreme transient events (e.g., snowmelt and run-on events) if they result in saturated or nearly saturated conditions in regions with fast preferential pathways. Proper assessment of deep recharge and effects related to enhanced transport down borehole annular space or any near surface preferential pathways and/or man-made structures must be addressed at a higher resolution both spatially and temporally. How spatial and temporal variations (particularly the extreme events) interact with heterogeneity and interfaces (particularly sloping ones with breaks or holes) to change the pathway and rates, needs more investigation. The effects of geologic complexity and the spatial and temporal complexity of adjacent, interacting sources (e.g., water line leaks, fire hydrant flushing, adjacent cribs) have also not been adequately addressed.

\subsubsection{Funneled Flow Coupled with Colloid Transport}

The Tank Waste Remediation System (TWRS) Expert Panel (DOE 1997) hypothesized that structure controlled flow coupled with colloid transport was the most likely mechanism to move large quantities of contaminants (such as cesium-137). If important to the transport of key contaminants, this combination of processes needs to be investigated. Research is currently underway to investigate the impact of colloids on contaminant transport in Hanford sediment (Zhuang et al. 2003; Cherrey et al. 2003).

\subsubsection{Temperature and Density Effects}

Other important issues raised by the TWRS Expert Panel relate to how the hot $\left(177^{\circ} \mathrm{C}\right)$ caustic waste from tank leaks interacts with the geohydrologic system through time to affect both the fluid movement and contaminant transport processes. Many of the heat effects related to the high temperatures of the tanks, elevated temperatures surrounding the tanks, and self-heating nature of the leaked waste have yet to be investigated and resolved.

The high heat load of the single-shell tanks coupled with vapor transfer could potentially set up a system whereby soluble briny waste, leaked from the tank, could migrate toward the heat source (e.g., center of the bottom of the tank). The possibility of a heat pipe being created needs to be investigated, as does the nature and scale of the effect. In addition, the possibility that the high heat lowered infiltration rates needs to be investigated.

Density effects have only been investigated to a limited degree (e.g., Ward et al. 1997). These studies did not fully investigate the interactions of density with temperature, unstable flow effects, structurally controlled preferential flow (e.g., clastic dikes), colloidal transport, and/or waste-soil chemical and physical effects to determine inter-relationships and importance among the processes. 


\subsubsection{Geochemical Processes}

As discussed in detail in the Groundwater/Vadose Zone Integration Project Specification (DOE 1998) and Science and Technology Summary Description (DOE 2000), more studies are needed to improve the knowledge and databases for the vadose zone.

The vadose zone is not well characterized in a quantitative fashion. Field studies will corroborate lab tests and extend the time to study reactions from months to tens of years. Field studies will allow some key questions to be investigated such as the extent of existing physical, chemical, and mineralogic associations between contaminants and major chemical components in the waste and sediment and identification of the primary processes that produced these associations. Such "forensic" characterization will identify migration profiles (transport distances and concentrations) of key constituents and changes in the mineralogy, sorption capacity, and buffer capacity. Subsequent to characterization and analysis of the resulting data, laboratory testing to quantify the key controlling processes will begin. The goal will be to evaluate the key short- and long-term processes controlling the key risk driving contaminants. Processes to be quantified include adsorption, mineral precipitation and dissolution, biomineralization, matrix diffusion, pore plugging, and colloid formation and transport.

In the area of geochemistry, field studies are in progress on representative contaminated sites to improve the conceptual models for waste interactions and on contaminant transport processes and directed laboratory research to clarify details of the chemical processes. Another activity in which geochemists will contribute is development of a credible reactive transport model. At the present time, $\mathrm{SAC}$ will likely rely on the $K_{d}$ construct to describe all contaminant retardation reactions/processes. More sophisticated descriptions of contaminant/sediment interactions may be required for future iterations of SAC.

Field studies to characterize the near-field geochemical environments at representative inactive liquid waste disposal sites and past leaks at single-shell tanks and complementary laboratory studies under more controlled conditions are in progress. The field studies (vadose zone geochemical and hydrologic characterization) will provide the ranges of conditions and field scale observations on contaminant distributions and migration rates versus time or volume discharge. Once the field characterization data bound the conditions and define the nature and extent of the near field, laboratory tests can be chosen to better quantify the physical and chemical processes that control the interaction of contaminants and sediment. Currently at most liquid disposal sites, information is available on the chemistry and volumes disposed, and groundwater monitoring data are available to describe existing contaminants within the upper unconfined aquifer.

These efforts are likely to focus on the "extreme-pH" chemical environments such as acidic process liquids and highly alkaline tank liquors. The latter were also high temperature fluids and both are known to have contained organic complexing agents. Our knowledge base is most sparse for these extreme-pH wastes that are far from chemical equilibrium with the sediments. During interactions of these highly reactive solutions with the sediments, large amounts of mineral dissolution and precipitation can occur. Such large changes in mass between phases can significantly influence the pore structure and hydraulics (permeability) of the vadose zone sediments. The formation and sequestration of colloids may also be most active in this dynamic zone. It is this highly interactive near-field zone that merits detailed study to 
improve current modeling approaches which rely on the simplistic $\mathrm{K}_{\mathrm{d}}$ construct. More detailed discussions of the planned field characterization and focused laboratory studies can be found in DOE $(1998,2000)$ and individual project work plans such the ORP's RFI/CMS Single-Shell Tank Vadose Program Work Plan (DOE/RL 2000b) and the Immobilized Low-Activity Waste Multi-Year Statement of Work (LMHC 1999).

\subsection{Technical Basis and Approach for Vadose Zone Modeling}

Kincaid et al. (2004) describe the basis and technical approach for the 2004 Composite Analysis, indicating that the SAC (Kincaid et al. 2000; Bryce et al. 2002; Eslinger et al. 2002 a, b) would be used for the analysis. The SAC consists of a set of modules (models and data) that have been assembled since the previous 1998 Composite Analysis was performed to allow the collective impact of all the waste that will remain at the Hanford Site to be estimated. These modules include: Inventory, Release, Air Transport, Vadose Zone Transport, Groundwater Transport, Soil, River, Riparian Zone, and Risk/Impact Modules. These modules have been organized to simulate the transport and fate of contaminants through the environment. In general, inventory feeds to release, which feeds to the atmospheric, vadose zone, groundwater, and Columbia River pathways. The atmosphere, groundwater, Columbia River and riparian zone modules provide media-specific concentration estimates used in the risk and impact assessment.

Kincaid et al. (2004) identified 1,046 waste sites from the 2,730 Waste Information Data System (WIDS) sites and several existing and future storage sites for inclusion in the 2004 Composite Analysis. Analysis of liquid discharge and unplanned release sites will be conducted on a site-by-site basis whenever inventory and release data permit. This is because the superposition of liquid discharge to a single soil column results in non-representative contaminant migration and release from the vadose zone. Solid waste burial grounds will be simulated at the burial ground scale; for example, individual burial trenches would be aggregated for a single burial ground. The inventory of solid waste disposal will be increased over time until all burial grounds are closed. Vadose zone flow and transport simulations for the assessment will be based on 1) hydrogeologic profiles and properties for selected areas of the Hanford Site, 2) estimates of deep drainage rates that drive contaminant migration, 3) estimates of geochemical reactions between contaminants and the soil and sediment of the vadose zone profile, and 4) waste inventory and release projections. The first three of these data types are the focus of this data package. The fourth, waste inventory and release projections, is the subject of other data packages.

The behavior of contaminants in the vadose zone can be complex and subject to many unresolved issues and levels of uncertainty. The options for numerically simulating this behavior can be equally as complex. Table 2.1 attempts to summarize some of the important features and processes that can be incorporated into the simulations, depending on the complexity of the model. On a large scale, and for 
Table 2.1. Options for the Composite Analysis (after the Preliminary Concepts Document) ${ }^{(a)}$

\begin{tabular}{|c|c|c|c|c|}
\hline Model Type & $\begin{array}{c}\text { Dimensions and } \\
\text { Hydrogeology }\end{array}$ & Transport Processes & $\begin{array}{c}\text { Scale and Temporal } \\
\text { Factors }\end{array}$ & $\begin{array}{c}\text { Degradation and Decay } \\
\text { Processes }\end{array}$ \\
\hline Simple & $\begin{array}{ll}- & 1-\mathrm{D} \\
- & 4-6 \text { Horizontal Layers } \\
- & \text { Homogeneous, } \\
& \text { Isotropic }\end{array}$ & $\begin{array}{ll}\bullet & \text { Aqueous Phase } \\
& \text { Transport } \\
\text { - } & \text { Linear Sorption } \\
& \text { Isotherm }\left(K_{d}\right)\end{array}$ & $\begin{array}{l}\text { - Step-Wise Steady } \\
\text { State } \\
\text { One Site per area per } \\
\text { waste type }\end{array}$ & $\begin{array}{ll}\text { - } & \text { Radioactive Decay } \\
\text { Diological Pseudo- } \\
\text { Decay }\end{array}$ \\
\hline Semi-Complex & $\begin{array}{ll}\text { - } & \text { 2-D } \\
\text { - } & \text { Up to } 10 \text { Sloping } \\
& \text { Layers } \\
- & \text { Homogeneous, } \\
& \text { Isotropic }\end{array}$ & $\begin{array}{ll}\bullet & \text { Density and } \\
\text { Temperature Effects } \\
\text { - Linear Sorption } \\
\text { Isotherms ( } K_{d} \text { values) } \\
\text { - Peak Arrivals }\end{array}$ & $\begin{array}{l}\text { - Long Term Climate } \\
\text { Changes } \\
\text { - Sites on finer grid }\end{array}$ & $\begin{array}{ll}\bullet & \text { Radioactive Decay } \\
\text { - } & \text { Biological Decay }\end{array}$ \\
\hline Complex & $\begin{array}{ll}\text { - } & 2 \text { and 3-D } \\
\text { - } & \text { Numerous complexly } \\
& \text { formed layers } \\
\text { - } & \text { Heterogeneous and } \\
& \text { Anisotropic } \\
\text { - } & \text { Preferential Flowpaths } \\
\text { - } & \text { Chemically enhanced } \\
& \text { permeability }\end{array}$ & 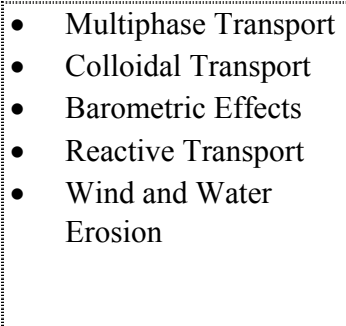 & $\begin{array}{ll}\bullet & \text { Episodic, Seasonal } \\
\text { Variations } \\
\text { Long Term Climate } \\
\text { Changes } \\
\text { Scale on site-specific } \\
\text { basis } \\
\text { Near and long term }\end{array}$ & $\begin{array}{ll}\bullet & \text { Radioactive Decay } \\
\bullet & \text { Inological Decay } \\
\text { (Oxidative/ } \\
\text { Reductive) }\end{array}$ \\
\hline \multicolumn{5}{|c|}{$\begin{array}{l}\text { (a) Groundwater/Vadose Zone Integration Project Preliminary System Assessment Capability Concepts for Architecture, } \\
\text { Platform, and Data Management. September 30, 1999. http://www.hanford.gov/cp/gpp/modeling/sacarchive/9-30rpt.pdf } \\
\text { (b) Shaded area identifies the model type options selected for the Composite Analysis. }\end{array}$} \\
\hline
\end{tabular}

the purposes of simulating the release of mobile contaminants from the vadose zone to the groundwater, the vadose zone can be simulated in a fairly simple manner to account for the most dominant features, events, and processes, as highlighted in Table 2.1.

\subsubsection{Features}

The physical structure (e.g., geology, hydrologic properties, geochemical properties) of the vadose zone and its principal transport pathways varies by location on the Hanford Site. Because the geometry and configuration of various hydrostratigraphic facies and heterogeneities are not well defined, the effects of these features will be captured via sensitivity or uncertainty analyses, within the context of larger hydrostratigraphic units. Not accounting for small-scale stratifications and variations in texture will likely lead to an under estimation of lateral spreading.

The limited quantity of site-specific data requires that values for the hydraulic properties be estimated from existing hydraulic property values provided by Freeman et al. (2002) and Freeman and Last (2003). For the 2004 Composite Analysis, the relationships between moisture content, pressure head, and unsaturated hydraulic conductivity are assumed to be nonhysteretic and representable using the van Genuchten (1980) and Mualem (1976) functions.

Predictions of unsaturated conductivity can be markedly improved by simultaneously fitting van Genuchten parameters to retention and unsaturated conductivity data (Kosugi et al. 2002). A subset of the samples tested at Hanford were analyzed for unsaturated hydraulic conductivity. Because unsaturated conductivity data were unavailable for a majority of samples, the parameter database was established 
using only those parameters determined using just retention data, so as to have an internally consistent set of parameters. Setting up the database in this manner allowed the generation of statistical distributions that support the Monte Carlo approach to be used for the 2004 CA. For future composite analyses, methods are being developed to incorporate and benefit from actual unsaturated conductivity data. Just as important, methods will also be developed to scale lab-derived parameters to field-scale appropriate parameters as well as develop methods to use field-derived parameters.

Again, with only limited site-specific geochemical data, values for the geochemical properties (i.e., $K_{d}$ values) must be estimated from the sediment type (e.g., grain-size data and the presence of secondary mineralization like the iron oxide coatings often found in the Ringold Formation) and waste type, based on data from existing laboratory measurements (Cantrell et al. 2003a). For most circumstances, the linear sorption model approach is adequate for modeling transport, especially for the far-field and low impact sites where geochemical conditions remain fairly constant and contaminant loading of the adsorption sites is low (Cantrell et al. 2003b). However, in situations where large changes in chemical conditions occur within a small spatial zone (e.g., where highly concentrated, alkaline or acidic wastes have been discharged), a more sophisticated approach to surface adsorption modeling may be warranted. A simplified way to account for changes in mobility is to use a multitude of different $K_{d}$ values to represent the sorptive capacity of the soil as the waste becomes more diluted and/or buffered by meteoric recharge and waste-sediment interactions (i.e., mimicking the decrease in competing ions along the flowpath) as was done in the previous Composite Analysis (Kincaid et al. 1998) and SAC initial assessment (Bryce et al. 2002).

\subsubsection{Events}

Various events could be considered in the implementation model for the composite analysis include those that are naturally occurring (e.g., meteoric recharge), those that are manmade (e.g., intentional or unintentional contaminant and water releases), those that are rather normally occurring (e.g., occur slowly over a long period of time), and those that represent extreme or unusual occurrences (e.g., 500 year storms, volcanism). Of primary importance to the composite analysis are the source release events, which discharged large volumes of waste water to the vadose zone, and the deep drainage (recharge) of meteoric water. Climate change and other disruptive events such as volcanism, flooding, or human disturbance are believed to be of rather low probability or consequence and are outside the scope of the composite analysis (Kincaid et al. 2004).

\subsubsection{Processes}

For the majority of contaminants, movement through the vadose zone is contingent on being dissolved within flowing water. The primary long term source of flowing water is precipitation that has infiltrated below the zone of evaporation and the influence of plant roots. Such water eventually flows to the water table, carrying with it whatever dissolved species may be present. Other important transport mechanisms such as: gaseous transport, temperature gradients, and possibly colloidal transport, are not considered significant on the scale and complexity of the composite analysis.

The rate of recharge (deep drainage) at a particular location can be influenced by climate, soil, vegetation, topography, springs and streams, animal activity, fire, water and wind erosion and deposition, 
plant community changes, disturbance, and human structures (e.g., roads, buildings). For most applications, flow rates through the vadose zone can be calculated using Richards equation with gravity and capillary potential gradients providing the dominant forces.

The formation of colloids and occurrence of colloid-facilitated transport of contaminants have been identified as a potentially important process for the vadose zone (DOE 1997). However, for most waste sites at Hanford, the low water content and simple geochemistry are not conducive to colloid formation or colloid-facilitated transport. Little or no data exist at the Hanford Site to adequately characterize the potential for colloidal transport.

Various preferential pathways such as clastic dikes and fractures are capable of concentrating or contributing to phenomena such as fingering and funnel flow. Because of the nature of some waste, the local routes of contaminant movement will vary. The Vadose Zone Expert Panel (DOE 1997) stated that a likely mode of transport for leaked or disposed tank waste in the Hanford geology is along preferential, vertical, and possibly tortuous pathways. However, detailed analyses of tank farm plumes as well as vadose zone transport field studies suggest that these mechanisms are not significant contributors to groundwater contamination under normal recharge environments (i.e., fluxes $<100 \mathrm{~mm} / \mathrm{yr}$ ) (Knepp 2002; CH2M HILL Hanford Group 2002; Murray et al. 2003).

The fate of contaminants in the vadose zone depends on geochemical conditions, the speciation of the contaminant, residence time, and microbial activity. Sediment has the capacity to sorb most contaminants from solution. The amount of sorption is a function of many factors. Some contaminants do not sorb at all. Sorption can be described using a simple linear relationship (i.e., a distribution coefficient or $K_{d}$ ) that is determined empirically. The $K_{d}$ approach is applicable for most analyses at Hanford where contaminant concentrations are low and the chemistry is relatively constant. However, conditions near some waste sources are highly variable due to strong influences from the chemical components in the wastes. The general consensus is that these wastes will likely decrease the sorption of normally sorbed contaminants (e.g., cesium-137), increasing in their mobility until concentrations in the sediments decrease to the range appropriate for the $K_{d}$ approach.

Contaminants that exist in the gas phase (e.g., radon, carbon-14, carbon tetrachloride) are subject to atmospheric venting and vapor extraction. Carbon-14 as carbon dioxide also reacts strongly with alkaline earth cations to form insoluble carbonates at neutral to basic $\mathrm{pH}$ values, and can also react with cement (Krupka and Serne 1996; Serne et al. 1992). Contaminants near the soil surface are subject to animal and plant uptake and dispersal within the aboveground environment. Contaminants can also be consumed by microbes, degrading into other compounds that may or may not be considered contaminants. Sometimes it is the water that is consumed rather than the wastes. Waste forms such as the immobilized low-activity waste undergo a corrosion process that consumes water. In a dry disposal, this consumption process will create a water vapor gradient that draws vapor toward the waste form.

\subsection{Implementation}

The large scale and complexity of a cumulative effects assessment for the entire Hanford Site together with the lack of detailed characterization data and/or understanding of some of the fate and transport 
processes necessitates simplification of the site features, release events, and the contaminant fate and transport processes to enable timely results. Thus, the model approach shown in Table 2.1 was selected for this analysis.

Implementation of this modeling approach is schematically illustrated in Figure 2.5. The primary transport mechanism to be simulated is aqueous phase transport in the porous media of the vadose zone, with radiological decay simulated using first order decay models.

\subsubsection{Hydrogeologic Profiles}

The 2004 Composite Analysis will in general use a one-dimensional vadose zone model, with some analysis performed to explore the use of multidimensional models to explicitly account for structural features within the Hanford Site, and/or to condition the one-dimensional model results (Kincaid et al. 2004). To account for large scale variability in the hydrostratigraphy across the Hanford Site, the
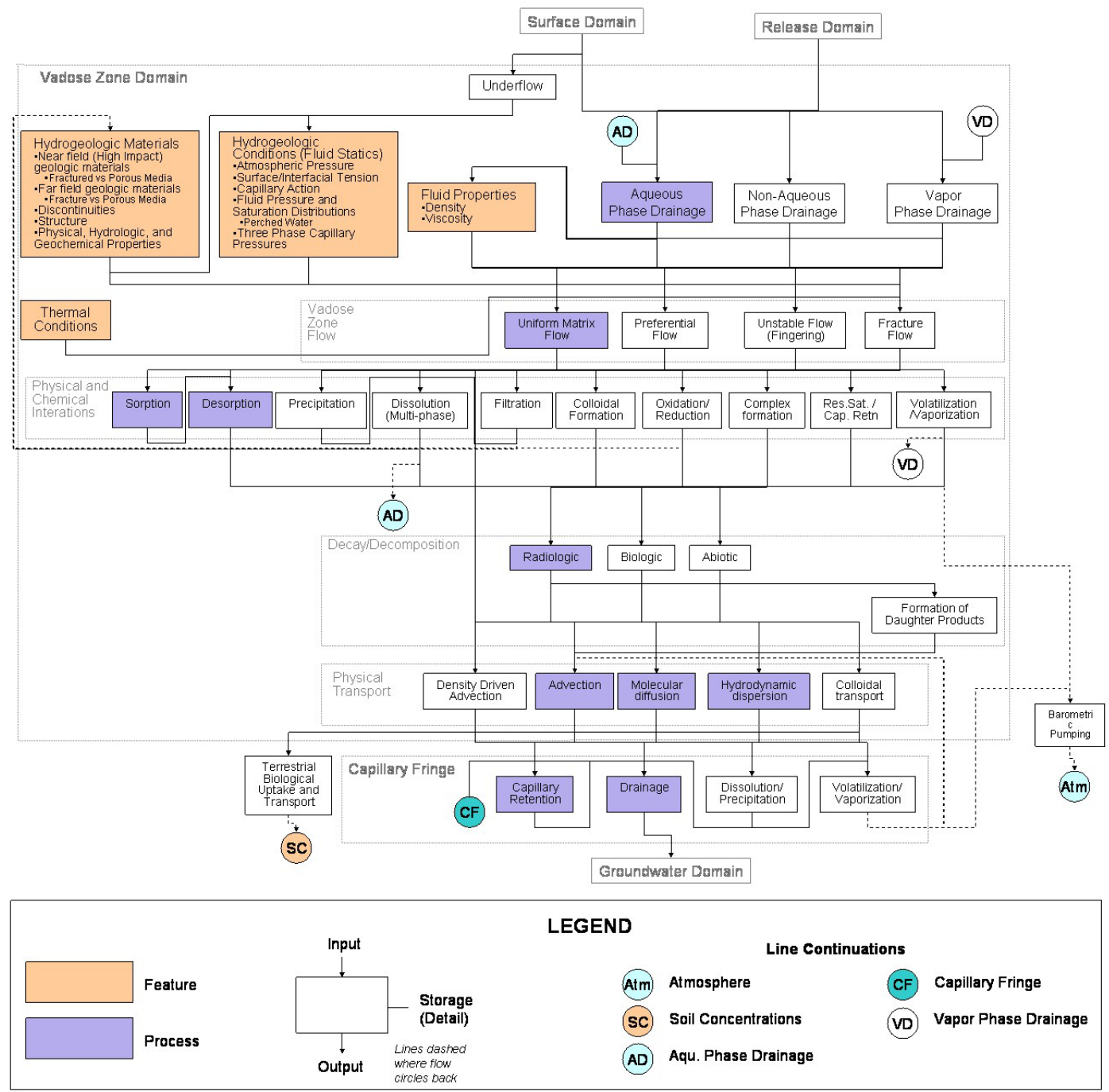

Figure 2.5. Schematic of Vadose Zone Implementation Model for the Composite Analysis 
preparation of hydrogeologic profiles and hydraulic and transport property datasets for each site were grouped into a number of geographic areas assumed to have similar hydrogeologic structure and properties. Hydrogeologic units are identified and their thickness ranges specified for each of these hydrogeologic provinces. To account for finer scale variability and uncertainty in the model parameters, probability distribution functions for each process model parameter were developed for each hydrogeologic unit of the hydrogeologic province.

Kincaid et al. (2000) identified the Subsurface Transport Over Multiple Phases (STOMP) computer code (White and Oostrom 1996) as the code of choice for the Vadose Zone Flow and Transport Module for the System Assessment Capability. Properties that would be represented include unsaturated hydraulic conductivity, porosity, water retention parameters, dispersivity, and diffusion coefficient. Kincaid et al. (2004) also indicated that care would be taken to develop and apply correlated model parameters, where necessary, to appropriately model properties (for example, parameters of the van Genuchten and Mualem models - van Genuchten 1980) of unsaturated hydraulics and water retention). Data to support the vadose zone profile and property models would be assembled for each geographic area.

\subsubsection{Deep Drainage Rates}

Deep drainage rates (also called recharge rates) are critical to the 2004 Composite Analysis because they affect both the release of waste from the disposal zone and the transport of waste to the water table. Deep drainage rates are a function of the climate, surface soil, topography, and vegetation. Kincaid et al. (2004) indicated that estimates of deep drainage and water-table elevation for the 2004 Composite Analysis will be based on the assumption of a continuation of current climate as defined by Hanford Site weather records (Hoitink et al. 2003). Hanford weather data have been collected regularly since 1946 at the Hanford Meteorological Station, which is located between the 200 East and 200 West Areas.

For the 2004 Composite Analysis, a set of deep drainage rates will be assigned for specific intervals of time. The first interval, called the pre-Hanford period, is the natural environment that existed prior to the start of Hanford activities. The undisturbed soil profiles and the shrub-steppe plant community determine the rates during this interval.

The second interval is called the operations period, during which much of the land surface at waste sites was disturbed (e.g., trenches excavated; cribs constructed; waste disposed and buried) and maintained free of vegetation.

The third interval is the remediation period, during which sites will be covered with a protective surface barrier, remediated by retrieval and/or treatment, or left intact. For sites receiving a surface barrier, the remediation period begins with construction of the barrier and lasts for the period of institutional control followed by the design life of the barrier. For sites being remediated by retrieval, the remediation period encompasses the time to remove the contamination (and inventory) to a prescribed depth, place it in the Environmental Remediation Disposal Facility, and backfill with sediment. For sites being treated in place, the Remediation period encompasses the time to treat the contaminants so that they are altered or destroyed and then restore the site. For both retrieval and treatment activities, the remediation period includes the period of institutional control during which a shrub-steppe plant community is 
re-established. In both cases, the vadose zone simulations will continue to predict the migration and fate of residual contamination in the vadose zone below the cleanup depth.

The fourth and final interval is the post-Hanford period, during which long-term changes can occur after the site is no longer under active institutional control. The post-Hanford period represents the longest time interval evaluated. During this period, the design life of surface barriers is exceeded. For a period of time equivalent to the design life of the barrier, the deep drainage rate is changed in stages till it reaches the rate associated with an equivalent natural soil.

\subsubsection{Geochemical Reactions}

Kincaid et al. (2004) indicated that adsorption of contaminants with vadose zone sediment will be approximated using the linear sorption isotherm model. The mobility of contamination is highly dependent on its speciation and surrounding environment. It is assumed that upon introduction to the vadose zone environment, waste mobility is dominated by waste characteristics. After being in contact with vadose zone sediment and soil water for some distance, it is assumed the waste undergoes a change in its mobility based on buffering of the contaminant solution by the vadose zone hydrogeologic units. Finally, it is assumed once contaminants have migrated a short distance in the Hanford Site unconfined aquifer, another mobility state is defined by the highly buffered, neutralized, and diluted contaminant. Distribution coefficients would be defined for each contaminant in several zones; for example, upper (near field) vadose zone, lower (far field) vadose zone, and unconfined aquifer. Where indicated, $K_{d}$ dependency on hydrogeologic units would be included. Broad ranges of distribution coefficient may be necessary to represent the suite of waste speciation and surrounding environment conditions that are possible. Data to support the vadose zone and aquifer geochemical reaction model would be assembled.

\subsubsection{Interaction with the Inventory, Release, and Groundwater Modules}

The inventory and release modeling results for the composite analysis will provide input to the vadose zone module. In addition to curie or kilogram amounts of waste and waste volume, the inventory module provides data on the location and dimensions of each storage or disposal facility. The release module, in concert with the inventory module, provides the contaminant flux to the vadose zone. Large-volume contaminant releases to sites where the vadose zone is thin, such as the cooling water discharges to retention basins in the 100 Areas, are routed directly to the Columbia River, bypassing the vadose zone.

The Vadose Zone Module will provide estimates of the mass flux of contaminant as a function of time entering the unconfined aquifer. The estimates will address releases from all operational areas for the radionuclide and chemical contaminants selected for the 2004 Composite Analysis. Released flux to the aquifer will be provided for individual waste sites and/or aggregations of waste sites where available (for example, liquid discharge sites), and for solid waste burial grounds where applicable (for example, the combination of trenches that comprise solid waste burial grounds). The vadose zone releases to the aquifer will be aggregated to groundwater model nodes in order to introduce contaminants into the aquifer model.

The Vadose Zone Module will provide estimates of mass flux of contaminants from the vadose zone to groundwater for the period of analysis. 


\subsection{Data Compilation}

Kincaid et al. (2004) selected a reduced model approach for simulating vadose zone flow and transport for the composite analysis. In this approach, flow and transport are treated as either onedimensional processes or as one-dimensional approximation of two-dimensional processes. Vadose zone simulations will be conducted using the STOMP computer code (White and Oostrom 1996). Needed input parameters include: 1) hydrostratigraphy; 2) physical and hydraulic properties (e.g., unsaturated hydraulic conductivity, porosity, water retention parameters, dispersivity, diffusion coefficients); 3) contaminant distribution coefficients; and 4) estimates of deep drainage rates.

Input parameters for the vadose zone model were obtained from existing geologic, soil physics, and geochemical databases. To facilitate sensitivity and uncertainty analyses, probability distribution functions were developed for each of the primary transport parameters.

\subsection{HydroStratigraphy}

The vadose zone stratigraphic profiles and hydrogeochemical property distributions for the composite analysis are represented by 26 generalized one-dimensional vertical columns. These 26 stratigraphic profiles represent 17 general geographic areas and 9 site-specific locations. Each hydrostratigraphic profile (template) was configured with the hydraulic and geochemical parameters necessary for STOMP to simulate the flow and transport through the vadose zone. As many as five variations of a single hydrostratigraphic template were necessary to more accurately represent the depth of waste releases and thickness of the vadose zone beneath the point of injection. Additional variations of the hydrostratigraphic templates were necessary to accommodate variations in $K_{d}$ values associated with different waste chemistry designations. Thus, a series of 63 templates were ultimately identified for application in the 17 geographic areas shown in Figure 3.1. These templates consist of the one-dimensional stratigraphy, hydrologic properties, and geochemical properties as well as the waste site type (e.g., crib, tank, etc.) and waste chemistry designation. An additional template was added to identify those sites that discharged waste effluents directly to the river. A more complete discussion regarding the development of the templates is provided in Section 3.2 and Last et al. 2004.

The preferred approach for modeling contaminant transport through the vadose zone uses these templates to represent the vadose zone beneath each waste site within a given geographic area. The actual simulation of each waste site assigned to a given template is implemented at that site's centroid coordinates.

Each template consists of a few major hydrostratigraphic units that are horizontally layered with constant thicknesses and are homogeneous and isotropic (Figure 3.2). Hydrologic and geochemical parameters for each hydrostratigraphic unit are represented by stochastic distributions to facilitate sensitivity and uncertainty analyses. Once each site was assigned to a geographic area and representative stratigraphic template, site-specific parameters such as the site location (centroid), and recharge rates (based on surface cover changes) were added. Each site was then assigned a unique alphanumeric identifier (refer to Last et al. 2004). 


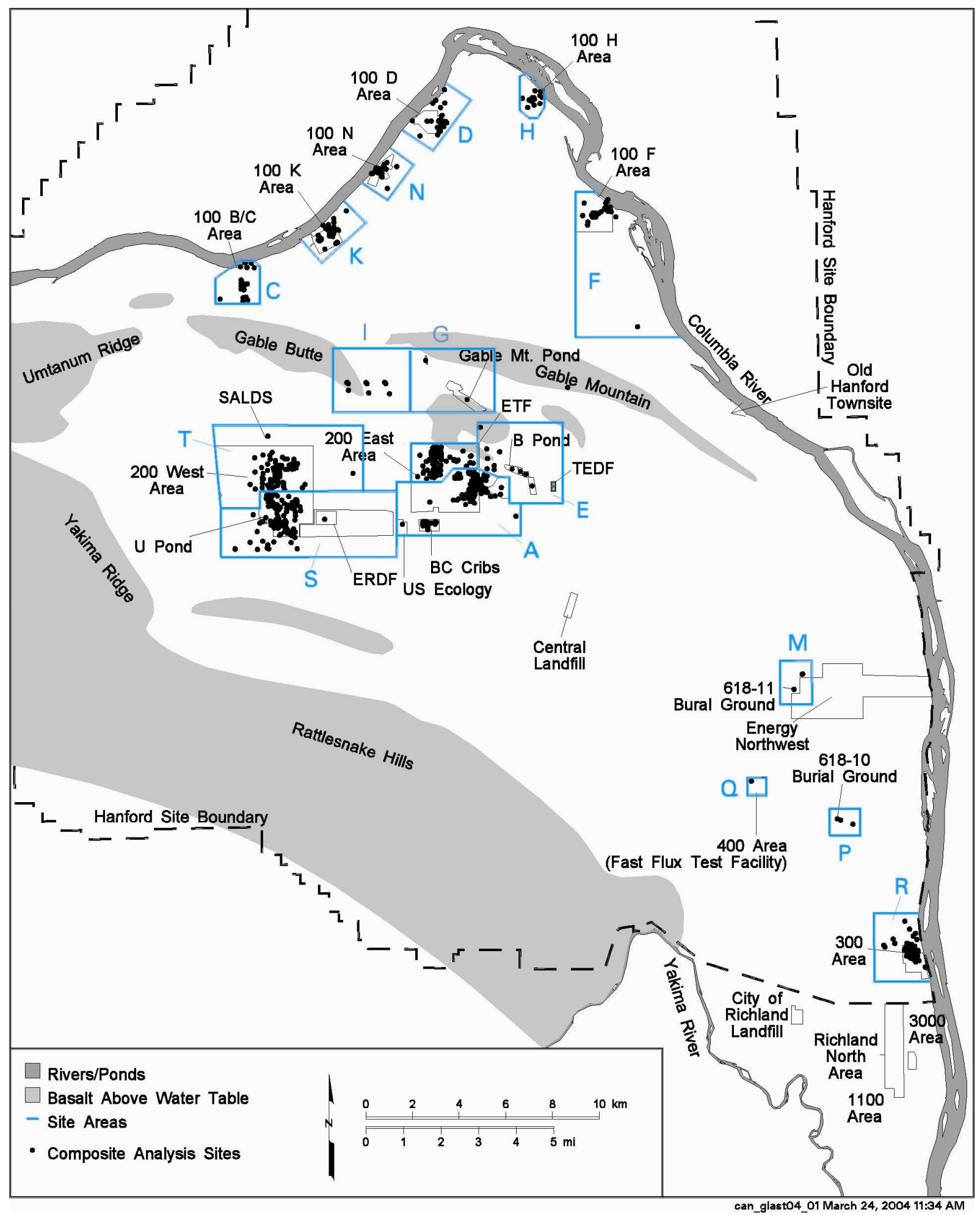

Figure 3.1. Location of Geographic Areas Represented by a Single Generalized Stratigraphic Column 


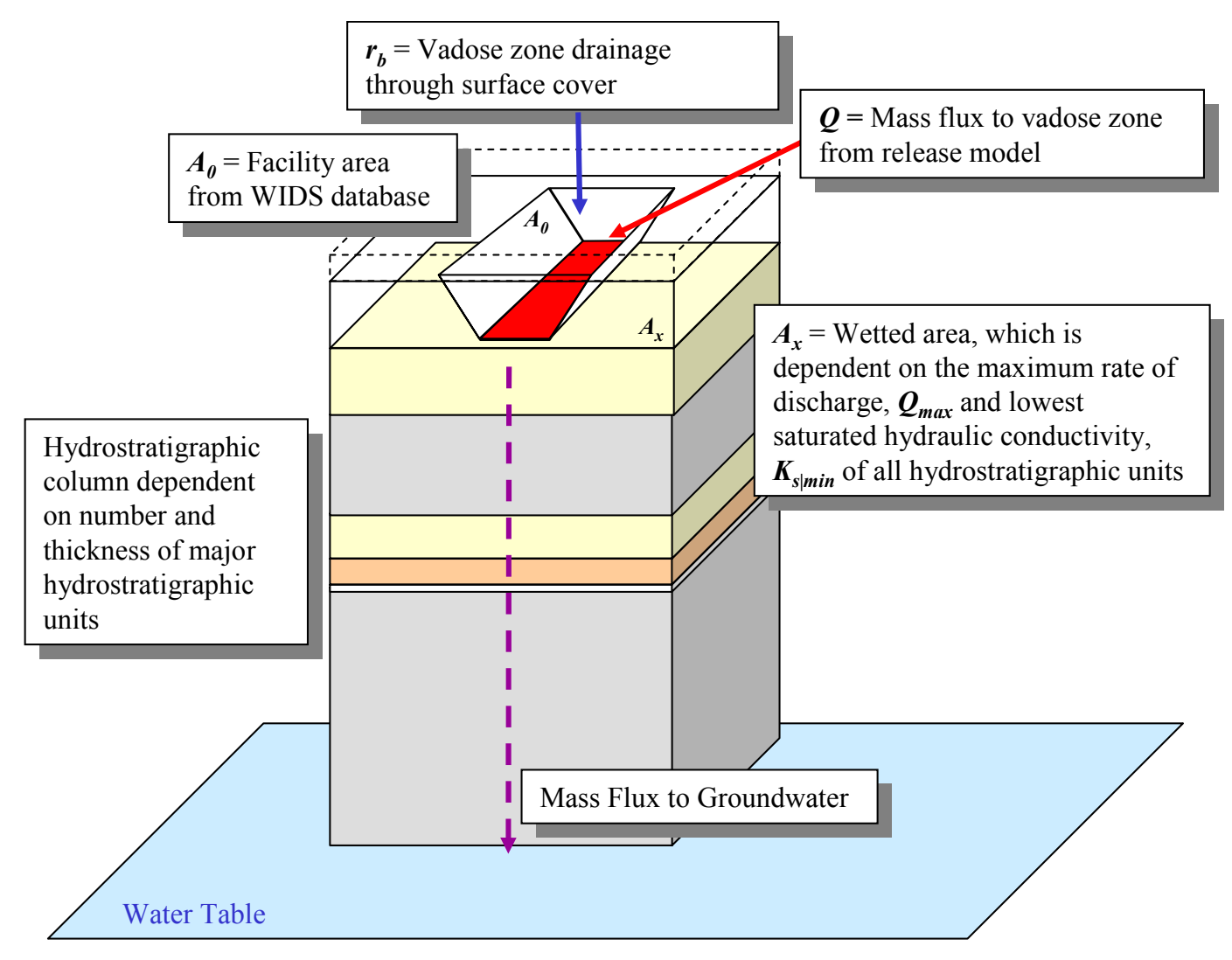

Figure 3.2. Schematic of One-Dimensional Vadose Zone Simulation

\subsection{Hydrostratigraphic Templates}

Sixty-three hydrostratigraphic templates were defined on the basis of 1) the types of waste sites, 2) the general hydrostratigraphy for 17 selected geographic areas (Figure 3.1), and 3) the chemical characteristics of the waste streams. To accommodate the large number of hydrostratigraphic templates, an alphanumeric code was developed to identify each unique hydrostratigraphic template. This code generally consists of a three-digit number that reflects the waste site type, a letter designating the geographic area, and a number designating the waste chemistry group for assigning $K_{d}$ values. Nine sitespecific hydrostratigraphic templates were created by adding additional alphanumeric characters to the geographic area designation. These codes are explained in Section 3.2.1.

\subsubsection{Waste Site Type (reflecting the depth of waste injection)}

Nearly all waste sites selected for simulation in the 2004 Composite Analysis have a Waste Information Data System (WIDS) site code. This code generally includes a three-digit number, with the first digit identifying the operational area where the facility is located, and the second and third digits identifying the type of facility. For example, the site code 116 indicates that the facility is in the 100 Area and that it is a liquid disposal facility (i.e., crib, pond, ditch); the site code 241 indicates that it is in the 200 Area and that it is an underground high-level waste tank. For the purposes of defining the base templates, five main categories of waste sites were distinguished: 1) surface facilities such as ponds, 
ditches, retention basins, buildings, unplanned releases; 2) near surface facilities such as cribs, specific retention trenches, French drains, burial grounds; 3) underground storage tanks; 4) reverse (injection) wells; and 5) river outfalls. Each of these site types (except the river outfalls) release waste to the vadose zone at increasingly deeper depths, making the hydrostratigraphic column shorter, and moving the location of high impact versus intermediate impact $\mathrm{K}_{\mathrm{d}}$ zones deeper in the soil profile. The waste site designation scheme for implementation in the base template nomenclature is shown in Table 3.1.

\subsubsection{Geographic and Site-Specific Areas Designations}

Seventeen geographic areas (Figure 3.1) were identified that could each be represented by a single generalized hydrostratigraphic column. Each of the six 100 Areas were designated as separate geographic areas because each area is geographically distinct and has distinct hydrogeologic characteristics. The 200 Areas were divided into six aggregate areas based on differences in hydrogeologic characteristics. The 200 West and 200 East Areas were each divided into two geographic areas. Additional geographic areas were designated for the 200 North, Gable Mountain Pond, and the B Pond areas. A single geographic area was designated to encompass waste sites in the 300 Area. Finally, three additional geographic areas were defined for isolated sites in the 400 and 600 Areas. Table 3.2 presents the letter designations and brief descriptions of each geographic area. Nine site-specific designations were created by adding additional alphanumeric characters to two of the geographic area designations (Table 3.3).

\subsubsection{Waste Chemistry Groupings (for assigning $K_{d}$ ranges)}

Six waste chemistry types were defined by Kincaid et al. (1998) for use in the 2004 Composite Analysis. These waste chemistry types describe chemically distinct waste streams that impact the sorption of contaminants. These same waste chemistry designations were adapted for use in the initial assessment conducted using SAC to assign $K_{d}$ values to the vadose zone base templates (Bryce et al.

Table 3.1. Waste Site Type Designations Used in the Hydrostratigraphic Template Codes

\begin{tabular}{||l|l||}
\hline \multicolumn{1}{|c||}{$\begin{array}{c}\text { Waste Site Type } \\
\text { Designation }\end{array}$} & \multicolumn{1}{|c||}{ Facility Types (reflecting depth of waste injection) } \\
\hline \hline $100,200,300,400$ & $\begin{array}{l}\text { Surface facilities (e.g., process sewers, reactor buildings, laboratory buildings, stacks, } \\
\text { ponds, ditches, valve pits, process plants, unplanned releases [except tank leaks]). }\end{array}$ \\
\hline $116,216,217,316,616$ & $\begin{array}{l}\text { Near surface, shallow liquid and/or dry waste disposal facilities (e.g., cribs, burial } \\
\text { grounds, retention basins, trenches, French drain, storage tunnels, drain/tile fields, } \\
\text { pipelines, sewers). }\end{array}$ \\
\hline 241 & $\begin{array}{l}\text { High level waste tanks, settling tanks, diversion boxes, catch tanks, tank leak unplanned } \\
\text { releases. }\end{array}$ \\
\hline $166,266,276$ & Deep injection sites (e.g., reverse wells) \\
\hline River ${ }^{\text {(b) }}$ & River outfalls and associated pipelines \\
\hline $\begin{array}{l}\text { (a) First digit represents the area: 1 = 100 Area, 2 = 200 Area, 3 = 300 Area, 4 = 400 Area, 6=600 Area. Second } \\
\text { and third digits indicate the facility type. } \\
\text { River outfall discharged wastes directly to the river; thus, there is no vadose zone flow and transport } \\
\text { component for these sites. }\end{array}$ \\
\hline \hline
\end{tabular}


Table 3.2. Geographic Area Designations Used in the Hydrostratigraphic Template Codes

\begin{tabular}{||c|l||}
\hline \hline Designation & \multicolumn{1}{|c|}{ Geographic Area Description } \\
\hline \hline A & $\begin{array}{l}\text { Southern 200 East Area - encompassing the PUREX (A plant), hot semi-works (C-Plant), } \\
\text { associated facilities (including PUREX tunnels), BC cribs, US Ecology, and the A, AN, AP, AW, } \\
\text { AX, AY, AZ, C Tank Farms }\end{array}$ \\
\hline B & $\begin{array}{l}\text { Northwestern 200 East Area - encompassing the B-plant, associated waste disposal facilities, and } \\
\text { the B, BX, BY Tank Farms }\end{array}$ \\
\hline C & $100-$ B/C Area \\
\hline D & $100-$ D/DR Area \\
\hline E & East of 200 East - B Pond \\
\hline F & $100-$ F Area \\
\hline G & Gable Mountain Pond Areas \\
\hline H & $100-$ H Area \\
\hline I & 200 North \\
\hline K & $100-$ KE/KW Area \\
\hline M & 600 Area near Energy Northwest and the 618-11 burial ground \\
\hline N & $100-N$ Area \\
\hline P & 600 Area southwest of the 400 area near the 618-10 burial ground \\
\hline Q & 400 Area \\
\hline R & 300 Area (and a few isolated facilities in and near the 400 Area) \\
\hline T & $\begin{array}{l}\text { Southern 200 West Area - encompassing the REDOX (S-Plant), U-plant, Z-plant associated } \\
\text { facilities, ERDF, and the S, SX, SY, U Tank Farms }\end{array}$ \\
\hline Forthern 200 West Area - encompassing T Plant, associated facilities, and the T, TX, TY Tank \\
\hline
\end{tabular}

Table 3.3. Site-Specific Area Designations Used in the Hydrostratigraphic Template Codes

\begin{tabular}{||l|l||}
\hline \hline Designation & \multicolumn{1}{|c||}{ Site-Specific Area Description } \\
\hline \hline A_BC_W & Southern 200 East Area - representing the western portion of the BC cribs area \\
\hline A_BC_E & Southern 200 East Area - representing the eastern portion of the BC cribs area \\
\hline A_BT_N & Southern 200 East Area - representing the northern portion of the BC trench area \\
\hline A_BT_S & Southern 200 East Area - representing the southern portion of the BC trench area \\
\hline A_BT_W & Southern 200 East Area - representing the western portion of the BC trench area \\
\hline A_ILAW_C & Southern 200 East Area - representing the central portion of the ILAW site \\
\hline S_U_N & Southern 200 West Area - representing the northern portion of the 216-U-1\&2 crib area \\
\hline S_U_S & Southern 200 West Area - representing the southern portion of the 216-U-1\&2 crib area \\
\hline S_Z9 & Southern 200 West Area - representing the 216-Z-9 trench area \\
\hline
\end{tabular}

2002). However, based on the results of a recent compilation of contaminant distribution coefficients $\left(K_{d}\right)$ for Hanford sediment (Cantrell et al. 2002), the six waste stream categories used in these assessments have been reduced to four. ${ }^{(\text {a) }}$

(a) Cantrell KJ, RJ Serne, and GV Last, Pacific Northwest National Laboratory, Richland, Washington. A white paper, Waste Stream Descriptions, Impact Zones and Associated $K_{d}$ Estimates Including Rational for Selections, dated May 16, 2003. 
$K_{d}$ values used in the 1998 Composite Analysis were initially tabulated for six source term categories (Kincaid et al. 1998, Table E.2) and three impact zone categories (Kincaid et al. 1998, Table E.3). In addition to the three impact zone categories (High Impact, Intermediate Impact and Groundwater), another $K_{d}$ category (Intermediate Impact Zone - Gravel) was included in the SAC initial assessment to represent very coarse lithologies composed of $90 \%$ by weight gravel. $K_{d}$ measurements are generally conducted on material that is $<2$ millimeters in size. The first three impact zone categories mentioned assume that the material is sand size and that $K_{d}$ values measured using $<2$ millimeter-size material are applicable. For materials that contain significant amounts of gravel, $K_{d}$ values will be much lower than those determined with $<2$ millimeter-size material because the surface area and corresponding quantity of adsorption sites is much lower. For the Intermediate Impact Zone - Gravel category it is necessary to make a correction to $K_{d}$ values due to the high gravel content. For the Intermediate Impact Zone - Gravel case, it was assumed that the material was $90 \%$ gravel and the corresponding correction factor was taken to be 0.31 for relatively high $K_{d}$ contaminants (cesium, strontium, and plutonium) and 0.1 for low $K_{d}$ contaminants (see Kaplan and Serne 2000, Appendix A). In future versions of the composite analysis, stratigraphic correlations will be used to estimate gravel contents of sediment to make gravel corrections to the $K_{d}$ values rather than using an assumed gravel content of $90 \%$ for gravel rich sediment.

To better justify the selection of the $K_{d}$ values for each waste stream designation and impact zone, it was determined that quantitative values (chemical concentrations), for each waste stream category should be assigned. This provides for a systematic approach for the assignment of $K_{d}$ values that is less ambiguous and more technically defensible.

Based on review of the six waste stream designations, six designations were reduced to four. The previous six waste stream designations were:

1. High Organic/Very Acidic

2. High Organic/Near Neutral

3. High Salt/Very Basic

4. Chelates/High Salt

5. Low Organic/Low Salt/Acidic

6. Low Organic/Low Salt/Near Neutral

These were simplified to the following four:

1. Very Acidic (simplified from 1 above)

2. High Salt/Very Basic (same as 3 above)

3. Chelates/High Salt (same as 4 above)

4. Low Salt/Near Neutral (same 6 above with incorporation of 2 and 5)

The reasons for these simplifications are discussed in the following paragraphs. The high organic designation can be eliminated because waste streams that were termed high organic generally refer to waste streams containing significant concentrations of tributyl phosphate, hexone, kerosene, lard oil, and/or carbon tetrachloride. Except for tributyl phosphate, these organics compounds do not complex metals and radionuclides under normal aqueous environmental conditions and as a result will not enhance 
their transport through chemical mechanisms. However, it is possible that if these materials occur as a free organic phase, they could significantly affect transport through multiphase flow and alteration of the hydrologic properties of the sediments.

Tributyl phosphate is a weak complexant and after any dilution will not be capable of significantly mobilizing metals and radionuclides. These organic compounds, if disposed in large quantities and high concentration, could potentially affect radionuclide and metal migration by creating a reducing zone; however, no field evidence for such an occurrence has been found. As a result of this simplification, the High Organic/Very Acidic waste stream was redesignated as the Very Acidic waste stream and the High Organic/Near Neutral waste stream was combined with the Low Salt/Near Neutral waste stream. The Low Organic/Low Salt/Acidic waste stream was combined with the Low Salt/Near Neutral waste stream because mildly acidic waste streams will generally be neutralized relatively quickly near the disposal location by calcite that occurs naturally in most Hanford sediment. Slower reactions with aluminosilicate minerals could also account for some acid neutralization.

To better justify the selection of $K_{d}$ values, specific compositions have been assigned to each waste stream (high impact zone). These compositions are shown in Table 3.4. The compositions are meant to represent a major component that is generic for each waste stream category and not an actual measured component. Only major components that are expected to have a significant influence on adsorption are included. In the case of the Very Acidic waste stream, the assumed composition is largely a guess. No actual acid concentration data could be located for this waste stream. The composition of the High Salt/Very Basic waste stream provided in Table 3.4 is meant to represent a generic composite composition of Hanford fuel processing waste that has leaked from single-shell tanks or intentionally discharged to specific retention cribs. Because a large number of leaking single-shell tanks occur in the single-shell waste management areas (S-SX, B-BX-BY, T and TX-TY, and U), estimated compositions available for SX Tanks and Tank T-106 (Agnew et al. 1996) were used to guide the selected compositions. Similar to the High Salt/Very Basic waste stream, the composition selected to represent the Chelates/High Salt waste stream should be considered to be a generic composite composition and does not represent any single or specific waste stream. The concentration of ethylenediamine-tetraocietic acid (EDTA) was selected based on measured concentrations of chelating agents in actual tank waste (Campbell et al. 1998a, 1998b).

Intermediate impact zone compositions are assumed to be $10 \%$ of the concentrations assumed for the high impact zone (Table 3.4), except in the case of the Very Acidic waste stream where it is assumed that all the acid is neutralized in the High Impact zone. The un-impacted zone is assumed to have the composition of typical Hanford groundwater. Several typical compositions of Hanford groundwater (uncontaminated) are tabulated in (Cantrell et al. 2002). In general, Hanford groundwater is a calcium

\section{Table 3.4. Waste Stream Designation and Assumed Compositions for Determination of $K_{d}$} Values

\begin{tabular}{|c|c|}
\hline Waste Stream & Composition \\
\hline Very Acidic & $1.0 \mathrm{M} \mathrm{HNO}_{3}$ \\
\hline High Salt/Very Basic & $2 \mathrm{M} \mathrm{NaOH}, 4 \mathrm{M} \mathrm{NaNO}_{3}, 2 \mathrm{M} \mathrm{NaNO}_{2}$ \\
\hline Chelates/High Salt & $1.0 \mathrm{M} \mathrm{NaNO}_{3}, 0.05 \mathrm{M}$ EDTA, pH 12 \\
\hline Low Salt/Near Neutral & Same as Hanford Groundwater \\
\hline
\end{tabular}


bicarbonate dominated water with a $\mathrm{pH}$ that typically ranges from approximately 7.5 to 8.5 . Other prominent major ions are sodium, chloride, sulfate, and magnesium. A total ion composition of between 4 and $10 \mathrm{meq} / \mathrm{L}$ is typical. Table 3.5 presents the waste chemistry designations used in the hydrostratigraphic templates.

\subsubsection{Hydrostratigraphic Template Designations}

A total of 63 hydrostratigraphic templates have been identified based on various combinations of the geographic areas, site types, and waste chemistry types. Table 3.6 provides a description of the general hydrostratigraphic templates established for each geographic area. Table 3.7 describes the site-specific templates set up for a number of key facilities within two of these general geographic areas.

Table 3.5. Waste Chemistry Designations Used in the Base Template Codes

\begin{tabular}{||c|l||}
\hline $\begin{array}{c}\text { Waste Chemistry } \\
\text { Designation }\end{array}$ & \multicolumn{1}{||}{ Waste Stream Description } \\
\hline \hline 1 & Very Acidic \\
\hline 2 & High Salt/Very Basic \\
\hline 3 & Chelates/High Salt \\
\hline 4 & Low Salt/Near Neutral \\
\hline
\end{tabular}


Table 3.6. General Hydrostratigraphic Templates for Each Geographic Area

\begin{tabular}{|c|c|c|c|c|c|}
\hline \multirow{2}{*}{$\begin{array}{c}\text { Template } \\
\text { Designation }\end{array}$} & \multicolumn{2}{|c|}{ Geographic Area } & \multicolumn{2}{|c|}{ Waste Site Types } & \multirow{2}{*}{$\begin{array}{c}\text { Waste } \\
\text { Chemistry } \\
\text { Designation }^{(\mathrm{d})}\end{array}$} \\
\hline & Area & Designation $^{(\mathrm{a})}$ & Description & Designation $^{(b)}$ & \\
\hline $100 \mathrm{C}-4$ & \multirow[t]{2}{*}{$\overline{10} 100 \mathrm{~B} / \mathrm{C}$} & \multirow[t]{2}{*}{$\overline{\mathrm{C}}$} & Surface Facilities & 100 & 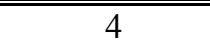 \\
\hline $116 \mathrm{C}-4$ & & & Near Surface Facilities & 116 & 4 \\
\hline 100D-4 & \multirow[t]{2}{*}{$100 \mathrm{D}$} & \multirow[t]{2}{*}{$\mathrm{D}$} & Surface Facilities & 100 & 4 \\
\hline $116 \mathrm{D}-4$ & & & Near Surface Facilities & 116 & 4 \\
\hline $100 \mathrm{~F}-4$ & \multirow[t]{2}{*}{$100 \mathrm{~F}$} & \multirow[t]{2}{*}{$\mathrm{F}$} & Surface Facilities & 100 & 4 \\
\hline $116 \mathrm{~F}-4$ & & & Near Surface Facilities & 116 & 4 \\
\hline $100 \mathrm{H}-4$ & \multirow[t]{2}{*}{$100 \mathrm{H}$} & \multirow[t]{2}{*}{$\mathrm{H}$} & Surface Facilities & 100 & 4 \\
\hline $116 \mathrm{H}-4$ & & & Near Surface Facilities & 116 & 4 \\
\hline $100 \mathrm{~K}-4$ & \multirow[t]{3}{*}{$100 \mathrm{~K}$} & \multirow[t]{3}{*}{ K } & Surface Facilities & 100 & 4 \\
\hline $116 \mathrm{~K}-4$ & & & Near Surface Facilities & 116 & 4 \\
\hline $166 \mathrm{~K}-4$ & & & Reverse Wells & 166 & 4 \\
\hline $100 \mathrm{~N}-4$ & \multirow[t]{2}{*}{$100 \mathrm{~N}$} & \multirow[t]{2}{*}{$\mathrm{N}$} & Surface Facilities & 100 & 4 \\
\hline $116 \mathrm{~N}-4$ & & & Near Surface Facilities & 116 & 4 \\
\hline 200G-4 & Gable Mtn. & $\mathrm{G}$ & Surface Facilities & 200 & 4 \\
\hline $200 I-4$ & $200 \mathrm{~N}$ & I & Surface Facilities & 200 & 4 \\
\hline $200 \mathrm{E}-4$ & E 200 E (B-Pond) & $\bar{E}$ & Surface Facilities & 200 & 4 \\
\hline 200B-2 & \multirow[t]{7}{*}{ N 200 E (B-Plant) } & \multirow[t]{7}{*}{ B } & \multirow[t]{2}{*}{ Surface Facilities } & \multirow[t]{2}{*}{200} & 2 \\
\hline 200B-4 & & & & & 4 \\
\hline $216 \mathrm{~B}-3$ & & & \multirow[t]{2}{*}{ Near Surface Facilities } & \multirow[t]{2}{*}{216} & 3 \\
\hline 216B-4 & & & & & 4 \\
\hline 241B-2 & & & \begin{tabular}{|l|} 
Tanks \\
\end{tabular} & 241 & 2 \\
\hline 266B-4 & & & \multirow[t]{2}{*}{ Reverse Wells } & 266 & 4 \\
\hline 267B-2 & & & & $267^{(c)}$ & 2 \\
\hline $200 \mathrm{~A}-2$ & \multirow{7}{*}{$\begin{array}{l}\text { S } 200 \text { E (PUREX, } \\
\text { BC Cribs) }\end{array}$} & \multirow[t]{7}{*}{ A } & \multirow[t]{2}{*}{ Surface Facilities } & \multirow[t]{2}{*}{200} & 2 \\
\hline $200 \mathrm{~A}-4$ & & & & & 4 \\
\hline $216 \mathrm{~A}-2$ & & & \multirow[t]{2}{*}{ Near Surface Facilities } & \multirow[t]{2}{*}{216} & 2 \\
\hline $216 \mathrm{~A}-4$ & & & & & 4 \\
\hline $241 \mathrm{~A}-2$ & & & \begin{tabular}{|l} 
Tanks \\
\end{tabular} & 241 & 2 \\
\hline $241 \mathrm{~A}-3$ & & & & & 3 \\
\hline $266 \mathrm{~A}-4$ & & & Reverse Wells & 266 & 4 \\
\hline $200 \mathrm{~S}-2$ & S 200 W (Redox, & $\mathrm{S}$ & Surface Facilities & 200 & 2 \\
\hline $200 \mathrm{~S}-4$ & U-Plant, Z-Plant) & & & & 4 \\
\hline
\end{tabular}


Table 3.6. (contd)

\begin{tabular}{|c|c|c|c|c|c|}
\hline $\begin{array}{c}\text { Template } \\
\text { Designation }\end{array}$ & \multicolumn{2}{|c|}{ Geographic Area } & \multicolumn{2}{|c|}{ Waste Site Types } & $\begin{array}{c}\text { Waste } \\
\text { Chemistry } \\
\text { Designation }^{(\mathrm{d})}\end{array}$ \\
\hline $216 \mathrm{~S}-1$ & \multirow{7}{*}{$\begin{array}{l}\text { S } 200 \text { W (Redox, } \\
\text { U-Plant, Z-Plant) }\end{array}$} & \multirow[t]{7}{*}{$\overline{\mathrm{SS}}$} & \multirow[t]{3}{*}{ Near Surface Facilities } & \multirow[t]{3}{*}{216} & 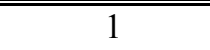 \\
\hline $216 \mathrm{~S}-2$ & & & & & 2 \\
\hline $216 \mathrm{~S}-4$ & & & & & 4 \\
\hline $241 \mathrm{~S}-2$ & & & \multirow[t]{3}{*}{ Tanks } & \multirow[t]{3}{*}{241} & 2 \\
\hline $241 \mathrm{~S}-3$ & & & & & 3 \\
\hline $241 \mathrm{~S}-4$ & & & & & 4 \\
\hline $266 \mathrm{~S}-4$ & & & Reverse Wells & 266 & 4 \\
\hline $200 \mathrm{~T}-2$ & \multirow[t]{8}{*}{ N 200 W (T-Plant) } & \multirow[t]{8}{*}{$\mathrm{T}$} & \multirow[t]{2}{*}{ Surface Facilities } & \multirow[t]{2}{*}{200} & 2 \\
\hline $200 \mathrm{~T}-4$ & & & & & 4 \\
\hline $216 \mathrm{~T}-2$ & & & \multirow[t]{3}{*}{ Near Surface Facilities } & \multirow[t]{3}{*}{216} & 2 \\
\hline $216 \mathrm{~T}-3$ & & & & & 3 \\
\hline $216 \mathrm{~T}-4$ & & & & & 4 \\
\hline $241 \mathrm{~T}-2$ & & & Tanks & 241 & 2 \\
\hline $266 \mathrm{~T}-2$ & & & \multirow[t]{2}{*}{ Reverse Wells } & \multirow[t]{2}{*}{266} & 2 \\
\hline $266 \mathrm{~T}-4$ & & & & & 4 \\
\hline $300 \mathrm{R}-4$ & \multirow{2}{*}{$\begin{array}{l}300 \text { Area (North } \\
\text { Richland }\end{array}$} & \multirow[t]{2}{*}{$\mathrm{R}$} & Surface Facilities & 300 & 4 \\
\hline 316R-4 & & & Near Surface Facilities & 316 & 4 \\
\hline 400Q-4 & 400 & Q & Surface Facilities & 400 & 4 \\
\hline $616 \mathrm{M}-4$ & 600 & $\mathrm{M}$ & Near Surface Facilities & 616 & 4 \\
\hline 616P-4 & 600 & $\mathrm{P}$ & Near Surface Facilities & 616 & 4 \\
\hline River & - & - & River & - & - \\
\hline \multicolumn{6}{|c|}{ (a) Assigned letter designation for geographic area. } \\
\hline \multicolumn{6}{|c|}{$\begin{array}{l}\text { (b) Assigned number designation for waste site type: First number designates traditional Hanford Site area (i.e., } \\
100,200,300,400,600 \text { Areas); last two numbers designate waste site type }(00=\text { surface facilities, } 16=\text { near } \\
\text { surface facilities, } 41=\text { tanks, } 66 / 67=\text { reverse wells). } \\
\text { (c) Two designations are used for reverse wells that have very different depths within a single geographic area. } \\
\text { The " } 67 \text { " designation distinguishes the very deep reverse wells from those at a more intermediate depth (66). } \\
\text { (d) Assigned number designation for waste chemistry type. }\end{array}$} \\
\hline
\end{tabular}




\subsection{Input Parameters}

This section describes the input data sets assembled for use in vadose zone modeling for the 2004 Composite Analysis.

\subsection{Hydrostratigraphy}

The geology of the vadose zone forms the framework through which contaminants move. The physical structure of the vadose zone, along with its hydraulic and geochemical properties, controls the migration and distribution of contaminants. Of particular interest are the interrelationships between the coarse- and fine-grained sediments within the vadose zone, and the degree of contrast in their physical and geochemical properties.

As described by Kincaid et al. 2004, the large scale and complexity of a cumulative effects assessment for the entire Hanford Site necessitates the use of a simplified modeling approach. In this approach, industrial waste sites were grouped into one of 17 geographic areas that were identified as having unique hydrostratigraphic properties. The vadose zone beneath each geographic area is represented as a single one-dimensional hydrostratigraphic column. The hydrostratigraphic information that described a geographic area was assembled into a common template for all waste sites within that area. These templates were assembled from existing information including:

- Driller's logs, geologists' logs, and geophysical logs

- Published interpretive depths to the top and bottom surfaces of hydrogeologic units

- Surface elevations (to convert hydrogeologic unit depths to elevations)

- Elevation of the 1944 water table (to define the bottom of the vadose zone prior to waste disposal)

In general, the main hydrostratigraphic units, contact depths, and thicknesses were taken from published maps and cross-sections, where available. The estimated average strata thicknesses were used to assemble the generalized columns extending from the surface to the 1944 water table (Kipp and Mudd 1973). However, because the sum of the average thicknesses did not always equal the distance from the ground surface to the water table, small adjustments were made to normalize the average strata thicknesses to equal the total thickness of the vadose zone. Table 4.1 lists the published references used to assign hydrogeologic units to each of the hydrostratigraphic templates.

Since lithofacies identification and geologic nomenclature has varied over time and by published sources, some translation was necessary to relate the major geologic units to a common classification. Table 4.2 describes the generalized hydrostratigraphic nomenclature used in this study based on that defined by DOE (2002), and Lindsey (1996). Appendix A provides the hydrostratigraphic column for each geographic area, including the layer thicknesses and their hydraulic and geochemical property designations. 
Table 4.1. Sources of Hydrogeologic Data for the Seventeen Geographic Areas to be Analyzed

\begin{tabular}{|c|c|c|}
\hline Geographic Area & Designation & References \\
\hline $100 \mathrm{~B} / \mathrm{C}$ & $\mathrm{C}$ & Lindberg 1993a; Lindsey 1992; Peterson et al. 1996 \\
\hline $100 \mathrm{D}$ & $\mathrm{D}$ & Lindsey and Jaeger 1993; DOE, 1993b; Lindsey 1992; Peterson et al. 1996 \\
\hline $100 \mathrm{~F}$ & $\mathrm{~F}$ & Raidl 1994; Lindsey 1992; Peterson et al. 1996 \\
\hline $100 \mathrm{H}$ & $\mathrm{H}$ & $\begin{array}{l}\text { Lindsey and Jaeger 1993; Liikala et al. 1988; Vermuel et al. 1995; DOE } \\
\text { 1993b; Peterson et al. } 1996\end{array}$ \\
\hline $100 \mathrm{~K}$ & K & Lindsey 1992; Lindberg 1995; Peterson et al. 1996 \\
\hline $100 \mathrm{~N}$ & $\mathrm{~N}$ & Hartman and Lindsey 1993 \\
\hline $\begin{array}{l}\text { Gable Mountain Pond } \\
\text { Area }\end{array}$ & G & Lindsey et al. 1992b; DOE 1993c; DOE 1993d; Wurstner et al. 1995 \\
\hline $200 \mathrm{~N}$ & I & Lindsey et al. 1992b; DOE 1993c; DOE 1993d; Wurstner et al. 1995 \\
\hline E 200 E (B-Pond) & $\mathrm{E}$ & $\begin{array}{l}\text { Barnett et al. 2000; Cearlock et al. 2000; Lindsey et al. 1992b; Wurstner et al. } \\
1995\end{array}$ \\
\hline N 200 E (B-Plant) & B & $\begin{array}{l}\text { Lindsey et al. 1992b; Price and Fecht 1976a, b, c; Tallman et al. 1979; } \\
\text { Wurstner et al. 1995; Wood et al. } 2000\end{array}$ \\
\hline $\begin{array}{l}\text { S } 200 \text { E (PUREX, BC } \\
\text { cribs, BC Trenches, } \\
\text { ILAW) }\end{array}$ & $\begin{array}{l}\text { A } \\
\text { A_BC } \\
\text { A_BT } \\
\text { A_ILAW }\end{array}$ & $\begin{array}{l}\text { Lindsey et al. 1992b; Reidel and Horton 1999; Valenta et al. 2000; Reidel } \\
\text { et al. 2001; Reidel and Ho 2002; Tallman et al. 1979; Wurstner et al. } 1995\end{array}$ \\
\hline $\begin{array}{l}\text { S } 200 \mathrm{~W} \text { (Redox, U- } \\
\text { Plant, Z-Plant) }\end{array}$ & \begin{tabular}{|l|} 
S \\
S-U \\
S-Z9
\end{tabular} & $\begin{array}{l}\text { Johnson and Chou 1988; Lindsey et al. 1992a; Price and Fecht 1976d; Slate } \\
\text { 2000; Tallman et al. 1979; Wurstner et al. 1995; Rohay et al. 1994; Connelly } \\
\text { et al. 1992a; Last et al. 1989; Last and Rohay 1993; Swanson et al. 1999; Well } \\
\text { logs for 299-W19-14, -15, and -16; and borehole data from wells 299-W15-8, } \\
-9,-83,-84,-86,-95,-101 \text {, and -207. }\end{array}$ \\
\hline N 200 W (T-Plant) & $\mathrm{T}$ & Lindsey et al. 1992a; Slate 2000; Tallman et al. 1979; Wurstner et al. 1995 \\
\hline $\begin{array}{l}300 \text { Area (North } \\
\text { Richland) }\end{array}$ & $\mathrm{R}$ & $\begin{array}{l}\text { Gaylord and Poeter 1991; Lindberg and Bond 1979; Schalla et al. 1988; } \\
\text { Swanson et al. } 1992\end{array}$ \\
\hline 400 Area & Q & $\begin{array}{l}\text { HEDL, 1975; Meier Associates Log Book Project V-749; Well logs from } \\
\text { 499-S1-8J, and 499-S1-7B. }\end{array}$ \\
\hline $\begin{array}{l}\text { 600 Area }(618-10 \\
\text { Area) }\end{array}$ & $\mathrm{P}$ & Well Logs from 699-S6-E4A \\
\hline $\begin{array}{l}600 \text { Area (618-11 } \\
\text { Area, Energy } \\
\text { Northwest) }\end{array}$ & M & Well Logs from 699-13-3A \\
\hline
\end{tabular}

In the simplified modeling approach selected for the composite analysis, the number and thicknesses of the hydrostratigraphic units within each template remain fixed. However, it must be recognized that there is uncertainty associated with the configuration of the hydrostratigraphic columns. The primary sources of uncertainty relate to drilling and sampling techniques, borehole logging, elevation control, and interpretation of the stratigraphy. 
Table 4.2. Hydrostratigraphic Units Used in this Study (after DOE 2002 and Lindsey 1996)

\begin{tabular}{|c|c|c|c|}
\hline Formation/Unit & Facies/Subunit & Code & Description \\
\hline \multirow[t]{2}{*}{ Holocene } & Backfill & $\mathrm{HDb}$ & $\begin{array}{l}\text { Poorly sorted gravel, sand, and silt derived from the Hanford } \\
\text { formation and/or Holocene deposits }\end{array}$ \\
\hline & $\begin{array}{l}\text { Medium-grained, } \\
\text { Cross-Bedded, } \\
\text { Well Sorted } \\
\end{array}$ & HDs & $\begin{array}{l}\text { Medium-grained dune sand, moderate to well sorted, and cross } \\
\text { laminated to cross-bedded. }\end{array}$ \\
\hline \multirow[t]{7}{*}{$\begin{array}{l}\text { Hanford } \\
\text { formation }\end{array}$} & $\begin{array}{l}\text { Interbedded } \\
\text { Sand- to Silt- } \\
\text { dominated } \\
\end{array}$ & HISSD & $\begin{array}{l}\text { Rhythmite sequences of slackwater deposits consisting of } \\
\text { graded beds of horizontal or climbing ripple laminated sand, to } \\
\text { fine sand, to silt (laminated to massively bedded). }\end{array}$ \\
\hline & $\begin{array}{l}\text { Sand-Dominated, } \\
\text { Silty Sand } \\
\end{array}$ & $\mathrm{HSD}(\mathrm{f})$ & $\begin{array}{l}\text { Silt to fine sand, massively bedded to horizontally laminated or } \\
\text { cross laminated. }\end{array}$ \\
\hline & \begin{tabular}{|l|} 
Sand-Dominated, \\
Fine Sand \\
\end{tabular} & HSD-Sm & Fine to coarse sand, massively bedded, with or without silt. \\
\hline & \begin{tabular}{|l} 
Sand-Dominated, \\
Coarse Sand \\
\end{tabular} & HSD-Sh(c) & $\begin{array}{l}\text { Medium to coarse sand with minor amounts of pebbly sand, } \\
\text { exhibiting horizontal to low-angle cross stratification. }\end{array}$ \\
\hline & $\begin{array}{l}\text { Sand-Dominated, } \\
\text { Gravelly Sand }\end{array}$ & $\operatorname{HSD}(\mathrm{c})$ & $\begin{array}{l}\text { Medium to coarse sand to pebbly sand (with up to } 30 \mathrm{wt} \% \text { very } \\
\text { fine pebble to cobble), with high angle planar-tabular cross } \\
\text { stratification to trough cross-stratification }\end{array}$ \\
\hline & \begin{tabular}{|l|} 
Gravel- \\
Dominated \\
\end{tabular} & HGD & $\begin{array}{l}\text { Silty sandy pebble to boulder gravel (with } 30-60 \mathrm{wt} \% \text { gravel), } \\
\text { massive to cross stratified. }\end{array}$ \\
\hline & \begin{tabular}{|l|} 
Gravel- \\
Dominated, \\
Coarse \\
\end{tabular} & HGD(c) & $\begin{array}{l}\text { Pebble to boulder gravel (with greater than } 60 \mathrm{wt} \% \text { gravel), to } \\
\text { silty sandy gravel, massive to cross stratified. }\end{array}$ \\
\hline \multirow[t]{2}{*}{ Cold Creek unit } & $\begin{array}{l}\text { Fine-Grained, } \\
\text { Laminated to } \\
\text { Massive }\end{array}$ & $\begin{array}{l}\text { CCUf(lam- } \\
\text { msv) }\end{array}$ & $\begin{array}{l}\text { Fine sand, silt, and/or clay, with a buff, pale to dark brown } \\
\text { color, well sorted to very well sorted, micaceous, and having } \\
\text { high natural-gamma activity }\end{array}$ \\
\hline & $\begin{array}{l}\text { Coarse to Fine- } \\
\text { Grained, } \\
\text { Carbonate } \\
\text { Cemented }\end{array}$ & $\begin{array}{l}\text { CCUf- } \\
\text { c(calc) }\end{array}$ & $\begin{array}{l}\text { Calcium-carbonate cemented clay, silt, sand, and/or gravel, } \\
\text { white to light gray in color, very poor to moderately sorted, } \\
\text { with a massive to platy structure and bioturbated with root casts } \\
\text { (rhyzoliths). }\end{array}$ \\
\hline \multirow[t]{2}{*}{\begin{tabular}{||l|l|} 
Ringold \\
Formation
\end{tabular}} & $\begin{array}{l}\text { Fluvial Sand } \\
\text { (Member of } \\
\text { Taylor Flat) } \\
\end{array}$ & Rtf & Interstratified sand and silt deposits \\
\hline & $\begin{array}{l}\text { Fluvial Gravel } \\
\text { (Member of } \\
\text { Wooded Island, } \\
\text { subunit E) }\end{array}$ & Rwi(e) & $\begin{array}{l}\text { Moderate to strongly cemented well rounded gravel and sand } \\
\text { deposits, and interstratified finer-grained deposits. }\end{array}$ \\
\hline
\end{tabular}

\subsection{Hydraulic Properties}

Hydraulic property data for the vadose zone simulations were derived from the laboratory measurements of 284 soil samples (both repacked and splitspoon samples) taken from the 100 and 200 Areas (Appendix B). These data were selected from a catalog of vadose zone hydraulic properties (Freeman et al. 2002) and a subsequent prototype database (Freeman and Last 2003). Because the 
hydraulic property data are rather limited in regard to the spatial location of samples and the soil types represented, individual stochastic data sets were developed to represent ten different soil classes. These ten classes build on the six soil classes originally identified by Khaleel and Freeman (1995) based on texture (i.e., particle size), International Society of Soil Science (ISSS) classification, and moisture retention curve characteristics. Four additional soil classes were incorporated to separate out the Cold Creek unit sediment, add additional detail for the Hanford formation sand-dominated sediment, and add a new class for very coarse gravel. The 10 soil hydraulic property classes and their associated hydraulic property distributions were later correlated to the hydrostratigraphic units used in the 17 geographic area templates. Table 4.3 describes the hydraulic-property soil classes to be used in the composite analysis.

The statistical distributions of van Genuchten model (van Genuchten 1980) parameters, saturated hydraulic conductivity, and bulk density data were developed from laboratory data described in a catalog of vadose zone hydraulic properties by Freeman et al. (2001, 2002), and a subsequent prototype database

Table 4.3. Description of Hydraulic-Property Soil Classes

\begin{tabular}{|c|c|c|c|c|}
\hline Formation & Soil Class & Code & Description & $\begin{array}{c}\text { Hydrostratigraphic } \\
\text { Unit Code(s) }\end{array}$ \\
\hline Holocene Deposits & Backfill & $\mathrm{Bf}$ & $\begin{array}{l}\text { Sand and gravel mixed with finer fraction. Same } \\
\text { as the SSG soil category identified by Khaleel and } \\
\text { Freeman (1995) }\end{array}$ & $\mathrm{HDb}$ \\
\hline \multirow[t]{6}{*}{ Hanford formation } & Silty Sand & Hss & $\begin{array}{l}\text { Sand mixed with finer fraction, containing }>50 \% \\
\text { fine sands, silt, and clay, with }>15 \% \text { silt and clay. } \\
\text { Derived from the SS soil category identified by } \\
\text { Khaleel and Freeman (1995) }\end{array}$ & HISSD/HSD(f) \\
\hline & Fine Sand & Hfs & $\begin{array}{l}\text { Sand, containing } 35-70 \% \text { fine sand, silt, and clay, } \\
\text { with }<15 \% \text { silt and clay. Derived from the S soil } \\
\text { category identified by Khaleel and Freeman (1995) }\end{array}$ & HSD-Sm \\
\hline & Coarse Sand & Hes & $\begin{array}{l}\text { Sand, containing }>60 \% \text { coarse sand. Derived from } \\
\text { the S soil category identified by Khaleel and } \\
\text { Freeman (1995) }\end{array}$ & HSD-Sh(c) \\
\hline & Gravelly Sand & $\mathrm{Hgs}$ & $\begin{array}{l}\text { Gravelly sand. Same as the GS soil category } \\
\text { identified by Khaleel and Freeman (1995) }\end{array}$ & $\mathrm{HSD}(\mathrm{c})$ \\
\hline & Sandy Gravel & $\mathrm{Hg}$ & $\begin{array}{l}\text { Sandy gravel for which gravel content is } \\
\text { approximately }<60 \% \text {. Same as the SG1 soil } \\
\text { category identified by Khaleel and Freeman } \\
(1995)\end{array}$ & HGD \\
\hline & Gravel & Hrg & $\begin{array}{l}\text { Very high gravel content soils ( }>60 \% \text { gravel) from } \\
\text { the } 100 \text { areas (along the river). }\end{array}$ & $\operatorname{HGD}(\mathrm{c})$ \\
\hline \multirow[t]{2}{*}{ Cold Creek unit } & Silt Dominated & PPlz & $\begin{array}{l}\text { Derived from the SS soil category identified by } \\
\text { Khaleel and Freeman (1995) but correlated to } \\
\text { Cold Creek unit silt. Includes additional samples } \\
\text { from borehole B } 8814 \text {. }\end{array}$ & CCUf(lam-msv) \\
\hline & Caliche & PPlc & $\begin{array}{l}\text { Derived from the SS soil category identified by } \\
\text { Khaleel and Freeman (1995) but correlated to the } \\
\text { Cold Creek unit carbonate. }\end{array}$ & CCUf-c(calc) \\
\hline \begin{tabular}{|l} 
Ringold \\
Formation
\end{tabular} & $\begin{array}{l}\text { Gravel } \\
\text { Dominated }\end{array}$ & $\operatorname{Rg}$ & $\begin{array}{l}\text { Sandy gravel for which gravel content is approxi- } \\
\text { mately }>60 \% \text {. Same as the SG2 soil category } \\
\text { identified by Khaleel and Freeman (1995). }\end{array}$ & Rwi(e) \\
\hline
\end{tabular}


(Freeman and Last 2003). Ideally, all parameters in this database should be corrected for gravel content using the same gravel-correction procedure. Some of the parameters are known to have been corrected using the Gardner method (e.g., Khaleel et al. 1997) However, it is not clear that all samples were treated in a consistent manner. Gravel percentages are included in Tables 4.4 to 4.8 to indicate which soil classes might be affected. Future revisions of this database ought to address any disparity that might exist among samples. Estimates for longitudinal dispersivity were primarily taken from Ho et al. (1999). Values for residual saturation $\left(S_{r}\right)$ were calculated by dividing the raw residual water content $\left(\theta_{R}\right)$ by the raw saturated content $\left(\theta_{S}\right)$. Effective porosity is assumed to be equal to the saturated water content $\left(\theta_{s}\right)$.

The high, low, mean, and standard deviation values were calculated for each soil hydraulic property class. However, it should be noted that most of these soil classes do not have enough data points to qualify as a statistically significant distribution (Warrick et al. 1986). The residual water content $\left(S_{r}\right)$, saturated water content $\left(\theta_{s}\right)$, bulk density $\left(\rho_{b}\right)$, gravel content, and fitting parameter $n$ are assumed as normal Gaussian distributions based, in part on the report of Khaleel and Freeman (1995). The saturated hydraulic conductivity $\left(K_{s}\right)$ and the fitting parameter $\alpha$, are treated as lognormal distributions, in accordance with Domenico and Schwartz (1990) and Carsel and Parrish (1988), respectively. In addition to the normal distribution statistics, the statistics for the log-normal parameters are also included and truncation values are calculated for all parameters. Although Carsel and Parrish (1988) have reported cross-correlations between a number of these parameters, recent examination of the Hanford Site data have not found any statistically significant correlations. ${ }^{(a)}$

In addition to statistical tables for the full suite of samples, subsets of samples were also assembled near specific sites of interest. Site-specific data sets for the 200 West Area, BC cribs and trenches, 200-UP-1 (216-U-1 and -2 cribs), and the 200-ZP-1 (216-Z-9 trench) were also assembled. The sitespecific data for the 216-U-1 and -2 cribs were derived from the S-SX tank farm, 216-U-1 and -2 crib, and Environmental Restoration Disposal Facility samples. The 216-Z-9 site-specific data consists of samples from T Tank Farms, the 216-ZP-1 area, the 218-W-5 burial grounds, and project C-018-H. A composite table consisting of only 200 West Area samples was also created as part of this task. This data set provides a greater sample population that is unique to the unsaturated hydraulic properties found in the 200 West Area plateau sediments. The site-specific data for the BC cribs and trenches are derived from the closest sites to the facility, the immobilized low-activity waste (ILAW) site, the Sission and Lu Injection test site, and U.S. Ecology. A disadvantage to using only those sample sets close to the site of interest is that the population size is greatly diminished resulting in cases where the statistical distribution may not adequately represent the actual formation properties.

Methods to increase the sample size (e.g., use an inverse distance weighting) ${ }^{(\mathrm{b})}$ or otherwise incorporate information from large data sets (e.g., Bayesian Updating) ${ }^{(\mathrm{b})}$ yet still account for site-specific

(a) Freeman EJ and ML Rockhold. 2003. Estimation of Site-Specific Probability Distribution Functions for Soil Hydraulic Parameters using Bayesian Updating. Letter Report, Pacific Northwest National Laboratory, Richland, Washington.

(b) Freeman EJ. May 14, 2003. Revised SAC Statistical Properties Tables of Vadose Hydraulic Properties. Letter Report, Pacific Northwest National Laboratory, Richland, Washington. 
information are being examined. However, for the purposes of the 2004 Composite Analysis, the sitespecific parameter distributions were based on equally weighted parameter values from samples nearest the site of interest. Tables 4.4 to 4.8 present the hydraulic property distributions for the Hanford site-wide data set as well as the site-specific data sets.

Table 4.4. Statistical Mean Values for Site-Wide Samples

\begin{tabular}{|c|c|c|c|c|c|c|c|c|c|}
\hline \multicolumn{10}{|c|}{ Site-Wide } \\
\hline $\begin{array}{c}\text { Soil } \\
\text { Class } \\
\end{array}$ & Count & $\begin{array}{c}\alpha \\
(1 / \mathrm{cm}) \\
\end{array}$ & $n$ & $\begin{array}{c}\theta_{R} \\
\left(\mathrm{~cm}^{3} / \mathrm{cm}^{3}\right) \\
\end{array}$ & $\begin{array}{c}\theta_{s} \\
\left(\mathrm{~cm}^{3} / \mathrm{cm}^{3}\right) \\
\end{array}$ & $\begin{array}{c}K_{s} \\
(\mathrm{~cm} / \mathrm{sec}) \\
\end{array}$ & $S_{r}$ & $\begin{array}{c}\% \\
\text { gravel }\end{array}$ & $\begin{array}{c}\text { Bulk Density } \\
\left(\mathrm{g} / \mathrm{cm}^{3}\right)\end{array}$ \\
\hline $\mathrm{Bf}$ & 6 & $3.20 \mathrm{E}-02$ & 1.400 & 0.030 & 0.262 & $1.50 \mathrm{E}-02$ & 0.10 & ----- & 1.94 \\
\hline Hss & 38 & 7.71E-03 & 1.915 & 0.072 & 0.445 & $8.58 \mathrm{E}-05$ & 0.16 & 0.18 & 1.61 \\
\hline $\mathrm{Hfs}$ & 40 & 2.49E-02 & 2.107 & 0.049 & 0.397 & $2.87 \mathrm{E}-04$ & 0.11 & 0.57 & 1.60 \\
\hline $\mathrm{Hcs}$ & 82 & $5.85 \mathrm{E}-02$ & 2.020 & 0.031 & 0.353 & $2.19 \mathrm{E}-03$ & 0.08 & 2.55 & 1.66 \\
\hline $\mathrm{Hgs}$ & 17 & $1.34 \mathrm{E}-02$ & 2.111 & 0.046 & 0.250 & 4.73E-04 & 0.17 & 25.78 & 1.92 \\
\hline $\mathrm{Hg}$ & 29 & $1.79 \mathrm{E}-02$ & 1.727 & 0.023 & 0.167 & $3.56 \mathrm{E}-04$ & 0.14 & 51.42 & 1.91 \\
\hline Hrg & 40 & $7.40 \mathrm{E}-03$ & 1.831 & 0.020 & 0.102 & $1.46 \mathrm{E}-03$ & 0.20 & 67.63 & 1.97 \\
\hline $\mathrm{PPlz}$ & 9 & $5.52 \mathrm{E}-03$ & 2.101 & 0.034 & 0.420 & $5.57 \mathrm{E}-05$ & 0.08 & 0.44 & 1.68 \\
\hline PPlc & 16 & $1.08 \mathrm{E}-02$ & 1.727 & 0.072 & 0.306 & $5.00 \mathrm{E}-04$ & 0.21 & 16.73 & 1.71 \\
\hline $\mathrm{Rg}$ & 18 & $7.81 \mathrm{E}-03$ & 1.697 & 0.063 & 0.178 & $4.13 \mathrm{E}-04$ & 0.23 & 46.08 & 1.90 \\
\hline
\end{tabular}

Table 4.5. Statistical Mean Values for BC-Crib Samples

\begin{tabular}{|c|c|c|c|c|c|c|c|c|c|}
\hline \multicolumn{10}{|c|}{ BC-Cribs } \\
\hline $\begin{array}{c}\text { Soil } \\
\text { Class } \\
\end{array}$ & Count & $\begin{array}{c}\alpha \\
(1 / \mathrm{cm}) \\
\end{array}$ & $n$ & $\begin{array}{c}\theta_{R} \\
\left(\mathrm{~cm}^{3} / \mathrm{cm}^{3}\right) \\
\end{array}$ & $\begin{array}{c}\theta_{s} \\
\left(\mathrm{~cm}^{3} / \mathrm{cm}^{3}\right) \\
\end{array}$ & $\begin{array}{c}K_{s} \\
(\mathrm{~cm} / \mathrm{sec}) \\
\end{array}$ & $S_{r}$ & $\begin{array}{c}\% \\
\text { gravel } \\
\end{array}$ & \begin{tabular}{|c} 
Bulk Density \\
$\left(\mathrm{g} / \mathrm{cm}^{3}\right)$
\end{tabular} \\
\hline $\mathrm{Bf}$ & 6 & $3.20 \mathrm{E}-02$ & 1.400 & 0.030 & 0.262 & $1.50 \mathrm{E}-02$ & 0.10 & ------ & 1.94 \\
\hline Hfs_BC & 18 & $2.08 \mathrm{E}-02$ & 2.507 & 0.033 & 0.380 & $2.25 \mathrm{E}-03$ & 0.09 & 0.38 & 1.65 \\
\hline Hcs_BC & 46 & 7.19E-02 & 2.047 & 0.026 & 0.357 & $5.32 \mathrm{E}-03$ & 0.07 & 2.68 & 1.67 \\
\hline $\mathrm{Hgs}$ & 5 & $3.07 \mathrm{E}-02$ & 1.872 & 0.040 & 0.271 & $3.02 \mathrm{E}-03$ & 0.15 & 17.66 & 1.95 \\
\hline
\end{tabular}

Table 4.6. Statistical Mean Values for U1 \& U2 Samples

\begin{tabular}{||c|c|c|c|c|c|c|c|c|c||}
\hline \hline \multicolumn{1}{||c|}{$\begin{array}{c}\text { Soil } \\
\text { Class }\end{array}$} & Count & $\begin{array}{c}\alpha \\
(1 / \mathrm{cm})\end{array}$ & $n$ & $\begin{array}{c}\theta_{R} \\
\left(\mathrm{~cm}^{3} / \mathrm{cm}^{3}\right)\end{array}$ & $\begin{array}{c}\theta_{s} \\
\left(\mathrm{~cm}^{3} / \mathrm{cm}^{3}\right)\end{array}$ & $\begin{array}{c}K_{s} \\
(\mathrm{~cm} / \mathrm{sec})\end{array}$ & $S_{r}$ & $\%$ gravel & $\begin{array}{c}\text { Bulk Density } \\
\left(\mathrm{g} / \mathrm{cm}^{3}\right)\end{array}$ \\
\hline \hline Bf & 6 & $3.20 \mathrm{E}-02$ & 1.400 & 0.030 & 0.262 & $1.50 \mathrm{E}-02$ & 0.10 & ------ & 1.94 \\
\hline Hss_U & 6 & $6.78 \mathrm{E}-03$ & 2.347 & 0.066 & 0.437 & $2.49 \mathrm{E}-05$ & 0.15 & 0.00 & 1.58 \\
\hline Hfs_U & 4 & $1.25 \mathrm{E}-02$ & 2.451 & 0.042 & 0.347 & $1.71 \mathrm{E}-05$ & 0.12 & 0.00 & 1.72 \\
\hline Hg_U & 3 & $1.14 \mathrm{E}-02$ & 1.845 & 0.029 & 0.150 & $2.88 \mathrm{E}-04$ & 0.20 & 57.10 & 2.09 \\
\hline PPlz_U & 5 & $4.73 \mathrm{E}-03$ & 2.020 & 0.035 & 0.398 & $7.27 \mathrm{E}-06$ & 0.09 & 0.08 & 1.71 \\
\hline Rg_U & 7 & $1.33 \mathrm{E}-02$ & 1.768 & 0.144 & 0.318 & $7.83 \mathrm{E}-05$ & 0.38 & 16.49 & 1.82 \\
\hline \hline
\end{tabular}


Table 4.7. Statistical Mean Values for 200-ZP-1 Samples

\begin{tabular}{||l|c|c|c|c|c|c|c|c|c||}
\hline \hline \multicolumn{1}{|c|}{$\begin{array}{c}\text { Soil } \\
\text { Class }\end{array}$} & Count & $\begin{array}{c}\alpha \\
(1 / \mathrm{cm})\end{array}$ & $n$ & $\begin{array}{c}\theta_{R} \\
\left(\mathrm{~cm}^{3} / \mathrm{cm}^{3}\right)\end{array}$ & $\begin{array}{c}\theta_{s} \\
\left(\mathrm{~cm}^{3} / \mathrm{cm}^{3}\right)\end{array}$ & $\begin{array}{c}K_{s} \\
(\mathrm{~cm} / \mathrm{sec})\end{array}$ & $S_{r}$ & $\begin{array}{c}\text { Bulk Density } \\
\left(\mathrm{g} / \mathrm{cm}^{3}\right)\end{array}$ \\
\hline \hline Bf & 6 & $3.20 \mathrm{E}-02$ & 1.400 & 0.030 & 0.262 & $1.50 \mathrm{E}-02$ & 0.10 & ----- & 1.94 \\
\hline Hss_Z & 5 & $2.79 \mathrm{E}-03$ & 1.840 & 0.047 & 0.351 & $6.55 \mathrm{E}-06$ & 0.13 & 0.00 & 1.80 \\
\hline Hfs_Z & 4 & $8.33 \mathrm{E}-03$ & 1.903 & 0.042 & 0.366 & $7.88 \mathrm{E}-05$ & 0.11 & 0.75 & 1.68 \\
\hline Hcs_Z & 5 & $6.65 \mathrm{E}-02$ & 1.692 & 0.021 & 0.292 & $1.49 \mathrm{E}-03$ & 0.07 & 0.00 & 1.56 \\
\hline Hg_Z & 9 & $1.86 \mathrm{E}-02$ & 1.711 & 0.026 & 0.156 & $3.51 \mathrm{E}-03$ & 0.16 & 53.44 & 1.79 \\
\hline PPlz_Z & 4 & $6.69 \mathrm{E}-03$ & 2.203 & 0.033 & 0.448 & $7.11 \mathrm{E}-04$ & 0.07 & 1.00 & 1.58 \\
\hline PPlc_Z & 15 & $1.09 \mathrm{E}-02$ & 1.734 & 0.075 & 0.312 & $5.74 \mathrm{E}-04$ & 0.22 & 15.07 & 1.68 \\
\hline \hline
\end{tabular}

\subsubsection{Site-Wide Hydraulic Property Distributions}

The site-wide sample distribution (Table 4.4) uses all the data in each of the soil classes to calculate the statistical mean van Genuchten parameters that were then used to generate the hydraulic properties curves shown in Figures 4.1, 4.2, and 4.3. Figure 4.1 shows that the Hanford formation silty sand and the Cold Creek unit silt attain the highest saturated water content, while the Hanford formation coarse gravels and Hanford formation sandy gravels have the lowest water content. Table 4.4 illustrates that the finer textured sediments typically have greater saturated water content, lower saturated hydraulic conductivity

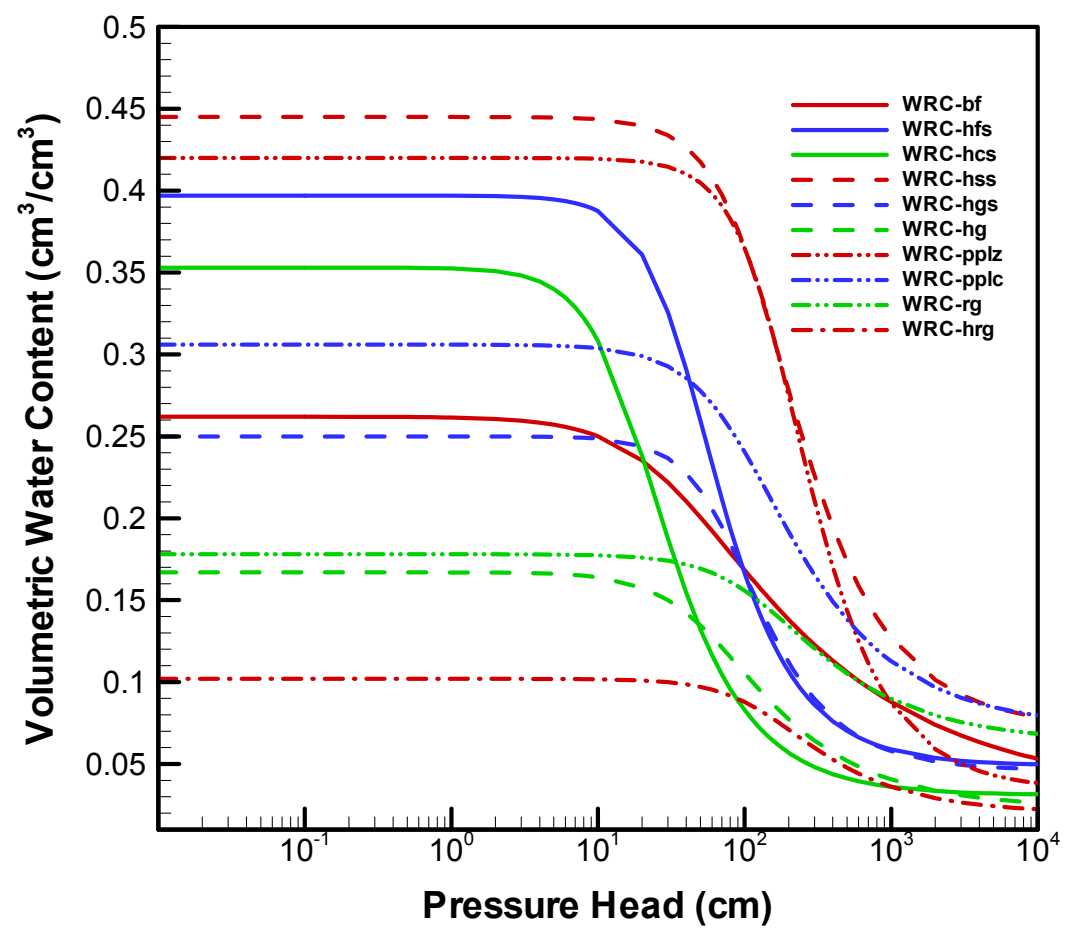

Figure 4.1. Formation Specific Water Retention Curves for the Site-Wide Distribution 


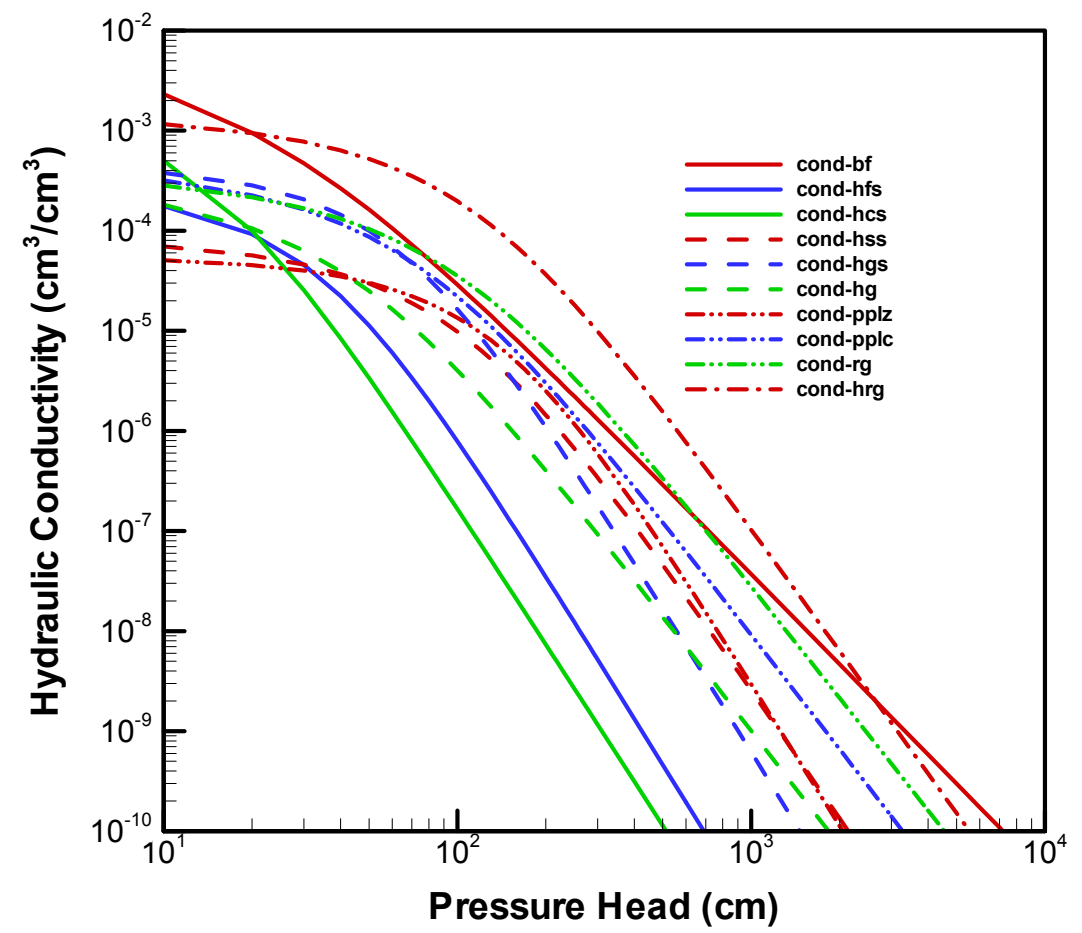

Figure 4.2. Formation Specific Hydraulic Conductivity Curves for the Site-Wide Distribution

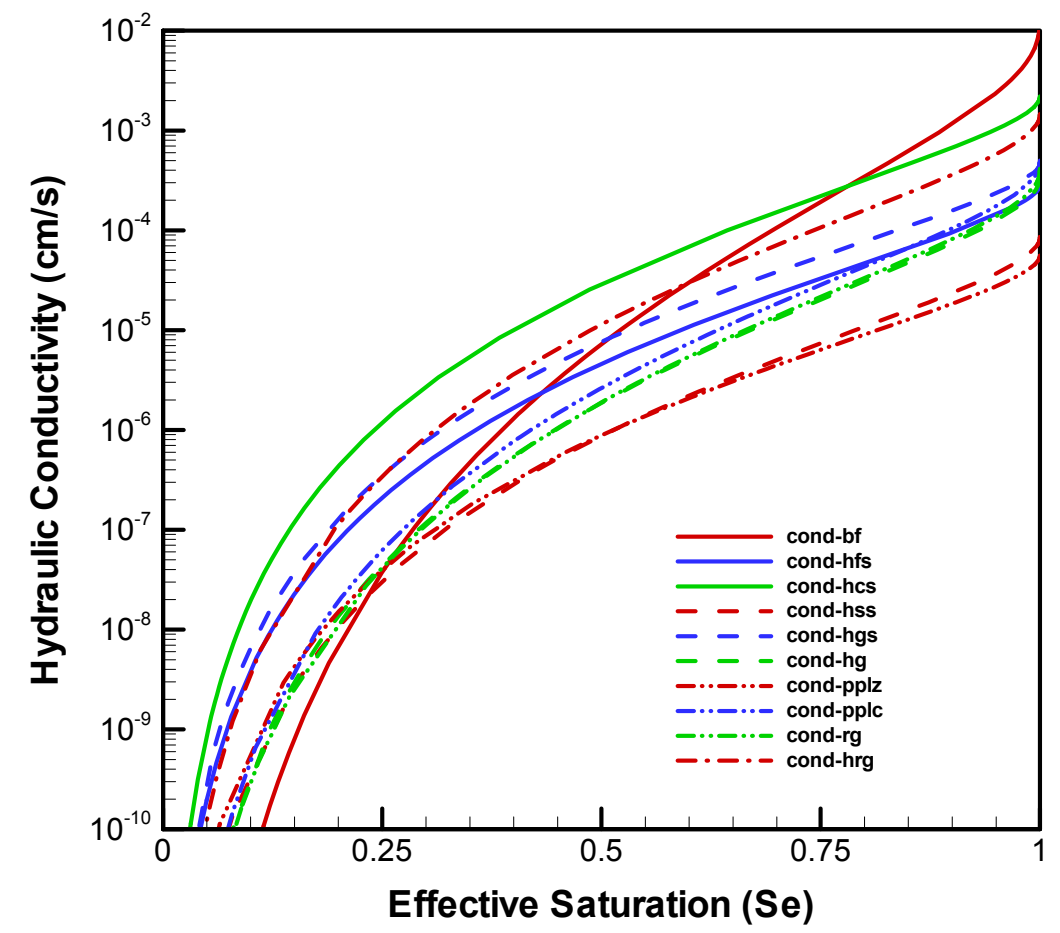

Figure 4.3. Formation Specific Hydraulic Conductivity Curves Versus Saturation for the Site-Wide Distribution 
and lower bulk density. As the samples become coarser the water content declines, saturated hydraulic conductivity increases and bulk density increases. The properties in Table 4.4 and Figure 4.1 represent matrix characteristics and do not account for preferential flow through cracks (refer to et al. 2002, 2003).

Uncertainties arise from the drilling and sampling methods used to collect the samples (e.g., corebarrel, splitspoon), how the samples are handled in the lab (e.g., repacked), subjectivity in assigning the samples to various geologic formations and facies (i.e., soil classes), systematic or measurement errors associated with the laboratory analyses, and scaling issues when using small sample data to represent larger field scale processes.

The saturated hydraulic conductivity is highest for the backfill (B) and Hanford coarse gravel (Hcg) and lowest for the silty Cold Creek unit (PPlz) and Hanford formation silty sand (Hss). The hydraulic conductivity does not drop off rapidly as would be expected for the coarse textured sediment. This may indicate a higher fraction of fines than accounted for.

\subsubsection{Site-Specific Hydraulic Property Distributions}

When evaluating the hydraulic properties at a particular location it is valuable to only use those data that are most representative of the hydraulic properties at that site. Three sites were selected from which to generate site-specific hydraulic properties data sets: 1) the BC cribs and trenches, 2) the 216-U-1 and -2 crib area, and 3) the 216-Z-9 trench area. A fourth set of hydraulic property data was generated for all 200 West Area samples. Tables 4.5 to 4.8 list the mean hydraulic property data derived for each of these specific areas. Appendix B provides the hydraulic property distributions for the each site-wide and sitespecific soil class.

\subsubsection{Application to Vadose Zone Simulations}

Each vadose zone hydrostratigraphic template represents a one-dimensional soil column made up of several hydrostratigraphic units. Each hydrostratigraphic unit occupies a number of model nodes depending on the thickness of the hydrostratigraphic unit. The hydraulic properties for each hydrostratigraphic unit are determined by stochastically sampling the probability distribution function for each parameter, for a given simulation (realization). All model nodes within a single hydrogeologic unit are assigned the same hydraulic properties for a single realization.

\subsubsection{Conditioning of One-Dimensional Flow Simulations Against Detailed Site-Specific Assessments}

Several studies were conducted to examine multiple hydrostratigraphic models and two-dimensional vadose zone simulations of selected waste sites where previous one-dimensional simulations failed to provide reasonable results. One of the main areas of interest was the $\mathrm{BC}$ cribs and trenches. Here multiple hydrostratigraphic profiles (templates) were developed to generate reasonable two-dimensional representations of the vadose zone. Multiple two-dimensional flow simulations were conducted to provide the basis with which to estimate the wetted column area needed as input for one-dimensional flow 
and transport simulations (Appendix C). Additional work was aimed at trying to incorporate the up scaling techniques developed through the Science and Technology Project (Zhang et al. 2002) to improve hydraulic property estimates for the $\mathrm{BC}$ crib and trench area.

Table 4.8. Statistical Mean Values for 200 West Area Samples

\begin{tabular}{||l|c|c|c|c|c|c|c|c|c||}
\hline \multicolumn{1}{|c|}{$\begin{array}{c}\text { Soil } \\
\text { Class }\end{array}$} & Count & $\begin{array}{c}\alpha \\
(1 / \mathrm{cm})\end{array}$ & $n$ & $\begin{array}{c}\theta_{R} \\
\left(\mathrm{~cm}^{3} / \mathrm{cm}^{3}\right)\end{array}$ & $\begin{array}{c}\theta_{s} \\
\left(\mathrm{~cm}^{3} / \mathrm{cm}^{3}\right)\end{array}$ & $\begin{array}{c}K_{s} \\
(\mathrm{~cm} / \mathrm{sec})\end{array}$ & $S_{r}$ & $\begin{array}{c}\% \\
\text { gravel }\end{array}$ & $\begin{array}{c}\text { Bulk Density } \\
\left(\mathrm{g} / \mathrm{cm}^{3}\right)\end{array}$ \\
\hline \hline Bf & 6 & 0.032 & 1.4 & 0.03 & 0.262 & $1.50 \mathrm{E}-02$ & 0.102 & ----- & 1.94 \\
\hline Hss_2W & 11 & $4.53 \mathrm{E}-03$ & 2.116 & 0.057 & 0.398 & $1.91 \mathrm{E}-05$ & 0.141 & 0.00 & 1.67 \\
\hline Hfs_2W & 8 & $1.02 \mathrm{E}-02$ & 2.177 & 0.042 & 0.356 & $3.67 \mathrm{E}-05$ & 0.118 & 0.38 & 1.70 \\
\hline Hcs_2W & 7 & $4.15 \mathrm{E}-02$ & 1.759 & 0.026 & 0.318 & $1.09 \mathrm{E}-03$ & 0.077 & 2.14 & 1.65 \\
\hline Hgs_2W & 2 & $7.90 \mathrm{E}-03$ & 2.223 & 0.030 & 0.273 & $2.35 \mathrm{E}-04$ & 0.133 & 24.00 & 1.81 \\
\hline Hg_2W & 12 & $1.65 \mathrm{E}-02$ & 1.745 & 0.027 & 0.154 & $1.48 \mathrm{E}-03$ & 0.172 & 54.36 & 1.89 \\
\hline PPlz & 9 & $5.52 \mathrm{E}-03$ & 2.101 & 0.034 & 0.420 & $5.57 \mathrm{E}-05$ & 0.080 & 0.49 & 1.66 \\
\hline PPlc & 16 & $1.08 \mathrm{E}-02$ & 1.727 & 0.072 & 0.306 & $5.00 \mathrm{E}-04$ & 0.214 & 16.73 & 1.71 \\
\hline Rg_2W & 8 & $1.32 \mathrm{E}-02$ & 1.753 & 0.126 & 0.297 & $1.06 \mathrm{E}-04$ & 0.334 & 22.18 & 1.84 \\
\hline \hline
\end{tabular}

Another main area of interest was the 216-U-1 and -2 cribs. Here, another approach has been taken to model this site as two separate sites to account for the multiple release mechanisms. Field data indicate this location experienced a fast path release (perhaps due to flow through a borehole annulus or similar mechanism) that allowed a significant quantity of contamination to effectively bypass the vadose zone and travel directly to the surface aquifer. Because the mechanism for this fast path is not characterized, the 216-U-1 and -2 site was modeled with an empirical two-site arrangement wherein a duplicate site, "216-U-1 and -2-Fast" was defined that uses a special hydrostratigraphic template that immediately releases any waste it receives directly to groundwater. No waste is routed to this "fast" site by the inventory model. However, a remedial action is declared in the overall SAC model input set that declares that a fraction of the waste in the vadose zone in the year of the suspected fast path event (1988) is to be remediated from 216-U-1 and -2 site and sent to the 216-U-1 and -2-Fast site (which effectively sends it immediately to the surface aquifer). The fraction used for this remediation was determined by dividing the estimated contaminant mass in the aquifer after the fast path event (as determined by history matching data prepared by Murray et al. (2004) by the total mass in the vadose zone at 216-U-1 and -2 in 1988 (as modeled in an initial median-inputs simulation of the 216-U-1 and -2 site). Thus, the model is effectively forced to deliver the field-observed mass of contaminant directly from the vadose zone to groundwater in a single event in 1988.

Several other sites (e.g., the Integrated Disposal Facility [IDF, formerly the Immobilized Low-Level Activity Waste facility], and the tank farms) are the subject of more detailed site-specific performance assessments. Thus, efforts were made to incorporate the results of these performance assessments more directly into the composite analysis, and/or to scale the composite analysis model results so that the central tendency of the results mimics the deterministic results from these site-specific assessments. None of these more-detailed site-specific performance assessments are stochastic, so the results are used 
directly in SAC median-inputs runs in place of the embedded STOMP one-dimensional model results. The results are also used to calibrate the STOMP one-dimensional model at these sites so that the stochastic simulations will better mimic the expected behavior of the site-specific assessments where they run stochastically with the SAC data. This is done by comparing the release rates of the median-inputs STOMP model in SAC for these sites to the more-detailed site-specific modeling results for a range of vadose zone wetted area scaling factors, and choosing the factor that results in the best agreement for use in later stochastic simulations. This is similar to the approach used for the $\mathrm{BC}$ cribs and trenches in which the one-dimensional model used in SAC was calibrated against idealized two-dimensional models.

\subsubsection{Transport Parameters}

For the 2004 Composite Analysis, the two key parameters that will govern transport of contaminants in the subsurface are the dispersivity and the species-specific water content dependent diffusion coefficient. The product of dispersivity $(\lambda)$ and pore water velocity yields the mechanical dispersion coefficient, which relates the dispersive solute flux to the solute concentration gradient. Longitudinal dispersivity (i.e., in the direction of flow) is generally larger than dispersivity in the transverse direction and it is also scale dependent (Khaleel et al. 2002). Field measurements of dispersivity are extremely rare and small-scale laboratory measurements have only marginal utility in estimating field values (Meyer et al. 2004). Estimates of longitudinal dispersivity for the composite analysis were primarily taken from Ho et al. (1999). In the absence of data, dispersivity values are often based on simple guidelines related to the size of the computational elements in numerical simulation codes.

Dispersion during transport of contaminants can potentially be enhanced when the contaminants react with either the sediments or the fluid or gas constituents. The enhanced macrodispersion phenomenon is not well understood and is therefore a current research topic (e.g., Khaleel et al. 2003). Although not entirely understood, enhanced macrodispersion has been estimated at specific sites at Hanford. For example, the modeling data package for the S-SX FIR (Khaleel et al. 2001) suggested that dispersion of cesium was enhanced by 10 to $15 \%$ for all but the plio-pleistocene layer, for which the enhancement factor was roughly a factor of 2 . Enhanced macrodispersion is not addressed in the current version of the Composite Analysis but will be considered for future versions.

The diffusion coefficient is the proportionality factor in Fick's law that relates the diffusive transport flux to the gradient in solute concentration (Meyer et al. 2004). According to Meyer et al., the diffusion process results in mass transport from regions of high solute concentration to regions of lower concentration and occurs as a result of the random thermal motion (Brownian motion) of molecules and atoms. The diffusion process will be represented in the 2004 Composite Analysis. Each contaminant species will be assigned a unique free-water diffusion coefficient that applies to diffusion in dilute water solution. In the subsurface environment, porous medium and the water content will affect the diffusion process. Thus, the effective diffusion coefficient will be a function of the tortuosity of the porous medium and the water content. The tortuosity will be represented using the Millington and Quirk tortuosity model. Finally, reactive solutes can affect diffusion. The resulting apparent coefficient will be represented as a function of the water content, bulk density, and sorption coefficient as explained by Meyer et al. (2004). 


\subsection{Contaminant Distribution Coefficients}

Geochemical properties were assigned to each hydrogeologic unit, in a manner similar to that done for the 1998 Composite Analysis (Kincaid et al. 1998). The waste characteristics were assumed to dominate the near-field mobility of the contaminants in the vadose zone. After being in contact with vadose zone sediments and soil water for some distance, the waste undergoes a change in its mobility based on buffering of the contaminant solution by the vadose zone sediments. Thus, distribution coefficients were defined separately for each contaminant in the upper vadose zone (near-field or high impact zone) and in the lower vadose zone (far-field or intermediate impact zone) (Kincaid et al. 1998).

Distribution coefficient zones were defined as either high impact or intermediate impact depending on the nature of the contamination fluid. Zones in which the organic concentration, $\mathrm{pH}$, or salt concentration in the fluids may have affected the $K_{d}$ values were designated high-impact. Zones in which the acidic or basic nature of the wastes was estimated to have been neutralized by the natural soil were designated intermediate impact. Kincaid et al. (1998) estimated the depths of this transition zone by examining the peak location of beta/gamma contamination (as presented by Fecht et al. 1977) for 200 Area cribs receiving very acid or high-salt/very basic waste. In general, these transition depths ranged from 10 to 40 meters. Given the limited data available on which to base further interpretations on the depths of transition, and the desire to simplify the numerical simulations, a slightly different approach was used here. Generally, the hydrogeologic unit into which waste streams were introduced was designated as high-impact regardless of waste stream characteristics. If those hydrogeologic units were thin (e.g., $<1$ meter), then the hydrogeologic unit immediately below that into which the waste stream was introduced was also designated high-impact. All other hydrogeologic units lower in the profile were designated intermediate impact. This approach enables us to keep the numerical simulations relatively simple by using the existing number of hydrogeologic units (i.e., we did not have to add new layers to make the $K_{d}$ change where it might have occurred within a single hydrogeologic unit). At the same time, the depths of change, corresponding to the thickness of the hydrogeologic units, are still on the same scale (tens of meters) as those used by Kincaid et al. (1998). Appendix A provides the detailed hydrogeologic columns and locations of the various $K_{d}$ zones, for each base template.

As described in Section 3.2.3, several $K_{d}$ classes were defined for mapping distribution coefficients to high or intermediate impact zones and chemical waste type. These $K_{d}$ classes were labeled using a two or three digit alpha-numeric code. The first digit represents the waste chemistry type (numbers 1 through 4) (see Table 3.5). The second digit represents the impact zone (i.e., $\mathrm{H}$ for high impact [i.e., near field vadose zone], I for intermediate impact [i.e., far field vadose zone], or $\mathrm{G}$ for the zone not impacted [i.e., very far field vadose] and groundwater). For $K_{d}$ values in the intermediate impact zone, a third digit was added to identify those $K_{d}$ classes that were adjusted for the gravel-dominated hydrostratigraphic units. To account for the common observation that significant gravel content decreases $K_{d}$ values (Kaplan and Serne 2000), the intermediate impact zone for each $K_{d}$ class in the intermediate impact zone was subdivided into gravel rich and gravel poor zones. $K_{d}$ classes with a third digit of " 1 " pertain to gravel poor (i.e., sand-dominated) strata and $K_{d}$ classes ending in a "2" pertain to gravel rich (i.e., gravel dominated) strata (See Section 3.2.3). 
Kincaid et al. (2004) identified sixteen radionuclides as contaminants of concern to be addressed in the composite analysis, see Table 4.9. However, two of these radionuclides, radium-226 and protatctinium-231 are to be simulated as progeny of uranium-234 and uranium-238, and will not be directly incorporated into the flow and transport simulations for the 2004 Composite Analysis. Thus, $K_{d}$ estimates were not developed for those contaminants. For all other contaminants of interest, a best estimate $K_{d}$ value and range (minimum and maximum) were developed for each $K_{d}$ class. A brief discussion for each contaminant is presented below. Probability distribution functions for these $K_{d}$ values were generated according to the following set of rules and derived from the minimum, maximum, and best estimate $K_{d}$ values.

Table 4.9. List of Contaminants of Concern to be Included in the 2004 Composite Analysis (Kincaid et al. 2003)

\begin{tabular}{|c|c|c|}
\hline \multicolumn{3}{|c|}{ Contaminants of Concern } \\
\hline & Tritium & Carbon-14 \\
\hline & Chlorine-36 & Selenium-79 \\
\hline & Strontium-90 & Technetium-99 \\
\hline & Iodine-129 & Cesium-137 \\
\hline & Europium-152 (a) & Radium-226 ${ }^{(b)}$ \\
\hline & Protactinium-231 ${ }^{(c)}$ & Uranium-233 \\
\hline & Uranium-234 ${ }^{(\mathrm{d})}$ & Uranium-235 ${ }^{(\mathrm{e})}$ \\
\hline & Uranium-238 ${ }^{(\mathrm{d})}$ & Neptunium-237 \\
\hline (a) & \multicolumn{2}{|c|}{$\begin{array}{l}\text { Europium-152 will be simulated using median values in a deterministic simulation. Because of its relatively short decas } \\
\text { half-life, the simulation will extend at most two or three hundred years beyond Hanford Site closure. } \\
\text { Radium-226 will be simulated as progeny of U- } 234 \text { and U-238. It will be further evaluated in the } 2004 \text { Composite } \\
\text { Analysis because the chemical separation for uranium may have placed radium-226 in Hanford wastes at levels not in } \\
\text { secular equilibrium with the uranium in the waste. }\end{array}$} \\
\hline (c) & \multicolumn{2}{|c|}{$\begin{array}{l}\text { Protactinium- } 231 \text { will be simulated as progeny of U-238. It will be further evaluated in the } 2004 \text { Composite Analysis } \\
\text { because the chemical separation for uranium may have placed protactinium- } 231 \text { in Hanford wastes at levels not in } \\
\text { secular equilibrium with the uranium in the waste. }\end{array}$} \\
\hline (d) & \multicolumn{2}{|c|}{$\begin{array}{l}\text { Uranium- } 238 \text { and uranium- } 234 \text { will be summed and shown as uranium- } 238 \text { to represent both in this simulation. It is } \\
\text { assumed that these two uranium isotopes are always in secular equilibrium. }\end{array}$} \\
\hline (e) & \multicolumn{2}{|c|}{$\begin{array}{l}\text { Uranium-235 is modeled separately to properly generate protactinium- } 231 \text { through radioactive decay and progeny } \\
\text { ingrowth. }\end{array}$} \\
\hline
\end{tabular}

Case \#1: Where the minimum estimate, best estimate, and maximum estimate were all greater than zero, a lognormal distribution was assumed. The best estimate was assigned to the median value. The minimum estimate was assigned to the lower $1 \%$ tail of the distribution, and the maximum estimate was not used in defining the distribution.

Case \#2: Where the minimum estimate was zero, but the best estimate and maximum estimate were greater than zero. A lognormal distribution was used, with the best estimate assigned to the median value, the lower $1 \%$ tail of the distribution assigned to the value 0.001 , and the maximum estimate used to define a probability truncation limit for the upper tail of the distribution (if less than 0.99 probability, otherwise truncation was set to 0.99 ).

Case \#3: Where the minimum and best estimates were zero, but the maximum estimate was greater than zero. A composite distribution was used. The value zero was assigned a $50 \%$ 
probability. The other portion of the distribution was assigned a triangular distribution where the minimum and mode were both zero and the maximum was assigned to the upper tail estimate.

In those cases where a lognormal distribution was assumed, the lognormal distributions were truncated at the $1 \%$ and $99 \%$ levels, thereby preventing the generation of values that could fall below the minimum estimate.

Table 4.10 provides the current compilation of distribution coefficients for each waste stream category and impact zone (derived from the Contaminant Distribution Coefficient Database and Users Guide by Cantrell et al. 2002, 2003a). The hydrostratigraphic templates provided in Appendix A identify the $K_{d}$ classes assigned to each hydrostratigraphic unit for each geographic and site-specific area. As with the hydraulic parameters, all model nodes within a single hydrogeologic unit are assigned the same $K_{d}$ values for a given realization.

\subsubsection{Tritium}

The best estimates for $K_{d}$ values of tritium are zero, and the ranges were selected to be zero for all source and impact zone categories. It is assumed that tritium atoms are incorporated into water molecules and, as a result, no adsorption or other significant geochemical interactions are expected.

\subsubsection{Carbon-14}

Under typical Hanford conditions, it is assumed that carbon-14 will occur predominately as the bicarbonate ion $\left(\mathrm{H}^{14} \mathrm{CO}_{3}^{-}\right)$, though at high $\mathrm{pH}$ bicarbonate will deprotonate to carbonate $\left({ }^{14} \mathrm{CO}_{3}{ }^{2-}\right)$ and at low $\mathrm{pH}$ will protonate to form ${ }^{14} \mathrm{CO}_{2}(\mathrm{aq})$. In general, adsorption of any anion (through surface complexation) onto Hanford sediment in the alkaline $\mathrm{pH}$ range is expected to be negligible because the $\mathrm{pH}$ point of zero charge (pzc) or $\mathrm{pH}_{p z c}$ for most minerals is below the typical $\mathrm{pH}$ of Hanford groundwater. For example, the $p H_{p z c}$ for montmorillonite and feldspar is approximately 3 (Stumm and Morgan 1996). The $p H_{p z c}$ for calcite (at $p_{\mathrm{CO} 2}=10^{-3.5} \mathrm{~atm}$ ) is approximately 8.2 and goes down to 6.5 at $p_{\mathrm{CO} 2}=1 \mathrm{~atm}$. This indicates that Hanford sediments will be dominated by negatively charged sites in the alkaline $\mathrm{pH}$ range; conditions which are not conducive to adsorption of anions. This is clearly demonstrated with $\mathrm{CrO}_{4}{ }^{2-}$ for example (Cantrell et al. 2002).

Although surface adsorption of $\mathrm{H}^{14} \mathrm{CO}_{3}{ }^{-}$or ${ }^{14} \mathrm{CO}_{3}{ }^{2-}$ is not likely to be significant under Hanford conditions, two other processes could potentially remove these species from solution. These two mechanisms are isotopic exchange and precipitation. Calcite is common within Hanford sediment (often as caliche or mineral grain coatings) and is the most readily available carbonate phase within Hanford sediment available for solid surface exchange with ${ }^{14} \mathrm{CO}_{3}{ }^{2-}$. Like ion exchange, isotopic exchange can be written as a chemical reaction (Garnier 1985):

$$
{ }^{12} C_{s}+{ }^{14} C_{m}={ }^{14} C_{s}+{ }^{12} C_{m}
$$


Table 4.10. $\quad K_{d}$ Ranges by Waste Chemistry/Source Category

\begin{tabular}{|c|c|c|c|c|c|c|c|c|c|c|c|c|}
\hline \multirow[b]{3}{*}{ Analyte } & \multirow{2}{*}{\multicolumn{3}{|c|}{$\begin{array}{l}\text { High Impact }(\mathrm{A})-1 \mathrm{H} \\
\text { Kd Estimate }(\mathrm{mL} / \mathrm{g})\end{array}$}} & \multirow{2}{*}{\multicolumn{3}{|c|}{$\begin{array}{c}\text { Intermediate Impact - Sand (B1) - } 1 I 1 \\
\text { Kd Estimate (mL/g) }\end{array}$}} & \multirow{2}{*}{\multicolumn{3}{|c|}{$\begin{array}{c}\text { Intermediate Impact - Gravel (B2) - 1I2 } \\
\text { Kd Estimate (mL/g) }\end{array}$}} & \multirow{2}{*}{\multicolumn{3}{|c|}{$\begin{array}{c}\text { Groundwater }(\mathrm{F} 1)-1 \mathrm{G} \\
\text { Kd Estimate }(\mathrm{mL} / \mathrm{g})\end{array}$}} \\
\hline & & & & & & & & & & & & \\
\hline & Best & Min & Max & Best & Min & Max & Best & Min & Max & Best & Min & Max \\
\hline \multicolumn{13}{|c|}{ Non-Adsorbing Radionuclides } \\
\hline $\mathrm{H} 3$ & 0 & 0 & 0 & 0 & 0 & 0 & 0 & 0 & 0 & 0 & 0 & 0 \\
\hline Tc99 & 0 & 0 & 0.1 & 0 & 0 & 0.1 & 0 & 0 & 0.01 & 0 & 0 & 0.1 \\
\hline $\mathrm{Cl} 36$ & 0 & 0 & 0 & 0 & 0 & 0 & 0 & 0 & 0 & 0 & 0 & 0 \\
\hline \multicolumn{13}{|l|}{ Moderately Adsorbing } \\
\hline U238 & 0.2 & 0 & 4 & 0.8 & 0.2 & 4 & $\begin{array}{l}0.02 \\
0.08\end{array}$ & 0.02 & 0.4 & $\begin{array}{l}0.2 \\
0.8\end{array}$ & 0.2 & 4 \\
\hline Se79 & 5 & 3 & 10 & $\begin{array}{l}.0 \\
5\end{array}$ & 3 & 10 & 0.5 & 0.3 & 1 & 5 & 3 & 10 \\
\hline $\mathrm{Np} 237$ & 0 & 0 & 2 & 10 & 2 & 30 & 1 & 0.2 & 3 & 10 & 2 & 30 \\
\hline $\mathrm{C} 14$ & 0 & 0 & 0 & unsuitable & 0 & 100 & unsuitable & 0 & 100 & unsuitable & 0 & 100 \\
\hline \multicolumn{13}{|l|}{ Highly Adsorbing } \\
\hline $\begin{array}{l}\text { Sr90 } \\
\text { Cs137 }\end{array}$ & 1000 & 200 & 10000 & 2000 & 200 & $\begin{array}{c}50 \\
10000\end{array}$ & $\begin{array}{l}6.8 \\
620\end{array}$ & $\begin{array}{l}3.1 \\
62\end{array}$ & 3100 & 2000 & $\begin{array}{l}10 \\
200\end{array}$ & $\begin{array}{c}50 \\
10000\end{array}$ \\
\hline Pu239 & 0.4 & 0.1 & 1 & 600 & 200 & 2000 & 186 & 62 & 620 & 600 & 200 & 2000 \\
\hline Eu152 & 20 & 1 & 100 & 200 & 10 & 1000 & 62 & 3.1 & 310 & 200 & 10 & 1000 \\
\hline \multirow{2}{*}{$\begin{array}{l}\text { Organic Contaminants } \\
\text { CCl4 } \\
\text { Inorganic Contaminants } \\
\text { CrVI }\end{array}$} & 0.2 & 0.1 & 2 & 0.2 & 0.1 & 0.6 & 0.02 & 0.01 & 0.06 & 0.2 & 0.1 & 0.6 \\
\hline & 4 & 2 & 20 & 0 & 0 & 0.3 & 0 & 0 & 0.03 & 0 & 0 & 0.3 \\
\hline
\end{tabular}

\begin{tabular}{|c|c|c|c|c|c|c|c|c|c|c|c|c|}
\hline \multirow[b]{2}{*}{ Analyte } & \multicolumn{3}{|c|}{$\begin{array}{c}\text { High Impact (D) - } 2 \mathrm{H} \\
\text { Kd Estimate }(\mathrm{mL} / \mathrm{g}) \\
\end{array}$} & \multicolumn{3}{|c|}{$\begin{array}{c}\text { Intermediate Impact - Sand (E1) - 2I1 } \\
\text { Kd Estimate (mL/g) }\end{array}$} & \multicolumn{3}{|c|}{$\begin{array}{c}\text { Intermediate Impact - Gravel (E2) - 2I2 } \\
\text { Kd Estimate (mL/g) } \\
\end{array}$} & \multicolumn{3}{|c|}{$\begin{array}{c}\text { Groundwater (F1) - 2G } \\
\text { Kd Estimate }(\mathrm{mL} / \mathrm{g}) \\
\end{array}$} \\
\hline & Best & Min & Max & Best & Min & $\operatorname{Max}$ & Best & Min & Max & Best & Min & $\operatorname{Max}$ \\
\hline \multicolumn{8}{|l|}{ Non-Adsorbing Radionuclides } & & & & & \\
\hline $\begin{array}{l}\text { H3 } \\
\text { Tc99 }\end{array}$ & $\begin{array}{l}0 \\
0\end{array}$ & $\begin{array}{l}0 \\
0\end{array}$ & $\left.\begin{array}{c}0 \\
0.1\end{array}\right)$ & $\begin{array}{l}0 \\
0\end{array}$ & $\begin{array}{l}0 \\
0\end{array}$ & $\begin{array}{c}0 \\
0.1\end{array}$ & $\begin{array}{l}0 \\
0\end{array}$ & $\begin{array}{l}0 \\
0\end{array}$ & $\begin{array}{c}0 \\
0.01\end{array}$ & $\begin{array}{l}0 \\
0\end{array}$ & $\begin{array}{l}0 \\
0\end{array}$ & $\begin{array}{c}0 \\
0.1\end{array}$ \\
\hline $\mathrm{Cl} 36$ & 0 & 0 & 0 & 0 & 0 & 0 & 0 & 0 & 0 & 0 & 0 & $\begin{array}{c}0.1 \\
0\end{array}$ \\
\hline \multicolumn{13}{|l|}{ Moderately Adsorbing } \\
\hline I129 & 0.02 & 0 & 0.2 & 0.1 & 0 & 0.2 & 0.01 & 0 & 0.02 & 0.2 & 0 & 2 \\
\hline U238 & 0.8 & 0.2 & 4 & 0.8 & 0.2 & 4 & 0.08 & 0.02 & 0.4 & 0.8 & 0.2 & 4 \\
\hline Se79 & 0 & 0 & 0.1 & 0 & 0 & 1 & 0 & 0 & 0.1 & 5 & 3 & 10 \\
\hline Np237 & 200 & 100 & 500 & 200 & 100 & 500 & 200 & 100 & 500 & 10 & 2 & 30 \\
\hline $\mathrm{C} 14$ & unsuitable & 0 & 100 & unsuitable & 0 & 100 & unsuitable & 0 & 100 & unsuitable & 0 & 100 \\
\hline \multicolumn{13}{|l|}{ Highly Adsorbing } \\
\hline Sr90 & 22 & 10 & 50 & 22 & 10 & 50 & 6.8 & 3.1 & 15.5 & 22 & 10 & 50 \\
\hline Cs137 & 10 & 0 & 500 & 100 & 10 & 1000 & 31 & 3.1 & 310 & 2000 & 200 & 10000 \\
\hline Pu239 & 200 & 70 & 600 & 600 & 200 & 2000 & 190 & 62 & 620 & 600 & 200 & 2000 \\
\hline Eu152 & 200 & 10 & 1000 & 200 & 10 & 1000 & 62 & 3.1 & 310 & 200 & 10 & 1000 \\
\hline \multicolumn{13}{|l|}{$\begin{array}{l}\text { Organic Elements } \\
\text { CCl4 }\end{array}$} \\
\hline $\begin{array}{l}\text { CCl4 } \\
\text { Inorganic Elements }\end{array}$ & 0.2 & 0.1 & 0.6 & 0.2 & 0.1 & 0.6 & 0.02 & 0.01 & 0.06 & 0.2 & 0.1 & 0.6 \\
\hline $\mathrm{CrVI}$ & 0 & 0 & 0.3 & 0 & 0 & 0.3 & 0 & 0 & 0.03 & 0 & 0 & 0.3 \\
\hline
\end{tabular}

\begin{tabular}{|c|c|c|c|c|c|c|c|c|c|c|c|c|}
\hline \multirow[b]{2}{*}{ Analyte } & \multicolumn{3}{|c|}{$\begin{array}{c}\text { High Impact (G1) - 3H } \\
\text { Kd Estimate }(\mathrm{mL} / \mathrm{g})\end{array}$} & \multicolumn{3}{|c|}{$\begin{array}{l}\text { Intermediate Impact - Sand (G1) - 3I1 } \\
\text { Kd Estimate (mL/g) }\end{array}$} & \multicolumn{3}{|c|}{$\begin{array}{l}\text { Intermediate Impact - Gravel (G2) - 3I2 } \\
\text { Kd Estimate }(\mathrm{mL} / \mathrm{g})\end{array}$} & \multicolumn{3}{|c|}{$\begin{array}{c}\text { Groundwater }(\mathrm{C})-3 \mathrm{G} \\
\text { Kd Estimate }(\mathrm{mL} / \mathrm{g}) \\
\end{array}$} \\
\hline & Best & Min & Max & Best & Min & Max & Best & Min & Max & Best & Min & Max \\
\hline \multicolumn{13}{|l|}{ Highly Mobile Elements } \\
\hline $\mathrm{H} 3$ & 0 & 0 & 0 & 0 & 0 & 0 & 0 & 0 & 0 & 0 & 0 & 0 \\
\hline Tc99 & 0 & 0 & 0.1 & 0 & 0 & 0.1 & 0 & 0 & 0.01 & 0 & 0 & 0.1 \\
\hline $\mathrm{Cl} 36$ & 0 & 0 & 0 & 0 & 0 & 0 & 0 & 0 & 0 & 0 & 0 & 0 \\
\hline \multicolumn{13}{|l|}{ Somewhat Mobile Elements } \\
\hline I129 & 0.2 & 0 & 2 & 0.2 & 0 & 2 & 0.02 & 0 & 0.2 & 0.2 & 0 & 2 \\
\hline U238 & 0.2 & 0 & 4 & 0.8 & 0.2 & 4 & 0.08 & 0.02 & 0.4 & 0.8 & 0.2 & 4 \\
\hline Se79 & 0 & 0 & 0.1 & 0 & 0 & 1 & 0 & 0 & 0.1 & 5 & 3 & 10 \\
\hline Np237 & 2 & 1 & 15 & 5 & 2 & 30 & 0.5 & 0.2 & 3 & 10 & 2 & 30 \\
\hline C14 & unsuitable & 0 & 100 & unsuitable & 0 & 100 & unsuitable & 0 & 100 & unsuitable & 0 & 100 \\
\hline \multicolumn{13}{|c|}{ Moderately Immobile Elements } \\
\hline $\begin{array}{l}\mathrm{Sr} 90 \\
\end{array}$ & $\begin{array}{c}1 \\
10\end{array}$ & $\begin{array}{c}0.2 \\
0\end{array}$ & $\begin{array}{c}20 \\
500\end{array}$ & $\begin{array}{c}10 \\
100\end{array}$ & $\begin{array}{c}5 \\
10\end{array}$ & $\begin{array}{c}20 \\
1000\end{array}$ & 3.1 & $\begin{array}{l}1.6 \\
3.1\end{array}$ & $\begin{array}{l}6.2 \\
310\end{array}$ & 22 & 10 & $\begin{array}{c}50 \\
10000\end{array}$ \\
\hline $\begin{array}{l}\text { Sil } \\
\text { Pu239 }\end{array}$ & $\begin{array}{l}10 \\
10\end{array}$ & 1 & 100 & 600 & 200 & $\begin{array}{l}1000 \\
2000\end{array}$ & $\begin{array}{c}31 \\
190\end{array}$ & 62 & $\begin{array}{l}310 \\
620\end{array}$ & $\begin{array}{l}2000 \\
600\end{array}$ & $\begin{array}{l}200 \\
200\end{array}$ & 2000 \\
\hline Eu152 & 20 & 1 & 100 & 200 & 10 & 1000 & 62 & 3.1 & 310 & 200 & 10 & 1000 \\
\hline \multirow{3}{*}{$\begin{array}{l}\text { Organic Elements } \\
\text { CC14 } \\
\text { Inorganic Elements } \\
\text { CrVI }\end{array}$} & & & & & & & & & & & & \\
\hline & 0.2 & 0.1 & 2 & 0.2 & 0.1 & 0.6 & 0.02 & 0.01 & 0.06 & 0.2 & 0.1 & 0.6 \\
\hline & 0 & 0 & 0.3 & 0 & 0 & 0.3 & 0 & 0 & 0.03 & 0 & 0 & 0.3 \\
\hline
\end{tabular}

Waste Chemistry/Source Category 4: Low Organic/Low Salt/Near Neutral

\begin{tabular}{|c|c|c|c|c|c|c|c|c|c|c|c|c|}
\hline \multirow{2}{*}{ Analyte } & \multirow{2}{*}{\multicolumn{3}{|c|}{$\begin{array}{l}\text { High Impact (F1) - 4H } \\
\text { Kd Estimate }(\mathrm{mL} / \mathrm{g})\end{array}$}} & \multirow{2}{*}{\multicolumn{3}{|c|}{$\begin{array}{c}\text { Intermediate Impact - Sand (F1) - 4I1 } \\
\text { Kd Estimate (mL/g) } \\
\end{array}$}} & \multirow{2}{*}{\multicolumn{3}{|c|}{$\begin{array}{c}\text { Intermediate Impact - Gravel (F2) - 4I2 } \\
\text { Kd Estimate (mL/g) } \\
\end{array}$}} & \multirow{2}{*}{\multicolumn{3}{|c|}{$\begin{array}{c}\text { Groundwater }(\mathrm{F} 1)-4 \mathrm{G} \\
\text { Kd Estimate }(\mathrm{mL} / \mathrm{g}) \\
\end{array}$}} \\
\hline & & & & & & & & & & & & \\
\hline \multirow{2}{*}{\multicolumn{12}{|c|}{ Highly Mobile Elements }} & Max \\
\hline H3 & & & & & & & & 0 & & & & \\
\hline Тc99 & 0 & 0 & 0.1 & 0 & 0 & 0.1 & 0 & 0 & 0.01 & 0 & 0 & 0.1 \\
\hline $\mathrm{Cl} 36$ & 0 & 0 & 0 & 0 & 0 & 0 & 0 & 0 & 0 & 0 & 0 & 0 \\
\hline \multicolumn{13}{|l|}{ Somewhat Mobile Elements } \\
\hline I129 & 0.2 & 0 & 2 & 0.2 & 0 & 2 & 0.02 & 0 & 0.2 & 0.2 & 0 & 2 \\
\hline U238 & 0.8 & 0.2 & 4 & 0.8 & 0.2 & 4 & 0.08 & 0.02 & 0.4 & 0.8 & 0.2 & 4 \\
\hline Se79 & 5 & 3 & 10 & 5 & 3 & 10 & 0.5 & 0.3 & 1 & 5 & 3 & 10 \\
\hline Np237 & 10 & 2 & 30 & 10 & 2 & 30 & 1 & 0.2 & 3 & 10 & 2 & 30 \\
\hline \multirow{2}{*}{\multicolumn{13}{|c|}{ Moderately Immobile Elements }} \\
\hline & & & & & & & & & & & & \\
\hline $\begin{array}{l}\text { Sr90 } \\
\text { Cs137 }\end{array}$ & $\begin{array}{c}22 \\
2000\end{array}$ & $\begin{array}{c}10 \\
200\end{array}$ & $\begin{array}{c}50 \\
10000\end{array}$ & $\begin{array}{c}22 \\
2000\end{array}$ & $\begin{array}{c}10 \\
200\end{array}$ & $\begin{array}{c}50 \\
10000\end{array}$ & $\begin{array}{c}7 \\
620\end{array}$ & $\begin{array}{c}3 \\
62\end{array}$ & $\begin{array}{c}16 \\
3100\end{array}$ & $\begin{array}{c}22 \\
2000\end{array}$ & $\begin{array}{c}10 \\
200\end{array}$ & $\begin{array}{c}50 \\
10000\end{array}$ \\
\hline $\begin{array}{l}\text { Cs137 } \\
\text { Pu239 }\end{array}$ & 600 & 200 & 2000 & 600 & 200 & 2000 & 190 & 62 & 620 & 600 & 200 & 2000 \\
\hline \multirow{4}{*}{$\begin{array}{l}\text { Organic Elements } \\
\text { CCI4 } \\
\text { Inorganic Elements } \\
\text { CrVI }\end{array}$} & 200 & 10 & 1000 & 200 & 10 & 1000 & 62 & 3.1 & 310 & 200 & 10 & 1000 \\
\hline & 0.2 & 0.1 & 0.6 & 0.2 & 0.1 & 0.6 & 0.02 & 0.01 & 0.06 & 0.2 & 0.1 & 0.6 \\
\hline & & & & & & & & & & & & \\
\hline & 0 & 0 & 0.3 & 0 & 0 & 0.3 & 0 & 0 & 0.03 & 0 & 0 & 0.3 \\
\hline
\end{tabular}


where $C_{s}$ and $C_{m}$ refer to the carbon content in the stationary and mobile phases, respectively. The equilibrium constant can be defined as:

$$
K\left({ }^{14} C /{ }^{12} C\right)=\left[\left({ }^{14} C /{ }^{12} C\right)_{s} /\left({ }^{14} C /{ }^{12} C\right)_{m}\right]
$$

This equilibrium constant is a pure thermodynamic constant. At a given temperature, it leads to a selectivity that is based only on the mass difference. Application of this concept to selection of a $K_{d}$ value for ${ }^{14} \mathrm{C}$ is problematic. Previous work using columns composed of a natural carbonate sand (aragonite and calcite) has demonstrated that the exchange process occurs at the first mono-molecular layer (Garnier 1985); however, the adsorption process was found to be complicated by kinetic and other factors. Kinetic factors that affected the results included flow rate and sediment aging. Adsorption of other ions such as $\mathrm{HPO}_{4}^{-}$was also found to significantly reduce uptake of $\mathrm{H}^{14} \mathrm{CO}_{3}^{-}$by the carbonate surfaces.

In addition to isotopic exchange, the migration of $\mathrm{H}^{14} \mathrm{CO}_{3}{ }^{-}$or ${ }^{14} \mathrm{CO}_{3}{ }^{2-}$ could potentially be retarded through precipitation of sodium/calcium carbonates that could occur during exposure to high $\mathrm{pH}$, high salt concentrations in high level waste within tanks or released from leaking tanks or disposed in trenches. Because of the high $\mathrm{pH}$ conditions within the tanks, any $\mathrm{CO}_{2}$ within the system will be in the form of $\mathrm{CO}_{3}{ }^{2-}$. As a result of the extremely high sodium concentrations within the tanks, most of the $\mathrm{CO}_{3}{ }^{2-}$ will precipitate as $\mathrm{Na}_{2} \mathrm{CO}_{3}$. Initially the ${ }^{14} \mathrm{CO}_{3}{ }^{2-}$ within the tanks is likely to be at trace concentrations and could be below the solubility limit; however, as $\mathrm{CO}_{2}$ from the atmosphere enters the system from openings in the tank, $\mathrm{Na}_{2} \mathrm{CO}_{3}$ will precipitate, removing ${ }^{14} \mathrm{CO}_{3}{ }^{2-}$ in the process. If a tank leak were to occur, this process would continue within the vadose zone as $\mathrm{CO}_{2}$ from the atmosphere diffuses through the vadose zone into the tank leak impact zone.

Because of the complex processes described above that impact the mobility of ${ }^{14} C$, a simple linear adsorption model will not adequately describe its transport from a tank leak and through groundwater. As a result of these uncertainties with regard to $\mathrm{H}^{14} \mathrm{CO}_{3}{ }^{-}$or ${ }^{14} \mathrm{CO}_{3}{ }^{2-}$ retardation within Hanford sediments, a large range in $K_{d}$ values has been selected. The best estimate was taken to be zero and the minimum and maximum were taken to be zero and 100 , respectively.

\subsubsection{Chlorine-36 (as chloride)}

Chloride $K_{d}$ value measurements are not available for Hanford sediment. This species is not expected to form complexes in Hanford groundwater, nor is it expected to undergo significant adsorption. Chloride is generally considered to exhibit conservative behavior. Measurements of chloride adsorption on clay, sandstone and granite indicated no adsorption (Stenhouse 1995). In acid soil rich in kaolinite, and iron and aluminum hydrous oxides, some chloride adsorption can occur (Higgo 1988); however, Hanford sediment does not have these characteristics. As a result the minimum, maximum, and best value for the chloride $K_{d}$ value is taken to be $0.0 \mathrm{ml} / \mathrm{g}$.

\subsubsection{Selenium-79 (as selenate)}

A fair number of $\mathrm{Se}(V I) K_{d}$ values have been determined using natural Hanford sediment (Cantrell et al. 2002). These results indicate that at trace concentrations, adsorption of $\mathrm{Se}$ (VI) to Hanford sediment is low to moderate with $K_{d}$ values ranging from 3 to $10 \mathrm{~mL} / \mathrm{g}$. At higher $S e(V I)$ concentrations, the $K_{d}$ 
values are lower (0 to $3 \mathrm{~mL} / \mathrm{g}$ ). Acidic conditions typically increase adsorption for anions such as selenate, but this cannot be confirmed for Hanford sediments with the available data. Basic conditions significantly reduce adsorption.

\subsubsection{Strontium-90}

The best estimate $K_{d}$ value for strontium selected for most Hanford impact zones and source categories is $22 \mathrm{ml} / \mathrm{g}$ with a range of 10 to 50 . In acidic high impact zones the best estimate is reduced to $10 \mathrm{ml} / \mathrm{g}$ with a range of 5 to 15 . For the chelates/high salts source category, the best estimate for the high impact zone is $0.5 \mathrm{ml} / \mathrm{g}$ with an range of 0.2 to 20 and for the intermediate impact zone the best estimate is $10 \mathrm{ml} / \mathrm{g}$ with a range of 5 to 20 . It is expected that in future work will incorporate ongoing multicomponent ion exchange data to provide a more scientifically defensible approach for estimating $K_{d}$ values for strontium-90.

\subsubsection{Technetium-99 (as pertechnetate)}

The best estimates for the $K_{d}$ values of pertechnetate are zero. The ranges were taken to be from zero to $0.1 \mathrm{ml} / \mathrm{g}$ for all source and impact zone categories (except gravel corrected). When comparing this range to values tabulated in Cantrell et al. (2002), the range may appear to be somewhat narrow; however, in most cases when higher $K_{d}$ values were measured, the $K_{d}$ values were not significantly greater than the standard deviation. As a result of this and the fact that it is known that pertechnetate is a very weak adsorbate, this narrow range for the $K_{d}$ values was selected. It should be noted that in environments where reducing agents are present, significantly higher immobilization of pertechnetate could potentially occur that is not represented by this range of $K_{d}$ values.

\subsubsection{Iodine-129 (as iodide)}

The best estimate value selected for the iodide $K_{d}$ appropriate for most Hanford impact zones and source categories is $0.2 \mathrm{ml} / \mathrm{g}$ with a range of 0 to 2 . For acidic high impact zones, the best estimate value selected is 4 with a range of 0 to 15 . Because $\mathrm{pH}$ effects resulting from acidic discharges were assumed to impact only the high impact zone categories, intermediate impact zones $K_{d}$ values are assumed to be the same as for groundwater. High $\mathrm{pH}$ and high salt appear to reduce $K_{d}$ values. This would result from increasing negative charges on sediment surfaces at high $\mathrm{pH}$ and increased competition with other anions at high salt concentrations. As a result, for high $\mathrm{pH}$ and high salt in the high impact zone a range of $K_{d}$ values of 0 to 0.2 was selected with a best estimate of $0.02 \mathrm{ml} / \mathrm{g}$. For the intermediate impact zone, the best estimate is $0.1 \mathrm{ml} / \mathrm{g}$.

\subsubsection{Cesium-137}

For cesium the best estimate $K_{d}$ value selected for most Hanford impact zones and source categories is $2,000 \mathrm{ml} / \mathrm{g}$ with a range of 200 to 10,000 . For acidic source categories and high impact zones the best estimate is reduced somewhat to $1,000 \mathrm{ml} / \mathrm{g}$. For the high impact zones of the very high salt/very basic and chelates/high salts source categories the best estimate is $10 \mathrm{ml} / \mathrm{g}$ with a range of 0 to 500 ; for the 
intermediate impact zone the best estimate is $100 \mathrm{ml} / \mathrm{g}$ with a range of 10 to 1,000 . It is expected that in future work will incorporate available multi-component ion exchange data to provide a more scientifically defensible approach for estimating $K_{d}$ values for cesium-137.

\subsubsection{Europium-152}

$K_{d}$ value data are not available for adsorption of $E u^{3+}$ on Hanford sediments; however, the chemistry of $\mathrm{Eu}^{3+}$ is very similar to $\mathrm{Am}^{3+}$ (Cantrell 1988; Allard 1982), so $K_{d}$ data available for $\mathrm{Am}^{3+}$ adsorption onto Hanford sediments has been used as an analog for $\mathrm{Eu}^{3+}$ (Cantrell et al. 2002). Review of this data suggest a best estimate of $200 \mathrm{ml} / \mathrm{g}$ with a range of between 10 and 1,000 .

\subsubsection{Uranium}

The best estimate $K_{d}$ value for uranium selected for most Hanford impact zones and source categories is $0.8 \mathrm{ml} / \mathrm{g}$, with a range of 0.2 to 4 . For high impact zones with sources that are acidic or contain chelates, the best estimate value is reduced to $0.2 \mathrm{ml} / \mathrm{g}$ and with a range of 0 to 4 . Although the $K_{d}$ value for very basic conditions is taken to be the same across each impact zone, no reliable data are available at high $\mathrm{pH}$ (one measurement is available at $\mathrm{pH} \mathrm{11,} \mathrm{but} \mathrm{precipitation} \mathrm{of} \mathrm{the} \mathrm{uranium} \mathrm{is} \mathrm{believed} \mathrm{to} \mathrm{have}$ occurred in this case).

\subsubsection{Neptunium-237}

$N p(V) K_{d}$ values for Hanford sediment compiled in Cantrell et al. (2002) indicate $N p(V)$ adsorption is generally moderate, with $K_{d}$ values in the general range of 2 to $30 \mathrm{ml} / \mathrm{g}$. Lower values can result at contact times of 1 day or less, and high calcium or chelate concentrations in solution. High solution $\mathrm{pH}$ values can result in very high $K_{d}$ values; however, this may actually be due to precipitation. These results indicate that $N p(V)$ migration from a tank leak should be minimal except when the tank wastes contain chelates. Moderate migration of $N p(V)$ could occur in the vadose zone and groundwater under natural Hanford conditions. Because precipitation is the most likely removal mechanism for $N p(V)$ retardation at high $\mathrm{pH}$, the same range of high $K_{d}$ values was used for the High Impact, Intermediate Impact and the Intermediate Impact - Gravel Zones of the Very High Salt/Very Basic waste category.

\subsection{Hydrostratigraphic Templates}

Of the more than 2,730 waste sites at Hanford and several storage sites, a subset of 1,046 sites has been selected for inclusion in the 2004 Composite Analysis. A unique alphanumeric identification tag (i.e., the site code as given in the Hanford WIDS system), was used to identify each waste site for vadose zone simulation. For example, the 241-T-106 tank was identified by its WIDS site code "241-T-106." Initially each site was assigned to a hydrostratigraphic template based on its location within one of the 16 geographic areas, its site type (surface, near surface, tank, or injection well), and its waste chemistry designation. Other waste site-specific information (location, facility dimensions, and surface cover) was assigned to define the site-specific parameters needed to perform the vadose zone simulations. 


\subsubsection{Assignment of Waste Chemistry Types}

As described in Section 3.2.3, a waste chemistry designation was assigned to each facility to be simulated in the 2004 Composite Analysis. This assignment was based on the original waste chemistry designations used in the 1998 Composite Analysis (Kincaid et al. 1998) and translating these six waste chemistry categories to the four categories used in this study (see Section 3.2.3). In assigning waste chemistry designation to facilities not included in the 1998 Composite Analysis, the following approach was taken:

- Burial grounds, process sewers, ponds, retention basins, buildings, cooling water, stacks, steam condensate, and sand filters were assigned a "low salt, near neutral" waste type (waste type 4).

- All 241 facilities were assigned a "high salt, very basic" waste type (waste type 2). Note that some tank wastes are designated as containing "chelates and high salt" (waste type 3) (Kincaid et al. 1998). This simplifying assumption to group essentially all tank waste into just two waste types on which to assign $K_{d}$ values does have obvious limitations.

- Liquid waste facilities that lacked a waste type designation, were assigned a waste type based on waste descriptions by Maxfield (1979) and/or the various Source Aggregate Area Management Study Reports (e.g., DOE 1992; DOE 1993e).

- The WIDS was consulted for all remaining facilities. If the WIDS indicated a source for the effluent discharged to a facility, the facility was given the waste type for the source. In a few instances, WIDS provided no information and a waste type 4 was assigned.

- Unplanned releases associated with a facility were assigned the waste type given to the facility.

- Unplanned releases of solids (e.g., animal waste, contaminated equipment, particulates), and atmospheric releases were assigned waste type 4.

- Unplanned releases with insufficient information were assigned a best guess of waste type 4 .

- Petroleum spills are obviously high organic but they do not fit the idea of waste type 3. Therefore, petroleum spills were arbitrarily labeled waste type 4 .

The waste chemistry designations for all facilities represented in the 2004 Composite Analysis are provided in a master spreadsheet of site-specific parameters and model designations (the General Operational Site Parameters List [GOSPL], see Last et al. 2004).

\subsubsection{Facility Location, Dimensions, and Wetted Area}

The facility location is used to assign geohydrologic properties and specify where waste that is leaving the vadose zone enters the groundwater model. The locations of most waste facilities were obtained from the WIDS. If a facility location was not in WIDS, the location was estimated using other available resources such as the Hanford Site Waste Management Units Report (DOE 2003), the Hanford 
Site Atlas (BHI 1998) and Maxfield (1979). Facility locations were assumed to be the centroid of the facility (in state-plane coordinates). Long linear facilities (such as ditches) generally do not have center coordinates listed in WIDS, so their coordinates were estimated based on visual inspection of the Hanford Site Atlas and/or other site maps.

The facility surface area (also called the facility footprint) was used to estimate the waste release area (e.g., the bottom area of a crib) and the dimensions of the surface barrier (if any). Facility surface areas of many sites were obtained from the WIDS. If the WIDS did not contain the facility surface area, the area was estimated using the facility length and width or the facility diameter. If no data were found to estimate facility area, a default value was assigned. The default values are combinations of three "9"s for easy recognition as default values. Table 4.11 lists the default values used for the four different site types.

Table 4.11. Default Surface Areas

\begin{tabular}{||l|c|}
\hline \multicolumn{1}{|c|}{ Facility (site) Type } & Default Area $\left(\mathrm{m}^{2}\right)$ \\
\hline \hline Unplanned Release, French Drain & 0.999 \\
\hline Storage Tank, Trench & 9.99 \\
\hline Radioactive Process Sewer, Crib & 99.9 \\
\hline Burial Ground & 999 \\
\hline \hline
\end{tabular}

The wetted column area (in essence, the wetted vadose zone area) represents the maximum areal extent of the waste as it migrates to the water table. For at least some sites, the facility area in WIDS represents the fenced boundary rather than the actual waste release area, which can be significantly smaller. It is also possible that the waste at some sites could spread laterally and extend beyond the facility boundaries. Until the waste-zone area of each individual waste site is determined, we will continue to assume, as was done for the previous composite analysis, that the waste zone area equals the facility area. The result of this assumption is that, whenever the waste zone area is significantly smaller than the wetted column area, the source term will be dispersed over the larger wetted column and migrate downward more slowly. Conversely, when the waste zone area is larger than the wetted column, the source term will be dispersed over the smaller wetted column area and migrate downward more quickly.

In certain simulation cases, the volume of liquid disposed per facility area exceeds the capacity of the vadose zone to transmit it. Either the vadose zone sediments have very low conductivity values or the facility area is inordinately small (e.g., reverse wells listed as having a facility area equivalent to the borehole diameter). In the field, this situation would result in significant lateral spreading beyond the facility footprint. The impact of lateral spreading will be represented in the 2004 Composite Analysis using the $K_{s}$-dependent approach. In this approach, the wetted vadose zone area $A_{x}\left(m^{2}\right)$ is related to the facility footprint by the scaling factor $\lambda$ (dimensionless), as follows:

$$
A_{x}=\lambda A_{0}=\left[\frac{\left|Q_{\max }\right|}{K_{s / \min } A_{0}}\right] A_{0} ; \lambda \geq 1
$$


where $Q_{\max }=$ the maximum artificial liquid discharge rate $\left(\mathrm{m}^{3} / \mathrm{s}\right)$

$K_{s \mid \min }=$ the minimum hydraulic conductivity $(\mathrm{m} / \mathrm{s})$ of all layers for the given site and realization

$A_{0} \quad=$ the facility area $\left(\mathrm{m}^{2}\right)$ from the WIDS database

The major assumptions underlying Equation 4.3 are that the vadose zone layer with the lowest $K_{s}$ controls flow, a unit gradient is always present across the controlling layer, and flow is steady. The scaling factor, $\lambda$, is constrained by the SAC Environmental Settings Definition keyword file to be equal to or greater than 1.0 so that the effective area is not less than the facility footprint area, unless specified for a specific site. For example, $\lambda$ is usually permitted to be less than 1.0 for the underground storage tanks, for which the actual wetted area from leaks is commonly less than the facility footprint. For most sites with little or no artificial discharges, $\lambda$ usually resolves to 1.0 (no scaling) and hence the assigned WIDS area is used. For large-discharge sites, $\lambda$ values greater than 1.0 are common.

\subsection{Recharge Estimates}

This section provides recharge (deep drainage) estimates for use in the 2004 Composite Analysis. The recharge estimates were derived from a suite of available field data and computer simulation results (Fayer and Walters 1995; Murphy et al. 1996; Prych 1998; Fayer et al. 1999; Wittreich et al. 2003). The estimates do not account for overland flow from roadways or roofs, water line leaks, or any other manmade additions of water, the impacts wrought by future climate change or land use alterations, variations within soil types, or dune-sand deposition. The estimates were developed for fairly large geographic areas and may not represent the local recharge rates at specific locations.

This section provides recharge estimates for natural and distributed soils and for surface barriers for each of the four intervals: pre-Hanford, operations, remediation, and post-Hanford. The conditions during these periods include natural soil and shrub-steppe plant communities, disturbances that alter the surface soil and vegetation, emplacement of surface barriers, and long-term changes that occur as the waste sites stabilize and return to natural conditions. This section describes the probability distribution of the recharge estimates. These distributions will be used in a Monte Carlo analysis to represent the expected range of recharge rates. This section describes a method to examine the impact of surface barrier side slopes and the terrain surrounding surface barriers, both of which could significantly affect waste release and vadose zone transport. Finally, this section summarizes the recharge estimates for all conditions.

\subsubsection{Natural and Disturbed Soil}

Prior to the establishment of the Hanford Site in 1943, the undisturbed soil and shrub-steppe plant community generally resulted in very low recharge rates. Those low rates led to the very dry vadose zone conditions that characterized the pre-Hanford period. During the subsequent operations period, the soil and vegetation at many of the waste sites were disturbed, which increased recharge rates; similar conditions will exist during the remediation period. In addition to the recharge that occurs directly in a waste site, recharge in the immediate vicinity of the site could affect transport of contaminants to the groundwater.

Examination of the Hanford soil map produced by Hajek (1966) revealed five natural soil types prevalent in and around the waste areas. These soils are nominally 1 to 2 meters thick (at most) and 
easily disrupted during construction activities. Experience shows that the dominant soil condition following construction is the underlying sediment, i.e., the Hanford sands. The only other soil type that might occur in the waste areas is a silt loam. Such soil does not currently exist in these areas. However, surface barriers will eventually age to the point where they eventually resemble silt loam soil. Recharge estimates were assigned to the five undisturbed soil types and two sediment types for the following four plant community conditions:

1. Shrub-Steppe Plant Community. This condition is a mature plant community consisting of shrubs and bunchgrasses and associated fauna and flora. Table 4.12 lists the recharge estimates for the five soil types that dominate the areas being evaluated in the 2004 Composite Analysis. It is assumed that these soils, when undisturbed, will support a shrub-steppe plant community.

Table 4.12. Estimated Recharge Rates for Predominant Soil Types and Sediment with a ShrubSteppe Plant Community

\begin{tabular}{||l|c|l||}
\hline \multicolumn{1}{|c|}{ Soil Type } & $\begin{array}{c}\text { Recharge Rate Estimate } \\
(\mathrm{mm} / \mathrm{yr})\end{array}$ & \multicolumn{1}{c||}{ Description } \\
\hline \hline $\begin{array}{l}\text { Ephrata stony loam } \\
\left(E_{b}\right)\end{array}$ & 1.5 & No data; used estimate for $\mathrm{E}_{\mathrm{l}}$, which is a similar soil \\
\hline $\begin{array}{l}\text { Ephrata sandy loam } \\
\left(E_{l}\right)\end{array}$ & 1.5 & $\begin{array}{l}\text { Avg. of two estimates }(1.2 ; 1.8) \text { from deep }(>10 \mathrm{~m}) \text { chloride data collected } \\
\text { from the two boreholes B17 and B18 (Prych 1998) }\end{array}$ \\
\hline $\begin{array}{l}\text { Burbank loamy sand } \\
\left(B_{a}\right)\end{array}$ & 3.0 & $\begin{array}{l}\text { Avg. of three estimates }(0.66,2.8,5.5) \text { from deep }(>10 \mathrm{~m}) \text { chloride data } \\
\text { collected from the three boreholes B10, B12, and B20 (Prych 1998) }\end{array}$ \\
\hline $\begin{array}{l}\text { Rupert Sand }\left(R_{p}\right) \text { in } \\
200 \text { East }\end{array}$ & 0.9 & $\begin{array}{l}\text { Avg. of four estimates }(0.16,0.58,1.0, \text { and 1.8) from deep (>10 m) chloride } \\
\text { data collected from the four boreholes E24-161, E24-162, B8501, B8502 } \\
\text { (Fayer et al. 1999) }\end{array}$ \\
\hline $\begin{array}{l}\text { Rupert Sand }\left(R_{p}\right) \\
\text { outside of 200 East }\end{array}$ & 4.0 & $\begin{array}{l}\text { Estimated from chloride data collected from a borehole near the Wye } \\
\text { Barricade (Murphy et al. 1996) }\end{array}$ \\
\hline $\begin{array}{l}\text { Hanford-formation } \\
\text { sand }\end{array}$ & 4.0 & \begin{tabular}{l} 
No data; used estimate for Rupert sand outside the 200 East area \\
\hline Warden silt loam
\end{tabular} \\
\hline
\end{tabular}

2. No Plants. This condition describes the case in which vegetation was removed and plants were prevented from re-establishing (e.g., weed control). This condition can be applied to the analysis of fire effects, although the duration without plants will be short ( $<1$ year). Table 4.13 shows the recharge estimates for the case without vegetation.

3. Shallow-Rooted Plants. This condition describes the case in which a fire or Hanford operations destroys the existing shrub-steppe vegetation and the plants that re-vegetate the site are strictly shallow-rooted (e.g., cheatgrass). Very few recharge data are available for native soils and backfilled sediments with shallow rooted grasses such as cheatgrass (Fayer and Walters 1995). For the purposes of this analysis, it was estimated that a cheatgrass cover will reduce the recharge rates listed in Table 4.13 by $50 \%$. Thus, Ephrata stony loam will have an expected mean annual recharge of 8.5 millimeters per year and a graveled surface will have a recharge rate of 44.5 millimeters per year if the surface is covered with cheatgrass. 
Table 4.13. Estimated Recharge Rates for Soil Types and Sediment Without Vegetation

\begin{tabular}{||l|c|l||}
\hline \multicolumn{1}{|c|}{ Soil Type } & $\begin{array}{c}\text { Recharge Rate Estimate } \\
(\mathrm{mm} / \mathrm{yr})\end{array}$ & \multicolumn{1}{c||}{ Description } \\
\hline $\begin{array}{l}\text { Ephrata stony } \\
\text { loam }\left(E_{b}\right)\end{array}$ & 17 & Simulation estimate for period 1958 to 1992 (Fayer and Walters 1995) \\
\hline $\begin{array}{l}\text { Ephrata sandy } \\
\text { loam }\left(E_{l}\right)\left(E_{l}\right)\end{array}$ & 17 & Simulation estimate for period 1958 to 1992 (Fayer and Walters 1995) \\
\hline $\begin{array}{l}\text { Burbank loamy } \\
\text { sand }\left(B_{a}\right)\left(B_{a}\right)\end{array}$ & 53 & Simulation estimate for period 1957 to 1997 (Fayer et al. 1999) \\
\hline Rupert Sand $\left(R_{p}\right)$ & 44 & Simulation estimate for period 1957 to 1997 (Fayer et al. 1999) \\
\hline $\begin{array}{l}\text { Hanford- } \\
\text { formation sand }\end{array}$ & 55 & $\begin{array}{l}\text { 8-yr (July 1984 to June 1993) lysimeter record for Hanford sand (Fayer and } \\
\text { Walters 1995) }\end{array}$ \\
\hline Graveled surface & 89 & $\begin{array}{l}\text { 9-yr (Feb 1990 to Feb 1999) lysimeter record for graveled surface showed } \\
52 \% \text { of precipitation received became deep drainage (Fayer et al. 1999); } \\
\text { drainage rate scaled to precipitation rate of 172 mm/yr }\end{array}$ \\
\hline
\end{tabular}

4. Young Shrub-Steppe Plant Community. This condition describes the case in which a young shrubsteppe plant community is developing in an area that had previously been disturbed by an event such as a fire. It was estimated that recharge in such areas will be double the rates estimated for mature shrub-steppe conditions (Table 4.12).

Table 4.14 shows the estimated recharge rates for various surface conditions for the 16 geographic areas, along with a brief description of each setting and major soil type that was identified using the Hajek (1966) soil map. If a significant secondary soil type was present, that soil type and its estimated recharge rate are shown in parentheses.

Note that a recharge estimate of 1 millimeter per year was assumed for those sites that discharged directly to the river, and an estimate of 0.1 millimeter per year was assumed for those sites covered by asphalt, concrete, or building.

\subsubsection{Surface Barriers}

The Hanford Disposition Baseline and Kincaid et al. (2004) determined the schedule and type of engineered surface barriers to be applied to each site for the 2004 Composite Analysis. This section describes the recharge rates to be used for barriers during the institutional control period, their design life, and after their design life. A key assumption of the 2004 Composite Analysis is that deep drainage beneath barrier side slopes and the surrounding terrain does not appreciably affect contaminant release and transport. This assumption is consistent with the previous composite analysis as well as recent and ongoing assessments. To date, the assumption has not been tested. Therefore, estimates of side slope drainage are provided here for possible use in sensitivity tests.

\subsubsection{Barrier Tops}

DOE conducted a focused feasibility study of engineered surface barriers and identified four designs that met Hanford needs (DOE 1996). Table 4.15 lists the four designs and the expected design life of 
Table 4.14. Estimated Recharge Rates by Soil Type/Sediment and Vegetation Condition in Each Hanford Area. Significant secondary soil types and their associated recharge estimates are shown in parentheses

\begin{tabular}{|c|c|c|c|c|c|c|}
\hline \multirow[b]{2}{*}{$\begin{array}{l}\text { Area } \\
\text { Label }\end{array}$} & \multirow[b]{2}{*}{ Brief Description } & \multirow{2}{*}{$\begin{array}{l}\text { Major } \\
\text { (Secondary) }^{(\mathrm{a})} \\
\text { Soil Type(s) } \\
\text { and Sediments }\end{array}$} & \multicolumn{4}{|c|}{ "Estimated Recharge Rate (mm/yr) } \\
\hline & & & No Vegetation & Cheatgrass & $\begin{array}{c}\text { Young } \\
\text { Shrub-Steppe }\end{array}$ & Shrub-Steppe \\
\hline$\overline{\bar{C}}$ & Reactor along river & 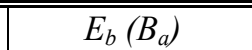 & $17(53)$ & $8.5(26.5)$ & $3.0(6.0)$ & $1.5(3.0)$ \\
\hline $\mathrm{K}$ & Reactor along river & $E_{b}\left(E_{l}\right)$ & $17(17)$ & $8.5(8.5)$ & $3.0(3.0)$ & $1.5(1.5)$ \\
\hline $\mathrm{N}$ & Reactor along river & $E_{b}$ & 17 & 8.5 & 3.0 & 1.5 \\
\hline $\mathrm{D}$ & Reactor along river & $E_{l}$ & 17 & 8.5 & 3.0 & 1.5 \\
\hline $\mathrm{H}$ & Reactor along river & $B_{a}$ & 53 & 26.5 & 6.0 & 3.0 \\
\hline $\mathrm{F}$ & Reactor along river & $R_{p}\left(E_{l}\right)$ & $44(17)$ & $22(8.5)$ & $8.0(3.0)$ & $4.0(1.5)$ \\
\hline $\mathrm{R}$ & 300 Area & $R_{p}\left(E_{l}\right)$ & $44(17)$ & $22(8.5)$ & $8.0(3.0)$ & $4.0(1.5)$ \\
\hline $\mathrm{Q}$ & 400 Area & $R_{p}\left(B_{a}\right)$ & $44(53)$ & $22(26.5)$ & $8.0(3.0)$ & $4.0(3.0)$ \\
\hline $\mathrm{P}$ & 618-10 Area & $R_{p}\left(B_{a}\right)$ & $44(53)$ & $22(26.5)$ & $8.0(3.0)$ & $4.0(3.0)$ \\
\hline $\bar{M}$ & 618-11 Area & $R_{p}\left(B_{a}\right)$ & $44(53)$ & $22(26.5)$ & $8.0(3.0)$ & $4.0(3.0)$ \\
\hline $\mathrm{G}$ & 200N Area & $E_{l}\left(B_{a}\right)$ & $17(53)$ & $8.5(26.5)$ & $3.0(6.0)$ & $1.5(3.0)$ \\
\hline $\mathrm{T}$ & Northern 200W Area & $R_{p}\left(B_{a}\right)$ & $44(53)$ & $22(26.5)$ & $8.0(3.0)$ & $4.0(3.0)$ \\
\hline $\bar{S}$ & $\begin{array}{l}\text { Southern 200W Area } \\
\text { and ERDF }\end{array}$ & $R_{p}$ & 44 & 22 & 8.0 & 4.0 \\
\hline $\mathrm{A}$ & Southern 200E Area & $R_{p e}\left(B_{a}\right)$ & $44(53)$ & $22(26.5)$ & $1.8(6.0)$ & $0.9(3.0)$ \\
\hline $\mathrm{B}$ & $\begin{array}{l}\text { Northwestern 200E } \\
\text { Area }\end{array}$ & $E_{l}$ & 17 & 8.5 & 3.0 & 1.5 \\
\hline $\mathrm{E}$ & Eastern 200E Area & $B_{a}\left(R_{p e}\right)$ & $53(44)$ & $26.5(22)$ & $6.0(1.8)$ & $3.0(0.9)$ \\
\hline-- & $\begin{array}{l}\text { All Areas with soils } \\
\text { disturbed by } \\
\text { excavations }\end{array}$ & Hanford sand & 55 & 27.5 & 8.0 & 4.0 \\
\hline-- & $\begin{array}{l}\text { All Areas with a } \\
\text { surface barrier }\end{array}$ & $\begin{array}{l}\text { Warden silt } \\
\text { loam }\end{array}$ & na & na & 0.22 & 0.11 \\
\hline-- & $\begin{array}{l}\text { All Areas with gravel } \\
\text { surface and no plants }\end{array}$ & gravel & 89 & 44.5 & na & na \\
\hline \multicolumn{7}{|c|}{$\begin{array}{l}E_{b}=\text { Ephrata stony loam } \quad E_{l}=\text { Ephrata sandy loam } \quad B_{a}=\text { Burbank loamy sand } R_{p}=\text { Rupert sand } \\
R_{p e}=\text { Rupert sand in } 200 \text { East Area. } \\
\text { (a) Note: Only the major soil types were used to represent each aggregate area. }\end{array}$} \\
\hline
\end{tabular}

each. For the 2004 Composite Analysis analyses, only the Hanford barrier and the modified RCRA C barrier are being evaluated for sites that require protection. Recharge rates for the top portion of the surface barriers were estimated from field studies of surface barrier systems at Hanford (Fayer et al. 1999; Wittreich et al. 2003) and are shown in Table 4.15.

\subsubsection{Barrier Side Slopes}

This discussion of recharge through barrier side slopes is provided only for completeness and to provide the basis for possible use in sensitivity analyses. A significant number of the surface barriers 
Table 4.15. Barrier Design Life and Estimated Recharge Rates for Barrier Tops

\begin{tabular}{||l|c|c|l||}
\hline \multicolumn{1}{|c|}{$\begin{array}{c}\text { FFS Design } \\
\text { (DOE/RL 1996) }\end{array}$} & $\begin{array}{c}\text { Design Life } \\
(\mathrm{yr})\end{array}$ & $\begin{array}{c}\text { Recharge Rate } \\
(\mathrm{mm} / \mathrm{yr})\end{array}$ & \multicolumn{1}{|c||}{ Source } \\
\hline \hline Hanford Barrier & 1,000 & 0.1 & $\begin{array}{l}\text { Based on lysimeter data and simulation results } \\
\text { (Fayer et al. 1999; Wittreich et al. 2003) }\end{array}$ \\
\hline Modified RCRA C & 500 & 0.1 & $\begin{array}{l}\text { Based on lysimeter data and simulation results } \\
\text { (Fayer et al. 1999) }\end{array}$ \\
\hline $\begin{array}{l}\text { Standard RCRA C } \\
\text { (not evaluated in the 2004 } \\
\text { Composite Analysis) }\end{array}$ & 30 & 0.1 & $\begin{array}{l}\text { No data; recommendation is based on presence of } \\
\text { Geomembrane and 2-ft thick clay admix layer }\end{array}$ \\
$\begin{array}{l}\text { Modified RCRA D } \\
\text { (not evaluated in the 2004 } \\
\text { Composite Analysis) }\end{array}$ & 100 & 0.1 & $\begin{array}{l}\text { Based on simulation results using parameters from } \\
\text { Fayer et al. (1999) }\end{array}$ \\
\hline
\end{tabular}

being planned at Hanford will be above-grade structures that require stabilizing side slopes. Two side slope designs are currently being tested at the Prototype Surface Barrier (Wittreich 2003). One design, called "Gravel," is a sandy gravel/gravelly sand mix emplaced at a 10 horizontal (H):1 vertical (V) slope. The second design, called "Basalt," is open-work basalt riprap emplaced at a $2 \mathrm{H}: 1 \mathrm{~V}$ slope. Neither design incorporates any plant-promoting features. Since being constructed in November 1994, the sandy gravel side slope has had very few plants established and the basalt side slope has had none.

Drainage data have been collected since November 1994. During that period, records show that Hanford received higher-than-normal precipitation. Therefore, the side slope drainage data were scaled to the long-term precipitation average to yield long-term estimates of side slope recharge rates. Hoitink et al. (2003) reported an annual mean precipitation at the Hanford Meteorological Station (HMS) of 172 millimeters per year, based on HMS records from 1946 through 2002. For the 2004 Composite Analysis, we assumed the long-term precipitation average was 172 millimeters per year and scaled the drainage data accordingly. The full set of drainage data encompassed the period from November 1994 to September 2002. For the estimation process, the drainage data from the first year (up to October 1995) were not included so as to avoid any effects from the initial conditions. Drainage was not measured during the period from October 1998 to September 1999. The remaining data, which spanned a total of six years, were used to estimate recharge rates for the period immediately following barrier construction. Table 4.16 shows these estimates for the two side slope materials in the current baseline for above-grade surface barriers.

Table 4.16. Initial Side Slope Recharge Rates for Hanford Site Climate Conditions

\begin{tabular}{||c|c|c|l||}
\hline Side Slope Type & Slope & $\begin{array}{c}\text { Initial Recharge Rate } \\
(\mathrm{mm} / \mathrm{yr})\end{array}$ & \multicolumn{1}{c||}{ Source } \\
\hline \hline $\begin{array}{l}\text { Gravel (mix of sand } \\
\text { and gravel) }\end{array}$ & $10 \mathrm{H}: 1 \mathrm{~V}$ & 42 & $\begin{array}{l}\text { Based on six years of drainage data from the prototype } \\
\text { surface barrier (Wittreich et al. 2003) scaled to average } \\
\text { precipitation of 172 mm/yr. }\end{array}$ \\
\hline $\begin{array}{l}\text { Basalt (open-work } \\
\text { riprap) }\end{array}$ & $2 \mathrm{H}: 1 \mathrm{~V}$ & $\begin{array}{l}\text { Based on six years of drainage data from the prototype } \\
\text { surface barrier (Wittreich et al. 2003) scaled to average } \\
\text { precipitation of } 172 \mathrm{~mm} / \mathrm{yr} .\end{array}$ \\
\hline
\end{tabular}


We do not expect the initial recharge rates shown in Table 4.16 to persist forever. During the 100 years of institutional control, we expect the plant community on the side slopes to slowly develop and mature to the point where recharge rates beneath the side slopes resemble Burbank loamy sand and a shrub-steppe plant community. Therefore, we propose representing side slope recharge rates in a timedependent fashion during the period of institutional control.

\subsubsection{Surface Barriers Post-Hanford}

No guidance is available for specifying barrier performance after the design life. In the previous composite analysis (Kincaid et al. 1998) barrier performance after the design life was simply assumed to end, after which recharge rates were set equal those of the original soil type at each location. However, there is no basis for assuming the surface barrier will disappear or evolve to resemble the local soil. What will happen is that the barrier will continue to experience soil and ecological processes that will alter the nature of the barrier and affect it's performance.

Appendix D describes processes that could potentially affect barrier performance and outlines several scenarios that could be used to simulate performance after the design life. Fayer et al. (1999) examined two key natural processes (erosion of the silt loam layer and deposition of dune sand on the barrier) that could alter barrier performance. Their results suggested that neither process would significantly alter barrier performance. Thus, after the barrier design life, the barrier would continue to function as designed; the barrier top would most likely resemble a Warden silt loam and the side slope would most likely resemble the Ephrata stony loam.

For the 2004 Composite Analysis, the approach chosen to describe barrier performance after the design life was to retain some functioning after the design life but for a limited duration equivalent to the design life. For example, the modified RCRA C barrier top would perform as designed for it's 500-year design life, after which the barrier performance would be changed linearly to the final rate (the recharge rate for the equivalent soil type, which in this case would be Warden silt loam). For simplicity and ease of implementation, the changes in performance after the design life will be represented by five equal stepwise changes in recharge during the degradation period.

\subsubsection{Probability Distribution Functions}

After reviewing the possible probability distributions, we chose a three-point triangular distribution to represent recharge at all sites. In this distribution, the low value is equal to the mean value minus the standard deviation and the high value is equal to twice the mean value. The number of recharge estimates is too small to calculate adequate statistics, so recharge statistics (mean and standard deviations) were estimated using statistics from winter precipitation. Data from HMS precipitation records from Hoitink et al. (2003) and current Hanford Site weather records (http://hms.rl.gov/products.htm) were used to obtain the mean value and standard deviation of the extended-winter (November through March) precipitation for the period from November 1946 to March 2003 and resulted in a mean value of 101 millimeters per year and standard deviation of 40 millimeters per year. We reasoned that winter precipitation was the primary source of recharge and that recharge would seldom, if ever, exceed winter precipitation; so all recharge values were keyed to the mean extended winter precipitation as the upper limit of recharge. Because the available data were limited, we estimated the standard deviation for all 
surfaces as equal to half the mean value. This appears to be a conservative estimate based on the statistic for the extended winter precipitation. As more data are collected for various surface conditions the actual standard deviations can be substituted.

\subsubsection{Integrated Drainage Calculations}

A key assumption of the baseline analysis of the 2004 Composite Analysis is that vadose zone waste is only affected by the recharge that occurs beneath the surface barrier tops. The implication of this assumption is that recharge occurring beneath the barrier side slopes (if present) or in the areas immediately surrounding the surface barrier will not affect the mobilization of waste beneath the surface barrier nor the transport of the waste contaminants to the water table. To test the assumption, a method was developed to integrate the drainage rates from the barrier top and side slopes (or surrounding terrain if no side slopes) into a single composite rate that could be used for sensitivity analyses in the 2004 Composite Analysis.

In the composite analysis, each waste site is characterized by two drainage estimates defined as follows:

Release Model Drainage. This drainage rate directly affects the behavior of the release model. The assumption is that the waste form is directly beneath the intact and functional part of the surface barrier and affected only by recharge through the barrier top. Any recharge through the barrier side slopes or in the areas surrounding the barrier is assumed to have no impact on the waste form.

Vadose Zone Model Drainage. This drainage rate directly impacts the transport of contaminants released by the waste form through the vadose zone and to the water table. In the baseline 2004 Composite Analysis, the vadose zone drainage rate is equivalent to the barrier top drainage rate. However, for sensitivity tests of this assumption, the vadose zone drainage rate could be assigned a value that is a composite of recharge through the barrier and recharge through a portion of the barrier side slopes or surrounding terrain.

The impact of higher drainage rates around a surface barrier is a function of individual site characteristics such as barrier geometry and dimensions, distance to the water table, geology, physicalhydraulic-chemical properties, and contaminant depth and characteristics. Given the diversity of site characteristics and the one-dimensional conceptual model used in the 2004 Composite Analysis, the analysis was simplified for the purpose of demonstrating sensitivity without having to represent the unique features of every site. For this purpose, the recharge rates were integrated by weighting the recharge contributions from the barrier and the contributing portion of the side slope based on their respective areas referenced to the total area. Some of the recharge beneath the side slope will affect contaminant transport beneath the barrier and some will move away from the barrier and have negligible impact on contaminants. This partitioning was represented by assuming that half the side slope area would contribute to contaminant transport. The resulting integrated vadose zone drainage rate $\left(r_{b}\right)$ is computed as follows:

$$
r_{b}=\left(r_{b t} A_{b t}+r_{b s} 0.5 A_{b s}\right) / A_{b}
$$


where $r_{b t}=$ drainage rate of the barrier top

$r_{b s}=$ drainage rate of the barrier side slope

$A_{b t}=$ area of the barrier top

$A_{b s}=$ area of the barrier side slope

$A_{b}=$ total area of the barrier and contributing side slope; sum of $A_{b t}$ and $0.5^{*} A_{b s}$

The following example illustrates how the integrated recharge rate from a modified RCRA C barrier with side slopes might affect the overall vadose zone drainage rate.

\section{Modified RCRA C Barrier}

- shape $=$ square, $316 \mathrm{~m}$ on a side, yielding area $A_{b t}=10$ ha

- height $=5 \mathrm{~m}$ above the surrounding terrain

- surface barrier drainage rate $r_{b t}=0.1 \mathrm{~mm} / \mathrm{yr}$

\section{Gravel Side Slope}

- $\quad$ slope $=5 \mathrm{H}: 1 \mathrm{~V}$

- slope length $=25 \mathrm{~m}$

- contributing area, $0.5 * A_{b s}=1.71$ ha (equal to one-half of the side slope area)

- drainage rate $r_{b s}=3.0 \mathrm{~mm} / \mathrm{yr}$ (assumed mature shrub-steppe plant community)

Using Equation 4.4 and the values provided above, the integrated vadose zone drainage rate is

$$
r_{b}=[0.1 \times 10+3.0 \times 1.71] / 11.7=0.52 \mathrm{~mm} / \mathrm{yr}
$$

If the waste site requires the barrier area to be doubled to 20 hectares, the contributing side slope area would be 2.35 hectares and the integrated vadose zone drainage rate would be

$$
r_{b}=[0.1 \times 20+3.0 \times 2.36] / 22.4=0.41 \mathrm{~mm} / \mathrm{yr}
$$

The integrated drainage rate for the 10-hectare waste site is 5 times larger than the barrier top drainage rate. For the 20 -hectare site, the integrated drainage rate drops to 0.41 millimeter per year, but it is still 4 times larger than the barrier top drainage rate. These examples show that, for surface barriers in the range from 2 to 20 hectares (typical of what might be expected for the Hanford Site), side slope drainage can significantly increase the vadose zone drainage rate. To further dramatize the significance, consider the case where the side slope drainage rate is equal to the rate currently measured beneath the gravel side slope at the prototype barrier. If plants never establish on the side slope and the rate remains at 42 millimeters per year, the integrated vadose drainage rate would be 6.2 millimeters per year for the 10-hectare barrier and 4.5 millimeters per year for the 20 -hectare barrier. To further illustrate the effect of barrier dimensions on drainage, if the barrier were reduced to 1 ha with a corresponding side slope area of 0.62 hectare, the integrated drainage rate would be increased to 16.2 millimeters per year.

The impact of the side slopes on integrated drainage rates decreases as the size of the barrier increases. Plans for surface barriers typically assume that the barrier top will extend 10 meters beyond 
the edge of the waste to provide more protection. The extent of such overbuilding is colloquially referred to as the barrier overhang distance. The overhang will increase the functional area of the surface barrier and somewhat decrease the impact of any side slope. For the 2004 Composite Analysis, however, we assumed no overhang.

If surface barriers are built at or near ground level to eliminate side slopes, they will still be prone to the influence of drainage rates in the surrounding soils. The analysis of impacts from such drainage can be evaluated using a similar methodology to that used in evaluating side slope impacts.

\subsubsection{Recharge Classes}

To facilitate the assignment of recharge rates for individual waste sites, four sets of recharge classes were developed: 1) rates for baseline soil conditions with shrub-steppe plant community; 2) rates for disturbed conditions or for sensitivity tests (e.g., native soils or backfilled soils; with or without vegetation; asphalt, concrete, or gravel covers); 3) rates for surface barrier components; and 4) integrated rates for surface barriers with side slopes. In all cases, the waste site drainage rates described by Equation 4.4 were assumed to be directly equivalent to recharge rates (i.e., all drainage subsequently becomes recharge). Each recharge class was identified with a unique code based on either the primary native soil and vegetation type or the type and size of the surface barrier. Tables 4.17 through 4.21 provide the estimated recharge rates for each class.

Table 4.17. Estimated Recharge Rates for Baseline Soil Conditions

\begin{tabular}{|c|l|c|c|c|c||}
\hline $\begin{array}{c}\text { Recharge } \\
\text { Class Code }\end{array}$ & \multicolumn{1}{|c|}{ Description } & $\begin{array}{c}\text { Best } \\
\text { Estimate } \\
(\mathrm{mm} / \mathrm{yr})\end{array}$ & $\begin{array}{c}\text { Estimated Standard } \\
\text { Deviation } \\
(\mathrm{mm} / \mathrm{yr})\end{array}$ & $\begin{array}{c}\text { Minimum } \\
(\mathrm{mm} / \mathrm{yr})\end{array}$ & $\begin{array}{c}\text { Maximum } \\
(\mathrm{mm} / \mathrm{yr})\end{array}$ \\
\hline \hline$E_{b}$-s & $\begin{array}{l}\text { Ephrata stony loam }\left(E_{b}\right) \text { - with shrub- } \\
\text { steppe }(s) \text { plant community }\end{array}$ & 1.5 & 0.75 & 0.75 & 3.0 \\
\hline$E_{l}$-s & $\begin{array}{l}\text { Ephrata sandy loam }\left(E_{l}\right) \text { - with shrub- } \\
\text { steppe }(s) \text { plant community }\end{array}$ & 1.5 & 0.75 & 0.75 & 3.0 \\
\hline$B_{a}$-s & $\begin{array}{l}\text { Burbank loamy sand }\left(B_{a}\right) \text { - with shrub- } \\
\text { steppe }(s) \text { plant community }\end{array}$ & 3.0 & 1.5 & 1.5 & 6.0 \\
\hline$R_{p e^{-\mathrm{S}}}$ & $\begin{array}{l}\text { Rupert sand }\left(R_{p}\right) \text { in } 200 \text { East }(e)-\text { with } \\
\text { shrub-steppe }(s) \text { plant community }\end{array}$ & 0.9 & 0.45 & 0.45 & 1.8 \\
\hline$R_{p}$-s & $\begin{array}{l}\text { Rupert sand }\left(R_{p}\right) \text { outside } 200 \text { East - with } \\
\text { shrub-steppe }(s) \text { plant community }\end{array}$ & 4.0 & 2.0 & 2.0 & 8.0 \\
\hline$W_{a}$-s & $\begin{array}{l}\text { Warden silt loam }\left(W_{a}\right) \text { - with shrub- } \\
\text { steppe }(s) \text { plant community }\end{array}$ & 0.11 & 0.06 & 0.06 & 0.22 \\
\hline \hline
\end{tabular}


Table 4.18. Estimated Recharge Rates for Disturbed Conditions and Sensitivity Tests

\begin{tabular}{|c|c|c|c|c|c|}
\hline $\begin{array}{l}\text { Recharge } \\
\text { Class Code }\end{array}$ & Description & $\begin{array}{c}\text { Best } \\
\text { Estimate } \\
(\mathrm{mm} / \mathrm{yr})\end{array}$ & $\begin{array}{c}\begin{array}{c}\text { Estimated Standard } \\
\text { Deviation } \\
(\mathrm{mm} / \mathrm{yr})\end{array} \\
\end{array}$ & $\begin{array}{c}\text { Minimum } \\
(\mathrm{mm} / \mathrm{yr})\end{array}$ & $\begin{array}{l}\text { Maximum } \\
(\mathrm{mm} / \mathrm{yr})^{(\mathrm{a})}\end{array}$ \\
\hline 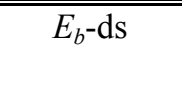 & $\begin{array}{l}\text { Ephrata stony loam }\left(E_{b}\right) \text {, disturbed }(d) \text { - } \\
\text { with young shrub-steppe }(s) \text { vegetation }\end{array}$ & 3.0 & 1.5 & 1.5 & 6.0 \\
\hline$E_{b}$-dg & $\begin{array}{l}\text { Ephrata stony loam }\left(E_{b}\right) \text {, disturbed }(d) \text { - } \\
\text { with cheatgrass }(g) \text { vegetation }\end{array}$ & 9 & 4.5 & 4.5 & 18 \\
\hline$E_{b}-\mathrm{dn}$ & $\begin{array}{l}\text { Ephrata stony loam }\left(E_{b}\right) \text {, disturbed }(d) \text { - } \\
\text { with no }(n) \text { vegetation }\end{array}$ & 17 & 8.5 & 8.5 & 34 \\
\hline$E_{l}-\mathrm{ds}$ & $\begin{array}{l}\text { Ephrata sandy loam }\left(E_{l}\right) \text {, disturbed }(d) \text { - } \\
\text { with young shrub-steppe }(s) \text { vegetation }\end{array}$ & 3.0 & 1.5 & 1.5 & 6.0 \\
\hline$E_{l}$-dg & $\begin{array}{l}\text { Ephrata sandy loam }\left(E_{l}\right) \text {, disturbed }(d) \text { - } \\
\text { with cheatgrass }(g) \text { vegetation }\end{array}$ & 9 & 4.5 & 4.5 & 18 \\
\hline$E_{l}$-dn & $\begin{array}{l}\text { Ephrata sandy loam }\left(E_{l}\right) \text {, disturbed }(d) \text { - } \\
\text { with no }(n) \text { vegetation }\end{array}$ & 17 & 8.5 & 8.5 & 34 \\
\hline$B_{a}$-ds & $\begin{array}{l}\text { Burbank loamy sand }\left(B_{a}\right) \text {, disturbed }(d) \text { - } \\
\text { with young shrub-steppe }(s) \text { plant } \\
\text { community }\end{array}$ & 6.0 & 3.0 & 3.0 & 12 \\
\hline$B_{a}-\mathrm{dg}$ & $\begin{array}{l}\text { Burbank loamy sand }\left(B_{a}\right) \text {, disturbed }(d) \text { - } \\
\text { with cheatgrass }(g) \text { plant community }\end{array}$ & 26 & 13.0 & 13.0 & 52 \\
\hline$B_{a}$-dn & $\begin{array}{l}\text { Burbank loamy sand }\left(B_{a}\right) \text {, disturbed }(d) \text { - } \\
\text { with no }(n) \text { vegetation }\end{array}$ & 53 & 26.5 & 26.5 & 101 \\
\hline$R_{p e}$-ds & $\begin{array}{l}\text { Rupert sand }\left(R_{p}\right) \text { in } 200 \text { East, disturbed } \\
(d) \text { - with young shrub-steppe }(s) \text { plant } \\
\text { community }\end{array}$ & 1.8 & 0.9 & 0.9 & 3.6 \\
\hline$R_{p e^{-\mathrm{dg}}}$ & $\begin{array}{l}\text { Rupert sand }\left(R_{p}\right) \text { in } 200 \text { East, disturbed } \\
(d) \text { - with cheatgrass }(g) \text { plant } \\
\text { community }\end{array}$ & 22 & 11 & 11 & 44 \\
\hline$R_{p e^{-\mathrm{dn}}}$ & $\begin{array}{l}\text { Rupert sand }\left(R_{p}\right) \text { in } 200 \text { East, disturbed } \\
(d) \text { - with no }(n) \text { vegetation }\end{array}$ & 44 & 22 & 22 & 88 \\
\hline$R_{p}$-ds & $\begin{array}{l}\text { Rupert sand }\left(R_{p}\right) \text { outside } 200 \text { East, } \\
\text { disturbed }(d) \text { - with young shrub-steppe } \\
(s) \text { plant community }\end{array}$ & 8.0 & 4.0 & 4.0 & 16.0 \\
\hline$R_{p}$-dg & $\begin{array}{l}\text { Rupert sand }\left(R_{p}\right) \text { outside } 200 \text { East, } \\
\text { disturbed }(d) \text { - with cheatgrass }(g) \text { plant } \\
\text { community }\end{array}$ & 22 & 11 & 11 & 44 \\
\hline$R_{p}-\mathrm{dn}$ & $\begin{array}{l}\text { Rupert sand }\left(R_{p}\right) \text { outside } 200 \text { East, } \\
\text { disturbed }(d) \text { - with no }(n) \text { vegetation }\end{array}$ & 44 & 22 & 22 & 88 \\
\hline$H_{s}-\mathrm{dn}$ & $\begin{array}{l}\text { Hanford Sand }\left(H_{s}\right) \text {, disturbed }(d) \text { - with } \\
\text { no }(n) \text { vegetation }\end{array}$ & 55 & 27.5 & 27.5 & 101 \\
\hline$G$-dn & $\begin{array}{l}\text { Gravel surface }(G) \text {, disturbed - with no } \\
(n) \text { vegetation }\end{array}$ & 89 & 44.5 & 44.5 & 101 \\
\hline $\mathrm{ABC}$ & $\begin{array}{l}\text { Soil Surface covered by Asphalt, } \\
\text { Building, or Concrete }\end{array}$ & 0.1 & 0.05 & 0.05 & 0.2 \\
\hline
\end{tabular}


Table 4.19. Estimated Recharge Rates for Surface Barrier Components

\begin{tabular}{||c|l|c|c|c|c||}
\hline $\begin{array}{c}\text { Recharge } \\
\text { Class Code }\end{array}$ & \multicolumn{1}{|c|}{ Description } & $\begin{array}{c}\text { Best } \\
\text { Estimate } \\
(\mathrm{mm} / \mathrm{yr})\end{array}$ & $\begin{array}{c}\text { Estimated Standard } \\
\text { Deviation } \\
(\mathrm{mm} / \mathrm{yr})\end{array}$ & $\begin{array}{c}\text { Minimum } \\
(\mathrm{mm} / \mathrm{yr})\end{array}$ & $\begin{array}{c}\text { Maximum } \\
(\mathrm{mm} / \mathrm{yr})\end{array}$ \\
\hline \hline RCRA C & $\begin{array}{l}\text { Modified RCRA C - barrier top during } \\
\text { design life }\end{array}$ & 0.1 & 0.05 & 0.05 & 0.20 \\
\hline Hanford & $\begin{array}{l}\text { Hanford Barrier- barrier top during } \\
\text { design life }\end{array}$ & 0.1 & 0.05 & 0.05 & 0.20 \\
\hline$W_{a}$-s & $\begin{array}{l}\text { Warden Silt Loam }\left(W_{a}\right) \text { - with shrub- } \\
\text { steppe }(s) \text { plant community (Could be } \\
\text { used to represent final degradation of } \\
\text { barrier top) }\end{array}$ & 0.11 & 0.06 & 0.06 & 0.22 \\
\hline$G_{r}$-s & $\begin{array}{l}\text { Gravel side slope - with shrub-steppe }(s) \\
\text { plant community }(\text { Could be used to } \\
\text { represent final degradation of gravel side } \\
\text { slope) }\end{array}$ & 3.0 & 1.5 & 1.5 & 6.0 \\
\hline$G_{r}$-n & Gravel side slope - no vegetation $(n)$ & 42 & 21 & 21 & 84 \\
\hline
\end{tabular}

Table 4.20. Estimated Recharge Rates for Surface Barriers with Side Slopes and $\boldsymbol{r}_{b s}=\mathbf{3 . 0} \mathrm{mm} / \mathrm{yr}$

\begin{tabular}{||c|c|c|c|c|c||}
\hline \multirow{3}{*}{ Barrier Type } & $\begin{array}{c}\text { Recharge Class } \\
\text { Code }\end{array}$ & $\begin{array}{c}\text { Cover Area, } A_{b t} \\
\left(\mathrm{~m}^{2}\right)\end{array}$ & $\begin{array}{c}\text { Best Estimate } \\
(\mathrm{mm} / \mathrm{yr})\end{array}$ & $\begin{array}{c}\text { Minimum } \\
(\mathrm{mm} / \mathrm{yr})\end{array}$ & $\begin{array}{c}\text { Maximum } \\
(\mathrm{mm} / \mathrm{yr})\end{array}$ \\
\hline \hline \multirow{5}{*}{$\begin{array}{l}\text { Modified } \\
\text { RCRA C or }\end{array}$} & $-\mathrm{I} 8$ & $128 \leq A_{b t}<256$ & 2.81 & 1.40 & 5.62 \\
\cline { 2 - 6 } & $-\mathrm{I} 9$ & $256 \leq A_{b t}<512$ & 2.68 & 1.34 & 5.36 \\
\cline { 2 - 6 } & $-\mathrm{I} 10$ & $512 \leq A_{b t}<1024$ & 2.49 & 1.24 & 4.97 \\
\cline { 2 - 6 } & $-\mathrm{I} 11$ & $1024 \leq A_{b t}<2048$ & 2.23 & 1.12 & 4.47 \\
\cline { 2 - 6 } & $-\mathrm{I} 12$ & $2048 \leq A_{b t}<4096$ & 1.93 & 0.97 & 3.86 \\
\cline { 2 - 6 } & $-\mathrm{I} 13$ & $4096 \leq A_{b t}<8192$ & 1.61 & 0.81 & 3.22 \\
\cline { 2 - 6 } & $-\mathrm{I} 14$ & $8192 \leq A_{b t}<16384$ & 1.30 & 0.65 & 2.60 \\
\cline { 2 - 6 } & $-\mathrm{I} 15$ & $16384 \leq A_{b t}<32768$ & 1.02 & 0.51 & 2.05 \\
\cline { 2 - 6 } & $-\mathrm{I} 16$ & $32768 \leq A_{b t}<65536$ & 0.79 & 0.40 & 1.59 \\
\cline { 2 - 6 } & $-\mathrm{I} 17$ & $65536 \leq A_{b t}<131072$ & 0.61 & 0.31 & 1.22 \\
\cline { 2 - 6 } & $-\mathrm{I} 18$ & $131072 \leq A_{b t}<262144$ & 0.47 & 0.24 & 0.95 \\
\cline { 2 - 6 } & $-\mathrm{I} 19$ & $262144 \leq A_{b t}<524288$ & 0.37 & 0.18 & 0.74 \\
\cline { 2 - 6 } & $-\mathrm{I} 20$ & $524288 \leq A_{b t}<1048576$ & 0.29 & 0.15 & 0.59 \\
\cline { 2 - 6 } & $-\mathrm{I} 21$ & $1048576 \leq A_{b t}<2097152$ & 0.24 & 0.12 & 0.48 \\
\cline { 2 - 6 } & $-\mathrm{I} 22$ & $2097152 \leq A_{b t}<4194304$ & 0.20 & 0.10 & 0.40 \\
\hline
\end{tabular}


Table 4.21. Estimated Recharge Rates for Surface Barriers with Side Slopes and $\boldsymbol{r}_{b s}=42.0 \mathrm{~mm} / \mathrm{yr}$

\begin{tabular}{||c|c|c|c|c|c||}
\hline \multirow{3}{*}{ Barrier Type } & $\begin{array}{c}\text { Recharge Class } \\
\text { Code }\end{array}$ & $\begin{array}{c}\text { Cover Area, } A_{b t} \\
\left(\mathrm{~m}^{2}\right)\end{array}$ & $\begin{array}{c}\text { Best Estimate } \\
(\mathrm{mm} / \mathrm{yr})\end{array}$ & $\begin{array}{c}\text { Minimum } \\
(\mathrm{mm} / \mathrm{yr})\end{array}$ & $\begin{array}{c}\text { Maximum } \\
(\mathrm{mm} / \mathrm{yr})\end{array}$ \\
\hline \hline \multirow{5}{*}{$\begin{array}{l}\text { Modified } \\
\text { RCRA C or }\end{array}$} & $-\mathrm{I} 8$ & $128 \leq A_{b t}<256$ & 39.2 & 19.6 & 78.5 \\
\cline { 2 - 6 } & $-\mathrm{I} 9$ & $256 \leq A_{b t}<512$ & 37.3 & 18.7 & 74.7 \\
\cline { 2 - 6 } & $-\mathrm{I} 10$ & $512 \leq A_{b t}<1024$ & 34.6 & 17.3 & 69.2 \\
\cline { 2 - 6 } & $-\mathrm{I} 11$ & $1024 \leq A_{b t}<2048$ & 30.9 & 15.5 & 61.8 \\
\cline { 2 - 6 } & $-\mathrm{I} 12$ & $2048 \leq A_{b t}<4096$ & 26.6 & 13.3 & 53.1 \\
\cline { 2 - 6 } & $-\mathrm{I} 13$ & $4096 \leq A_{b t}<8192$ & 21.9 & 11.0 & 43.8 \\
\cline { 2 - 6 } & $-\mathrm{I} 14$ & $8192 \leq A_{b t}<16384$ & 17.4 & 8.7 & 34.9 \\
\cline { 2 - 6 } & $-\mathrm{I} 15$ & $16384 \leq A_{b t}<32768$ & 13.4 & 6.7 & 26.9 \\
\cline { 2 - 6 } & $-\mathrm{I} 16$ & $32768 \leq A_{b t}<65536$ & 10.1 & 5.1 & 20.2 \\
\cline { 2 - 6 } & $-\mathrm{I} 17$ & $65536 \leq A_{b t}<131072$ & 7.5 & 3.7 & 15.0 \\
\cline { 2 - 6 } & $-\mathrm{I} 18$ & $131072 \leq A_{b t}<262144$ & 5.5 & 2.7 & 11.0 \\
\cline { 2 - 6 } & $-\mathrm{I} 19$ & $262144 \leq A_{b t}<524288$ & 4.0 & 2.0 & 8.0 \\
\cline { 2 - 6 } & $-\mathrm{I} 20$ & $524288 \leq A_{b t}<1048576$ & 2.9 & 1.4 & 5.8 \\
\cline { 2 - 6 } & $-\mathrm{I} 21$ & $1048576 \leq A_{b t}<2097152$ & 2.1 & 1.0 & 3.2 \\
\cline { 2 - 6 } & $-\mathrm{I} 22$ & $2097152 \leq A_{b t}<4194304$ & 1.5 & 0.8 & 3.0 \\
\hline
\end{tabular}




\subsection{Conclusions and Recommendations}

The 2004 Composite Analysis will include one-dimensional stochastic simulations of flow and transport through the vadose zone for 1,022 of the 1,046 waste sites selected for inclusion in the 2004 Composite Analysis. The remaining 24 sites are just place holders to account for offsite transfers and nuclear materials and thus are not directly simulated. Data and interpreted information needed to define the input parameters for the vadose zone simulations have been extracted from existing documents and databases.

This report describes the assumptions and rationale for 1) defining the hydrostratigraphy, hydraulic properties, and distribution coefficients for each site to be simulated; and 2) defining the recharge estimates for each site. To simplify the preparation of input files for the large number of sites, and to improve the computational efficiencies, the Hanford Site was subdivided into 17 geographically similar areas that could each be represented by a single generalized hydrostratigraphic column. The hydrostratigraphic columns for each of the 17 geographic areas were further modified to account for differences in the depth of waste releases, and differences in solid/liquid distribution coefficients $\left(K_{d}\right.$ values) affected by different waste chemistries. This resulted in 63 base templates, each with their own unique hydrogeologic stratigraphy, hydraulic parameter distributions, and $K_{d}$ distributions. Flow and transport parameters are to be stochastically sampled for each hydrogeologic unit for each realization. Thus, each model node within a given hydrogeologic unit has the same set of parameters for a given realization.

Recharge estimates are provided for four different conditions: pre-Hanford, operations, remediation, and post-Hanford. The conditions during these periods include natural soil with shrub-steppe plant communities, disturbed soil and vegetation, surface barriers, and degraded surface barriers as the waste sites stabilize and return to natural conditions. Probability distributions have been provided for each recharge estimate to facilitate Monte Carlo analysis in representing the expected range of recharge rates.

There are many issues and sources of uncertainty that can affect the ability to predict the behavior of contaminants in the vadose zone. These include scale effects, spatial resolution of data, preferential flow, funneled flow, colloid transport, density effects, and thermal effects. Fogwell et al. 2003 has identified a number of data gaps related to key technical issues and parameter uncertainties. This includes a number of site characterization and laboratory study needs related to interpreting observations from past tank leaks, spills, and deliberate discharges. Adequate site characterization is important to estimate existing inventories, initial conditions, and also to demonstrate the validity of our understanding and the predictive ability of the models used for flow and transport. Estimating inventories and contaminant distributions is difficult because there is much about the history and character of the leaks, spills, and water losses that is difficult to characterize with a reasonable level of uncertainty. This level of uncertainty will always hamper the ability of models to predict observed distributions of contaminants in the vadose zone, even if the distributions were well known. 
Recommendations to reduce uncertainty and improve the site-wide data sets presented in this document include the following:

- Increase the number of hydrostratigraphic profiles to better represent the site-specific conditions beneath the waste sites. A first step might be to further differentiate the 200 Areas into 24 zones (representative of the regional closure zones) rather than the 6 general geographic areas currently used. Additional site-specific hydrostratigraphic profiles (or even two or three dimensional representations), should also be developed for those sites found to be high risk drivers and with correspondingly high uncertainty.

- Improve our quantitative representation (i.e., through geostatistics) of the geologic structure and heterogeneities associated with the various hydrogeologic facies.

- Improve defensibility and traceability of assigning physical and hydrologic properties to the hydrostratigraphic units. This could entail improving our understanding and semi-quantification of the relationship/correlation between geologic facies and hydraulic properties.

- Improve the hydraulic property database to include all the available data. These data include measured values of unsaturated conductivity, parameter estimates from resulting outflow experiments, and data and parameters resulting from field-scale tests.

- Address the impacts of gravel on hydraulic and sorption behavior of all samples, in a systematic and consistent manner.

- Improve the physical and hydraulic property distribution estimates. This could entail improving the number of sample analyses we have for each of the hydraulic property classes, improving these data via pedotransfer functions tied to particle-size data, using Bayesian updating to improve site-specific property distributions, and incorporating concepts for scaling up sample analytical data to the field and model cell scale.

- Improve contaminant distribution coefficient estimates by correcting for gravel content based on particle-size data of the geologic facies and addressing scale-up issues from sample derived $K_{d}$ values to field and model cell scales.

- Improve our recharge estimates, particularly for coarse surface soil and side slope material.

- Improve our technical basis and modeling parameters to investigate the effect of side-slope design on deep infiltration rates.

- Improve the technical basis and modeling parameters for barrier performance after the design life. 


\subsection{References}

Agnew SF, J Boyer, RA Corbin, TB Duran, JR Fitzpatrick, KA Jurgensen, TP Ortiz, and BL Young. 1996. Hanford Tank Chemical and Radionuclide Inventories: HDW Model Rev. 3. LA-UR-96-858, Los Alamos National Laboratory, Los Alamos, New Mexico.

Allard B. 1982. Actinides in Perspective. NM Edenlstein (ed.), pp. 553-580, Pergamon Press, Oxford.

Bailey LEF and DE Billington. 1998. Overview of the FEP Analysis Approach to Model Development. NIREX Science Report S/98/009, United Kingdom Nirex Limited, Oxfordshire, United Kingdom.

Baker SM, RF Lorang, RP Elmore, AJ Rossi, and MD Freshley. 1988. U1/U2 Uranium Plume Characterization, Remedial Action Review and Recommendation for Future Action. WHC-EP-0133, Westinghouse Hanford Company, Richland, Washington.

Barnett DB, RM Smith, and CJ Chou. 2000. Groundwater Monitoring Plan for the Hanford Site 216-B-3 Pond RCRA Facility. PNNL-13367, Pacific Northwest National Laboratory, Richland, Washington.

BHI. 1998. Hanford Site Atlas. BHI-01119, Rev. 2, Bechtel Hanford Inc., Richland, Washington.

Bjornstad BN. 1990. Geohydrology of the 218-W-5 Burial Ground, 200-West Area, Hanford Site. PNL-7336, Pacific Northwest Laboratory, Richland, Washington.

Bryce RW, CT Kincaid, PW Eslinger, and LF Morasch (eds.). 2002. An Initial Assessment of Hanford Impact Performed with the System Assessment Capability. PNNL-14027, Pacific Northwest National Laboratory, Richland, Washington.

Caggiano JA. 1996. Assessment Groundwater Monitoring Plan for Single-Shell Tank Waste Management Area S-SX. WHC-SD-EN-AP-191, Westinghouse Hanford Company, Richland, Washington.

Campbell JA, AK Sharma, SA Clauss, GM Mong, and D Bellofatto. 1998b. Organic Speciation of $A X-102, B X-104, C-104, C-201$, and C-202 Tank Wastes. PNNL-11955, Pacific Northwest National Laboratory, Richland, Washington.

Campbell JA, SA Clauss, KE Grant, V Hoopes, GM Mong, R Steele, D Bellofatto, and A Sharma. 1998a. Organic Analysis Progress Report FY1997. PNNL-11738, Pacific Northwest National Laboratory, Richland, Washington.

Cantrell KJ, RJ Serne, and GV Last. 2002. Hanford Contaminant Distribution Coefficient Database and Users Guide. PNNL-13895, Pacific Northwest National Laboratory, Richland, Washington.

Cantrell KJ, RJ Serne, and GV Last. 2003a. Hanford Contaminant Distribution Coefficient Database and Users Guide. PNNL-13895, Rev. 1, Pacific Northwest National Laboratory, Richland, Washington. 
Cantrell KJ, RJ Serne, and GV Last. 2003b. Applicability of the Linear Sorption Isotherm Model to Represent Contaminant Transport Processes in Site-Wide Performance Assessments - A White Paper. CP-17089, Fluor Hanford, Inc., Richland, Washington.

Cantrell KJ. 1988. “Actinide(III) Carbonate Complexation.” Polyhedron 7(7):573-574.

Carsel RF and RS Parrish. 1988. "Developing Joint Probability Distributions of Soil Water Retention Characteristics." Water Resour. Res. 24(5):755-769.

Cearlock CS, KM Singleton, ME Todd, and DB Barnett. 2000. 200-CW-1 Operable Unit Borehole/Test Pit Summary Report. BHI-01367, Bechtel Hanford, Inc., Richland Washington.

CH2M HILL Hanford Group, Inc. 2002. Field Investigation Report for Waste Management Area S-SX; Volume 1, Main Text and Appendices A - C, Volume 2, Appendices D - I. RPP-7884, Rev. 0, CH2M HILL Hanford Group, Inc., Richland, Washington.

Cherrey KD, M Flury, and JB Harsh. 2003. "Nitrate and Colloid Transport through Coarse Hanford Sediments under Steady-State, Variably-Saturated Flow.” Water Resour. Res. 39, 1165, doi:10.1029/2002WR001944.

Comprehensive Environmental Response, Compensation, and Liability Act (CERCLA). 1980. Public Law 96-150, as amended, 94 Stat. 2767, 42 USC 9601 et seq.

Connelly MP, JD Davis, and PD Rittman. 1991. Numerical Simulation of Strontium-90 Transport from the 100-N Area Liquid Waste Disposal Facility. WHC-SD-ER-TA-001, Rev. 0, Westinghouse Hanford Company, Richland, Washington.

Connelly MP, BH Ford, and JV Borghese. 1992a. Hydrogeologic Model for the 200 West Area Groundwater Aggregate Area. WHC-SD-EN-TI-014, Westinghouse Hanford Company, Richland, Washington.

Connelly MP, JV Borghese, CD Delaney, BH Ford, JW Lindberg, and SJ Trent. 1992b. Hydrogeologic Model for the 200 East Groundwater Aggregate Area. WHC-SD-EN-TI-019, Westinghouse Hanford Company, Richland, Washington.

Crews WS and DD Tillson. 1969. Analysis of Travel Time of I-131 from the 1301-N Crib to the Columbia River During July 1969. BNWL-CC-2326, Pacific Northwest Laboratory, Richland, Washington.

Cushing CE and BE Vaughan. 1988. "“Springs and Streams' in Shrub-Steppe Balance and Change in a Semi-Arid Terrestrial Ecosystem." WH Rickard et al. (ed.), Developments in Agricultural and ManagedForest Ecology 20, Elsevier Science Publishers, New York.

Delaney CD, KA Lindsey, and SP Reidel. 1991. Geology and Hydrology of the Hanford Site: A Standardized Text for Use in Westinghouse Hanford Company Documents and Reports. WHC-SD-ER-TI-003, Westinghouse Hanford Company, Richland, Washington. 
DOE. 1992. Z-Plant Source Aggregate Area Management Study. DOE/RL-91-58, U.S. Department of Energy, Richland Operations Office, Richland, Washington.

DOE. 1993a. 200 East Groundwater Aggregate Area Management Study Report. DOE/RL-92-19, Rev. 0, U.S. Department of Energy, Richland Operations Office, Richland, Washington.

DOE. 1993b. Limited Field Investigation Report for the 100-HR-3 Operable Unit. DOE/RL-93-34, U.S. Department of Energy, Richland Operations Office, Richland, Washington.

DOE. 1993c. B Plant Source Aggregate Area Management Study Report. DOE/RL-92-05, U.S. Department of Energy, Richland Operations, Richland, Washington.

DOE. 1993d. 200 North Aggregate Area Source AAMS Report. DOE/RL-92-17, U.S. Department of Energy, Richland Operations, Richland, Washington.

DOE. 1993e. PUREX Source Aggregate Area Management Study Report. DOE/RL-92-04, U.S. Department of Energy, Richland Operations, Richland, Washington.

DOE. 1994. Remedial Investigation and Feasibility Study Report for the Environmental Restoration Disposal Facility. DOE/RL-93-99, Rev. 1, U.S. Department of Energy, Richland Operations Offices, Richland, Washington.

DOE. 1996. Focused Feasibility Study of Engineered Barriers for Waste Management Units in the 200 Areas. DOE/RL-93-33, Rev. 0, U.S. Department of Energy, Richland, Washington.

DOE. 1996a. 1301-N and 1325-N Liquid Waste Disposal Facilities Limited Field Investigation Report. DOE/RL-96-11, Rev. 0, U.S. Department of Energy, Richland Operations Office, Richland, Washington.

DOE. 1997. TWRS Vadose Zone Contamination Issue, Expert Panel Status Report. DOE/RL-97-49, Rev. 0, U.S. Department of Energy, Richland, Washington.

DOE. 1998. Groundwater/Vadose Zone Integration Project Specification. DOE/RL-98-48, Draft C, U.S. Department of Energy, Richland Operations Office, Richland, Washington.

DOE. 1999. Groundwater/Vadose Zone Integration Project Background Information and State of Knowledge. DOE/RL-98-48, Vol. II, Rev. 0, U.S. Department of Energy, Richland Operations Office, Richland, Washington.

DOE. 2000a. Groundwater/Vadose Zone Integration Project Science and Technology Summary Description. DOE/RL-98-48, Vol. III, Rev. 1, U.S. Department of Energy, Richland Operations Office, Richland, Washington.

DOE. 2000b. Phase I RCRA Facility Investigation/Corrective Measures Study Work Plan for SingleShell Tank Waste Management Areas. DOE/RL-99-36, Rev. 1, U.S. Department of Energy, Richland Operations Office, Richland, Washington. 
DOE. 2002. Standardized Stratigraphic Nomenclature for Post-Ringold-Formation Sediments within the Central Pasco Basin. DOE/RL-2002-39, Rev. 0, U.S. Department of Energy, Richland Operations Office, Richland, Washington.

DOE. 2003. Hanford Site Waste Management Units Report. DOE/RL-88-30, Rev. 12, U.S. Department of Energy, Richland Operations Office, Richland, Washington.

DOE M 435.1-1. 1999. Radioactive Waste Management Manual. U.S. Department of Energy, Washington, D.C. Available on the Internet at http://www.directives.doe.gov/pdfs/doe/doetext/neword/435/m4351-1c1.html

DOE Order 435.1. 1999. Radioactive Waste Management. U.S. Department of Energy, Washington, D.C. Available on the Internet at http://www.hanford.gov/wastemgt/doe/psg/pdf/doeo435.1.pdf

Domenico PA and FW Schwartz. 1990. Physical and Chemical Hydrogeology. Wiley and Sons, New York, New York.

Durner W. 1992. "Predicting the Unsaturated Hydraulic Conductivity using Multi-Porosity Water Retention Curves." Proceedings of the International Workshop on Indirect Methods for Estimating the Hydraulic Properties of Unsaturated Soils, Riverside, California, October 11-13, 1989, MTh van Genuchten, FJ Leij, and LJ Lund (eds.), University of California, Riverside, California, p. 185-202.

Enfield CG, JJC Hsieh, and AW Warrick. 1973. "Evaluation of Water Flux above a Deep Water Table Using Thermocouple Psychrometers" in Soil Sci. Soc. Amer. Proc. 37:968-970.

Eslinger PW, C Arimescu, DW Engel, BA Kanyid, and TB Miley. 2002b. "User Instructions for the Systems Assessment Capability, Rev. 0," in Computer Codes, Volume 2: Impacts Modules. PNNL13932, Volume 2, Pacific Northwest National Laboratory, Richland, Washington.

Eslinger PW, DW Engel, LH Gerhardstein, CA Lo Presti, WE Nichols, and DL Strenge. 2002a. "User Instructions for the Systems Assessment Capability, Rev. 0," in Computer Codes, Volume 1: Inventory, Release, and Transport Modules. PNNL-13932, Volume 1, Pacific Northwest National Laboratory, Richland, Washington.

Fayer MJ and TB Walters. 1995. Estimated Recharge Rates at the Hanford Site. PNL-10285, Pacific Northwest Laboratory, Richland, Washington.

Fayer MJ, EM Murphy, JL Downs, FO Khan, CW Lindenmeier, and BN Bjornstad. 1999. Recharge Data Package for the Immobilized Low-Activity Waste 2001 Performance Assessment. PNNL-13033, Pacific Northwest National Laboratory, Richland, Washington.

Fecht KR, GV Last, and KR Price. 1977. Evaluation of Scintillation Probe Profiles from 200 Area Crib Monitoring Wells, Volumes II and III. ARH-ST-156, Atlantic Richfield Hanford Company, Richland, Washington. 
Fecht KR, KA Lindsey, DG Horton, GV Last, and SP Reidel. 1999. An Atlas of Clastic Injection Dikes of the Pasco Basin and Vicinity. BHI-01103, Rev. 0, Bechtel Hanford, Inc., Richland, Washington.

Fogwell TW, GV Last, AL Bunn, KJ Cantrell, FM Coony, JL Downs, MJ Fayer, EJ Freeman, GW Gee, DG Horton, CT Kincaid, CJ Murray, BA Napier, GW Patton, VV Rawhalf, RG Riley, and PD Thorne. 2003. Characterization of Systems Task Fiscal Year 2003 Status Report. WMP-18045, Fluor Hanford, Inc., Richland, Washington.

Freeman EJ and GV Last. 2003. Vadose Zone Hydraulic Property Letter Reports. WMP-17524, Rev. 0, Fluor Hanford, Richland, Washington.

Freeman EJ, R Khaleel, and PR Heller. 2001. A Catalog of Vadose Zone Hydraulic Properties for the Hanford Site. PNNL-13672, Pacific Northwest National Laboratory, Richland, Washington.

Freeman EJ, R Khaleel, and PR Heller. 2002. A Catalog of Vadose Zone Hydraulic Properties for the Hanford Site. PNNL-13672, Rev. 1, Pacific Northwest National Laboratory, Richland, Washington.

Frind EO, RW Gillham, and J Pickens. 1977. "Application of Unsaturated Flow Properties in the Design of Geologic Environments for Radioactive Waste Storage Facilities" in Finite Elements in Water Resources, pp. 3.144-3.163. WG Gray, GF Pinder, and CA Brebbia (eds.), Pantech, London.

Garnier JM. 1985. "Retardation of Dissolved Radiocarbon through a Carbonated Matrix." Geochim. Cosmochim. Acta 49:683-693.

Gaylord DR and EP Poeter. 1991. Geology and Hydrology of the 300 Area and Vicinity, Hanford Site, South Central Washington. WHC-EP-0500, Westinghouse Hanford Company, Richland, Washington.

Gee GW and D Hillel. 1988. "Groundwater Recharge in Arid Regions: Review and Critique of Estimation Methods" in Journal of Hydrological Processes 2:255-266.

Gee GW, MJ Fayer, ML Rockhold, and MD Campbell. 1992. "Variations in Recharge at the Hanford Site" in Northwest Science 66:237-250.

Gelhar LW and CL Axness. 1983. "Three-Dimensional Analysis of Macrodispersion in a Stratified Aquifer" in Water Resources Research 19:161-180.

Gelhar LW, C Welty, and KR Rehfeldt. 1992. "A Critical Review of Data on Field-Scale Dispersion in Aquifers," in Water Resources Research 28:1955-1974.

Gelhar LW. 1993. Stochastic Subsurface Hydrology. Prentice Hall, New York.

Hajek BF. 1966. Soil Survey Hanford Project in Benton County, Washington. BNWL-243, Pacific Northwest Laboratory, Richland, Washington.

Hartman MJ (ed.). 2000. Hanford Site Groundwater Monitoring: Setting, Sources, and Methods. PNNL-13080, Pacific Northwest National Laboratory, Richland, Washington. 
Hartman MJ and KA Lindsey. 1993. Hydrogeology of the 100-N Area, Hanford Site, Washington. WHC-SD-EN-EV-027, Westinghouse Hanford Company, Richland, Washington.

Hartman MJ and RE Peterson. 1992. Hydrologic Information Summary for the Northern Portion of the Hanford Site. WHC-SD-EN-TI-023, Westinghouse Hanford Company, Richland, Washington.

HEDL (Hanford Engineering Development Laboratory). 1975. Site Investigation Report for the Fast Flux Test Facility, Richland, Washington. BCL-1701, prepared by Hanford Engineering Development Laboratory, Westinghouse Hanford Company, Richland, Washington, for the United States Atomic Energy Commission.

Higgo JJW. 1988. Review of Sorption Data Applicable to the Geologic Environment of Interest for Deep Disposal of ILW and LLW in the UK. NSS/R-162, British Geological Survey, Keyworth, Nottingham, UK.

Ho CK, RG Baca, SH Conrad, GA Smith, L Shyr, and TA Wheeler. 1999. Stochastic Parameter Development for PORFLOW Simulations of the Hanford AX Tank Farm. SAND98-2880, Sandia National Laboratories, Albuquerque, New Mexico.

Hoitink DJ, KW Burk, JV Ramsdell, and WJ Shaw. 2003. Hanford Site Climatological Data Summary 2002 with Historical Data. PNNL-14242, Pacific Northwest National Laboratory, Richland, Washington.

Jacobs Engineering Group, Inc. 1999. Retrieval Performance Evaluation Methodology for the AX Tank Farm. DOE/RL-98-72, prepared by Jacobs Engineering Group Inc. for U.S. Department of Energy, Richland Operations Office, Richland, Washington.

Johnson VG and CJ Chou. 1998. Results of Phase I Groundwater Quality Assessment for Single-Shell Tank Waste Management Areas S-SX at the Hanford Site. PNNL-11810, Pacific Northwest National Laboratory, Richland, Washington.

Jones TL. 1989. Simulating the Water Balance of an Arid Site. PNL-SA-17633, Pacific Northwest Laboratory, Richland, Washington.

Kaplan DI and RJ Serne. 1995. Distribution Coefficient Values Describing Iodine, Neptunium, Selenium, Technetium, and Uranium Sorption to Hanford Sediments. PNL-10379, SUP. 1, Pacific Northwest Laboratory, Richland, Washington.

Kaplan DI and RJ Serne. 2000. Geochemical Data Package for the Hanford Immobilized Low-Activity Tank Waste Performance Assessment (ILAW PA). PNNL-13037, Rev. 1, Pacific Northwest National Laboratory, Richland, Washington.

Kaplan DI, KE Parker, and JC Ritter. 1998. Effects of Aging a Hanford Sediment and Quartz Sand with Sodium Hydroxide on Radionuclide Sorption Coefficients and Sediment Physical and Hydrological Properties: Final Report for Subtask 2a. PNNL-11965, Pacific Northwest National Laboratory, Richland, Washington. 
Kaplan DI, RJ Serne, AT Owen, JA Conca, TW Wietsma, and TL Gervais. 1996. Radionuclide Adsorption Distribution Coefficients Measured in Hanford Sediments for the Low Level Waste Performance Assessment Project. PNNL-11385, Pacific Northwest National Laboratory, Richland, Washington.

Khaleel R. 1999. Far-Field Hydrology Data Package for Immobilized Low-Activity Tank Waste Performance Assessment. HNF-4769, Rev. 1, Fluor Daniel Northwest, Inc., Richland, Washington.

Khaleel R and EJ Freeman. 1995. Variability and Scaling of Hydraulic Properties for 200 Area Soils, Hanford Site. WHC-EP-0883, Westinghouse Hanford Company, Richland, Washington.

Khaleel R and PR Heller. 2003. "On the Hydraulic Properties of Coarse-Textured Sediments at Intermediate Water Contents.” Water Resour. Res. 39(9):1233.

Khaleel R and JF Relyea. 1997. "Correcting Laboratory-Measured Moisture Retention Data for Gravel” in Water Resources Research 33(8):1875-1878.

Khaleel R, JF Relyea, and JL Conca. 1995. "Evaluation of van Genuchten-Mualem Relationships to Estimate Unsaturated Hydraulic Conductivity at Low Water Contents." Water Resources Research 31(11):2659-2668.

Khaleel R, T-CJ Yeh, and Z Lu. 2002. "Upscaled Flow and Transport Properties for Heterogeneous Unsaturated Media." Water Resources Research 38(5).

Khaleel R, TE Jones, AJ Knepp, FM Mann, DA Myers, PM Rogers, RJ Serne, and MI Wood. 2001. Modeling Data Package for S-SX Field Investigation Report (FIR). RPP-6296, Rev. 0, CH2M HILL Hanford Group, Inc., Richland, Washington.

Kincaid CT, RW Bryce, and JW Buck. 2004. Technical Scope and Approach for the 2004 Composite Analysis of Low-Level Waste Disposal at the Hanford Site. PNNL-14372, Pacific Northwest National Laboratory, Richland, Washington.

Kincaid CT, PW Eslinger, WE Nichols, AL Bunn, RW Bryce, TB Miley, MC Richmond, SF Snyder, and RL Aaberg. 2000. Groundwater/Vadose Zone Integration Project, System Assessment Capability (Revision 0), Assessment Description, Requirements, Software Design, and Test Plan. BHI-01365, Draft A, Bechtel Hanford, Inc., Richland, Washington.

Kincaid CT, MP Bergeron, CR Cole, MD Freshley, NL Hassig, VG Johnson, DI Kaplan, RJ Serne, GP Streile, DL Strenge, PD Thorne, LW Vail, GA Whyatt, and SK Wurstner. 1998. Composite Analysis for Low-Level Waste Disposal in the 200 Area Plateau of the Hanford Site. PNNL-11800, Pacific Northwest National Laboratory, Richland, Washington.

Kipp KL and RD Mudd. 1974. Selected Water Table Contour Maps and Well Hydrographs for the Hanford Reservation, 1944-1973. BNWL-B-360, Pacific Northwest Laboratory, Richland, Washington. 
Knepp AJ. 2002. Field Investigation Report for Waste Management Area B-BX-BY; Volume 1, Main Text and Appendices $A$ - C, Volume 2, Appendices D - I. RPP-10098, Rev. 0. CH2M HILL Hanford Group, Inc., Richland, Washington.

Kosugi K, JW Hopmans, and JH Dane. 2002. "3.3.4 Parameteric Models" in Methods of Soil Analysis" Part 4-Physical Methods. Soil Science Society of America, Madison, Wisconsin, p. 739-757.

Krupka KM and RJ Serne. 1996. Performance Assessment of Low-Level Radioactive Waste Disposal Facilities: Effects on Radionuclide Concentrations by Cement/Ground-Water Interactions.

NUREG/CR-6377, U.S. Nuclear, Regulatory Commission, Washington, D.C.

Last GV and VJ Rohay. 1993. Refined Conceptual Model for the Volatile Organic Compounds-Arid Integrated Demonstration and 200 West Area Carbon Tetrachloride Expedited Response Action. PNL-8597, Pacific Northwest Laboratory, Richland, Washington.

Last GV, BN Bjornstad, MP Bergeron, DW Wallace, DR Newcomer, JA Schramke, MA Chamness, CS Cline, SP Airhart, and JS Wilbur. 1989. Hydrogeology of the 200 Areas Low-Level Burial Grounds - An Interim Report. PNL-6820, Vol. 1 and 2, Pacific Northwest Laboratory, Richland, Washington.

Last GV, VJ Rohay, FJ Schelling, and L Soler. 2001. Use of Process Relationship Diagrams in Development of Conceptual Models. PNNL-SA-34515, Pacific Northwest National Laboratory, Richland, Washington.

Last GV, WE Nichols, and CT Kincaid. 2004. Geographic and Operational Site Parameters List (GOSPL) for the 2004 Composite Analysis. PNNL-14702, Rev. 0, Pacific Northwest National Laboratory, Richland, Washington.

Last GV, VJ Rohay, FJ Schelling, AL Bunn, MA Delamare, RL Dirkes, RD Hildebrand, JG Morse, BA Napier, RG Riley, L Soler, PD Thorne. 2004. "A Comprehensive and Systematic Approach to Developing and Documenting Conceptual Models of Contaminant Release and Migration at the Hanford Site.” Journal of Stochastic Environmental Research and Risk Assessment 18(2):190-116.

LHMC. 1999. Statements of Work for FY 2000 to FY 2005 for the Hanford Low-Activity Tank Waste Performance Assessment Program. HNF-SD-WM-PAP-062, Rev. 4, Lockheed Martin Hanford Company, Richland, Washington.

Liikala TL, RL Aaberg, NJ Aimo, DJ Bates, TJ Gilmore, EJ Jensen, GV Last, PL Oberlander, KB Olsen, KR Oster, LR Roome, JC Simpson, SS Teel, and EJ Westergard. 1988. Geohydrologic Characterization of the Area Surrounding the 183-H Solar Evaporation Basin. PNL-6728, Pacific Northwest Laboratory, Richland, Washington.

Lindberg JW and FW Bond. 1979. Geohydrology and Ground-Water Quality Beneath the 300 Area, Hanford Site, Washington. PNL-2949, Pacific Northwest Laboratory, Richland, Washington.

Lindberg JW. 1993a. Geology of the 100-B/C Area, Hanford Site, South-Central Washington. WHCSD-EN-TI-133, Westinghouse Hanford Company, Richland, Washington. 
Lindberg JW. 1993b. Geology of the 100-K Area, Hanford Site, South-Central Washington. WHC-SD-EN-TI-155, Westinghouse Hanford Company, Richland, Washington.

Lindberg JW. 1995. Hydrogeology of the 100-K Area, Hanford Site, South-Central Washington. WHC-SD-EN-TI-294, Westinghouse Hanford Company, Richland, Washington.

Lindsey KA and GK Jaeger. 1993. Geologic Setting of the 100-HR-3 Operable Unit, Hanford Site, South-Central Washington. WHC-SD-EN-TI-132, Westinghouse Hanford Company, Richland, Washington.

Lindsey KA, BN Bjornstad, JW Lindberg, and KM Hoffmann. 1992b. Geologic Setting of the 200 East Area: An Update. WHC-SD-EN-TI-012, Rev. 0, Westinghouse Hanford Company, Richland, Washington.

Lindsey KA, MP Connelly, and BN Bjornstad. 1992a. Geologic Setting of the 200 West Area: An Update. WHC-SD-EN-TI-008, Westinghouse Hanford Company, Richland, Washington.

Lindsey KA. 1992. Geology of the Northern Part of the Hanford Site: An Outline of Data Sources and Geologic Setting of the 100 Areas. WHC-SD-EN-TI-011, Westinghouse Hanford Company, Richland, Washington.

Lindsey KA. 1995. Miocene- to Pliocene-Aged Suprabasalt Sediments of the Hanford Site, SouthCentral Washington. BHI-00184, Rev. 00, Bechtel Hanford, Inc., Richland, Washington.

Lindsey KA. 1996. Miocene to Pliocene Ringold Formation and Associated Deposits of the Ancestral Columbia River System, South-Central Washington and North Central Oregon. Open File Report 96-8, Washington State Department of Natural Resources, Olympia, Washington.

Looney BB and RW Falta (eds.). 2000. Vadose Zone, Science and Technology Solutions. Two Volumes, Battelle Press, Columbus, Ohio.

Maxfield HL. 1979. Handbook - 200 Areas Waste Sites. RHO-CD-673, Volumes I, II, and III. Rockwell Hanford Operations, Richland, Washington.

Meyer PD, KP Saripalli, and VL Freedman. 2004. Near-Field Hydrology Data Package for the Integrated Disposal Facility 2005 Performance Assessment. PNNL-14700, Pacific Northwest National Laboratory, Richland, Washington.

Mualem Y. 1976. "A New Model for Predicting the Hydraulic Conductivity of Unsaturated Porous Media" in Water Resources Research 12:513.

Murphy EM, TR Ginn, and JL Phillips. 1996. "Geochemical Estimates of Paleorecharge in the Pasco Basin: Evaluation of the Chloride Mass-Balance Technique." Water Resources Research 32(9):2853-2868. 
Murray CJ, Y Chien, and PD Thorne. 2004. A Geostatistical Analysis of Historical Field Data on Tritium, Technetium-99, Iodine-129, and Uranium. PNNL-14618, Rev. 0, Pacific Northwest National Laboratory, Richland, Washington.

Murray CJ, AL Ward, and JL Wilson. 2003. Influence of Clastic Dikes on Vertical Migration of Contaminants in the Vadose Zone at Hanford. PNNL-14224, Pacific Northwest National Laboratory, Richland, Washington.

Murray CJ, DG Horton, AL Ward, and GW Gee. 2002. "Hydrogeologic Influence of Clastic Dikes on Vadose Zone Transport," Section 7.3.3 pp. 7.26-7.27, in Hanford Site Environmental Report for Calendar Year 2001. PNNL-13910, Pacific Northwest National Laboratory, Richland, Washington.

NEA (Nuclear Energy Agency). 2000. Features, Events and Processes (FEPs) for Geologic Disposal of Radioactive Waste, An International Database. Organization For Economic Co-Operation and Development (OECD) Publications, France.

Neitzel DA, AL Bunn, KW Burk, SD Cannon, JP Duncan, RA Fowler, BG Fritz, DW Harvey, PL Hendrickson, DG Horton, GV Last, TM Poston, EP Prendergast-Kennedy, SP Reidel, MJ Scott, PD Thorne, and DM Woody. 2003. Hanford Site National Environmental Policy Act (NEPA) Characterization, Revision 15. PNNL-6415, Rev. 15, Pacific Northwest National Laboratory, Richland, Washington.

Pearce GG, RE Brown, and TP O'Farrell. 1969. The Arid Lands Ecology Reserve at Pacific Northwest Laboratory, Richland, Washington. BNWL-SA-2574, Pacific Northwest Laboratory, Richland, Washington.

Peterson RE, RF Raidl, and CW Denslow. 1996. Conceptual Site Models for Groundwater Contamination at the 100-BC-5, 100-KR-4, 100-HR-3, and 100-FR-3 Operable Units. BHI-00917, Bechtel Hanford Company, Richland, Washington.

Peterson RE and MP Connelly. 2001. Zone of Interaction Between Hanford Site Groundwater and Adjacent Columbia River. PNNL-13674, Pacific Northwest National Laboratory, Richland, Washington.

Price WH and KR Fecht. 1976a. Geology of the 241-U Tank Farm. ARH-LD-138, Informal Report, Atlantic Richfield Hanford Company, Richland, Washington.

Price WH and KR Fecht. 1976b. Geology of the 241-B Tank Farm. ARH-LD-129, Atlantic Richfield Hanford Company, Richland, Washington.

Price WH and KR Fecht. 1976c. Geology of the 241-BX Tank Farm. ARH-LD-130, Atlantic Richfield Hanford Company, Richland, Washington.

Price WH and KR Fecht. 1976d. Geology of the 241-BY Tank Farm. ARH-LD-131, Atlantic Richfield Hanford Company, Richland, Washington. 
Prych EA. 1998. Using Chloride and Chlorine-36 as Soil-Water Tracers to Estimate Deep Percolation at Selected Locations on the U.S. Department of Energy Hanford Site, Washington. Water-Supply Paper 2481, U.S. Geological Survey, Tacoma, Washington.

Raidl RF. 1994. Geology of the 100-FR-3 Operable Unit, Hanford Site, South-Central Washington. WHC-SD-EN-TI-221, Westinghouse Hanford Company, Richland, Washington.

Reidel SP and AM Ho. 2002. Geologic and Wireline Summaries from Fiscal Year 2002 ILAW Boreholes. PNNL-14029, Pacific Northwest National Laboratory, Richland, Washington.

Reidel SP and DG Horton. 1999. Geologic Data Package for 2001 Immobilized Low-Activity Waste Performance Assessment. PNNL-12257, Rev. 1, Pacific Northwest National Laboratory, Richland, Washington.

Reidel SP, DG Horton, and MM Valenta. 2001. Geologic and Wireline Borehole Summary from the Second ILAW Borehole (299-E24-21). PNNL-13652, Pacific Northwest National Laboratory, Richland, Washington.

Riley RG and C LoPresti. 2004. Release Model Data Package for the 2004 Composite Analysis. PNNL-14760, Rev. 0, Pacific Northwest National Laboratory, Richland, Washington.

Rohay VJ, KJ Swett, and GV Last. 1994. 1994 Conceptual Model of the Carbon Tetrachloride Contamination in the 200 West Area at the Hanford Site. WHC-SD-EN-TI-248, Westinghouse Hanford Company, Richland, Washington.

Schalla R, RW Wallace, RL Aaberg, SP Airhart, DJ Bastes, JVM Carlile, CS Cline, DI Dennison, MD Freshley, PR Heller, EJ Jensen, KB Olsen, RG Parkhurst, JT Rieger, and EJ Westergard. 1988. Interim Characterization Report for the 300 Area Process Trenches. PNL-6716, Pacific Northwest Laboratory, Richland, Washington.

Serne RJ and MI Wood. 1990. Hanford Waste-Form Release and Sediment Interaction: A Status Report with Rationale and Recommendations for Additional Studies. PNL-7297, Pacific Northwest Laboratory, Richland, Washington.

Serne RJ and VL LeGore. 1996. Strontium-90 Adsorption-Desorption Properties and Sediment Characterization at the 100-N Area. PNNL-10899, Pacific Northwest National Laboratory, Richland, Washington.

Serne RJ, JL Conca, VL LeGore, KJ Cantrell, CW Lindenmeier, JA Campbell, JE Amonette, and MI Wood. 1993. Solid-Waste Leach Characteristics and Contaminant-Sediment Interactions, Volume 1: Batch Leach and Adsorption Tests and Sediment Characterization. PNL-8889, Vol. 1, Pacific Northwest Laboratory, Richland, Washington.

Serne RJ, RO Lokken, and LJ Criscenti. 1992. “Characterization of Grouted LLW to Support Performance Assessment” in Waste Management 12:271-287. 
Skaggs RL and WH Walters. 1981. Flood Risk Analysis of Cold Creek Near the Hanford Site. RHO-BWI-C-120, Rockwell Hanford Operations, Richland, Washington.

Slate JL. 1996. "Buried Carbonate Paleosols Developed in Plio-Pleistocene Deposits of the Pasco Basin, South-Central Washington" in Quaternary International 34-36:191-196.

Slate JL. 2000. Nature and Variability of the Plio-Pleistocene Unit in the 200 West Area of the Hanford Site. BHI-01203, Bechtel Hanford, Inc., Richland, Washington.

Soler L, GV Last, BA Napier, VJ Rohay, and FJ Schelling. 2001. The Application of Features, Events, and Process Methodology at the Hanford Site. BHI-01573, Rev. 0, Bechtel Hanford, Inc., Richland, Washington.

Stenhouse MJ. 1994. Sorption Databases for Crystalline, Marl and Bentonite for Performance Assessment. NTB 93-06, Nagra, Wettingen, Switzerland.

Stephens DB. 1992. "A Comparison of Calculated and Measured Unsaturated Hydraulic Conductivity of Two Uniform Soils in New Mexico." Proceedings of the International Workshop on Indirect Methods for Estimating the Hydraulic Properties of Unsaturated Soils, Riverside, California, October 11-13, 1989, MTh van Genuchten, FJ Leij, and LJ Lund (eds.), University of California, Riverside, California, p. 249-261.

Stumm W and JJ Morgan. 1996. “Aquatic Chemistry,” Chemical Equilibria and Rates in Natural Waters, $3^{\text {rd }}$ ed., John Wiley and Sons, Inc., New York.

Swanson LC, GG Kelty, KA Lindsey, KR Simpson, RK Price, and SD Consort. 1992. Phase I Hydrogeologic Summary of the 300-FF-5 Operable Unit, 300 Area. WHC-SD-EN-TI-052, Rev. 0, Westinghouse Hanford Company, Richland, Washington.

Swanson LD, VJ Rohay, and JM Faurote. 1999. Hydrogeologic Conceptual Model for the Carbon Tetrachloride and Uranium/Technetium Plumes in the 200 West Area: 1994 through 1999 Update. BHI01311, Bechtel Hanford, Inc., Richland, Washington.

Tallman AM, KR Fecht, MC Marratt, and GV Last. 1979. Geology of the Separation Areas, Hanford Site, South-Central Washington. RHO-ST-23, Rockwell Hanford Operations, Richland, Washington.

Thorne PD, MA Chamness, FA Spane, Jr., VR Vermeul, and WD Webber. 1993. Three-Dimensional Conceptual Model for the Hanford Site Unconfined Aquifer System, FY93 Status Report. PNL-8971, Pacific Northwest Laboratory, Richland, Washington.

Thorne PD, MA Chamness, VR Vermeul, QC MacDonald, and SE Schubert. 1994. Three-Dimensional Conceptual Model for the Hanford Site Unconfined Aquifer System, FY 1994 Status Report. PNL-10195, Pacific Northwest Laboratory, Richland, Washington. 
Valenta MM, MB Martin, JR Moreno, RM Ferri, DG Horton, and SP Reidel. 2000. Particle Size Distribution Data From Existing Boreholes at the Immobilized Low-Activity Waste Site. PNNL-13328, Pacific Northwest National Laboratory, Richland, Washington.

van Genuchten MTh. 1980. "A Closed-Form Solution for Predicting the Conductivity of Unsaturated Soils.” Soil Sci. Soc. Am. J. 44:892-898.

Vermeul VR, SS Teel, JE Amonette, CR Cole, JS Fruchter, YA Gorby, FA Spane, JE Szecsody, MD Williams, and SB Yabusaki. 1995. Geologic, Geochemical, Microbiologic, and Hydrologic

Characterization at the In Situ Redox Manipulation Test Site. PNL-10633, Pacific Northwest Laboratory, Richland, Washington.

Ward AL, GW Gee, and MD White. 1997. A Comprehensive Analysis of Contaminant Transport in the Vadose Zone Beneath Tank SX-109. PNNL-11463, Pacific Northwest National Laboratory, Richland, Washington.

Warrick A, DE Myers, and D Nelson. 1986. "Geostatistical Methods Applied to Soil Science, in Methods of Soil Analysis," Part I, Soil Science Society Amer. 53-82.

White MD and M Oostrom. 1996. STOMP Subsurface Transport Over Multiple Phases Theory Guide. PNNL-11217, Pacific Northwest National Laboratory, Richland, Washington.

Williams BA, BN Bjornstad, R Schalla, and WD Webber. 2000. Revised Hydrogeology for the Suprabasalt Aquifer System, 200-East Area and Vicinity, Hanford Site, Washington. PNNL-12261, Pacific Northwest National Laboratory, Richland, Washington.

Williams BA, BN Bjornstad, R Schalla, and WD Webber. 2002. Revised Hydrogeology for the Suprabasalt Aquifer System, 200-West Area and Vicinity, Hanford Site, Washington. PNNL-13858, Pacific Northwest National Laboratory, Richland, Washington.

Wilson LG, LG Everett, and SJ Cullen. 1995. Handbook of Vadose Zone Characterization and Monitoring. CRC Press, Inc., Lewis Publishers, Raton, Florida.

Wittreich CD, JK Linville, GW Gee, and AL Ward. 2003. 200-OP-1 Prototype Hanford Barrier Annual Monitoring Report for Fiscal Year 2002. CP-14873, Rev. 0, Fluor Hanford, Inc., Richland, Washington.

Wood MI, R Khaleel, PD Rittman, AH Lu, SH Finfrock, RJ Serne, KJ Cantrell, and TH DeLorenzo. 1995. Performance Assessment for the Disposal of Low-Level Waste in the 200-West Area Burial Grounds. WHC-D-0645, Westinghouse Hanford Company, Richland, Washington.

Wood MI, R Khaleel, PD Rittman, SH Finfrock, TH DeLorenzo, and DY Gorbrick. 1996. Performance Assessment for the Disposal of Low-Level Waste in the 200-East Area Burial Grounds. WHC-SD-WM-TI-730, Westinghouse Hanford Company, Richland, Washington. 
Wood MI, R Schalla, BM Bjornstad, and SM Narbutovskih. 2000. Subsurface Conditions Description of the B-BX-BY Waste Management Area. HNF-5507, Rev. 0, CH2M HILL Hanford Group, Inc., Richland, Washington.

Wurstner SK, PD Thorne, MA Chamness, MD Freshly, and MD Williams. 1995. Development of a Three-Dimensional Ground-Water Model of the Hanford Site Unconfined Aquifer System: FY 1995 Status Report. PNL-10886, Pacific Northwest Laboratory, Richland, Washington.

Xie Y, CJ Murray, GV Last, and R Mackley. 2003. Mineralogical and Bulk-Rock Geochemical Signatures of Ringold and Hanford Formation Sediments. PNNL-14202, Pacific Northwest National Laboratory, Richland, Washington.

Yao T-M and JMH Hendricks. 1996. "Stability of Wetting Forests in Dry Homogeneous Soils Under Low Infiltration Ratios." Soil Science Society of America Journal, 60, 20-28, Madison, Wisconsin: Soil Science Society of America TIC 286692.

Zhang ZF, AL Ward, and GW Gee. 2002. Estimating Field-Scale Hydraulic Parameters Using a Combination of Parameter Scaling and Inverse Methods. PNNL-14109, Pacific Northwest National Laboratory, Richland, Washington.

Zhang ZF, AL Ward, and GW Gee. 2003. "Estimating Soil Hydraulic Parameters of a Field Drainage Experiment Using Inverse Techniques.” Vadose Zone J. 2:201-211.

Zhuang J, M Flury, and Y Jin. 2003. "Colloid-Facilitated Cs Transport through Water-Saturated Hanford Sediment and Ottawa Sand.” Environ. Sci. Technol. 37:4905-4911. 


\section{Appendix A}

\section{Hydrostratigraphic Templates}


VZ Base Templates A

South 200 East Area (A Plant, C Plant, U. S. Ecology) Stratigraphic Columns

Notes/Assumptions:

1) Topography ranges from $735 \mathrm{ft}$ MSL in southwest corner of 200 East Area to $645 \mathrm{ft}$ MSL in the 241-C area (USGS Gable Butte 7.5 min.

Quadrangle Map).

2) The pre-Hanford Water Table (January 1944) is estimated to range from an elevation of $116 \mathrm{~m}(380 \mathrm{ft}$ ) in the eastern part of 200 East to $119 \mathrm{~m}$ (390

ft) in the western part (BNwL (J-360).

Will assume an average water table elevation of $117 \mathrm{~m}(385 \mathrm{ft}) \mathrm{MSL}$.

3) A thin blanket of eolian sand and silt covers the surface of the site where not disturbed

However, this material was generally removed during excavation and construction of the waste disposal sites and then incorporated into backfill

The depth of the sites and thus, the backfull over these sites range from $0 \mathrm{~m}$ for ponds and unplanned releases, to an average of about $4.5 \mathrm{~m}$ for

cribs and burial grounds, and upto $16.4 \mathrm{~m}$ for tanks.

4) Injection well 216-C-2 is screened from 15-40 ft. Well 299-E24-11 is $60 \mathrm{ft}$ deep (Hanford Wells). Assume average depth of $50 \mathrm{ft}$.

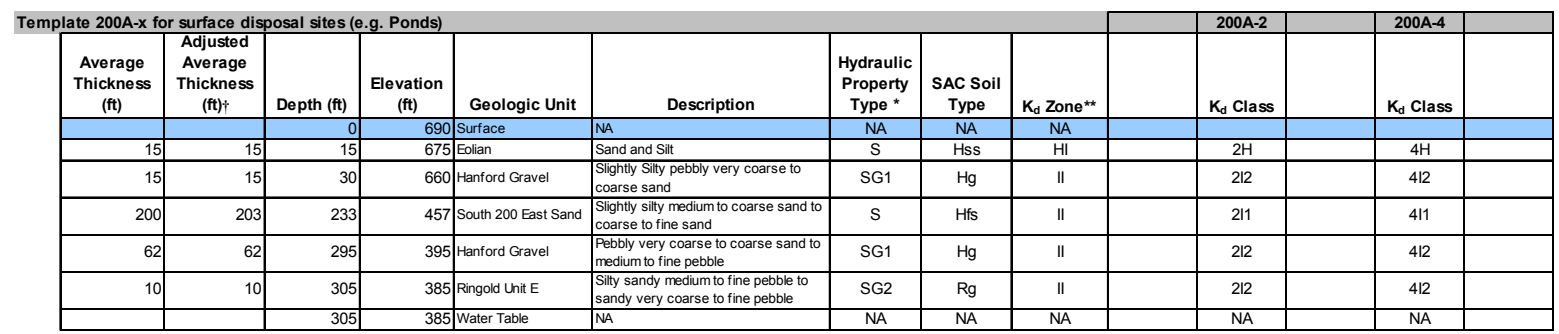

\begin{tabular}{|l|l|l|l|l|l|l|l|}
\cline { 2 - 4 } Template 216A-x for shallow disposal sites (e.g. Cribs, Burial Grounds) & 216A-2 & 216A-3 & 216A-4 & \\
\hline
\end{tabular}

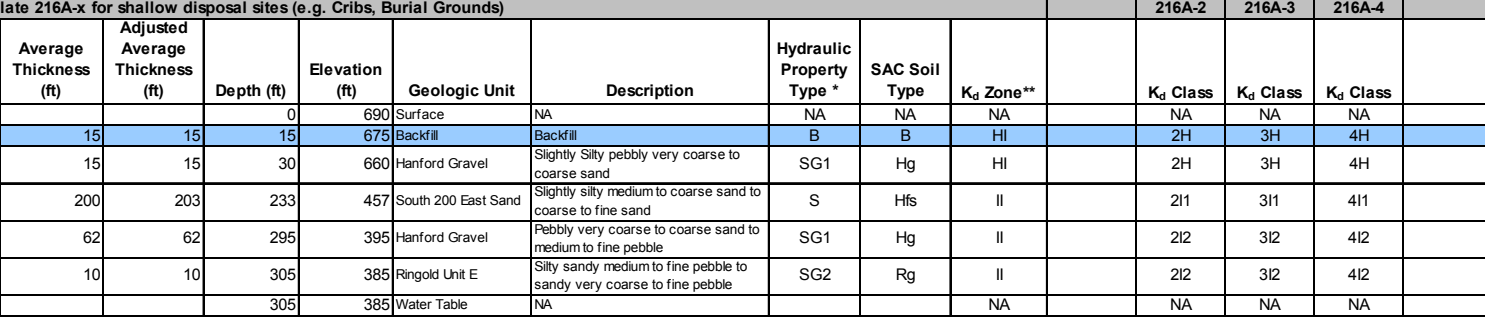

\begin{tabular}{|c|c|c|c|c|c|c|c|c|c|c|c|c|}
\hline \multicolumn{9}{|c|}{ Template 241A-3 for tanks } & $241 \mathrm{~A}-2$ & $241 \mathrm{~A}-3$ & & \\
\hline $\begin{array}{l}\text { Average } \\
\text { Thickness } \\
\text { (ft) }\end{array}$ & $\begin{array}{c}\text { Adjusted } \\
\text { Average } \\
\text { Thickness } \\
\text { (ft) }\end{array}$ & Depth (ft) & $\begin{array}{c}\text { Elevation } \\
\text { (ft) }\end{array}$ & Geologic Unit & Description & $\begin{array}{c}\text { Hydraulic } \\
\text { Property } \\
\text { Type * }\end{array}$ & $\begin{array}{l}\text { SAC Soil } \\
\text { Type }\end{array}$ & $\mathrm{K}_{\mathrm{d}}$ Zone ¿ $^{\star \star}$ & Kd Class & Kd Class & & \\
\hline & & 0 & 690 & Surface & NA & $\mathrm{NA}$ & NA & $\mathrm{NA}$ & $\mathrm{NA}$ & $\mathrm{NA}$ & & \\
\hline 50 & 50 & 50 & 640 & Backfill & Backfill & $B$ & $B$ & $\mathrm{HI}$ & $2 \mathrm{H}$ & $3 \mathrm{H}$ & & \\
\hline 180 & 183 & 233 & 457 & South 200 East Sand & $\begin{array}{l}\text { Slightly silty medium to coarse sand to } \\
\text { coarse to fine sand }\end{array}$ & s & Hfs & $\mathrm{HI}$ & $2 \mathrm{H}$ & $3 \mathrm{H}$ & & \\
\hline 62 & 62 & 295 & 395 & Hanford Gravel & $\begin{array}{l}\begin{array}{l}\text { Pebbly very coarse to coarse sand to } \\
\text { medium to fine pebble }\end{array} \\
\end{array}$ & SG1 & $\mathrm{Hg}$ & II & 212 & 312 & & \\
\hline 10 & 10 & 305 & 385 & Ringold Unit E & $\begin{array}{l}\begin{array}{l}\text { Silty sandy medium to fine pebble to } \\
\text { sandy very coarse to fine pebble }\end{array} \\
\text { s. }\end{array}$ & SG2 & $\mathrm{Rg}$ & $\|$ & 212 & 312 & & \\
\hline & & 305 & 385 & Water Table & NA & NA & NA & NA & 212 & 312 & & \\
\hline
\end{tabular}

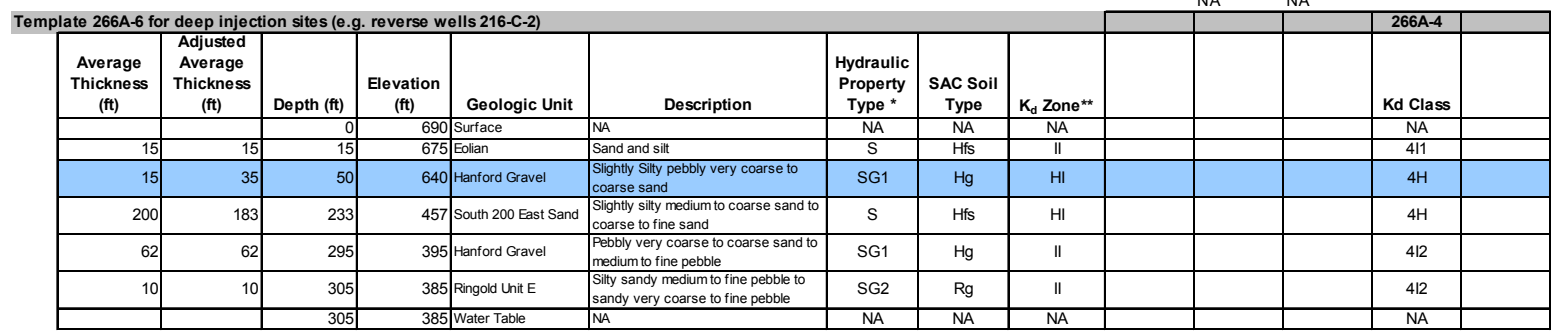

* After Khaleel and Freeman (1995), per white paper by Khaleel (September 2000)

${ }^{* *} \mathrm{HI}=$ high impact, II=Intermediate Impact (After Composite Analysis)

BLUE $=$ Injection/release point

$\dagger$ Average thickness adjusted to normalize the average strata thicknesses to equal the total thickness of the vadose zone. 


\section{VZ Base Templates - A_BC Cribs}

\section{BC-Cribs (216-B-14 through -19), South 200 East Area Stratigraphic Columns}

Notes/Assumptions:

1) Topography ranges from $229 \mathrm{~m}(751 \mathrm{ft}) \mathrm{MSL}$ northeast of the cribs to $227 \mathrm{~m}\left(745^{\prime}\right) \mathrm{ft} \mathrm{MSL}$ southeast of the cribs (as taken from the Hanford Site Atlas).

2) The pre-Hanford Water Table (January 1944) is estimated to have been at an elevation of $387 \mathrm{ft}$ (118 m) MSL (based on Kipp and Mud, 1974 BNWL-B-360)

3) The site depth to the crib bottom is reported to be $13 \mathrm{ft}(4 \mathrm{~m})$ based on Maxfield, 1979 - RHO-CD-673. Thus, the backfill is assumed to be $13 \mathrm{ft}$ deep.

4) However, the site was interim stabilized in 1981 by covering with a minium of $2 \mathrm{ft}(0.61 \mathrm{~m})$ of clean soil and revegetated (WIDS).

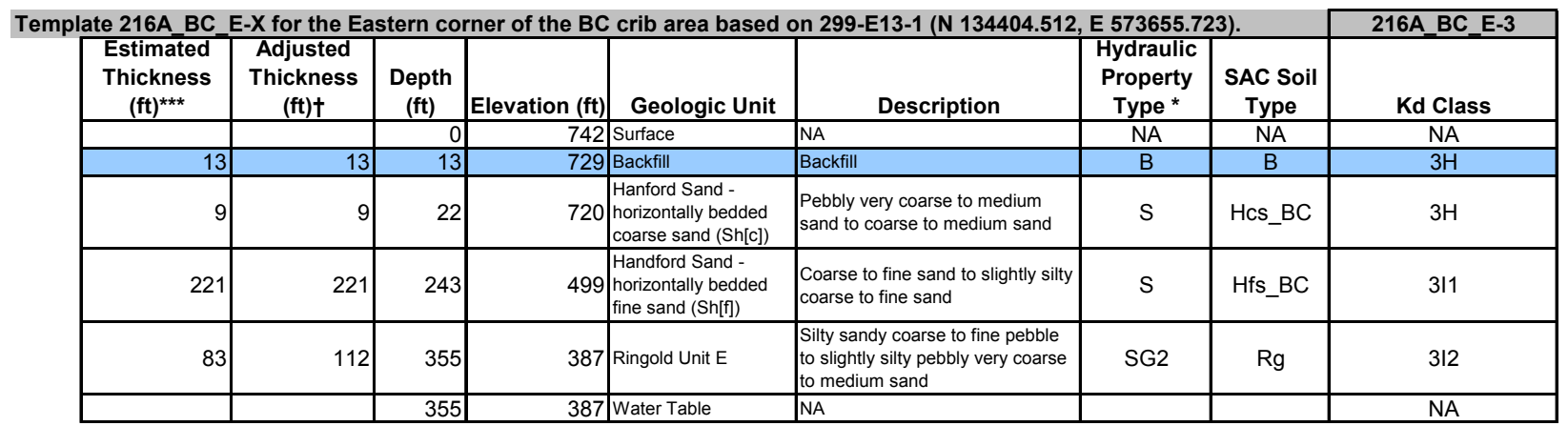

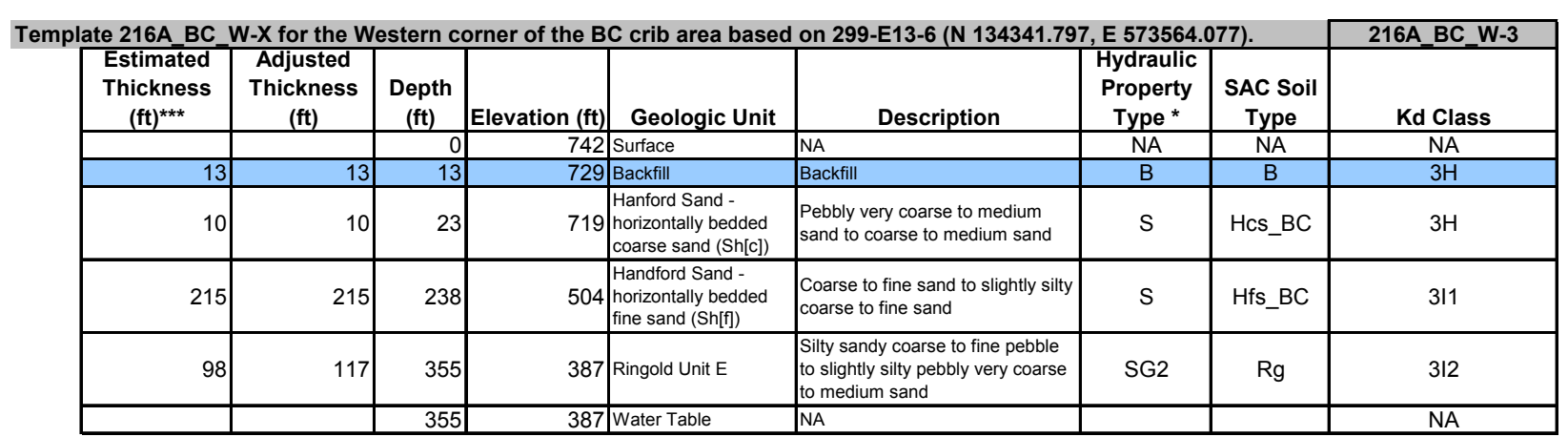

* After Khaleel and Freeman (1995), per white paper by Khaleel (September 2000)

** $\mathrm{HI}=$ high impact, II=Intermediate Impact (After Composite Analysis)

*** Based on Fecht, Last, and Marratt, 1979 - RHO-LD-72.

BLUE = Injection/release point

$\dagger$ Average thickness adjusted to normalize the average strata thicknesses to equal the total thickness of the vadose zone. 
VZ Base Templates - A_BC Trenches

BC-Trenches (216-B-20 through -31, -52 through -54, and -58), South 200 East Area Stratigraphic Columns

Notes/Assumptions:

1) Topography ranges from $228.5 \mathrm{~m}$ (750 ft) MSL near the 216-B-58 trench to $225 \mathrm{~m}\left(738^{\prime}\right) \mathrm{ft}$ MSL south of the 216-B-28 trench (as taken from the Hanford Site Atlas). Note however, that the site was interim stabilized in 1981 by covering with a minium of $2 \mathrm{ft}$

2) The pre-Hanford Water Table (January 1944) is estimated to have been at an elevation of $387 \mathrm{ft}$ (118 m) MSL (based on Kipp and Mud, 1974 - BNWL-B-360).

3) The site depth to the trench bottom is reported to be 8 to $10 \mathrm{ft}-\mathrm{min}$. $(2.4-3 \mathrm{~m})$ based on Maxfield, $1979-\mathrm{RHO}-\mathrm{CD}-673$. Thus, the backfill is assumed to be $10 \mathrm{ft}$ deep.

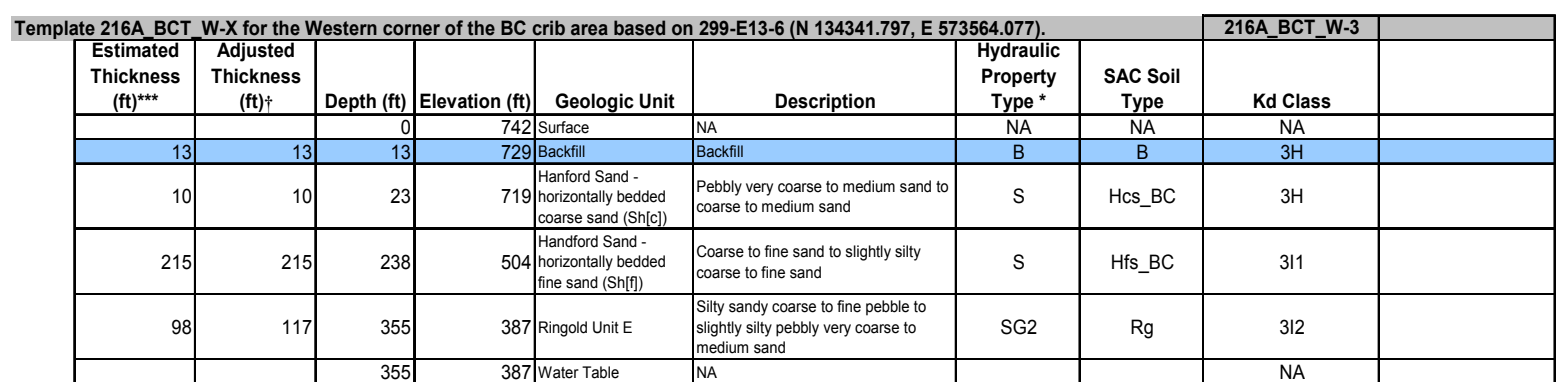

Template 216A BCT N-X for the northwestern corner of the BC trench area based on 299-E13-14 (N 134474.132, E 573087.497).

\begin{tabular}{|c|c|c|c|c|c|c|c|c|c|}
\hline $\begin{array}{c}\text { Estimated } \\
\text { Thickness } \\
(\mathrm{ft})^{\star \star *}\end{array}$ & $\begin{array}{l}\text { Adjusted } \\
\text { Thickness } \\
\text { (ft) }\end{array}$ & Depth $(\mathrm{ft})$ & Elevation $(\mathrm{ft})$ & Geologic Unit & Description & $\begin{array}{c}\text { Hydraulic } \\
\text { Property } \\
\text { Type * }\end{array}$ & $\begin{array}{l}\text { SAC Soil } \\
\text { Type }\end{array}$ & Kd Class & Kd Class \\
\hline & & 0 & 745 & Surface & NA & NA & NA & NA & NA \\
\hline 10 & 10 & 10 & 735 & Backfill & Backfill & $B$ & $B$ & $3 \mathrm{H}$ & $4 \mathrm{H}$ \\
\hline 17 & 17 & 27 & 718 & $\begin{array}{l}\text { Hanford Sand - } \\
\text { horizontally bedded } \\
\text { coarse sand (Sh[c]) }\end{array}$ & $\begin{array}{l}\text { Pebbly very coarse to medium sand to } \\
\text { coarse to medium sand }\end{array}$ & S & Hcs_BC & $3 \mathrm{H}$ & $4 \mathrm{H}$ \\
\hline 188 & 188 & 215 & 530 & $\begin{array}{l}\text { Handford Sand - } \\
\text { horizontally bedded } \\
\text { fine sand (Sh[f]) }\end{array}$ & $\begin{array}{l}\text { Coarse to fine sand to slightly silty } \\
\text { coarse to fine sand }\end{array}$ & S & Hfs_BC & 311 & $4 \mid 1$ \\
\hline 58 & 58 & 273 & 472 & $\begin{array}{l}\text { Hanford Sand - } \\
\text { horizontally bedded } \\
\text { coarse sand (Sh[c]) }\end{array}$ & $\begin{array}{l}\text { Slightly pebbly very coarse to medium } \\
\text { sandy coarse to fine pebble }\end{array}$ & $\mathrm{s}$ & Hcs_BC & 311 & $4 \mid 1$ \\
\hline 22 & 22 & 295 & 450 & \begin{tabular}{|l} 
Handford Sand - \\
horizontally bedded \\
fine sand (Sh[f])
\end{tabular} & $\begin{array}{l}\text { Coarse to fine sand to slightly sity } \\
\text { coarse to fine sand }\end{array}$ & $\mathrm{s}$ & Hfs_BC & 311 & $4 \mid 1$ \\
\hline 43 & 114 & 387 & 358 & Ringold Unit E & $\begin{array}{l}\text { Silty sandy coarse to fine pebble to } \\
\text { slightly silty pebbly very coarse to } \\
\text { medium sand }\end{array}$ & SG2 & $\mathrm{Rg}$ & 412 & 412 \\
\hline & & 358 & 387 & Water Table & NA & & & $\mathrm{NA}$ & $\mathrm{NA}$ \\
\hline
\end{tabular}

Template 216A BCT_S-X for the southwestern portion of the BC trench area based on 299-E13-12 (N 134146.593, E 573188.669).

\begin{tabular}{|c|c|c|c|c|c|c|c|c|c|}
\hline $\begin{array}{c}\text { Estimated } \\
\text { Thickness } \\
\text { (ft) }\end{array}$ & $\begin{array}{c}\text { Adjusted } \\
\text { Thickness } \\
\text { (ft) }\end{array}$ & Depth (ft) & Elevation $(\mathrm{ft}$ ) & Geologic Unit & Description & $\begin{array}{c}\text { Hydraulic } \\
\text { Property } \\
\text { Type * } \\
\end{array}$ & $\begin{array}{c}\text { SAC Soil } \\
\text { Type }\end{array}$ & Kd Class & Kd Class \\
\hline & & 0 & 731 & Surface & NA & NA & NA & NA & $\mathrm{NA}$ \\
\hline 10 & 10 & 10 & 721 & Backfill & Backfill & $B$ & $B$ & $3 \mathrm{H}$ & $4 \mathrm{H}$ \\
\hline 187 & 187 & 197 & 534 & $\begin{array}{l}\text { Handford Sand - } \\
\text { horizontally bedded } \\
\text { fine sand (Sh[f]) }\end{array}$ & $\begin{array}{l}\text { Coarse to fine sand to slightly silty } \\
\text { coarse to fine sand }\end{array}$ & $\mathrm{s}$ & Hfs_BC & 311 & $4 \mid 1$ \\
\hline 87 & 87 & 284 & 447 & \begin{tabular}{|l} 
Hanford Sand - \\
horizontally bedded \\
coarse sand (Sh[c])
\end{tabular} & $\begin{array}{l}\begin{array}{l}\text { Slightly pebbly very coarse to medium } \\
\text { sandy coarse to fine pebble }\end{array} \\
\end{array}$ & $\mathrm{s}$ & Hcs_BC & 311 & $4 \mid 1$ \\
\hline 5 & 5 & 289 & 442 & $\begin{array}{l}\text { Handford Sand - } \\
\text { horizontally bedded } \\
\text { fine sand (Shff) }\end{array}$ & $\begin{array}{l}\text { Coarse to fine sand to slightly silty } \\
\text { coarse to fine sand }\end{array}$ & $\mathrm{s}$ & Hfs_BC & $3 \mid 1$ & $4 \mid 1$ \\
\hline 35 & 98 & 387 & 344 & Ringold Unit E & $\begin{array}{l}\text { Silty sandy coarse to fine pebble to } \\
\text { slightly silty pebbly very coarse to } \\
\text { medium sand }\end{array}$ & SG2 & $\mathrm{Rg}$ & 312 & 412 \\
\hline & & 344 & 387 & Water Table & NA & & & NA & NA \\
\hline
\end{tabular}

${ }^{*}$ After Khaleel and Freeman (1995), per white paper by Khaleel (September 2000)

** $\mathrm{HI}=$ high impact, II=Intermediate Impact (After Composite Analysis)

*** Based on Fecht, Last, and Marratt, 1979 - RHO-LD-72.

BLUE = Injection/release point

$\dagger$ Average thickness adjusted to normalize the average strata thicknesses to equal the total thickness of the vadose zone. 
VZ Base Templates - A_ILAW

\section{South 200 East Area (ILAW) Stratigraphic Columns}

Notes/Assumptions:

1) Thicknesses, elevation, and water table are averages from wells 299-W17-21, 299-E17-23, and 199-E17-25 for the south template, averages from wells 299-

2) A thin blanket of eolian sand and silt covers the surface of the site where not disturbed. This is ignored because ILAW activities will remove this unit prior to

3) All data from PNNL-11957, PNNL-13652, and PNNL-14029

4) Coordinates are for well 299-E17-21 (south template), 299-E24-7 (central template), and 299-E24-21 (north template)

\begin{tabular}{|c|c|c|c|c|c|c|c|c|c|}
\hline $\begin{array}{c}\text { Average } \\
\text { Thickness (ft) }\end{array}$ & $\begin{array}{l}\text { Adjusted } \\
\text { Average } \\
\text { Thickness } \\
\text { (ft) }+\end{array}$ & $\begin{array}{c}\text { Depth } \\
\text { (ft) }\end{array}$ & $\begin{array}{c}\text { Elevation } \\
\text { (ft) }\end{array}$ & Geologic Unit & Description & $\begin{array}{c}\text { Hydraulic } \\
\text { Property } \\
\text { Type * }\end{array}$ & $\begin{array}{c}\text { SAC Soil } \\
\text { Type }\end{array}$ & $\mathrm{Kd}_{\text {Zone }}{ }^{* *}$ & Kd Class \\
\hline & & & 736 & Surface & $\mathrm{NA}$ & NA & NA & NA & \\
\hline 50 & 50 & 0 & 736 & Backfill & Sand and gravel & $\mathrm{B}$ & $\mathrm{B}$ & $\mathrm{HI}$ & $4 \mathrm{H}$ \\
\hline 187 & 187 & 50 & & $\begin{array}{l}\text { Hanford formation, } \\
\text { sand-dominated }\end{array}$ & Sand (S2) & $\mathrm{s}$ & $\mathrm{Hfs}$ & $\mathrm{HI}$ & $4 \mathrm{H}$ \\
\hline 11 & 11 & 237 & & $\begin{array}{l}\text { Hanford formation, } \\
\text { gravel-dominated }\end{array}$ & Gravelly sand to sandy gravel (G3) & SG1 & $\mathrm{Hg}$ & II & 412 \\
\hline 11 & 11 & 248 & & $\begin{array}{l}\text { Hanford formation, } \\
3 \text { sand-dominated }\end{array}$ & Sand (S3) & $\mathrm{s}$ & $\mathrm{Hfs}$ & II & $4 \mid 1$ \\
\hline 75 & 75 & 259 & 477 & $\begin{array}{l}\text { Hanford formation, } \\
\text { gravel-dominated }\end{array}$ & Gravel to sandy gravel (G4) & SG2 & $\mathrm{Rg}$ & II & 412 \\
\hline & & 334 & 402 & Water Table & $\mathrm{NA}$ & NA & NA & NA & NA \\
\hline
\end{tabular}

Template 216A-ILAW_C-X for the central portion of the ILAW site. Nearsurfa Easting $=574,407 \mathrm{~m}$, Northing $=135,560 \mathrm{~m}$

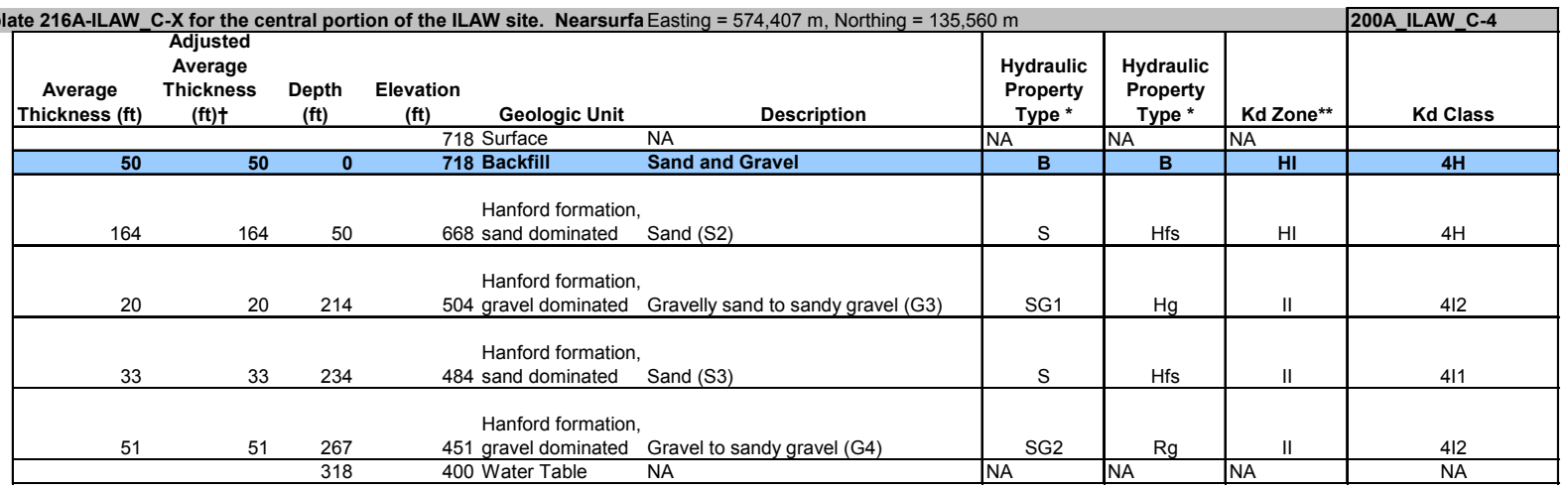

Template 216A-ILAW_N-X, for the northern portion of the ILAW Site. Surfac $€$ Easting $=574,636 \mathrm{~m}$, Northing $=135,698 \mathrm{~m}$

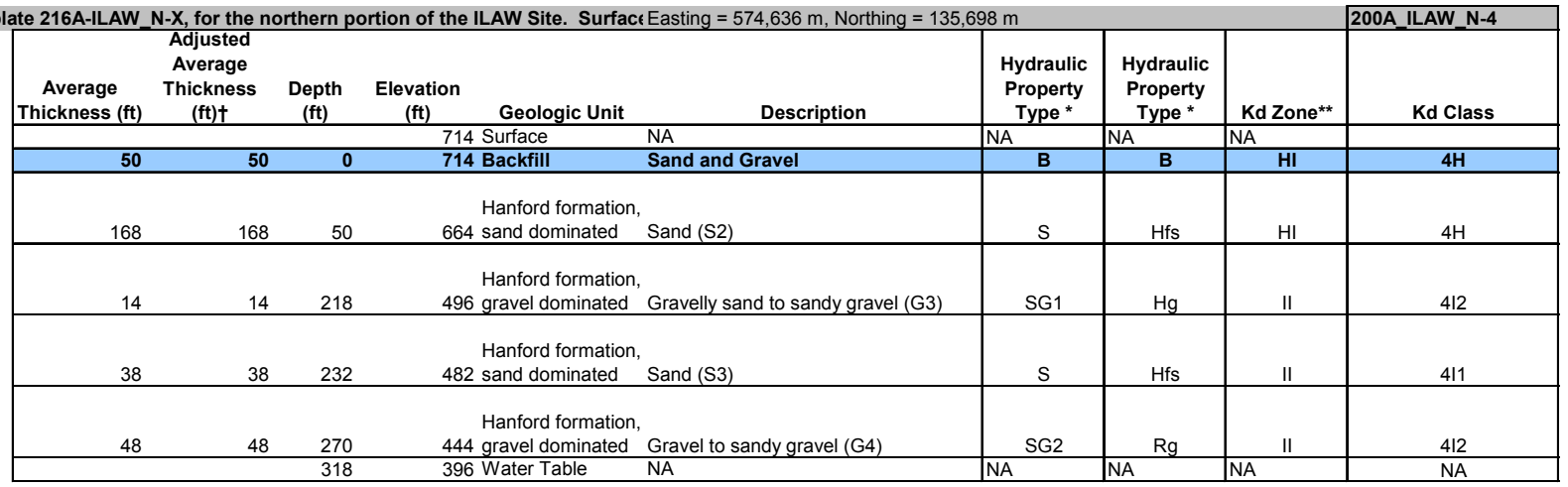

* After Khaleel and Freeman (1995), per white paper by Khaleel (September 2000)

${ }^{* *} \mathrm{HI}=$ high impact, II=Intermediate Impact (After Composite Analysis)

*** Based on Fecht, Last, and Marratt, 1979 - RHO-LD-72.

BLUE $=$ Injection/release point

$\dagger$ Average thickness adjusted to normalize the average strata thicknesses to equal the total thickness of the vadose zone. 


\section{VZ Base Templates B}

\section{North 200 East Area (B Plant facilities and burial grounds) Stratigraphic Columns}

Notes/Assumptions:

1) Topography ranges from $700 \mathrm{ft}$ MSL east of B Plant to $590 \mathrm{ft} \mathrm{MSL}$ in the northeast corner of 200 East Area (USGS Gable Butte $7.5 \mathrm{~min}$. Quadrangle Map).

Will assume an average elevation of $645 \mathrm{ft}$ MSL.

2) The pre-Hanford Water Table (January 1944) is estimated to range from an elevation of $116 \mathrm{~m}$ (380 ft) in the eastern part of 200 East to $119 \mathrm{~m}$ $(390 \mathrm{ft})$ in the western part (BNWL-B-360).

Will assume an average water table elevation of $117 \mathrm{~m}$ ( $385 \mathrm{ft}) \mathrm{MSL}$

3) A thin blanket of eolian sand and silt covers the surface of the site where not disturbed.

However, this material was generally removed during excavation and construction of the waste disposal sites and then incorporated into backfill materials.

The depth of the sites and thus, the backfull over these sites range from $0 \mathrm{~m}$ for ponds and unplanned releases, to an average of about $4.5 \mathrm{~m}$ for cribs and burial grounds, and up to $16.4 \mathrm{~m}$ for tanks.

4) Five reverse wells are located in this area ranging in depth from $15-92 \mathrm{~m}$. Assume average depth of $50 \mathrm{~m}$ (164ft), with an average preforated interval of $11.5 \mathrm{~m}(38 \mathrm{ft})$

5) Injection well 216-B-4 is $108^{\prime}$ deep; $216-B-5$ is perfed 252-302'; 216-B-6 is perfed 73-75'

Template 200B-X for surface disposal sites (e.g. Buildings, Ponds, Ditches, Unplanned Releases)

\begin{tabular}{|c|c|c|c|c|c|c|c|c|c|c|c|}
\hline $\begin{array}{c}\text { Average } \\
\text { Thickness (ft) }\end{array}$ & $\begin{array}{c}\text { Adjusted } \\
\text { Average } \\
\text { Thickness } \\
(\mathrm{ft}) \dagger\end{array}$ & Depth (ft) & Elevation (ft) & Geologic Unit & Description & $\begin{array}{l}\text { Hydraulic } \\
\text { Property } \\
\text { Type * }\end{array}$ & $\begin{array}{l}\text { SAC Soil } \\
\text { Type }\end{array}$ & $\mathrm{K}_{\mathrm{d}}$ Zone $^{\star *}$ & $K_{d}$ Class & $K_{d}$ Class & $K_{d}$ Class \\
\hline & & 0 & 645 & Surface & NA & NA & NA & NA & NA & NA & NA \\
\hline 2 & 2 & 2 & 643 & Eolian & Sand and silt & $\mathrm{S}$ & Hss & $\mathrm{HI}$ & $2 \mathrm{H}$ & $3 \mathrm{H}$ & $4 \mathrm{H}$ \\
\hline 60 & 64 & 66 & 579 & Hanford Gravel & $\begin{array}{l}\text { Silty sandy medium to fine pebble to } \\
\text { slightly silty pebbly very coarse to } \\
\text { coarse sand }\end{array}$ & SG1 & $\mathrm{Hg}$ & $\mathrm{HI}$ & $2 \mathrm{H}$ & $3 \mathrm{H}$ & $4 \mathrm{H}$ \\
\hline 173 & 183 & 249 & 396 & $\begin{array}{l}\text { North } 200 \text { East } \\
\text { Hanford Sand }\end{array}$ & $\begin{array}{l}\text { Coarse to medium sand to slightly } \\
\text { pebbly slightly silty coarse to medium } \\
\text { sand }\end{array}$ & $\mathrm{s}$ & Hcs & II & 211 & 311 & $4 \mid 1$ \\
\hline 10 & 11 & 260 & 385 & \begin{tabular}{|l} 
Undifferenciated \\
Hanford/Plio- \\
Pleistocene
\end{tabular} & $\begin{array}{l}\text { Pebbly very coarse to coarse sand to } \\
\text { sandy medium to fine pebble }\end{array}$ & SG1 & $\mathrm{Hg}$ & II & 212 & 312 & 412 \\
\hline & & 260 & 385 & Water Table & NA & NA & $\mathrm{NA}$ & $\mathrm{NA}$ & $\mathrm{NA}$ & $\mathrm{NA}$ & $\mathrm{NA}$ \\
\hline
\end{tabular}

Template 216B-X for shallow disposal sites (e.g. Cribs, Burial Grounds)

\begin{tabular}{|c|c|c|c|c|c|c|c|c|c|c|c|}
\hline $\begin{array}{c}\text { Average } \\
\text { Thickness (ft) }\end{array}$ & $\begin{array}{l}\text { Adjusted } \\
\text { Average } \\
\text { Thickness } \\
\text { (ft) } \dagger\end{array}$ & Depth (ft) & Elevation (ft) & Geologic Unit & Description & $\begin{array}{c}\text { Hydraulic } \\
\text { Property } \\
\text { Type * }\end{array}$ & $\begin{array}{l}\text { SAC Soil } \\
\text { Type }\end{array}$ & $\mathrm{K}_{\mathrm{d}}$ Zone $^{\star \star}$ & $K_{d}$ Class & $K_{d}$ Class & $K_{d}$ Class \\
\hline & & 0 & 645 & Surface & NA & NA & $\mathrm{NA}$ & $\mathrm{NA}$ & $\mathrm{NA}$ & $\mathrm{NA}$ & $\mathrm{NA}$ \\
\hline 15 & 15 & 15 & 630 & Backfill & Backfill & $\mathrm{B}$ & $\mathrm{B}$ & $\mathrm{NA}$ & $2 \mathrm{H}$ & $3 \mathrm{H}$ & $4 \mathrm{H}$ \\
\hline 47 & 51 & 66 & 579 & Hanford Gravel & $\begin{array}{l}\text { Silty sandy medium to fine pebble to } \\
\text { slightly silty pebbly very coarse to } \\
\text { coarse sand }\end{array}$ & SG1 & $\mathrm{Hg}$ & $\mathrm{HI}$ & $2 \mathrm{H}$ & $3 \mathrm{H}$ & $4 \mathrm{H}$ \\
\hline 173 & 183 & 249 & 396 & $\begin{array}{l}\text { North } 200 \text { East } \\
\text { Hanford Sand }\end{array}$ & $\begin{array}{l}\text { Coarse to medium sand to slightly } \\
\text { pebbly slighly silty coarse to medium } \\
\text { sand }\end{array}$ & $\mathrm{s}$ & Hcs & II & 211 & 311 & $4 \mid 1$ \\
\hline 10 & 11 & 260 & 385 & \begin{tabular}{|l} 
Undifferenciated \\
Hanford/Plio- \\
Pleistocene-
\end{tabular} & $\begin{array}{l}\text { Pebbly very coarse to coarse sand to } \\
\text { sandy medium to fine pebble }\end{array}$ & SG1 & $\mathrm{Hg}$ & II & 212 & 312 & 412 \\
\hline 20 & 20 & 260 & 385 & Water Table & NA & $\mathrm{NA}$ & $\mathrm{NA}$ & NA & $\mathrm{NA}$ & NA & $\mathrm{NA}$ \\
\hline
\end{tabular}

\begin{tabular}{|c|c|c|c|c|c|c|c|c|c|c|c|}
\hline \multicolumn{9}{|c|}{ Template 241B-X for tanks } & 241B-2 & & \\
\hline $\begin{array}{c}\text { Average } \\
\text { Thickness (ft) }\end{array}$ & $\begin{array}{c}\text { Adjusted } \\
\text { Average } \\
\text { Thickness } \\
\text { (ft) } \dagger\end{array}$ & Depth (ft) & Elevation (ft) & Geologic Unit & Description & $\begin{array}{l}\text { Hydraulic } \\
\text { Property } \\
\text { Type * }\end{array}$ & $\begin{array}{l}\text { SAC Soil } \\
\text { Type }\end{array}$ & $\mathrm{K}_{\mathrm{d}}$ Zone $^{\star *}$ & $K_{d}$ Class & & \\
\hline & & 0 & 645 & Surface & NA & NA & NA & NA & NA & & \\
\hline 50 & 50 & 50 & 595 & Backfill & Backfill & $\mathrm{B}$ & $\mathrm{B}$ & NA & $2 \mathrm{H}$ & & \\
\hline 12 & 16 & 66 & 579 & Hanford Gravel & $\begin{array}{l}\text { Silty sandy medium to fine pebble to } \\
\text { slightly silty pebbly very coarse to } \\
\text { coarse sand }\end{array}$ & SG1 & $\mathrm{Hg}$ & $\mathrm{HI}$ & $2 \mathrm{H}$ & & \\
\hline 173 & 183 & 249 & 396 & $\begin{array}{l}\text { North } 200 \text { East } \\
\text { Hanford Sand }\end{array}$ & $\begin{array}{l}\text { Coarse to medium sand to slightly } \\
\text { pebbly slightly silty coarse to medium } \\
\text { sand }\end{array}$ & $\mathrm{s}$ & Hcs & II & $2 \mid 1$ & & \\
\hline 10 & 11 & 260 & 385 & \begin{tabular}{|l|} 
Undifferenciated \\
Hanford/Plio- \\
Pleistocene-
\end{tabular} & $\begin{array}{l}\text { Pebbly very coarse to coarse sand to } \\
\text { sandy medium to fine pebble }\end{array}$ & SG1 & $\mathrm{Hg}$ & II & 212 & & \\
\hline & & 260 & 385 & Water Table & NA & NA & NA & NA & $\mathrm{NA}$ & & \\
\hline
\end{tabular}




\begin{tabular}{|c|c|c|c|c|c|c|c|c|c|}
\hline Template 266B-X for & deep injection & sites (e.g. & reverse wells & - except 216-B- & -5 (a). & & & & 266B-4 \\
\hline \begin{tabular}{|c|} 
Average \\
Thickness (ft)
\end{tabular} & $\begin{array}{c}\text { Adjusted } \\
\text { Average } \\
\text { Thickness } \\
\text { (ft) } \dagger\end{array}$ & Depth (ft) & Elevation (ft) & Geologic Unit & Description & $\begin{array}{l}\text { Hydraulic } \\
\text { Property } \\
\text { Type * }\end{array}$ & $\begin{array}{l}\text { SAC Soil } \\
\text { Type }\end{array}$ & $\mathrm{K}_{\mathrm{d}}$ Zone $^{* *}$ & $\mathrm{~K}_{\mathrm{d}}$ Class \\
\hline & & 0 & 645 & Surface & NA & NA & NA & NA & NA \\
\hline 2 & 2 & 2 & 643 & Eolian & Sand and silt & $\mathrm{S}$ & Hss & NA & $4 \mid 1$ \\
\hline 60 & 64 & 66 & 579 & Hanford Gravel & $\begin{array}{l}\text { Silty sandy medium to fine pebble to } \\
\text { slightly silty pebbly very coarse to } \\
\text { coarse sand }\end{array}$ & SG1 & $\mathrm{Hg}$ & NA & 412 \\
\hline & 60 & 126 & 519 & $\begin{array}{l}\text { North } 200 \text { East } \\
\text { Hanford Sand }\end{array}$ & $\begin{array}{l}\text { Coarse to medium sand to slightly } \\
\text { pebbly slightly silty coarse to medium } \\
\text { sand }\end{array}$ & $\mathrm{s}$ & Hcs & NA & $4 \mid 1$ \\
\hline & 98 & 164 & 481 & & & $\mathrm{~s}$ & Hos & NA & $4 \mathrm{H}$ \\
\hline 173 & 183 & 249 & 396 & & & $\mathrm{~s}$ & HcS & II & $4 \mathrm{H}$ \\
\hline 10 & 11 & 260 & 385 & \begin{tabular}{|l} 
Undifferenciated \\
Hanford/Plio- \\
Pleistocene
\end{tabular} & $\begin{array}{l}\text { Pebbly very coarse to coarse sand to } \\
\text { sandy medium to fine pebble }\end{array}$ & SG1 & $\mathrm{Hg}$ & $H I$ & 412 \\
\hline & & 260 & 385 & Water Table & NA & NA & $\mathrm{NA}$ & $N A$ & NA \\
\hline
\end{tabular}

(a) Injection well 216-B-4 is 108' deep; 216-B-5 is perfed 252-302'; 216-B-6 is perfed 73-75'

\begin{tabular}{|c|c|c|c|c|c|c|c|c|c|c|c|}
\hline Template 267B-X for & rery deep injec & ction sites & (i.e., the 216-B & $3-5$ reverse well & (a)) & & & & 267B-2 & & \\
\hline $\begin{array}{c}\text { Average } \\
\text { Thickness (ft) }\end{array}$ & $\begin{array}{c}\text { Ádjusted } \\
\text { Average } \\
\text { Thickness } \\
\text { (ft) } \dagger\end{array}$ & Depth (ft) & Elevation (ft) & Geologic Unit & Description & $\begin{array}{l}\text { Hydraulic } \\
\text { Property } \\
\text { Type * }\end{array}$ & $\begin{array}{l}\text { SAC Soil } \\
\text { Type }\end{array}$ & $\mathrm{K}_{\mathrm{d}}$ Zone $^{\star *}$ & $K_{d}$ Class & & \\
\hline & & 0 & 645 & Surface & NA & NA & NA & NA & NA & & \\
\hline 2 & 2 & 2 & 643 & Eolian & Sand and silt & $\mathrm{S}$ & Hss & NA & 211 & & \\
\hline 60 & 64 & 66 & 579 & Hanford Gravel & $\begin{array}{l}\text { Silty sandy medium to fine pebble to } \\
\text { slightly silty pebbly very coarse to } \\
\text { coarse sand }\end{array}$ & SG1 & $\mathrm{Hg}$ & NA & 212 & & \\
\hline & 183 & 249 & 396 & $\begin{array}{l}\text { North } 200 \text { East } \\
\text { Hanford Sand }\end{array}$ & $\begin{array}{l}\text { Coarse to medium sand to slightly } \\
\text { pebbly slightly silty coarse to medium } \\
\text { sand }\end{array}$ & $\mathrm{s}$ & Hcs & NA & 211 & & \\
\hline 10 & 3 & 252 & 393 & \begin{tabular}{|l} 
Undifferenciated \\
Hanford/Plio- \\
Pleistocene-
\end{tabular} & $\begin{array}{l}\text { Pebbly very coarse to coarse sand to } \\
\text { sandy medium to fine pebble }\end{array}$ & $\mathrm{s}$ & Hcs & NA & $2 \mathrm{H}$ & & \\
\hline 10 & 8 & 260 & 385 & & & SG1 & $\mathrm{Hg}$ & HI & $2 \mathrm{H}$ & & \\
\hline & & 260 & 385 & Water Table & NA & NA & NA & $N A$ & NA & & \\
\hline
\end{tabular}

* After Khaleel and Freeman (1995)

${ }^{* *} \mathrm{HI}=$ high impact, II=Intermediate Impact (After Composite Analysis)

BLUE $=$ Injection/release point

$\dagger$ Average thickness adjusted to normalize the average strata thicknesses to equal the total thickness of the vadose zone. 


\section{VZ Base Templates $C$}

\section{0-B/C Stratigraphic Columns}

Notes/Assumptions:

1) Elevation ranges from $500 \mathrm{ft}$ AMSL in the south to about $400 \mathrm{ft}$ AMSL to the north along the rivers edge (USGS Vernita Bridge and Riverland 7.5 min. Quad Maps).

Average elevation near retention basins $\sim 40 \mathrm{ft}$ and increases to the south (up to $460 \mathrm{ft}$ ) away from the river.

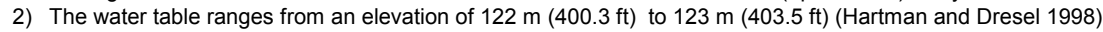

Assume an average water table elevation of $122.5 \mathrm{~m}$ (402 ft) AMSL

3) A thin $(\leq 1 \mathrm{~m})$ blanket of eolian or fluvial sand or silt may cover the surface of the site where not disturbed. Some backfill may also be present but it is not documented in existing reports.

4) No reverse wells are located in this aggregate area.

\begin{tabular}{|c|c|c|c|c|c|c|c|c|c|}
\hline \multicolumn{9}{|c|}{ Template $100 \mathrm{C}-\mathrm{X}$ - For surface disposal sites (i.e. reactors) } & \multirow{2}{*}{\begin{tabular}{|c|}
$100 \mathrm{C}-4$ \\
Kd Class
\end{tabular}} \\
\hline $\begin{array}{l}\text { Average } \\
\text { Thickness } \\
\text { (ft) }\end{array}$ & $\begin{array}{c}\text { Adjusted } \\
\text { Average } \\
\text { Thickness } \\
\text { (ft) } \dagger\end{array}$ & Depth (ft) & Elevation (ft) & Geologic Unit & Description & $\begin{array}{l}\text { Hydraulic } \\
\text { Property } \\
\text { Type * }\end{array}$ & $\begin{array}{c}\text { SAC Soil } \\
\text { Type }\end{array}$ & Kd Zone ${ }^{* *}$ & \\
\hline & & 0 & 460 & Surface & NA & NA & NA & $\mathrm{HI}$ & $4 \mathrm{H}$ \\
\hline & 30 & 30 & 430 & Hanford fm gravel & $\begin{array}{l}\text { Silty sandy pebble to boulder gravel } \\
\text { with lenses of gravelly medium to } \\
\text { coarse sand. (DOE 1993) }\end{array}$ & SG1 & $\mathrm{Hg}$ & $\mathrm{HI}$ & $4 \mathrm{H}$ \\
\hline & 28 & 58 & 402 & & & SG1 & $\mathrm{Hg}$ & II & $4 \mid 2$ \\
\hline & & 58 & 402 & Water Table & NA & NA & NA & NA & NA \\
\hline
\end{tabular}

\begin{tabular}{|c|c|c|c|c|c|c|c|c|c|}
\hline \multicolumn{9}{|c|}{ Template 116C-X - For shallow disposal sites (i.e. cribs, trenches, burial grounds, sand filter) } & \multirow{2}{*}{\begin{tabular}{|c|}
$116 C-4$ \\
Kd Class \\
\end{tabular}} \\
\hline $\begin{array}{l}\text { Average } \\
\text { Thickness } \\
\text { (ft) }\end{array}$ & $\begin{array}{c}\text { Adjusted } \\
\text { Average } \\
\text { Thickness } \\
\text { (ft) } \dagger\end{array}$ & Depth (ft) & Elevation (ft) & Geologic Unit & Description & $\begin{array}{c}\text { Hydraulic } \\
\text { Property } \\
\text { Type * }\end{array}$ & $\begin{array}{c}\text { SAC Soil } \\
\text { Type }\end{array}$ & Kd Zone** & \\
\hline & & 0 & 460 & Surface & NA & NA & NA & NA & NA \\
\hline & 15 & 15 & 445 & Backfill & & $\mathrm{B}$ & $\mathrm{B}$ & $\mathrm{HI}$ & $4 \mathrm{H}$ \\
\hline & 30 & 45 & 415 & Hanford fm gravel & $\begin{array}{l}\text { Silty sandy pebble to boulder gravel } \\
\text { with lenses of gravelly medium to } \\
\text { coarse sand. (DOE 1993) }\end{array}$ & SG1 & $\mathrm{Hg}$ & $\mathrm{HI}$ & $4 \mathrm{H}$ \\
\hline & 13 & 58 & 402 & & & SG1 & $\mathrm{Hg}$ & ॥ & 412 \\
\hline & & 58 & 402 & Water Table & NA & NA & NA & NA & NA \\
\hline
\end{tabular}

* After Khaleel and Freeman (1995), per white paper by Khaleel (September 2000)

** $\mathrm{HI}=$ high impact, II=Intermediate Impact (After Composite Analysis) BLUE = injection/release point

$\dagger$ Average thickness adjusted to normalize the average strata thicknesses to equal the total thickness of the vadose zone. 


\section{VZ Base Templates D}

\section{0-D/DR Stratigraphic Columns}

Notes/Assumptions:

1) Surface elevation ranges from $470 \mathrm{ft}$ MSL along the southern boundary to about $390 \mathrm{ft} \mathrm{MSL}$ to the northwest along rivers edge (USGS Coyote Rapids 7.5 min. Quad Map).

Will assume an average elevation of $460 \mathrm{ft} \mathrm{MSL}$.

2) Water table ranges from an elevation of $116.5 \mathrm{~m}$ (382 ft) along the eastern boundary to $119 \mathrm{~m}(390.5 \mathrm{ft})$ to the northwest (DOE 1993 , Hartman and Dresel 1998).

Will assume an average water table elevation of $118 \mathrm{~m}(387 \mathrm{ft}) \mathrm{MSL}$.

3) A thin $(\leq 1 \mathrm{~m})$ blanket of eolian or fluvial sand or silt may cover the surface of the site where not disturbed. Some backfill may also be present but it is not well documented in existing reports.

4) No reverse wells are located in the 100-D/DR aggregate area.

\begin{tabular}{|c|c|c|c|c|c|c|c|c|c|}
\hline \multicolumn{9}{|c|}{ Template 100D-X - For surface disposal sites (i.e. reactors) } & \multirow[b]{2}{*}{$\begin{array}{r}\text { 100D-4 } \\
\text { Kd Class }\end{array}$} \\
\hline $\begin{array}{c}\text { Average } \\
\text { Thickness } \\
\text { (ft) }\end{array}$ & $\begin{array}{l}\text { Adjusted } \\
\text { Average } \\
\text { Thickness } \\
\text { (ft) } \dagger\end{array}$ & - & $\begin{array}{c}\text { Elevation } \\
\text { (ft) }\end{array}$ & Geologic Unit & Description & $\begin{array}{c}\text { Hydraulic } \\
\text { Property } \\
\text { Type * }\end{array}$ & $\begin{array}{c}\text { SAC Soil } \\
\text { Type }\end{array}$ & Kd Zone ${ }^{\star *}$ & \\
\hline & & 0 & 460 & Surface & NA & NA & NA & NA & NA \\
\hline & 30 & 30 & 430 & Hanford fm gravel & $\begin{array}{l}\text { Sandy gravel and gravelly sand, with } \\
\text { local sandy and silty interbeds } \\
\text { (Peterson et. al., 1996) }\end{array}$ & SG1 & $\mathrm{Hg}$ & $\mathrm{HI}$ & $4 \mathrm{H}$ \\
\hline & 23 & 53 & 407 & & & SG1 & $\mathrm{Hg}$ & II & 412 \\
\hline & 20 & 73 & 387 & Ringold Unit E & Silty sandy gravel & SG2 & $\mathrm{Rg}$ & II & 412 \\
\hline & & 73 & 387 & Water Table & & $\mathrm{NA}$ & NA & NA & NA \\
\hline
\end{tabular}

\begin{tabular}{|c|c|c|c|c|c|c|c|c|c|}
\hline \multicolumn{9}{|c|}{ Template 116D-X - For shallow disposal sites (i.e. cribs, trenches, burial grounds, sand filter) } & \multirow{2}{*}{\begin{tabular}{|c|}
$116 \mathrm{D}-4$ \\
Kd Class \\
\end{tabular}} \\
\hline $\begin{array}{c}\text { Average } \\
\text { Thickness } \\
\text { (ft) }\end{array}$ & $\begin{array}{c}\text { Adjusted } \\
\text { Average } \\
\text { Thickness } \\
\text { (ft) } \dagger\end{array}$ & Depth (ft) & $\begin{array}{c}\text { Elevation } \\
\text { (ft) }\end{array}$ & Geologic Unit & Description & $\begin{array}{l}\text { Hydraulic } \\
\text { Property } \\
\text { Type * }\end{array}$ & $\begin{array}{c}\text { SAC Soil } \\
\text { Type }\end{array}$ & Kd Zone ${ }^{\star \star}$ & \\
\hline & & 0 & 460 & Surface & NA & NA & NA & NA & NA \\
\hline & 15 & 17 & 443 & Backfill & & $\mathrm{B}$ & $\mathrm{B}$ & $\mathrm{HI}$ & $4 \mathrm{H}$ \\
\hline & 30 & 47 & 413 & Hanford fm gravel & $\begin{array}{l}\text { Sandy gravel and gravelly sand, with } \\
\text { local sandy and silty interbeds } \\
\text { (Peterson et. al., 1996) }\end{array}$ & SG1 & $\mathrm{Hg}$ & $\mathrm{HI}$ & $4 \mathrm{H}$ \\
\hline & 6 & 53 & 407 & & & SG1 & $\mathrm{Hg}$ & II & 412 \\
\hline & 20 & 73 & 387 & Ringold Unit E & Silty sandy gravel & SG2 & $\mathrm{Rg}$ & II & 412 \\
\hline & & 73 & 387 & Water Table & & $\mathrm{NA}$ & $\mathrm{NA}$ & $\mathrm{NA}$ & $\mathrm{NA}$ \\
\hline
\end{tabular}

${ }^{*}$ After Khaleel and Freeman (1995), per white paper by Khaleel (September 2000)

${ }^{* *} \mathrm{HI}=$ high impact, II=Intermediate Impact (After Composite Analysis)

BLUE = injection/release point

$\dagger$ Average thickness adjusted to normalize the average strata thicknesses to equal the total thickness of the vadose zone. 


\section{VZ Base Templates E}

\section{East 200 East Area (B-Pond) Stratigraphic Columns}

Notes/Assumptions:

1) Topography ranges from460 to $650 \mathrm{ft}$ (137 to $198 \mathrm{~m}$ ) MSL (USGS Gable Butte $7.5 \mathrm{~min}$. Quadrangle Map). Will assume an average elevation of $169 \mathrm{~m}(555 \mathrm{ft}) \mathrm{MSL}$.

2) The pre-Hanford Water Table (January 1944) is estimated to range from an elevation of $113 \mathrm{~m}$ (370 ft) to $116 \mathrm{~m}$ (380 ft) MSL (BNWL-B360).

Will assume an average water table elevation of $115 \mathrm{~m}(375 \mathrm{ft}) \mathrm{MSL}$.

3) A thin blanket of eolian sand and silt covers the surface of the site where not disturbed.

However, this material was generally removed during excavation and construction of the waste disposal sites and then incorporated into backfill materials.

4) The depth of the sites and thus, the backfull over these sites range from $0 \mathrm{~m}$ for ponds and unplanned releases, to an average of about $4.5 \mathrm{~m}$ for cribs and burial grounds, and upto $16.4 \mathrm{~m}$ for tanks.

\begin{tabular}{|c|c|c|c|c|c|c|c|c|c|}
\hline \multicolumn{9}{|c|}{ Template 200E-X for surface disposal sites (e.g. Ponds) } & $200 \mathrm{E}-4$ \\
\hline $\begin{array}{c}\text { Average } \\
\text { Thickness } \\
\text { (ft) }\end{array}$ & $\begin{array}{c}\text { Adjusted } \\
\text { Average } \\
\text { Thickness } \\
\text { (ft) } \dagger\end{array}$ & Depth (ft) & $\begin{array}{c}\text { Elevation } \\
\text { (ft) }\end{array}$ & Geologic Unit & Description & $\begin{array}{c}\text { Hydraulic } \\
\text { Property } \\
\text { Type * }\end{array}$ & $\begin{array}{l}\text { SAC Soil } \\
\text { Type }\end{array}$ & Kd Zone ${ }^{* *}$ & Kd Class \\
\hline & & 0 & 555 & Surface & NA & NA & NA & $\mathrm{HI}$ & $4 \mathrm{H}$ \\
\hline 3 & 3 & 3 & 552 & Eolian & Sand and silt & $\mathrm{S}$ & Hss & $\mathrm{HI}$ & $4 \mathrm{H}$ \\
\hline 12 & 11 & 14 & 541 & Hanford Gravel & $\begin{array}{l}\text { Silty sandy gravel to sandy } \\
\text { gravel to gravelly sand }\end{array}$ & SG1 & $\mathrm{Hg}$ & $\mathrm{HI}$ & 412 \\
\hline 62 & 58 & 72 & 483 & Hanford sand & $\begin{array}{l}\text { Slightly pebbly, slightly silty } \\
\text { coarse to medium sand to } \\
\text { coarse to fine sand }\end{array}$ & S & Hcs & II & $4 \mid 1$ \\
\hline 85 & 79 & 151 & 404 & Hanford gravel & $\begin{array}{l}\text { Sandy gravel to silty sandy } \\
\text { gravel }\end{array}$ & SG1 & $\mathrm{Hg}$ & II & 412 \\
\hline 30 & 28 & 179 & 376 & $\begin{array}{l}\text { Ringold Lower } \\
\text { Mud }\end{array}$ & silt, sandy silt & SS & PPIz & II & $4 \mid 1$ \\
\hline & & 180 & 375 & Water Table & NA & $\mathrm{NA}$ & $\mathrm{NA}$ & $\mathrm{NA}$ & $\mathrm{NA}$ \\
\hline
\end{tabular}

BLUE = injection/release point

$\dagger$ Average thickness adjusted to normalize the average strata thicknesses to equal the total thickness of the vadose zone. 


\section{VZ Base Templates F}

\section{0-F Stratigraphic Columns}

Notes/Assumptions:

1) Surface elevation ranges from $420 \mathrm{ft} \mathrm{MSL}$ within the north-central 100-F Area to about $380 \mathrm{ft} \mathrm{MSL}$ to the northeast along rivers edge (USGS Locke Island 7.5 min. Quad Map).

Will assume an average elevation of $410 \mathrm{ft}$ MSL.

2) Water table ranges from an elevation of $113.5 \mathrm{~m}$ (372 ft) in the southeast to $115 \mathrm{~m}(377 \mathrm{ft})$ to the north (Hartman and Dresel 1998).

Will assume an average water table elevation of $114 \mathrm{~m}(374 \mathrm{ft}) \mathrm{MSL}$.

3) A thin $(\leq 1 \mathrm{~m})$ blanket of eolian or fluvial sand or silt may cover the surface of the site where not disturbed. Some backfill may also be present but it is not well documented in existing reports.

4) No reverse wells are located in the $100-\mathrm{F}$ aggregate area.

\begin{tabular}{|c|c|c|c|c|c|c|c|c|c|}
\hline \multicolumn{9}{|c|}{$\begin{array}{l}\text { Template 100F-X for surface disposal sites (i.e. reactors) } \\
\end{array}$} & \multirow[b]{2}{*}{$\begin{array}{r}100 \mathrm{~F}-4 \\
\text { Kd Class }\end{array}$} \\
\hline $\begin{array}{c}\text { Average } \\
\text { Thickness (ft) }\end{array}$ & $\begin{array}{c}\text { Adjusted } \\
\text { Average } \\
\text { Thickness } \\
(\mathrm{ft}) \dagger\end{array}$ & $\begin{array}{c}\text { Depth } \\
\text { (ft) }\end{array}$ & $\begin{array}{l}\text { Elevation } \\
\text { (ft) }\end{array}$ & Geologic Unit & Description & $\begin{array}{l}\text { Hydraulic } \\
\text { Property } \\
\text { Type * }\end{array}$ & $\begin{array}{l}\text { SAC Soil } \\
\text { Type }\end{array}$ & Kd Zone** & \\
\hline & & 0 & 410 & Surface & NA & NA & NA & NA & NA \\
\hline & 30 & 30 & 380 & Hanford Gravel & $\begin{array}{l}\text { Sandy gravel to silty sandy gravel (Peterson et al. } \\
\text { 1996). Gravel-dominated with subordinate sand- } \\
\text { dominated facies (Raidl 1994). }\end{array}$ & SG1 & $\mathrm{Hg}$ & $\mathrm{HI}$ & $4 \mathrm{H}$ \\
\hline & 6 & 36 & 374 & & & SG1 & $\mathrm{Hg}$ & II & 412 \\
\hline & & 36 & 374 & Water Table & NA & NA & NA & NA & NA \\
\hline
\end{tabular}

\begin{tabular}{|c|c|c|c|c|c|c|c|c|c|}
\hline \multicolumn{9}{|c|}{ Template $116 \mathrm{~F}-\mathrm{X}$ for shallow disposal sites (e.g. cribs, trenches, burial grounds, sand filter) } & \multirow[b]{2}{*}{$\begin{array}{r}116 \mathrm{~F}-4 \\
\text { Kd Class }\end{array}$} \\
\hline $\begin{array}{c}\text { Average } \\
\text { Thickness (ft) }\end{array}$ & $\begin{array}{c}\text { Adjusted } \\
\text { Average } \\
\text { Thickness } \\
\text { (ft) } \dagger \\
\end{array}$ & $\begin{array}{c}\text { Depth } \\
(\mathrm{ft})\end{array}$ & $\begin{array}{c}\text { Elevation } \\
\text { (ft) }\end{array}$ & Geologic Unit & Description & $\begin{array}{l}\text { Hydraulic } \\
\text { Property } \\
\text { Type * }\end{array}$ & $\begin{array}{c}\text { SAC Soil } \\
\text { Type }\end{array}$ & Kd Zone** & \\
\hline & & 0 & 410 & Surface & NA & NA & NA & NA & NA \\
\hline & 15 & 15 & 395 & Backfill & & $\mathrm{B}$ & $\mathrm{B}$ & $\mathrm{HI}$ & $4 \mathrm{H}$ \\
\hline & 21 & 36 & 374 & Hanford fm gravel & $\begin{array}{l}\text { Sandy gravel to silty sandy gravel (Peterson et al. } \\
\text { 1996). Gravel-dominated with subordinate sand- } \\
\text { dominated facies (Raidl 1994). }\end{array}$ & SG1 & $\mathrm{Hg}$ & $\mathrm{HI}$ & $4 \mathrm{H}$ \\
\hline & & 36 & 374 & Water Table & NA & NA & NA & NA & NA \\
\hline
\end{tabular}

* After Khaleel and Freeman (1995), per white paper by Khaleel (September 2000)

** $\mathrm{HI}=$ high impact, II=Intermediate Impact (After Composite Analysis)

BLUE = injection/release point

$\dagger$ Average thickness adjusted to normalize the average strata thicknesses to equal the total thickness of the vadose zone 


\section{VZ Base Templates G}

\section{North Area and Gable Mountain Pond (Aggregate Area G) Stratigraphic Columns}

Notes/Assumptions:

1) Topography ranges from $435 \mathrm{ft} \mathrm{MSL}$ at Gable Mountain Pond to $584 \mathrm{ft} \mathrm{MSL}$ in the 200 North Area (DOE/RL-92-17) Will assume an average elevation of $510 \mathrm{ft} \mathrm{MSL}$.

2) The pre-Hanford Water Table (January 1944) is estimated to range from an elevation of $116 \mathrm{~m}(380 \mathrm{ft})$ to $119 \mathrm{~m}(390 \mathrm{ft})(\mathrm{BNWL}-\mathrm{B}-360)$.

Will assume an average water table elevation of $117 \mathrm{~m}(385 \mathrm{ft}) \mathrm{MSL}$.

3) A thin blanket of eolian sand and silt covers the surface of the site where not disturbed.

However, this material was generally removed during excavation and construction of the waste disposal sites and then incorporated into backfill materials.

The depth of the sites and thus, the backfull over these sites range from $0 \mathrm{~m}$ for ponds and unplanned releases, to an average of about 4.5 $\mathrm{m}$ for cribs and burial grounds.

4) There are no tanks or reverse wells in this aggregate area.

Template 200G-X for surface disposal sites (e.g. Ponds, trenches, buildings)

\begin{tabular}{|c|c|c|c|c|c|c|c|c|c|}
\hline $\begin{array}{c}\text { Average } \\
\text { Thickness (ft) }\end{array}$ & $\begin{array}{c}\text { Adjusted } \\
\text { Average } \\
\text { Thickness } \\
\text { (ft) } \dagger\end{array}$ & Depth (ft) & Elevation (ft) & Geologic Unit & Description & $\begin{array}{c}\text { Hydraulic } \\
\text { Property } \\
\text { Type * }\end{array}$ & $\begin{array}{l}\text { SAC Soil } \\
\text { Type }\end{array}$ & Kd Zone ${ }^{* *}$ & Kd Class \\
\hline & & 0 & 510 & Surface & NA & NA & NA & NA & NA \\
\hline 3 & 3 & 3 & 507 & Eolian & Sand and silt & $S$ & $\mathrm{Hss}$ & $\mathrm{HI}$ & $4 \mathrm{H}$ \\
\hline 122 & 121 & 124 & 386 & $\begin{array}{l}\text { Undifferenciated } \\
\text { Hanford formation }\end{array}$ & $\begin{array}{l}\text { coarse gravel and sand to silty } \\
\text { sandy gravel }\end{array}$ & SG1 & $\mathrm{Hg}$ & $\mathrm{HI}$ & $4 \mathrm{H}$ \\
\hline & & 125 & 385 & Water Table & NA & NA & NA & NA & NA \\
\hline
\end{tabular}

Template 216G-X for shallow disposal sites (e.g. Cribs)

\begin{tabular}{|c|c|c|c|c|c|c|c|c|c|}
\hline & & & & & & & & & 216G-4 \\
\hline $\begin{array}{c}\text { Average } \\
\text { Thickness (ft) }\end{array}$ & $\begin{array}{c}\text { Adjusted } \\
\text { Average } \\
\text { Thickness } \\
\text { (ft)† }\end{array}$ & Depth (ft) & Elevation (ft) & Geologic Unit & Description & $\begin{array}{c}\text { Hydraulic } \\
\text { Property } \\
\text { Type * }\end{array}$ & $\begin{array}{l}\text { SAC Soil } \\
\text { Type }\end{array}$ & Kd Zone ${ }^{\star *}$ & Kd Class \\
\hline & & 0 & 510 & Surface & NA & NA & NA & NA & NA \\
\hline 15 & 15 & $\overline{15}$ & 495 & Backfill & Backfill & $\bar{B}$ & $\bar{B}$ & $\mathrm{HI}$ & $4 \mathrm{H}$ \\
\hline 110 & 109 & 124 & 386 & \begin{tabular}{|l|} 
Undifferenciated \\
Hanford formation
\end{tabular} & $\begin{array}{l}\text { Coarse gravel and sand to silty } \\
\text { sandy gravel }\end{array}$ & SG1 & $\mathrm{Hg}$ & $\mathrm{HI}$ & $4 \mathrm{H}$ \\
\hline & & 125 & 385 & Water Table & NA & NA & NA & NA & NA \\
\hline
\end{tabular}

* After Khaleel and Freeman (1995), per white paper by Khaleel (September 2000)

** $\mathrm{HI}=$ high impact, II=Intermediate Impact (After Composite Analysis)

BLUE = Injection/release point

$\dagger$ Average thickness adjusted to normalize the average strata thicknesses to equal the total thickness of the vadose zone. 


\section{VZ Base Templates $\mathrm{H}$}

\section{0-H Stratigraphic Columns}

Notes/Assumptions:

1) Surface elevation ranges from $425 \mathrm{ft} \mathrm{MSL}$ in the center of the 100-H Area to about $380 \mathrm{ft}$ MSL along rivers edge to the northeast (USDOE, Hanford Site Topography - Locke Island, Bechtel Job \#22192; USGS Locke Island 7.5 min. Quad Map).

Will assume an average elevation of $415 \mathrm{ft}$ MSL.

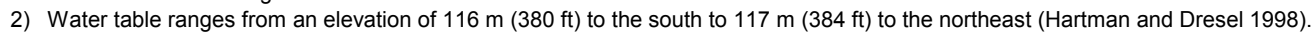

Will assume an average water table elevation of $116.5 \mathrm{~m}(382 \mathrm{ft}) \mathrm{MSL}$.

3) A thin $(\leq 1 \mathrm{~m})$ blanket of eolian or fluvial sand or silt may cover the surface of the site where not disturbed. Locally, up to $15 \mathrm{ft}$ of backfill may also be present (Peterson et al. 1996) but it is not well documented in existing reports.

4) There are no reverse (injection wells) in the 100-H Aggregate Area.

\begin{tabular}{|c|c|c|c|c|c|c|c|c|c|}
\hline Template $100 \mathrm{H}-\mathrm{X}$ for $\mathrm{s}$ & Irface disposa & a sites (i.e., & retention bas & sins) & & & & & $100 \mathrm{H}-4$ \\
\hline $\begin{array}{c}\text { Average } \\
\text { Thickness (ft) }\end{array}$ & $\begin{array}{c}\text { Adjusted } \\
\text { Average } \\
\text { Thickness } \\
\text { (ft) } \dagger \\
\end{array}$ & Depth (ft) & $\begin{array}{l}\text { Elevation } \\
\text { (ft) }\end{array}$ & Geologic Unit & Description & $\begin{array}{c}\text { Hydraulic } \\
\text { Property } \\
\text { Type * }\end{array}$ & $\begin{array}{l}\text { SAC Soil } \\
\text { Type }\end{array}$ & Kd Zone ${ }^{* *}$ & Kd Class \\
\hline & & 0 & 415 & Surface & NA & NA & NA & NA & NA \\
\hline & 30 & 30 & 385 & Hanford fm gravel & $\begin{array}{l}\text { Sandy gravel with subordinate gravelly } \\
\text { sand (Peterson et. al. 1996) }\end{array}$ & SG1 & $\mathrm{Hg}$ & $\mathrm{HI}$ & $4 \mathrm{H}$ \\
\hline & 3 & 33 & 382 & & & SG1 & $\mathrm{Hg}$ & II & 412 \\
\hline & & 33 & 382 & Water Table & NA & NA & NA & NA & NA \\
\hline
\end{tabular}

\begin{tabular}{|c|c|c|c|c|c|c|c|c|c|}
\hline \multicolumn{9}{|c|}{ Template 116H-X for shallow disposal sites (e.g. cribs, trenches, burial grounds) } & \multirow{2}{*}{\begin{tabular}{|c|}
$116 \mathrm{H}-4$ \\
Kd Class \\
\end{tabular}} \\
\hline $\begin{array}{c}\text { Average } \\
\text { Thickness (ft) }\end{array}$ & $\begin{array}{l}\text { Adjusted } \\
\text { Average } \\
\text { Thickness } \\
\text { (ft) } \dagger\end{array}$ & Depth (ft) & $\begin{array}{c}\text { Elevation } \\
\text { (ft) }\end{array}$ & Geologic Unit & Description & $\begin{array}{c}\text { Hydraulic } \\
\text { Property } \\
\text { Type * }\end{array}$ & $\begin{array}{l}\text { SAC Soil } \\
\text { Type }\end{array}$ & Kd Zone ${ }^{\star *}$ & \\
\hline & & 0 & 415 & Surface & NA & NA & $\mathrm{NA}$ & $\mathrm{NA}$ & NA \\
\hline & 15 & 15 & 400 & Backfill & & $\mathrm{B}$ & $\mathrm{B}$ & $\mathrm{HI}$ & $4 \mathrm{H}$ \\
\hline & 18 & 33 & 382 & Hanford fm gravel & $\begin{array}{l}\text { Sandy gravel with subordinate gravelly } \\
\text { sand (Peterson et. al. 1996) }\end{array}$ & SG1 & $\mathrm{Hg}$ & $\mathrm{HI}$ & $4 \mathrm{H}$ \\
\hline & & 33 & 382 & Water Table & NA & NA & NA & NA & NA \\
\hline
\end{tabular}

* After Khaleel and Freeman (1995), per white paper by Khaleel (September 2000)

** HI=high impact, II=Intermediate Impact (After Composite Analysis)

BLUE = injection/release point

$\dagger$ Average thickness adjusted to normalize the average strata thicknesses to equal the total thickness of the vadose zone. 
VZ Base Templates I

\section{North Area (Aggregate Area I) Stratigraphic Columns}

Notes/Ass

1) Topography ranges from $580 \mathrm{ft}$ MSL near $216-\mathrm{N}-3$ in the NW portion of this geographic area, to $540 \mathrm{ft}$ MSL beneath the old $216-\mathrm{N}-6$ Pond in the SE portion of the area (Gable Butte Quadrangle, 7.5 Minute Series, 1986).

Will assume an average water table elevation of $395 \mathrm{ft} \mathrm{MSL}$

3) Stratigraphy based on asbuilt drawings of 699-55-60A,B, and -51-63. A thin blanket of top soil (eolian sand and silt) covers the surface of However, this material was generally removed during excavation and construction of the waste disposal sites and then incorporated into backfill materials.

The depth of the sites and thus, the backfull over these sites range from $0 \mathrm{~m}$ for ponds and unplanned releases, to an average of about 4.5 $\mathrm{m}$ for cribs and burial grounds.

4) There are no tanks or reverse wells in this aggregate area.

\begin{tabular}{|c|c|c|c|c|c|c|c|c|c|}
\hline \multicolumn{9}{|c|}{ Template 200G-X for surface disposal sites (e.g. Ponds, trenches, buildings) } & \multirow{2}{*}{$\begin{array}{r}2001-4 \\
\text { Kd Class }\end{array}$} \\
\hline $\begin{array}{c}\text { Average } \\
\text { Thickness (ft) }\end{array}$ & $\begin{array}{l}\text { Adjusted } \\
\text { Average } \\
\text { Thickness } \\
\text { (ft)† }\end{array}$ & Depth (ft) & Elevation (ft) & Geologic Unit & Description & $\begin{array}{c}\text { Hydraulic } \\
\text { Property } \\
\text { Type * }\end{array}$ & $\begin{array}{l}\text { SAC Soil } \\
\text { Type }\end{array}$ & Kd Zone ${ }^{* *}$ & \\
\hline & & & 565 & Surface & $\mathrm{NA}$ & NA & NA & NA & NA \\
\hline 3 & 3 & 3 & 562 & Eolian & Sand and silt & $s$ & Hss & $\mathrm{HI}$ & $4 \mathrm{H}$ \\
\hline 122 & 172 & 175 & 390 & $\begin{array}{l}\text { Undifferenciated } \\
\text { Hanford formation }\end{array}$ & Gravel and sand to boulders & SG1 & $\mathrm{Hg}$ & $\mathrm{HI}$ & $4 \mathrm{H}$ \\
\hline & & 175 & 390 & Water Table & NA & $\mathrm{NA}$ & $\mathrm{NA}$ & $\mathrm{NA}$ & $\mathrm{NA}$ \\
\hline
\end{tabular}

\begin{tabular}{|c|c|c|c|}
\hline \multicolumn{3}{|c|}{ STOMP Node Ranges } & $2001-4$ \\
\hline \# Nodes & $\begin{array}{l}\text { Node } \\
\text { Index } \\
\text { Start } \\
\end{array}$ & $\begin{array}{c}\text { Node } \\
\text { Index } \\
\text { End }\end{array}$ & \\
\hline 6 & 345 & 350 & $\operatorname{Hss}(4 \mathrm{H}), 1,1,1,1,345,350$ \\
\hline 344 & 1 & 344 & $\mathrm{Hg}(4 \mathrm{H}), 1,1,1,1,1,344$ \\
\hline
\end{tabular}

\begin{tabular}{|c|c|c|c|c|c|c|c|c|c|}
\hline & Template 216G-X for shallow disposal sites (e.g. Cribs) \\
\hline $\begin{array}{c}\text { Average } \\
\text { Thickness (ft) }\end{array}$ & $\begin{array}{c}\text { Adjusted } \\
\text { Average } \\
\text { Thickness } \\
(\mathrm{ft}) \dagger\end{array}$ & Depth (ft) & Elevation $(\mathrm{ft}$ ) & Geologic Unit & Description & $\begin{array}{c}\text { Hydraulic } \\
\text { Property } \\
\text { Type * } \\
\end{array}$ & $\begin{array}{c}\text { SAC Soil } \\
\text { Type }\end{array}$ & Kd Zone* & Kd Class \\
\hline & & 0 & 565 & Surface & NA & NA & NA & NA & NA \\
\hline 15 & 15 & 15 & 550 & Backfill & Backfill & B & B & $\mathrm{HI}$ & $4 \mathrm{H}$ \\
\hline 110 & 160 & 175 & 390 & $\begin{array}{l}\text { Undifferenciated } \\
\text { Hanford formation }\end{array}$ & Gravel and sand to boulders & SG1 & $\mathrm{Hg}$ & HI & $4 \mathrm{H}$ \\
\hline & & 175 & 390 & Water Table & NA & $\mathrm{NA}$ & $\mathrm{NA}$ & $\mathrm{NA}$ & $\mathrm{NA}$ \\
\hline
\end{tabular}

\begin{tabular}{|c|c|c|c|}
\hline \multicolumn{3}{|c|}{ STOMP Node Ranges } & $2166-4$ \\
\hline \# Nodes & $\begin{array}{c}\text { Node } \\
\text { Index } \\
\text { Start }\end{array}$ & $\begin{array}{c}\text { Node } \\
\text { Index } \\
\text { End }\end{array}$ & \\
\hline 30 & 32 & 350 & $\mathrm{~B}(4 \mathrm{H}), 1,1,1,1,321,350$, \\
\hline 320 & ( & $32 C$ & $\mathrm{Hg}(4 \mathrm{H}), 1,1,1,1,1,320$ \\
\hline
\end{tabular}

* After Khaleel and Freeman (1995), per white paper by Khaleel (September 2000)

** $\mathrm{HI}=$ high impact, II=Intermediate Impact (After Composite Analysis)

$\dagger$ Average thickness adjusted to normalize the average strata thicknesses to equal the total thickness of the vadose zone 


\section{VZ Base Templates $\mathrm{K}$}

\section{0-K Stratigraphic Columns}

Notes/Assumptions:

1) Surface elevation ranges from $515 \mathrm{ft} M S L$ in adjacent waste sites south of $\mathrm{K}$ Area to about $390 \mathrm{ft}$ MSL to the northwest along rivers edge (USGS Coyote Rapids 7.5 min. Quad Map).

Will assume an average elevation of $480 \mathrm{ft}$ MSL, except injection wells which have projected surface elevation of $465 \mathrm{ft}$ MSL.

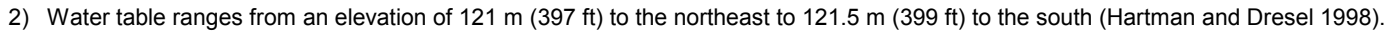
Will assume an average water-table elevation of $121.5 \mathrm{~m}(399 \mathrm{ft}) \mathrm{MSL}$.

3) A thin $(<1 \mathrm{~m})$ layer of eolian or fluvial sand or silt may cover the surface of the site where not disturbed (Lindberg 1995).

4) Two injection wells (116-KE-3 and 116-KE-2) extend $10 \mathrm{ft}$ into water table, and approximately $10 \mathrm{ft}$ of the perforated casings extend above

\begin{tabular}{|c|c|c|c|c|c|c|c|c|c|}
\hline Template $100 \mathrm{~K}-\mathrm{X}$ for & urface dispos & I sites (i.e & ponds and re & eactors) & & & & & $100 \mathrm{~K}-4$ \\
\hline $\begin{array}{c}\text { Average } \\
\text { Thickness (ft) }\end{array}$ & $\begin{array}{l}\text { Adjusted } \\
\text { Average } \\
\text { Thickness } \\
\text { (ft) } \dagger\end{array}$ & Depth (ft) & Elevation (ft) & Geologic Unit & Description & $\begin{array}{l}\text { Hydraulic } \\
\text { Property } \\
\text { Type * }^{*}\end{array}$ & $\begin{array}{l}\text { SAC Soil } \\
\text { Type }\end{array}$ & $\mathbf{K}_{\mathrm{d}}$ Zone $^{* *}$ & $\mathrm{~K}_{\mathrm{d}}$ Class \\
\hline & & 0 & 480 & Surface & NA & NA & NA & NA & NA \\
\hline & 30 & 30 & 450 & Hanford fm gravel & $\begin{array}{l}\text { Sandy gravel to silty sandy } \\
\text { gravel intercalated with gravelly } \\
\text { sand to sand (Lindberg 1995, } \\
\text { Peterson et. al. 1996) }\end{array}$ & SG1 & $\mathrm{Hg}$ & $\mathrm{HI}$ & $4 \mathrm{H}$ \\
\hline & 15 & 45 & 435 & & & SG1 & $\mathrm{Hg}$ & II & 412 \\
\hline & 36 & 81 & 399 & Ringold Unit E & $\begin{array}{l}\text { Fluvial sandy gravel to silty } \\
\text { sandy gravel (Lindberg 1995) }\end{array}$ & SG2 & $\mathrm{Rg}$ & II & 412 \\
\hline & & 81 & 399 & Water Table & NA & $\mathrm{NA}$ & $\mathrm{NA}$ & $\mathrm{NA}$ & NA \\
\hline
\end{tabular}

Template 116K-X for shallow disposal sites (e.g. cribs, trenches, burial grounds)

\begin{tabular}{|c|c|c|c|c|c|c|c|c|c|}
\hline $\begin{array}{c}\text { Average } \\
\text { Thickness (ft) }\end{array}$ & $\begin{array}{l}\text { Adjusted } \\
\text { Average } \\
\text { Thickness } \\
\text { (ft) } \dagger\end{array}$ & Depth (ft) & Elevation (ft) & Geologic Unit & Description & $\begin{array}{c}\text { Hydraulic } \\
\text { Property } \\
\text { Type * }\end{array}$ & $\begin{array}{l}\text { SAC Soil } \\
\text { Type }\end{array}$ & $\mathrm{K}_{\mathrm{d}}$ Zone $^{\star *}$ & $\mathrm{~K}_{\mathrm{d}}$ Class \\
\hline & & 0 & 480 & Surface & NA & NA & NA & NA & NA \\
\hline & 15 & 15 & 465 & Backfill & $\begin{array}{l}\text { Loose sandy gravel to silty } \\
\text { sandy gravel }\end{array}$ & B & B & $\mathrm{HI}$ & $4 \mathrm{H}$ \\
\hline & 30 & 45 & 435 & Hanford fm gravel & $\begin{array}{l}\text { Sandy gravel to silty sandy } \\
\text { gravel intercalated with gravelly } \\
\text { sand to sand (Lindberg 1995, } \\
\text { Peterson et. al. 1996) }\end{array}$ & SG1 & $\mathrm{Hg}$ & $\mathrm{HI}$ & $4 \mathrm{H}$ \\
\hline & 36 & 81 & 399 & Ringold Unit E & $\begin{array}{l}\text { Fluvial sandy gravel to silty } \\
\text { sandy gravel (Lindberg 1995) }\end{array}$ & SG2 & $\mathrm{Rg}$ & II & 412 \\
\hline & & 81 & 399 & Water Table & NA & NA & $\mathrm{NA}$ & NA & $\mathrm{NA}$ \\
\hline
\end{tabular}

\begin{tabular}{|c|c|c|c|c|c|c|c|c|c|}
\hline \multicolumn{9}{|c|}{ Template $166 \mathrm{~K}-\mathrm{X}$ for deep disposal sites (e.g. reverse wells) } & \multirow{2}{*}{$\begin{array}{c}166 \mathrm{~K}-4 \\
\mathrm{~K}_{\mathrm{d}} \text { Class }\end{array}$} \\
\hline $\begin{array}{c}\text { Average } \\
\text { Thickness (ft) } \\
\end{array}$ & $\begin{array}{c}\text { Adjusted } \\
\text { Average } \\
\text { Thickness } \\
\text { (ft) } \dagger \\
\end{array}$ & Depth (ft) & Elevation (ft) & Geologic Unit & Description & $\begin{array}{c}\text { Hydraulic } \\
\text { Property } \\
\text { Type * } \\
\end{array}$ & $\begin{array}{l}\text { SAC Soil } \\
\text { Type }\end{array}$ & $\mathrm{K}_{\mathrm{d}}$ Zone $^{* *}$ & \\
\hline & & 0 & 465 & Surface & NA & NA & NA & NA & NA \\
\hline & 20 & 20 & 445 & Backfill & \begin{tabular}{|l|} 
Loose sandy gravel to silty \\
sandy gravel
\end{tabular} & B & B & II & 412 \\
\hline & 20 & 40 & 425 & Hanford fm gravel & \begin{tabular}{|l|} 
Sandy gravel to silty sandy \\
gravel intercalated with gravelly \\
sand to sand (Lindberg 1995, \\
Peterson et. al. 1996)
\end{tabular} & SG1 & $\mathrm{Hg}$ & II & 412 \\
\hline & 16 & 56 & 409 & Ringold Unit E & $\begin{array}{l}\text { Fluvial sandy gravel to silty } \\
\text { sandy gravel (Lindberg 1995) }\end{array}$ & SG2 & $\mathrm{Rg}$ & II & 412 \\
\hline & 10 & 66 & 399 & & $\begin{array}{l}\text { Lowermost } 10 \text { feet of reverse } \\
\text { wells are open to the vadose } \\
\text { zone }\end{array}$ & SG2 & $\mathrm{Rg}$ & $\mathrm{HI}$ & $4 \mathrm{H}$ \\
\hline & & 66 & 399 & Water Table & NA & NA & $\overline{N A}$ & $\mathrm{NA}$ & $\mathrm{NA}$ \\
\hline
\end{tabular}

${ }^{*}$ After Khaleel and Freeman (1995), per white paper by Khaleel (September 2000)

${ }^{* *} \mathrm{HI}=$ high impact, II=Intermediate Impact (After Composite Analysis) BLUE = injection/release point

Red indicates changes based on e-mails from Cantrel to Last (12/19/01) and Freeman to Last (12/27/01)

$\dagger$ Average thickness adjusted to normalize the average strata thicknesses to equal the total thickness of the vadose zone. 


\section{VZ Base Templates $M$}

600 Area (M) Stratigraphic Columns (618-11)

Notes/Assumptions:

1) Assume an average elevation of $450 \mathrm{ft}$ (137.2 m) MSL. (USGS Topo - Richland, Wash, 15 min. Quad. 1951)

2) Assume an average water table elevation of $389 \mathrm{ft}(118.5 \mathrm{~m}) \mathrm{MSL}$. (Groundwater Monitoring Report, 2002, PNNL-14187).

3) Lithofacies taken from Well Logs (699-13-3A). In Hanford Well Log Library Sigma V.

\begin{tabular}{|c|c|c|c|c|c|c|c|c|c|}
\hline \multicolumn{9}{|c|}{ Template $600 \mathrm{M}-\mathrm{X}$ for surface disposal sites (e.g. Trenches, ponds, unplanned releases) } & \multirow[b]{2}{*}{$\begin{array}{l}600 \mathrm{M}-4 \\
\text { Kd Class }\end{array}$} \\
\hline $\begin{array}{c}\text { Average } \\
\text { Thickness } \\
\text { (ft) }\end{array}$ & $\begin{array}{l}\text { Adjusted } \\
\text { Average } \\
\text { Thickness } \\
\text { (ft) } \dagger\end{array}$ & Depth (ft) & Elevation (ft) & $\begin{array}{c}\text { Geologic } \\
\text { Unit }\end{array}$ & Description & $\begin{array}{c}\text { Hydraulic } \\
\text { Property } \\
\text { Type * }\end{array}$ & $\begin{array}{l}\text { SAC Soil } \\
\text { Type }\end{array}$ & Kd Zone $e^{* *}$ & \\
\hline & & 0 & 445 & Surface & NA & NA & NA & NA & $\overline{N A}$ \\
\hline & 6 & 6 & 439 & Hanford Hfs & Silty Silty Sand & $\mathrm{S}$ & Hcs & $\mathrm{HI}$ & $4 \mathrm{H}$ \\
\hline & 12 & 18 & 427 & Hanford $\mathrm{Hg}$ & Sandy Gravel & SG1 & $\mathrm{Hg}$ & II & 412 \\
\hline & 22 & 40 & 405 & Hanford Hgs & Gravelly Sand & GS & Hgs & II & $4 \mid 1$ \\
\hline & 10 & 50 & 395 & Hanford $\mathrm{Hg}$ & Gravel & SG1 & $\mathrm{Hg}$ & II & $4 \mid 2$ \\
\hline & 8 & 58 & 387 & Ringold Rg & $\begin{array}{l}\text { Gravelly Sand (Ringold } \\
\text { Formation) }\end{array}$ & SG2 & $\mathrm{Rg}$ & II & 412 \\
\hline & & 58 & 387 & Water Table & NA & $\mathrm{NA}$ & NA & NA & NA \\
\hline
\end{tabular}

\begin{tabular}{|c|c|c|c|c|c|c|c|c|c|}
\hline \multicolumn{9}{|c|}{ Template $616 \mathrm{M}-\mathrm{X}$ for shallow disposal (e.g. cribs, burial grounds) } & \multirow[b]{2}{*}{\begin{tabular}{|r|}
$616 \mathrm{M}-4$ \\
Kd Class \\
\end{tabular}} \\
\hline $\begin{array}{c}\text { Average } \\
\text { Thickness } \\
\text { (ft) }\end{array}$ & $\begin{array}{l}\text { Adjusted } \\
\text { Average } \\
\text { Thickness } \\
\text { (ft) } \dagger\end{array}$ & Depth (ft) & Elevation (ft) & $\begin{array}{c}\text { Geologic } \\
\text { Unit }\end{array}$ & Description & $\begin{array}{c}\text { Hydraulic } \\
\text { Property } \\
\text { Type * } \\
\end{array}$ & $\begin{array}{c}\text { SAC Soil } \\
\text { Type }\end{array}$ & Kd Zone ${ }^{\star *}$ & \\
\hline & & 0 & 380 & Surface & NA & NA & NA & NA & NA \\
\hline & $\overline{15}$ & 15 & 430 & Backfill & & $\mathrm{B}$ & $\mathrm{B}$ & $\mathrm{HI}$ & $4 \mathrm{H}$ \\
\hline & 3 & 18 & 427 & Hanford $\mathrm{Hg}$ & Sandy Gravel & SG1 & $\mathrm{Hg}$ & II & $4 \mid 2$ \\
\hline & 22 & 40 & 405 & Hanford Hgs & Gravelly Sand & GS & Hgs & II & $4 \mid 1$ \\
\hline & 10 & 50 & 395 & Hanford $\mathrm{Hg}$ & Gravel & SG1 & $\mathrm{Hg}$ & II & 412 \\
\hline & 8 & 58 & 387 & Ringold Rg & $\begin{array}{l}\text { Gravelly Sand (Ringold } \\
\text { Formation) }\end{array}$ & SG2 & $\mathrm{Rg}$ & II & $4 \mid 2$ \\
\hline & & 58 & 387 & Water Table & NA & $\mathrm{NA}$ & NA & NA & NA \\
\hline
\end{tabular}

* After Khaleel and Freeman (1995), per white paper by Khaleel (September 2000).

${ }^{* *} \mathrm{HI}=$ high impact, $\mathrm{II}=$ Intermediate Impact, (After Composite Analysis)

$\dagger$ Average thickness adjusted to normalize the average strata thicknesses to equal the total thickness of the vadose zone. 


\section{VZ Base Templates $N$}

\section{0-N Stratigraphic Columns}

Notes/Assumptions:

1) Surface elevation ranges from $460 \mathrm{ft} \mathrm{MSL}$ in the center of the $100-\mathrm{N}$ Area to about $390 \mathrm{ft}$ MSL along the rivers edge to the northwest (USGS Coyote Rapids $7.5 \mathrm{~min}$. Quad Map).

Will assume an average elevation of $455 \mathrm{ft} \mathrm{MSL}$

2) Water table ranges from an elevation of $119 \mathrm{~m}(390 \mathrm{ft})$ to the east to $120.5 \mathrm{~m}(395 \mathrm{ft})$ to the west (Hartman and Dresel 1998).

Will assume an average water table elevation of $119.5 \mathrm{~m}(392 \mathrm{ft}) \mathrm{MSL}$.

3) A thin $(\leq 1 \mathrm{~m})$ blanket of eolian or fluvial sand or silt may cover the surface of the site where not disturbed. Locally, backfill may also be present but it is not well documented in existing reports.

4) There are no reverse (injection wells) in the 100-N Aggregate Area.

Template $100 \mathrm{~N}-\mathrm{X}$ for surface disposal sites (i.e., ponds and reactor)

\begin{tabular}{|c|c|c|c|c|c|c|c|c|c|}
\hline $\begin{array}{c}\text { Average } \\
\text { Thickness } \\
\text { (ft) }\end{array}$ & $\begin{array}{c}\text { Adjusted } \\
\text { Average } \\
\text { Thickness } \\
\text { (ft) } \dagger\end{array}$ & Depth (ft) & $\begin{array}{l}\text { Elevation } \\
\text { (ft) }\end{array}$ & Geologic Unit & Description & $\begin{array}{c}\text { Hydraulic } \\
\text { Property } \\
\text { Type * }\end{array}$ & $\begin{array}{l}\text { SAC Soil } \\
\text { Type }\end{array}$ & Kd Zone** & Kd Class \\
\hline & & 0 & 455 & Surface & NA & NA & NA & NA & NA \\
\hline & 30 & 30 & 425 & Hanford fm gravel & $\begin{array}{l}\text { Glaciofluvial sandy pebble to boulder } \\
\text { gravel (Hartman and Lindsey 1993) }\end{array}$ & SG1 & $\mathrm{Hg}$ & $\mathrm{HI}$ & $4 \mathrm{H}$ \\
\hline & 10 & 40 & 415 & & & SG1 & $\mathrm{Hg}$ & II & $4 \mid 2$ \\
\hline & 23 & 63 & 392 & Ringold Unit E & $\begin{array}{l}\text { Fluvial, sandy pebble to cobble gravel } \\
\text { (Hartman and Lindsey 1993) }\end{array}$ & SG2 & $\mathrm{Rg}$ & II & $4 \mid 2$ \\
\hline & & 63 & 392 & Water Table & $\mathrm{N}$ & NA & NA & NA & $\overline{N A}$ \\
\hline
\end{tabular}

Template 116N-X for shallow disposal sites (e.g. cribs and trenches)

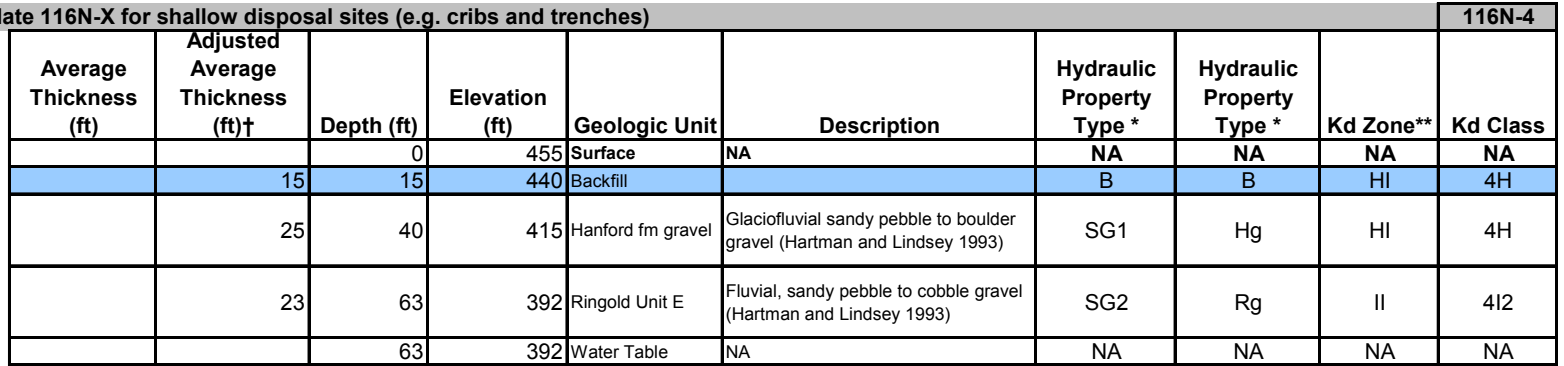

* After Khaleel and Freeman (1995), per white paper by Khaleel (September 2000)

${ }^{* *} \mathrm{HI}=$ high impact, II=Intermediate Impact (After Composite Analysis)

BLUE = injection/release point

$\dagger$ Average thickness adjusted to normalize the average strata thicknesses to equal the total thickness of the vadose zone. 


\section{VZ Base Templates $P$}

\section{Area (P) Stratigraphic Columns (316-4, 618-10)}

Notes/Assumptions:

1) Assume an average elevation of $440 \mathrm{ft}$ (134.1 m) MSL. (USGS Topo - Richland, Wash, $15 \mathrm{~min}$. Quad. 1951)

2) Assume an average water table elevation of $375.7 \mathrm{ft}(114.5 \mathrm{~m}) \mathrm{MSL}$. (Groundwater Monitoring Report, 2002, PNNL-14187).

3) Lithofacies taken from Well Logs (699-S6-E4A). In Hanford Well Log Library Sigma V.

\begin{tabular}{|c|c|c|c|c|c|c|c|c|c|}
\hline Template $600 \mathrm{P}-\mathrm{X}$ for $\mathrm{s}$ & Arface dispose & I sites (e.g. & Trenches, po & nds, unplanned & d releases) & & & & $600 \mathrm{P}-4$ \\
\hline \begin{tabular}{|c|} 
Average \\
Thickness (ft) \\
\end{tabular} & $\begin{array}{c}\text { Adjusted } \\
\text { Average } \\
\text { Thickness } \\
\text { (ft) } \dagger \\
\end{array}$ & Depth (ft) & Elevation $(\mathrm{ft})$ & Geologic Unit & Description & $\begin{array}{c}\text { Hydraulic } \\
\text { Property } \\
\text { Type * } \\
\end{array}$ & $\begin{array}{c}\text { SAC Soil } \\
\text { Type }\end{array}$ & Kd Zone ${ }^{\star *}$ & Kd Class \\
\hline & & 0 & 445 & Surface & NA & NA & NA & NA & NA \\
\hline & 35 & 35 & 410 & Hanford Hcs & Grey to Black Basaltic Sand & $\mathrm{S}$ & $\mathrm{Hcs}$ & $\mathrm{HI}$ & $4 \mathrm{H}$ \\
\hline & 35 & 70 & 375 & Hanford $\mathrm{Hg}$ & $\begin{array}{l}\text { Gravel with sand and small } \\
\text { amount of clay }\end{array}$ & SG1 & $\mathrm{Hg}$ & II & $4 \mid 2$ \\
\hline & & 70 & 375 & Water Table & NA & NA & NA & NA & NA \\
\hline
\end{tabular}

\begin{tabular}{|c|c|c|c|c|c|c|c|c|c|}
\hline \multicolumn{9}{|c|}{ Template 616P-X for shallow disposal (e.g. cribs, burial grounds) } & \multirow[b]{2}{*}{\begin{tabular}{|c|}
$616 \mathrm{P}-4$ \\
Kd Class \\
\end{tabular}} \\
\hline $\begin{array}{c}\text { Average } \\
\text { Thickness (ft) }\end{array}$ & $\begin{array}{c}\text { Adjusted } \\
\text { Average } \\
\text { Thickness } \\
\text { (ft) } \dagger\end{array}$ & Depth (ft) & Elevation (ft) & Geologic Unit & Description & $\begin{array}{c}\text { Hydraulic } \\
\text { Property } \\
\text { Type * }\end{array}$ & $\begin{array}{l}\text { SAC Soil } \\
\text { Type }\end{array}$ & Kd Zone ${ }^{* *}$ & \\
\hline & & 0 & 380 & Surface & NA & NA & NA & NA & NA \\
\hline & 15 & 15 & 430 & Backfill & & $\mathrm{B}$ & $\mathrm{B}$ & $\mathrm{HI}$ & $4 \mathrm{H}$ \\
\hline & 20 & 35 & 410 & Hanford Hcs & Grey to Black Basaltic Sand & $S$ & Hcs & $\mathrm{HI}$ & $4 \mathrm{H}$ \\
\hline & 35 & 70 & 375 & Hanford $\mathrm{Hg}$ & $\begin{array}{l}\text { Gravel with sand and small } \\
\text { amount of clay }\end{array}$ & SG1 & $\mathrm{Hg}$ & II & $4 \mid 2$ \\
\hline & & 70 & 375 & Water Table & NA & $\mathrm{NA}$ & NA & $\mathrm{NA}$ & $\mathrm{NA}$ \\
\hline
\end{tabular}

* After Khaleel and Freeman (1995), per white paper by Khaleel (September 2000).

** $\mathrm{HI}=$ high impact, II = Intermediate Impact, (After Composite Analysis)

$\dagger$ Average thickness adjusted to normalize the average strata thicknesses to equal the total thickness of the vadose zone. 


\section{VZ Base Templates Q}

\section{Area (Q) Stratigraphic Columns}

Notes/Assumptions:

1) Assume an average elevation of $540 \mathrm{ft}$ (164.6m) MSL. (USGS Topo - Richland, Wash, 15 min. Quad. 1951)

2) Assume an average water table elevation of $392 \mathrm{ft}$ (119.5m) MSL. (Groundwater Monitoring Report, 2001, PNNL-13788).

3) Lithofacies taken from Summary Report, FFTF Well No. 4 (499-S1-8J) in Project Inspection Log Book Project V-749, Meier Associates, Inc. and well logs for 499-S1-7B. In Hanford Well Log Library Sigma V.

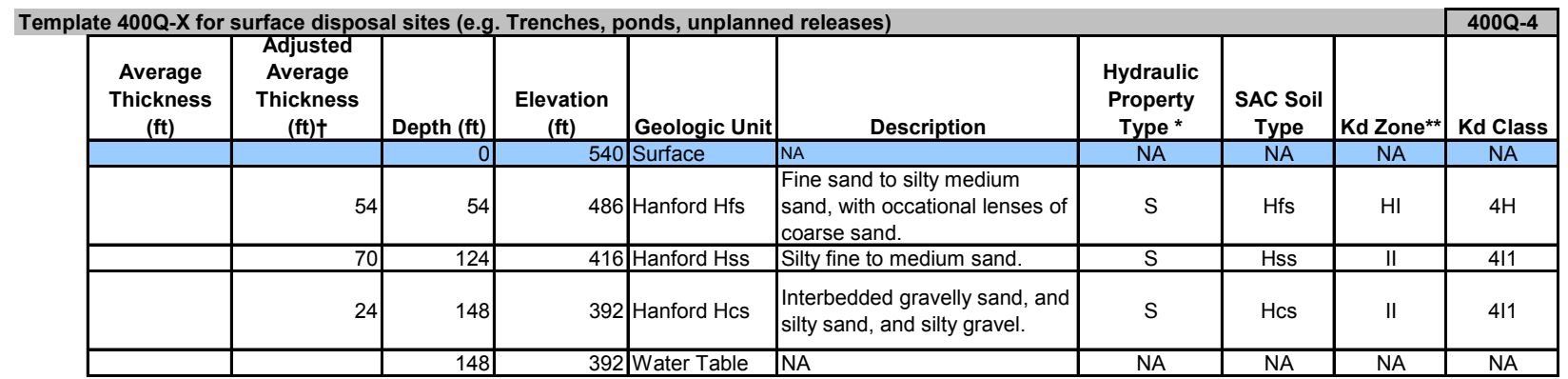

\begin{tabular}{|c|c|c|c|c|c|c|c|c|c|}
\hline \multicolumn{9}{|c|}{ Template 416Q-X for shallow disposal (e.g. cribs, burial grounds) } & \multirow{2}{*}{$\begin{array}{r}\text { 416Q-4 } \\
\text { Kd Class }\end{array}$} \\
\hline $\begin{array}{c}\text { Average } \\
\text { Thickness } \\
\text { (ft) }\end{array}$ & $\begin{array}{l}\text { Adjusted } \\
\text { Average } \\
\text { Thickness } \\
\text { (ft) } \dagger\end{array}$ & Depth (ft) & $\begin{array}{c}\text { Elevation } \\
\text { (ft) }\end{array}$ & Geologic Unit & Description & $\begin{array}{l}\text { Hydraulic } \\
\text { Property } \\
\text { Type * }\end{array}$ & $\begin{array}{c}\text { SAC Soil } \\
\text { Type }\end{array}$ & Kd Zone ${ }^{\star *}$ & \\
\hline & & 0 & 380 & Surface & NA & NA & NA & NA & NA \\
\hline & 15 & 15 & 525 & Backfill & & $\mathrm{B}$ & $\mathrm{B}$ & $\mathrm{HI}$ & $4 \mathrm{H}$ \\
\hline & 39 & 54 & 486 & Hanford Hfs & $\begin{array}{l}\text { Fine sand to silty medium } \\
\text { sand, with occational lenses of } \\
\text { coarse sand. }\end{array}$ & $S$ & $\mathrm{Hfs}$ & $\mathrm{HI}$ & $4 \mathrm{H}$ \\
\hline & 70 & 124 & 416 & Hanford Hss & Silty fine to medium sand. & $\mathrm{S}$ & Hss & II & $4 \mathrm{II}$ \\
\hline & 24 & 148 & 392 & Hanford Hcs & $\begin{array}{l}\text { Interbedded gravelly sand, and } \\
\text { silty sand, and silty gravel. }\end{array}$ & $S$ & Hcs & II & $4 \mid 1$ \\
\hline & & 148 & 392 & Water Table & NA & NA & $\mathrm{NA}$ & NA & NA \\
\hline
\end{tabular}

* After Khaleel and Freeman (1995), per white paper by Khaleel (September 2000).

${ }^{* *} \mathrm{HI}=$ high impact, II = Intermediate Impact, (After Composite Analysis)

† Average thickness adjusted to normalize the average strata thicknesses to equal the total thickness of the vadose zone. 


\section{VZ Base Templates $\mathbf{R}$}

\section{Area (R) Stratigraphic Columns}

Notes/Assumptions:

1) Assume an average elevation of $380 \mathrm{ft}(115.8 \mathrm{~m}) \mathrm{MSL}$. (Schalla et. al, 1988)

2) Assume an average water table elevation of $347 \mathrm{ft}(106 \mathrm{~m}) \mathrm{MSL}$. (Groundwater Monitoring Report, 1999).

Waterlevels flucutate daily, weekly and seasonally up to a meter depending on postion relative to the river Water levels have been increasing recently due to irrigation west of 300 Area

3) Lithofacies after Lindsey, 89, 91 and Gaylord Lindsey, 90; Lithofacies are highly varible in thickness and extent because of the fluvial nature of depostion

Template 300R-X for surface disposal sites (e.g. Trenches, ponds, unplanned releases)

\begin{tabular}{|c|c|c|c|c|c|c|c|c|c|}
\hline $\begin{array}{c}\text { Average } \\
\text { Thickness (ft) }\end{array}$ & $\begin{array}{c}\text { Adjusted } \\
\text { Average } \\
\text { Thickness } \\
\text { (ft) } \dagger\end{array}$ & Depth (ft) & Elevation $(\mathrm{ft})$ & Geologic Unit & Description & $\begin{array}{l}\text { Hydraulic } \\
\text { Property } \\
\text { Type* }\end{array}$ & $\begin{array}{c}\text { SAC Soil } \\
\text { Type }\end{array}$ & Kd Zone ${ }^{\star *}$ & Kd Class \\
\hline & & 0 & 380 & Surface & NA & NA & NA & NA & NA \\
\hline 2 & 2 & 2 & 378 & Eolian & $\begin{array}{l}\text { Sand and silt (absent for trenches and } \\
\text { ponds) }\end{array}$ & $S$ & Hss & $\mathrm{HI}$ & $4 \mathrm{H}$ \\
\hline 37 & 37 & 39 & 341 & Hanford $\mathrm{Hg}$ & $\begin{array}{l}\text { Gravel (Cobble/boulder to } \\
\text { gravel/pebble lithofacies after Lindsey, } \\
89,91 \text { and Gaylord Lindsey, 90) }\end{array}$ & SG1 & $\mathrm{Hg}$ & $\mathrm{HI}$ & $4 \mathrm{H}$ \\
\hline 71 & 71 & 110 & 270 & Ringold Rg & $\begin{array}{l}\text { Fluvial gravel lithofacies; sandy } \\
\text { granule- to pebble-sized gravel }\end{array}$ & SG2 & $\mathrm{Rg}$ & II & $4 \mid 2$ \\
\hline 61 & 61 & 171 & 209 & Ringold Rm & $\begin{array}{l}\text { massive to laminated silt; sand } \\
\text { comprises up to } 10 \%\end{array}$ & SS & PPIz & II & 412 \\
\hline 70 & & 171 & 209 & Water Table & NA & NA & NA & $\mathrm{NA}$ & $\mathrm{NA}$ \\
\hline
\end{tabular}

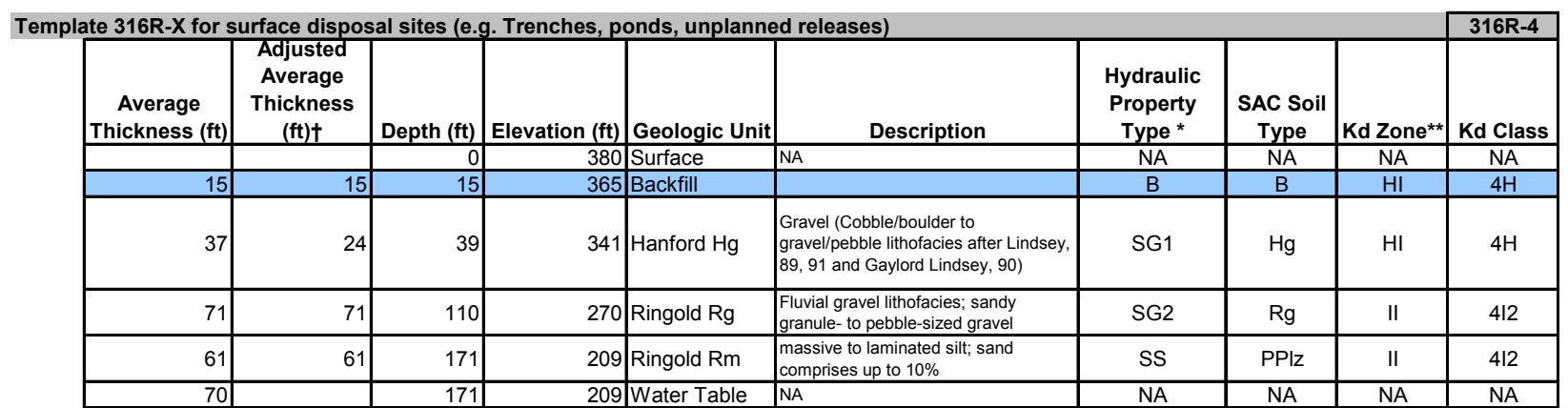

† Average thickness adjusted to normalize the average strata thicknesses to equal the total thickness of the vadose zone. 
VZ Base Templates S

South 200 West Area (S, U [except U-1\&2], Z Areas [except 216-Z-9]and ERDF) Stratigraphic Columns

Notes/Assumptions:

1) Topography ranges from $730 \mathrm{ft}$ MSL east of ERDF to $625 \mathrm{ft}$ MSL southwest of the S-16 Pond (USGS Gable Butte and Riverland 7.5 min. Quad Maps).

Will assume an average elevation of $680 \mathrm{ft} \mathrm{MSL}$.

2) The pre-Hanford Water Table (January 1944) is estimated to range from an elevation of $122 \mathrm{~m}$ (400 ft) east of ERDF to $127 \mathrm{~m}$ (417 ft) west of the S-16 Pond (DOE-EIS-0113, page 4.21).

Will assume an average water table elevation of $124 \mathrm{~m}(407 \mathrm{ft}) \mathrm{MSL}$

3) A thin blanket of eolian sand and silt covers the surface of the site where not disturbed.

However, this material was generally removed during excavation and construction of the waste disposal sites and then incorporated into backfill materials.

The depth of the sites and thus, the backfull over these sites range from 0-2.6 $\mathrm{m}$ for ponds and unplanned releases, to an average of about 4.5 to

$5.7 \mathrm{~m}$ for cribs and burial grounds, and 13.7 to $16.4 \mathrm{~m}$ for tanks.

4) Only two reverse wells are located in this area ranging in depth from $23-46 \mathrm{~m}$.

5) Injection well $216-Z-10$ is screened from $118-150 \mathrm{ft}$. 216-U-4 is screened from $50-75 \mathrm{ft}$.

\begin{tabular}{|c|c|c|c|c|c|c|c|c|c|c|c|c|}
\hline \multicolumn{9}{|c|}{ Template 200S-X for surface disposal sites (e.g. Ponds) } & $200 \mathrm{~S}-1$ & $200 \mathrm{~S}-2$ & $200 \mathrm{~S}-3$ & $200 \mathrm{~S}-4$ \\
\hline $\begin{array}{c}\text { Average } \\
\text { Thickness } \\
\text { (ft) }\end{array}$ & $\begin{array}{c}\text { Adjusted } \\
\text { Average } \\
\text { Thickness } \\
\text { (ft) } \dagger\end{array}$ & Depth (ft) & Elevation $(\mathrm{ft})$ & Geologic Unit & Description & $\begin{array}{c}\text { Hydraulic } \\
\text { Property } \\
\text { Type * }\end{array}$ & $\begin{array}{l}\text { SAC Soil } \\
\text { Type }\end{array}$ & $\mathrm{K}_{\mathrm{d}}$ Zone $^{* *}$ & $K_{d}$ Class & $K_{d}$ Class & $K_{d}$ Class & $K_{d}$ Class \\
\hline & & 0 & 680 & Surface & NA & NA & NA & NA & NA & NA & NA & NA \\
\hline 2.5 & 5 & 5 & 675 & Eolian & Sand and silt & $\mathrm{s}$ & Hss & $\mathrm{HI}$ & $1 \mathrm{H}$ & $2 \mathrm{H}$ & $3 \mathrm{H}$ & $4 \mathrm{H}$ \\
\hline 60 & 65 & 70 & 610 & Hanford Gravel & $\begin{array}{l}\text { Pebbly very coarse to medium sand to } \\
\text { silty sandy medium to fine pebble }\end{array}$ & SG1 & $\mathrm{Hg}_{2} 2 \mathrm{~W}$ & II & $1 / 2$ & 212 & 312 & $4 \mid 2$ \\
\hline 30 & 30 & 100 & 580 & Hanford Sand & Slightly silty coarse to very fine sand & $\mathrm{s}$ & $\mathrm{Hfs} 2 \mathrm{~W}$ & ॥ & 111 & $2 \mid 1$ & $3 / 1$ & $4 \mid 1$ \\
\hline 30 & 30 & 130 & 550 & Hanford Silty Sand & \begin{tabular}{|l|} 
Slightly sitty medium to very fine sand \\
to silty medium to very fine sand
\end{tabular} & $\mathrm{s}$ & Hss_2W & II & $1 / 1$ & 211 & $3 / 1$ & $4 \mid 1$ \\
\hline 15 & 20 & 150 & 530 & \begin{tabular}{|l|} 
Ild Hanford/Plio- \\
pleistocene ("Early \\
Palouse")
\end{tabular} & Silty fine to very fine sand & SS & PPlz & II & $1 / 1$ & 211 & 311 & $4 \mid 1$ \\
\hline 20 & 20 & 170 & 510 & $\begin{array}{l}\text { Plio-Pleistocene } \\
\text { Caliche }\end{array}$ & $\begin{array}{l}\text { Pebbly silty coarse to very fine sand to } \\
\text { silty medium to very fine sand }\end{array}$ & SS & PPIc & II & 111 & $2 \mid 1$ & 311 & $4 \mid 1$ \\
\hline & 102 & 272 & 408 & Ringold (Unit E) & $\begin{array}{l}\text { Silty Sandy Medium to fine pebble to } \\
\text { sandy very coarse to fine pebble (semi } \\
\text { indurated) }\end{array}$ & SG2 & $\operatorname{Rg} 2 \mathrm{~W}$ & II & 112 & 212 & 312 & $4 \mathrm{I} 2$ \\
\hline & & 273 & 407 & Water Table & NA & $\mathrm{NA}$ & $\mathrm{NA}$ & $\mathrm{NA}$ & & $\mathrm{NA}$ & $\mathrm{NA}$ & $\mathrm{NA}$ \\
\hline
\end{tabular}

\begin{tabular}{|c|c|c|c|c|c|c|c|c|c|c|c|c|}
\hline \multicolumn{9}{|c|}{ Template 216S-X for shallow disposal sites (e.g. Cribs, Burial Grounds) } & \multirow[b]{2}{*}{$\begin{array}{l}216 \mathrm{~S}-1 \\
\mathrm{~K} \\
\mathrm{~K}_{\mathrm{d}} \text { Class }\end{array}$} & \multirow{2}{*}{\begin{tabular}{|c|}
$216 \mathrm{~S}-2$ \\
$K_{d}$ Class
\end{tabular}} & \multirow[b]{2}{*}{$\begin{array}{l}216 \mathrm{~S}-3 \\
\mathrm{~K}_{\mathrm{d}} \text { Class }\end{array}$} & \multirow{2}{*}{$\begin{array}{l}216 \mathrm{~S}-4 \\
K_{d} \text { Class }\end{array}$} \\
\hline $\begin{array}{c}\text { Average } \\
\text { Thickness } \\
(\mathrm{ft})\end{array}$ & $\begin{array}{c}\text { Adjusted } \\
\text { Average } \\
\text { Thickness } \\
(\mathrm{ft}) \dagger\end{array}$ & Depth (ft) & Elevation (ft) & Geologic Unit & Description & $\begin{array}{c}\text { Hydraulic } \\
\text { Property } \\
\text { Type * }\end{array}$ & $\begin{array}{l}\text { SAC Soil } \\
\text { Type }\end{array}$ & $\mathrm{K}_{\mathrm{d}}$ Zone $^{\star *}$ & & & & \\
\hline & & 0 & 680 & Surface & NA & $\mathrm{NA}$ & $\mathrm{NA}$ & NA & NA & $\mathrm{NA}$ & $\mathrm{NA}$ & $\mathrm{NA}$ \\
\hline 15 & 15 & 15 & 665 & Backfill & Backfill & $\mathrm{B}$ & $\mathrm{B}$ & II & 112 & 212 & 312 & 412 \\
\hline 60 & 65 & 70 & 610 & Hanford Gravel & $\begin{array}{l}\begin{array}{l}\text { Pebbly very coarse to medium sand to } \\
\text { silty sandy medium to fine pebble }\end{array} \\
\end{array}$ & SG1 & $\mathrm{Hg}_{2} 2 \mathrm{~W}$ & $\mathrm{HI}$ & $1 \mathrm{H}$ & $2 \mathrm{H}$ & $3 \mathrm{H}$ & $4 \mathrm{H}$ \\
\hline 30 & 30 & 100 & 580 & Hanford Sand & Slightly silty coarse to very fine sand & $\mathrm{s}$ & $\mathrm{Hfs} 2 \mathrm{~W}$ & ॥ & $1 / 1$ & 211 & 311 & $4 \mid 1$ \\
\hline 30 & 30 & 130 & 550 & Hanford Silty Sand & $\begin{array}{l}\text { Slightly silty medium to very fine sand } \\
\text { to silty medium to very fine sand }\end{array}$ & $\mathrm{s}$ & Hss $2 \mathrm{~W}$ & II & 111 & 211 & 311 & $4 \mid 1$ \\
\hline 15 & 20 & 150 & 530 & \begin{tabular}{|l}
$\begin{array}{l}\text { Old Hanford/Plio- } \\
\text { pleistocene ("Early } \\
\text { Palouse") }\end{array}$ \\
\end{tabular} & Silty fine to very fine sand & SS & $\mathrm{PPlz}$ & II & $1 / 1$ & $2 \mid 1$ & 311 & $4 \mid 1$ \\
\hline 20 & 20 & 170 & 510 & $\begin{array}{l}\text { Plio-Pleistocene } \\
\text { Caliche }\end{array}$ & $\begin{array}{l}\text { Pebbly sitty coarse to very fine sand to } \\
\text { sitty medium to very fine sand }\end{array}$ & SS & PPIc & II & $1 / 1$ & $2 \mid 1$ & 311 & $4 \mid 1$ \\
\hline & 102 & 272 & 408 & Ringold (Unit E) & $\begin{array}{l}\text { Silty Sandy Medium to fine pebble to } \\
\text { sandy very coarse to fine pebble (semi } \\
\text { indurated) }\end{array}$ & SG2 & Rg_2W & II & 112 & 212 & 312 & 412 \\
\hline & & 273 & 407 & Water Table & NA & $\mathrm{NA}$ & NA & NA & NA & NA & NA & NA \\
\hline
\end{tabular}




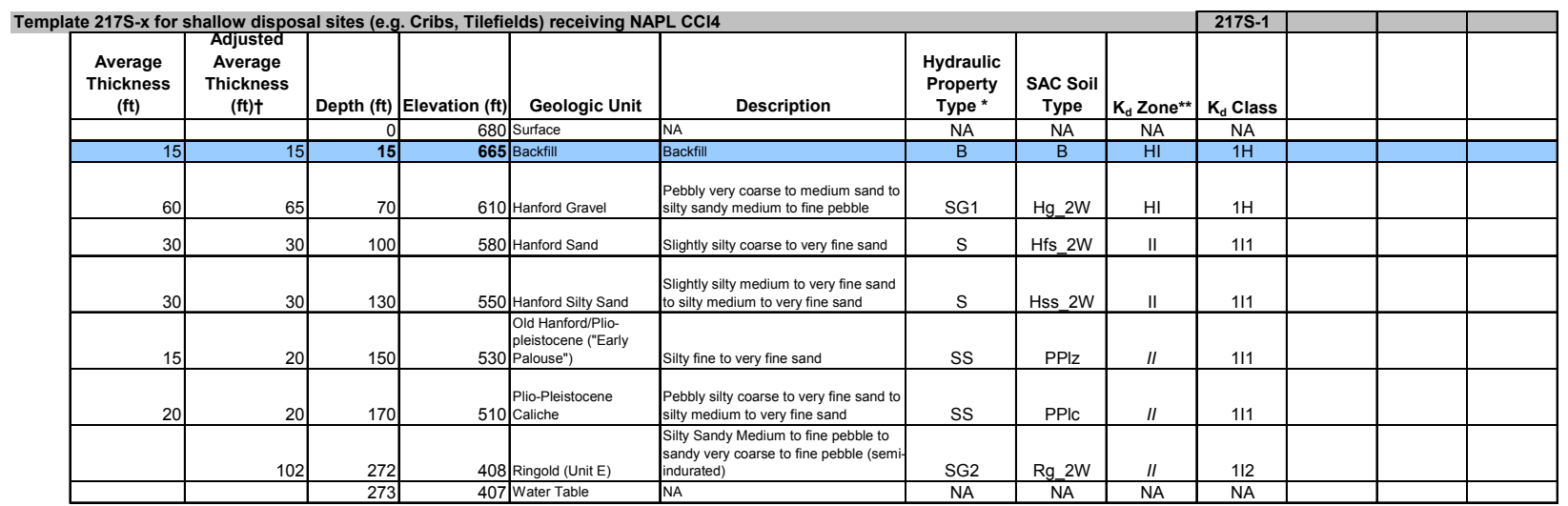

\begin{tabular}{|c|c|c|c|c|c|c|c|c|c|c|c|}
\hline \multicolumn{7}{|c|}{ Template 241S-X for intermediate depth disposal sites (e.g. high-level waste tanks) } & \multirow{2}{*}{\multicolumn{2}{|c|}{\begin{tabular}{c|c|}
$\begin{array}{c}\text { SAC Soil } \\
\text { Type }\end{array}$ & $K_{d} Z_{\text {Zone }}^{* *}$
\end{tabular}}} & \multirow{2}{*}{$\begin{array}{l}241 \mathrm{~S}-2 \\
\mathrm{~K}_{\mathrm{d}} \text { Class }\end{array}$} & \multirow{2}{*}{$\begin{array}{l}241 \mathrm{~S}-3 \\
\mathrm{~K}_{\mathrm{d}} \text { Class }\end{array}$} & \multirow{2}{*}{$\begin{array}{l}241 \mathrm{~S}-4 \\
\mathrm{~K}_{\mathrm{d}} \text { Class }\end{array}$} \\
\hline $\begin{array}{c}\text { Average } \\
\text { Thickness } \\
\text { (ft) }\end{array}$ & $\begin{array}{c}\text { Adjusted } \\
\text { Average } \\
\text { Thickness } \\
\text { (ft) } \dagger\end{array}$ & Depth (ft) & Elevation (ft) & Geologic Unit & Description & $\begin{array}{c}\text { Hydraulic } \\
\text { Property } \\
\text { Type * }\end{array}$ & & & & & \\
\hline & & 0 & 680 & Surface & NA & NA & $\mathrm{NA}$ & $\mathrm{NA}$ & NA & NA & NA \\
\hline 50 & 50 & 50 & 630 & Backfill & Backfill & $B$ & $\mathrm{~B}$ & $\mathrm{HI}$ & $2 \mathrm{H}$ & $3 \mathrm{H}$ & $4 \mathrm{H}$ \\
\hline 60 & 65 & 70 & 610 & Hanford Gravel & $\begin{array}{l}\text { Pebbly very coarse to medium sand to } \\
\text { sitty sandy medium to fine pebble }\end{array}$ & SG1 & Hg_2W & $\mathrm{HI}$ & $2 \mathrm{H}$ & $3 \mathrm{H}$ & $4 \mathrm{H}$ \\
\hline 30 & 30 & 100 & 580 & Hanford Sand & Slightly silty coarse to very fine sand & s & Hfs_2W & II & $2 \mathrm{l} 1$ & 311 & $4 \mid 1$ \\
\hline 30 & 30 & 130 & 550 & Hanford Silty Sand & \begin{tabular}{|l|} 
Slightly sitty medium to very fine sand \\
to silty medium to very fine sand
\end{tabular} & $\mathrm{s}$ & Hss 2W & II & 211 & 311 & $4 \mid 1$ \\
\hline 15 & 20 & 150 & 530 & \begin{tabular}{|l}
$\begin{array}{l}\text { Old Hanford/Plio- } \\
\text { pleistocene ("Early } \\
\text { Palouse") }\end{array}$ \\
\end{tabular} & Silty fine to very fine sand & SS & PPlz & II & 211 & 311 & $4 \mid 1$ \\
\hline 20 & 20 & 170 & 510 & $\begin{array}{l}\begin{array}{l}\text { Plio-Pleistocene } \\
\text { Caliche }\end{array} \\
\end{array}$ & $\begin{array}{l}\text { Pebbly silty coarse to very fine sand to } \\
\text { silty medium to very fine sand }\end{array}$ & SS & PPlc & II & 211 & 311 & $4 \mid 1$ \\
\hline & 102 & 272 & 408 & Ringold (Unit E) & \begin{tabular}{|l|}
$\begin{array}{l}\text { Silty Sandy Medium to fine pebble to } \\
\text { sandy very coarse to fine pebble (semi- } \\
\text { indurated) }\end{array}$ \\
\end{tabular} & SG2 & Rg_2W & II & 212 & 312 & $4 \mathrm{I} 2$ \\
\hline & & 273 & 407 & Water Table & NA & $\mathrm{NA}$ & NA & & NA & $\mathrm{NA}$ & NA \\
\hline
\end{tabular}

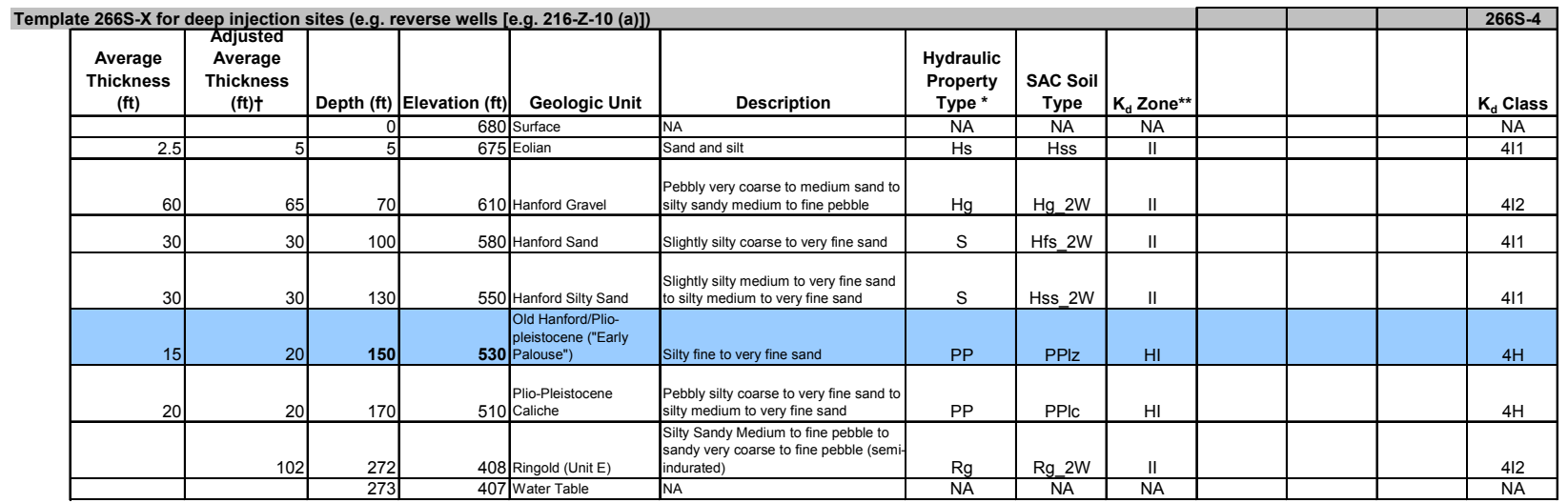

* After Khaleel and Freeman (1995), per white paper by Khaleel (September 2000)

** $\mathrm{HI}=$ high impact, II=Intermediate Impact (After Composite Analysis)

WE Nichols $(04 / 16 / 02)$

t Average thickness adjusted to normalize the average strata thicknesses to equal the total thickness of the vadose zone. 


\section{VZ Base Templates - U Cribs}

\section{U Cribs (216-U-1, -2 and -16)}

Notes/Assumptions:

1) Surface elevation ranges from $211.0 \mathrm{~m}(692.3 \mathrm{ft})$ near $216-\mathrm{U}-16$ to $212.5 \mathrm{~m}(697.2 \mathrm{ft}) \mathrm{MSL}$ near the $216-\mathrm{U}-1$ and -2 Cribs (as taken from the Hanford Site Atlas).

2) Ground surface and water-table elevations from PNNL HYDRODAT database.

3) The pre-Hanford Water Table (January 1944) is estimated to have been at an elevation of 405 MSL (based on Kipp and Mud, 1974 - BNWL-B-360).

4) The site depth to bottom of the 216-U-1 and -2 Cribs is reported to be $24 \mathrm{ft}-\mathrm{min}$. (7.3 m) based on Maxfield, 1979 - RHO-CD-673. No bottom is reported for the $216-\mathrm{U}-16$ Crib. Thus, the backfill is assumed to be 24 deep for all three cribs.

Template 216S_U_N-x for the area N-NE of the 216-U-1\&2 Cribs, based on well 299-W19-16 (N 135029.21, E $567270.68)$ located $24 \mathrm{~m}(80 \mathrm{ft})$ north of $216-\mathrm{U}-1$ Crib.

\begin{tabular}{|c|c|c|c|c|c|c|c|c|}
\hline $\begin{array}{c}\text { Estimated } \\
\text { Thickness } \\
(\mathrm{ft})^{\star \star *}\end{array}$ & $\begin{array}{c}\text { Adjusted } \\
\text { Thickness } \\
\text { (ft)† }\end{array}$ & $\begin{array}{c}\text { Bottom } \\
\text { Depth (ft) }\end{array}$ & $\begin{array}{c}\text { Bottom } \\
\text { Elevation } \\
\text { (ft) }\end{array}$ & Geologic Unit & Description & $\begin{array}{c}\text { Hydraulic } \\
\text { Property } \\
\text { Type * }\end{array}$ & $\begin{array}{c}\text { SAC Soil } \\
\text { Type }\end{array}$ & Kd Class \\
\hline & & 0 & 695.157 & Surface & NA & NA & NA & NA \\
\hline 24 & 24 & 24 & 671 & Backfill & Backfill & $\mathrm{B}$ & $B$ & $4 \mathrm{H}$ \\
\hline 67 & 67 & 91 & 604 & Hanford H1 & $\begin{array}{l}\text { Interbedded layers of fine to } \\
\text { coarse sand and sandy gravel }\end{array}$ & S & Hcs_2W & $4 \mathrm{H}$ \\
\hline 55 & 55 & 146 & 549 & Hanford H2 & $\begin{array}{l}\text { Interbedded layers of silty to } \\
\text { fine, medium, and coarse sand }\end{array}$ & $S$ & Hfs_U & $4 \mid 1$ \\
\hline 19 & 19 & 165 & 530 & CCU-upper & Silt and fine sand & SS & PPIz U & $4 I 1$ \\
\hline 2 & 2 & 167 & 528 & CCU-lower & $\begin{array}{l}\text { Calcium-carbonate cemented } \\
\text { sand, silt and clay (caliche) }\end{array}$ & SS & PPlc & $4 \mid 1$ \\
\hline 83 & 83 & 250 & 445 & Ringold Unit E & Sandy gravel & $\overline{S G 2}$ & $\overline{R g \_U}$ & $4 \mid 2$ \\
\hline & & 250.59 & 444.57 & Water Table & NA & & & NA \\
\hline
\end{tabular}

\begin{tabular}{|c|c|c|c|c|c|c|c|c|}
\hline \multicolumn{8}{|c|}{$\begin{array}{l}\text { Template 216S_U_C-x for the central area between } 216-\mathrm{U}-1 / 2 \text { Cribs and } 216-\mathrm{U}-16 \text { Crib based on well 299-W19-15 (N } \\
134975.78, E 567254.25) \text {, located about } 26 \mathrm{~m}(85 \mathrm{ft}) \text { south of } 216-\mathrm{U}-1 / 2 \text { Cribs and } 56 \mathrm{~m} \text { (185 ft) north of 216-U-16 Crib. }\end{array}$} & 216S_U_C-4 \\
\hline $\begin{array}{c}\text { Estimated } \\
\text { Thickness } \\
(\mathrm{ft})^{\star * *} \\
\end{array}$ & $\begin{array}{c}\text { Adjusted } \\
\text { Thickness } \\
\text { (ft)† } \\
\end{array}$ & $\begin{array}{c}\text { Bottom } \\
\text { Depth (ft) }\end{array}$ & $\begin{array}{c}\text { Bottom } \\
\text { Elevation } \\
(\mathrm{ft})\end{array}$ & Geologic Unit & Description & $\begin{array}{c}\text { Hydraulic } \\
\text { Property } \\
\text { Type * } \\
\end{array}$ & $\begin{array}{l}\text { SAC Soil } \\
\text { Type }\end{array}$ & Kd Class \\
\hline & & 0 & 693.501 & Surface & NA & NA & NA & NA \\
\hline 105 & 105 & 105 & 589 & Hanford $\mathrm{H} 1$ & $\begin{array}{l}\text { Interbedded layers of fine to } \\
\text { coarse sand and sandy gravel }\end{array}$ & NA & Hcs_2W & $4 \mid 1$ \\
\hline 43 & 43 & 148 & 546 & Hanford H2 & $\begin{array}{l}\text { Interbedded layers of silty to } \\
\text { fine, medium, and coarse sand }\end{array}$ & S & Hfs_U & $4 \mathrm{H}$ \\
\hline 16 & 16 & 164 & 530 & CCU-upper & Silt and fine sand & SS & PPlz_U & $4 \mathrm{H}$ \\
\hline 3 & 3 & 167 & 527 & CCU-lower & $\begin{array}{l}\text { Calcium-carbonate cemented } \\
\text { sand, silt and clay (caliche) }\end{array}$ & SS & PPIc & $4 \mid 1$ \\
\hline 9 & 9 & 176 & 518 & Upper Ringold & Medium to coarse sand & $\mathrm{S}$ & Hcs & $4 \mid 1$ \\
\hline 44 & 44 & 220 & 474 & Ringold Unit E & Sandy gravel & SG2 & $\mathrm{Rg} \_\mathrm{U}$ & 412 \\
\hline 30 & 30 & 250 & 444 & Ringold Unit E & Medium to coarse sand & $S$ & $\mathrm{HCS}$ & $4 \mid 1$ \\
\hline & & 249.55 & 443.95 & Water Table & NA & & & NA \\
\hline
\end{tabular}




\begin{tabular}{|c|c|c|c|c|c|c|c|c|}
\hline \multicolumn{8}{|c|}{$\begin{array}{l}\text { Template 216S_U_S-x for the southern portion of the } 216-\mathrm{U}-1 \& 2 \text { crib area, based on well } 299-\mathrm{W} 19-14 \text { (N } 134831.14 \text {, } \\
\text { E } 567267.99) \text {, located } 9 \mathrm{~m} \text { ( } 30 \mathrm{ft}) \text { from SE edge of } 216-\mathrm{U}-16 \mathrm{Crib} \text {. }\end{array}$} & \multirow{2}{*}{\begin{tabular}{|c} 
216S_U_S-4 \\
Kd Class \\
\end{tabular}} \\
\hline \begin{tabular}{|c|} 
Estimated \\
Thickness \\
$(\mathrm{ft})^{\star * *}$
\end{tabular} & $\begin{array}{c}\text { Adjusted } \\
\text { Thickness } \\
\text { (ft)† }\end{array}$ & \begin{tabular}{c|} 
Bottom \\
Depth (ft)
\end{tabular} & \begin{tabular}{|c|} 
Bottom \\
Elevation \\
(ft) \\
\end{tabular} & Geologic Unit & Description & $\begin{array}{c}\text { Hydraulic } \\
\text { Property } \\
\text { Type * }\end{array}$ & $\begin{array}{l}\text { SAC Soil } \\
\text { Type }\end{array}$ & \\
\hline & & 0 & 693.44 & Surface & NA & NA & NA & NA \\
\hline 24 & 24 & 24 & 669 & Backfill & Backfill & $\mathrm{B}$ & B & $4 \mathrm{H}$ \\
\hline 86 & 86 & 110 & 583 & Hanford $\mathrm{H} 1$ & $\begin{array}{l}\text { Interbedded layers of fine to } \\
\text { coarse sand and sandy gravel }\end{array}$ & $S$ & Hcs_2W & $4 \mathrm{H}$ \\
\hline 42 & 42 & 152 & 541 & Hanford H2 & $\begin{array}{l}\text { Interbedded layers of silty to } \\
\text { fine, medium, and coarse sand }\end{array}$ & $S$ & Hfs_U & $4 \mid 1$ \\
\hline 14 & 14 & 166 & 527 & CCU-upper & Silt and fine sand & SS & PPlz_U & $4 \mid 1$ \\
\hline 4 & 4 & 170 & 523 & CCU-lower & $\begin{array}{l}\text { Calcium-carbonate cemented } \\
\text { sand, silt and clay (caliche) }\end{array}$ & SS & PPlc & $4 \mid 1$ \\
\hline 78 & 78 & 248 & 445 & Ringold Unit E & Sandy gravel & SG2 & $\mathrm{Rg} \_\mathrm{U}$ & 412 \\
\hline & & 248.02 & 445.42 & Water Table & NA & & & NA \\
\hline
\end{tabular}

* After Khaleel and Freeman (1995), per white paper by Khaleel (September 2000)

** HI=high impact, II=Intermediate Impact (After Composite Analysis)

*** Based on Fecht, Last, and Marratt, 1979 - RHO-LD-72.

BLUE = Injection/release point

GREEN = Modifications by Nichols to support air phase modeling

$\dagger$ Average thickness adjusted to normalize the average strata thicknesses to equal the total thickness of the vadose zone. 
VZ Base Templates - S_Z9

216-Z-9 Trench

Notes/Assumptions:

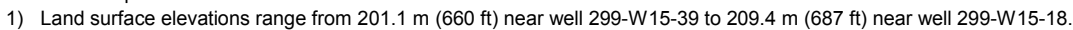

Will assume an average elevation of $205.2 \mathrm{~m}(673 \mathrm{ft}) \mathrm{MSL}$.

2) The pre-Hanford Water Table (January 1944) is estimated to range from an elevation of $122 \mathrm{~m}$ (400 ft) east of ERDF to $127 \mathrm{~m}$ (417 ft) west of the S-16 Pond (DOE-EIS-0113, page 4.21). The lowest measured water-level was $440.6 \mathrm{ft}$ in 299-W15-5 on April 18, 1

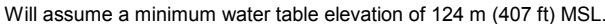

3) A thin blanket of eolian sand and silt covers the surface of the site where not disturbed. However, this material was generally removed during excavation and construction of the waste disposal sites and then incorporated into backfill materials

4) The depth of the $216-Z-9$ Trench is about $6.1 \mathrm{~m}(20 \mathrm{ft})$. Note that it has a concrete cover. A building also partially overlies the site.

\begin{tabular}{|c|c|c|c|c|c|c|c|c|c|c|c|}
\hline \multicolumn{11}{|c|}{ Template 217S_Z9-X for the 216-Z-9 Trench } & \multirow[b]{2}{*}{$\begin{array}{l}217 \mathrm{~S} \_Z 9-1 \\
K_{d} \text { Class }\end{array}$} \\
\hline Geologic Unit & Description & \begin{tabular}{|c} 
Depth to \\
Top \\
Contact (ft)
\end{tabular} & $\begin{array}{c}\text { Elevation } \\
\text { of Top } \\
\text { Contact }(\mathrm{ft})\end{array}$ & $\begin{array}{c}\text { Average } \\
\text { Thickness } \\
\text { (ft) }\end{array}$ & $\begin{array}{c}\text { Adjusted } \\
\text { Average } \\
\text { Thickness } \\
\text { (ft) } \dagger \\
\end{array}$ & \begin{tabular}{|c|} 
Depth to \\
Bottom \\
Contact (ft) \\
\end{tabular} & \begin{tabular}{|c|}
$\begin{array}{c}\text { Elevation } \\
\text { of Bottom } \\
\text { Contact (ft) }\end{array}$ \\
\end{tabular} & $\begin{array}{c}\text { VZ } \\
\text { Hydraulic } \\
\text { Property } \\
\text { Type * } \\
\end{array}$ & $\begin{array}{l}\text { SAC Soil } \\
\text { Type }\end{array}$ & $K_{d} Z_{\text {Zne }}^{* *}$ & \\
\hline Surface & Concrete & 0 & 0 & & & 0 & 673 & NA & NA & $\mathrm{NA}$ & NA \\
\hline Backfill & $\begin{array}{l}\text { Gravelly Medium } \\
\text { Sand }\end{array}$ & 0 & 673 & 15.5 & 20 & 20 & 653 & B & B & $\mathrm{HI}$ & $1 \mathrm{H}$ \\
\hline \begin{tabular}{|l} 
Hanford Gravel \\
$(\mathrm{H} 1)$
\end{tabular} & Sandy Gravel & 20 & 653 & 29.2 & 24 & 44 & 629 & SG1 & Hg_Z & $\mathrm{HI}$ & $1 \mathrm{H}$ \\
\hline Hanford Sand (H2) & $\begin{array}{l}\text { Coarse to Medium } \\
\text { Sand }\end{array}$ & 44 & 629 & 39.2 & 39 & 83 & 590 & S & Hfs_Z & II & $1 / 1$ \\
\hline \begin{tabular}{|l} 
Hanford \\
Interbedded sand \\
and mud $(\mathrm{H} 4)$
\end{tabular} & $\begin{array}{l}\text { Slightly Muddy } \\
\text { Medium to Fine } \\
\text { Sand to Sandy } \\
\text { Mud }\end{array}$ & 83 & 590 & 23.4 & 23 & 106 & 567 & S & Hss_Z & II & 111 \\
\hline CCU Silt & Sandy Mud & 106 & 567 & 8.7 & 9 & 115 & 558 & SS & PPlz_Z & II & $1 / 1$ \\
\hline CCU Carbonate & $\begin{array}{l}\text { Calcareous } \\
\text { Gravelly, Muddy, } \\
\text { Sand }\end{array}$ & 115 & 558 & 4.0 & 4 & 119 & 554 & SS & PPIc_Z & II & $1 / 1$ \\
\hline Ringold (Unit E) & $\begin{array}{l}\text { Semi-indurated } \\
\text { Muddy Sandy } \\
\text { Gravel }\end{array}$ & 119 & 554 & 146.1 & 147 & 266 & 407 & SG2 & Rg_2W & II & 112 \\
\hline $\begin{array}{l}\text { Ringold (Unit E) - } \\
\text { Saturated }\end{array}$ & $\begin{array}{l}\text { Semi-indurated } \\
\text { Muddy Sandy } \\
\text { Gravel }\end{array}$ & 266 & 407 & 127.0 & 163 & 429 & 244 & & & GW & \\
\hline \begin{tabular}{|l} 
Ringold Lower \\
Mud \\
\end{tabular} & $\begin{array}{l}\text { Muddy Medium to } \\
\text { Fine Sand }\end{array}$ & 429 & 244 & 54.0 & 54 & 483 & 190 & & & GW & \\
\hline \begin{tabular}{|l} 
Ringold Unit A \\
\end{tabular} & Sandy Gravel & 483 & 190 & 45.0 & 45 & 528 & 145 & & & GW & \\
\hline \begin{tabular}{|l} 
Elephant Mountain \\
Basalt
\end{tabular} & Basalt & 528 & 145 & & & & & & & & \\
\hline
\end{tabular}

\footnotetext{
Hand Entered Unsaturated Zone Geologic Data Taken from 8 wells near Z-9 (Wells 299-W15-8, -9, -83, -84, -86, -95, -101, -217). Hand Entered Unsaturated Property Class Designations taken from SAC Rev. 0 Inputs. Hand Entered Saturated Zone Geologic Data Taken from 299-W15-5.

Calculated Values
}

† Average thickness adjusted to normalize the average strata thicknesses to equal the total thickness of the vadose zone. 
VZ Base Templates T

North 200 West Area (T Areas) Stratigraphic Columns

Notes/Assumptions:

1) Topography ranges from $790 \mathrm{ft} \mathrm{MSL}$ in the NW corner of the $216-\mathrm{W}-5$ burial ground to about $665 \mathrm{ft}$ MSL east of the TX Tankfarm (USGS Gable Butte and Riverland $7.5 \mathrm{~min}$. Quad Maps).

Will assume an average elevation of $690 \mathrm{ft} \mathrm{MSL}$.

2) The pre-Hanford Water Table (January 1944) is estimated to range from an elevation of $122 \mathrm{~m}$ (400 ft) east of $200 \mathrm{~W}$ to $127 \mathrm{~m}$ (417 ft) on the west side of the 218-W-5 Burial Ground (Kipp and Mud, 1974; DOE-EIS-0113, page 4.21).

Will assume an average water table elevation of $124 \mathrm{~m}$ (407 ft) MSL.

3) A thin blanket of eolian sand and silt covers the surface of the site where not disturbed.

However, this material was generally removed during excavation and construction of the waste disposal sites and then incorporated into backfill materials.

The depth of the sites and thus, the backfull over these sites range from $0 \mathrm{~m}$ for ponds and most unplanned releases, to an average of about $8 \mathrm{~m}$ for cribs and burial grounds, and upto $15 \mathrm{~m}$ for tanks.

4) Only two reverse wells are located in this area ranging in depth from $22-62 \mathrm{~m}$.

5) Injection well $216-\mathrm{T}-2$ is $75 \mathrm{ft}$ deep. $216-\mathrm{T}-3$ is reported as $206 \mathrm{ft}$. Screened interval is unknown -- will assume $25 \mathrm{ft}$ screened interval.

\begin{tabular}{|c|c|c|c|c|c|c|c|c|c|c|}
\hline \multicolumn{9}{|c|}{ Template 200T-X for surface disposal sites (e.g. Ponds) } & 200T-2 & $200 \mathrm{~T}-4$ \\
\hline \begin{tabular}{|c|}
$\begin{array}{c}\text { Average } \\
\text { Thickness } \\
(\mathrm{ft})\end{array}$ \\
\end{tabular} & $\begin{array}{c}\text { Adjusted } \\
\text { Average } \\
\text { Thickness } \\
\text { (ft) } \dagger\end{array}$ & Depth (ft) & Elevation (ft) & $\begin{array}{c}\text { Geologic } \\
\text { Unit }\end{array}$ & Description & $\begin{array}{c}\text { Hydraulic } \\
\text { Property } \\
\text { Type * }\end{array}$ & $\begin{array}{l}\text { SAC Soil } \\
\text { Type }\end{array}$ & $\mathrm{K}_{\mathrm{d}}$ Zone $\mathrm{e}^{\star *}$ & $K_{d}$ Class & $K_{d}$ Class \\
\hline & & 0 & 690 & Surface & $\mathrm{NA}$ & NA & NA & NA & NA & NA \\
\hline 2.5 & 2 & 2 & 688 & Eolian & Sand and silt & $\mathrm{s}$ & Hss & $\mathrm{HI}$ & $2 \mathrm{H}$ & $4 \mathrm{H}$ \\
\hline 90 & 90 & 92 & 598 & Hanford Gravel & $\begin{array}{l}\text { Silty sandy medium to fine pebble to } \\
\text { slightly silty pebbly very coarse to } \\
\text { coarse sand. }\end{array}$ & SG1 & Hg_2W & $\mathrm{HI}$ & $2 \mathrm{H}$ & $4 \mathrm{H}$ \\
\hline 35 & 35 & 127 & 563 & $\begin{array}{l}\text { Hanford Gravelly } \\
\text { Sand }\end{array}$ & $\begin{array}{l}\begin{array}{l}\text { Pebbly very coarse to medium sand to } \\
\text { slightly silty very coarse to medium } \\
\text { sand }\end{array} \\
\end{array}$ & GS & Hgs_2W & II & $2 \mid 1$ & 411 \\
\hline 10 & 10 & 137 & 553 & \begin{tabular}{|l} 
Old Hanford/Plio- \\
pleistocene \\
("Early Palouse")
\end{tabular} & $\begin{array}{l}\text { Silty fine to very fine sand to slightly } \\
\text { silty fine to very fine sand }\end{array}$ & SS & $\mathrm{PPlz}$ & II & 211 & 411 \\
\hline 18 & 18 & 155 & 535 & \begin{tabular}{|l} 
Plio-Pleistocene \\
Caliche
\end{tabular} & $\begin{array}{l}\text { Pebbly silty coarse to fine sand to sitty } \\
\text { medium to very fine sand with caliche }\end{array}$ & SS & PPIc & II & 211 & $4 \mid 1$ \\
\hline 25 & 25 & 180 & 510 & Upper Ringold & $\begin{array}{l}\text { silty fine to very fine sand to silty } \\
\text { medium to very fine sand (semi- } \\
\text { indurated) }\end{array}$ & $\mathrm{s}$ & $\mathrm{PPlz}$ & II & 211 & $4 \mid 1$ \\
\hline & 103 & 283 & 407 & $\begin{array}{ll}7 \text { Ringold Unit E } \\
\end{array}$ & $\begin{array}{l}\text { Silty Sandy Medium to fine pebble to } \\
\text { sandy very coarse to fine pebble (semi- } \\
\text { indurated) }\end{array}$ & $\mathrm{SG} 2$ & $\mathrm{Rg}_{2} 2 \mathrm{~W}$ & II & 212 & $4 \mid 2$ \\
\hline & & 283 & 407 & |Water Table & NA & NA & NA & $\mathrm{NA}$ & $\mathrm{NA}$ & $\mathrm{NA}$ \\
\hline
\end{tabular}

\begin{tabular}{|c|c|c|c|c|c|c|c|c|c|c|c|}
\hline \multicolumn{9}{|c|}{ Template 216T-X for shallow disposal sites (e.g. Cribs, Burial Grounds) } & $216 \mathrm{~T}-2$ & $216 \mathrm{~T}-3$ & $216 \mathrm{~T}-4$ \\
\hline $\begin{array}{c}\text { Average } \\
\text { Thickness } \\
\text { (ft) }\end{array}$ & $\begin{array}{c}\text { Adjusted } \\
\text { Average } \\
\text { Thickness } \\
\text { (ft) } \dagger\end{array}$ & Depth (ft) & Elevation $(\mathrm{ft})$ & $\begin{array}{c}\text { Geologic } \\
\text { Unit }\end{array}$ & Description & $\begin{array}{l}\text { Hydraulic } \\
\text { Property } \\
\text { Type * }\end{array}$ & $\begin{array}{c}\text { SAC Soil } \\
\text { Type }\end{array}$ & $K_{d}$ Zone $e^{* *}$ & $K_{d}$ Class & $K_{d}$ Class & $K_{d}$ Class \\
\hline & & 0 & 690 & Surface & NA & NA & NA & NA & NA & NA & NA \\
\hline 17 & 17 & 17 & 673 & Backfill & & $B$ & $B$ & $\mathrm{HI}$ & $2 \mathrm{H}$ & $3 \mathrm{H}$ & $4 \mathrm{H}$ \\
\hline 90 & 75 & 92 & 598 & $\begin{array}{l}\text { Hanford } \\
\text { Gravel }\end{array}$ & \begin{tabular}{|l} 
Silty sandy medium to fine \\
pebble to slightly silty pebbly \\
very coarse to coarse sand. \\
\end{tabular} & SG1 & Hg_2W & $\mathrm{HI}$ & $2 \mathrm{H}$ & $3 \mathrm{H}$ & $4 \mathrm{H}$ \\
\hline 35 & 35 & 127 & 563 & $\begin{array}{l}\text { Hanford } \\
\text { Gravelly Sand }\end{array}$ & $\begin{array}{l}\text { Pebbly very coarse to medium } \\
\text { sand to slightly silty very coarse } \\
\text { to medium sand }\end{array}$ & GS & Hgs 2W & II & $2 \mid 1$ & $3 / 1$ & $4 \mid 1$ \\
\hline 10 & 10 & 137 & 553 & \begin{tabular}{|l|} 
Old \\
Hanford/Plio- \\
pleistocene \\
("Early \\
Palouse") \\
\end{tabular} & $\begin{array}{l}\text { Silty fine to very fine sand to } \\
\text { slightly silty fine to very fine } \\
\text { sand }\end{array}$ & SS & PPlz & II & 211 & 311 & $4 \mid 1$ \\
\hline 18 & 18 & 155 & 535 & \begin{tabular}{|l} 
Plio- \\
Pleistocene \\
Caliche
\end{tabular} & $\begin{array}{l}\text { Pebbly silty coarse to fine sand } \\
\text { to silty medium to very fine } \\
\text { sand with caliche }\end{array}$ & SS & PPIc & II & $2 \mid 1$ & $3 / 1$ & $4 \mid 1$ \\
\hline 25 & 25 & 180 & 510 & \begin{tabular}{|l} 
Upper \\
Ringold
\end{tabular} & $\begin{array}{l}\text { silty fine to very fine sand to } \\
\text { silty medium to very fine sand } \\
\text { (semi-indurated) }\end{array}$ & $\mathrm{s}$ & PPlz & II & $2 \mid 1$ & $3 / 1$ & $4 \mid 1$ \\
\hline & 103 & 283 & 407 & Ringold Unit & \begin{tabular}{|l|} 
Silty Sandy Medium to fine \\
pebble to sandy very coarse to \\
fine pebble (semi-indurated)
\end{tabular} & SG2 & $\mathrm{Rg} \_2 \mathrm{~W}$ & II & 212 & 312 & 412 \\
\hline & & 283 & 407 & Water Table & NA & $\mathrm{NA}$ & $\mathrm{NA}$ & NA & $\mathrm{NA}$ & $\mathrm{NA}$ & NA \\
\hline
\end{tabular}




\begin{tabular}{|c|c|c|c|c|c|c|c|c|c|c|c|}
\hline \multirow{2}{*}{$\begin{array}{l}\text { Template 241T- } \mathrm{X} \text { for } \\
\qquad \begin{array}{c}\text { Average } \\
\text { Thickness } \\
\text { (ft) }\end{array} \\
\end{array}$} & anks & & & & \multirow[b]{2}{*}{ Description } & \multirow{3}{*}{$\begin{array}{c}\begin{array}{c}\text { Hydraulic } \\
\text { Property } \\
\text { Type * }\end{array} \\
\text { NA }\end{array}$} & \multirow[b]{2}{*}{$\begin{array}{l}\text { SAC Soil } \\
\text { Type }\end{array}$} & \multirow[b]{2}{*}{$\mathrm{K}_{\mathrm{d}}$ Zone $^{\star * *}$} & \multirow[b]{2}{*}{$\begin{array}{l}241 \mathrm{~T}-2 \\
\mathrm{~K}_{\mathrm{d}} \text { Class }\end{array}$} & & \\
\hline & $\begin{array}{c}\text { Adjusted } \\
\text { Average } \\
\text { Thickness } \\
\text { (ft) } \dagger\end{array}$ & Depth (ft) & Elevation (ft) & $\begin{array}{c}\text { Geologic } \\
\text { Unit }\end{array}$ & & & & & & & \\
\hline & & 0 & 690 & Surface & NA & & NA & NA & NA & & \\
\hline 48 & 48 & 48 & 642 & Backfill & & $\mathrm{B}$ & $\mathrm{B}$ & $\mathrm{HI}$ & $2 \mathrm{H}$ & & \\
\hline 90 & 44 & 92 & 598 & Hanford Gravel & $\begin{array}{l}\text { Silty sandy medium to fine pebble to } \\
\text { slightly silty pebbly very coarse to } \\
\text { coarse sand. }\end{array}$ & SG1 & Hg_2W & $\mathrm{HI}$ & $2 \mathrm{H}$ & & \\
\hline 35 & 35 & 127 & 563 & $\begin{array}{l}\text { Hanford Gravelly } \\
\text { Sand }\end{array}$ & $\begin{array}{l}\begin{array}{l}\text { Pebbly very coarse to medium sand to } \\
\text { slightly silty very coarse to medium } \\
\text { sand }\end{array} \\
\end{array}$ & GS & Hgs_2W & II & 211 & & \\
\hline 10 & 10 & 137 & 553 & $\begin{array}{l}\text { Old Hanford/Plio- } \\
\text { pleistocene } \\
\text { ("Early Palouse") }\end{array}$ & $\begin{array}{l}\text { Silty fine to very fine sand to slightly } \\
\text { silty fine to very fine sand }\end{array}$ & SS & $\mathrm{PPlz}$ & II & 211 & & \\
\hline 18 & 18 & 155 & 535 & $\begin{array}{l}\text { Plio-Pleistocene } \\
\text { Caliche }\end{array}$ & $\begin{array}{l}\text { Pebbly sitty coarse to fine sand to sitty } \\
\text { medium to very fine sand with caliche }\end{array}$ & SS & PPIc & II & 211 & & \\
\hline 25 & 25 & 180 & 510 & Upper Ringold & $\begin{array}{l}\text { silty fine to very fine sand to silty } \\
\text { medium to very fine sand (semi- } \\
\text { indurated) }\end{array}$ & $\mathrm{s}$ & PPIz & II & 211 & & \\
\hline & 103 & 283 & 407 & Ringold Unit E & $\begin{array}{l}\text { Silty Sandy Medium to fine pebble to } \\
\text { sandy very coarse to fine pebble (semi } \\
\text { indurated) }\end{array}$ & $\mathrm{SG} 2$ & $\mathrm{Rg}_{2} 2 \mathrm{~W}$ & II & 212 & & \\
\hline & & 283 & 407 & Water Table & $\mathrm{NA}$ & NA & $\mathrm{NA}$ & $\mathrm{NA}$ & $\mathrm{NA}$ & & \\
\hline
\end{tabular}

\begin{tabular}{|c|c|c|c|c|c|c|c|c|c|c|}
\hline Template 266T-X for & deep injection & ites (e.g. rev & erse wells [e.g & g. $216-T-2 \&-3$ & (a)]) & & & & $266 \mathrm{~T}-2$ & $266 \mathrm{~T}-4$ \\
\hline $\begin{array}{c}\text { Average } \\
\text { Thickness } \\
\text { (ft) }\end{array}$ & $\begin{array}{c}\text { Adjusted } \\
\text { Average } \\
\text { Thickness } \\
\text { (ft) } \dagger\end{array}$ & Depth (ft) & Elevation (ft) & $\begin{array}{l}\text { Geologic } \\
\text { Unit }\end{array}$ & Description & $\begin{array}{l}\text { Hydraulic } \\
\text { Property } \\
\text { Type * }\end{array}$ & $\begin{array}{l}\text { SAC Soil } \\
\text { Type }\end{array}$ & $\mathrm{K}_{\mathrm{d}}$ Zone $\mathrm{e}^{\star *}$ & $K_{d}$ Class & $K_{d}$ Class \\
\hline & & 0 & 690 & Surface & $\mathrm{NA}$ & $\mathrm{NA}$ & $\mathrm{NA}$ & NA & NA & $\mathrm{NA}$ \\
\hline 2.5 & 2 & 2 & 688 & \begin{tabular}{|l|} 
Eolian \\
\end{tabular} & Sand and silt & $\mathrm{s}$ & Hss & II & $2 \mid 1$ & $4 \mid 1$ \\
\hline 90 & 90 & 92 & 598 & Hanford Gravel & $\begin{array}{l}\text { Silty sandy medium to fine pebble to } \\
\text { slightly silty pebbly very coarse to } \\
\text { coarse sand. }\end{array}$ & SG1 & Hg_2W & II & 212 & 412 \\
\hline 35 & 35 & 127 & 563 & $\begin{array}{l}\text { Hanford Gravelly } \\
\text { Sand }\end{array}$ & $\begin{array}{l}\begin{array}{l}\text { Pebbly very coarse to medium sand to } \\
\text { slightly silty very coarse to medium } \\
\text { sand }\end{array} \\
\end{array}$ & GS & Hgs_2W & II & $2 \mathrm{I} 1$ & $4 \mid 1$ \\
\hline 10 & 10 & 137 & 553 & $\begin{array}{l}\text { Old Hanford/Plio- } \\
\text { pleistocene } \\
\text { ("Early Palouse") }\end{array}$ & $\begin{array}{l}\text { Silty fine to very fine sand to slightly } \\
\text { silty fine to very fine sand }\end{array}$ & SS & $\mathrm{PPlz}$ & II & $2 \mid 1$ & $4 \mid 1$ \\
\hline 18 & 18 & 155 & 535 & \begin{tabular}{|l} 
Plio-Pleistocene \\
Caliche
\end{tabular} & $\begin{array}{l}\text { Pebbly sitty coarse to fine sand to sitty } \\
\text { medium to very fine sand with caliche }\end{array}$ & SS & PPIc & II & $2 \mid 1$ & $4 \mid 1$ \\
\hline 25 & 25 & 180 & 510 & Upper Ringold & $\begin{array}{l}\text { silty fine to very fine sand to sitty } \\
\text { medium to very fine sand (semi- } \\
\text { indurated) }\end{array}$ & $\mathrm{s}$ & PPlz & $\mathrm{HI}$ & $2 \mathrm{H}$ & $4 \mathrm{H}$ \\
\hline & 103 & 283 & 407 & Ringold Unit E & $\begin{array}{l}\text { Silty Sandy Medium to fine pebble to } \\
\text { sandy very coarse to fine pebble (semi- } \\
\text { indurated) }\end{array}$ & SG2 & $\mathrm{Rg} \_2 \mathrm{~W}$ & $\mathrm{HI}$ & 212 & 412 \\
\hline & & 283 & 407 & Water Table & NA & $\mathrm{NA}$ & $\mathrm{NA}$ & $\mathrm{NA}$ & $\mathrm{NA}$ & $\mathrm{NA}$ \\
\hline
\end{tabular}

* After Khaleel and Freeman (1995), per white paper by Khaleel (September 2000) ** HI=high impact, II=Intermediate Impact (After Composite Analysis)

BLUE = Injection/release point

$\dagger$ Average thickness adjusted to normalize the average strata thicknesses to equal the total thickness of the vadose zone. 


\section{Appendix B}

\section{Hydraulic Property Distributions}


Hydraulic Property Distributions - Revised (4/22/03)

(After Freeman's May 14, 2003 White Paper "Revised SAC Statistical Properties Tables of Vadose Hydraulic Properties"; Khaleel's Sept. 2000 White Paper, and

\begin{tabular}{|c|c|c|c|c|c|c|c|c|c|c|c|c|c|c|}
\hline B & \multirow{2}{*}{\begin{tabular}{|c|}
$\begin{array}{c}\text { Number } \\
\text { of } \\
\text { samples }\end{array}$ \\
\end{tabular}} & \multicolumn{4}{|c|}{ Raw } & \multirow[b]{2}{*}{ Transform } & \multicolumn{4}{|c|}{ Transformed (normal distribution) } & \multicolumn{2}{|c|}{ Beta Distribution } & \multicolumn{2}{|c|}{ Observed Data } \\
\hline & & Low & High & Mean & $\begin{array}{l}\text { Standard } \\
\text { Deviation }\end{array}$ & & $\begin{array}{c}\text { Upper } \\
\text { Limit }\end{array}$ & $\begin{array}{c}\text { Lower } \\
\text { Limit }\end{array}$ & Mean & $\begin{array}{l}\text { Standard } \\
\text { Deviation }\end{array}$ & A & $\mathrm{B}$ & Lower & Upper \\
\hline$a_{s}$ & 6 & 0.187 & 0.375 & 0.262 & 0.072 & $\mathrm{NO}$ & & & & & & & 0.149 & 0.942 \\
\hline$R$ & 6 & 0 & 0.064 & 0.03 & 0.029 & NO & & & & & & & 0.150 & 0.879 \\
\hline$s_{r}$ & 7 & 0 & 0.213 & 0.102 & 0.0895 & NO & & & & & & & 0.128 & 0.893 \\
\hline$\square(1 / \mathrm{cm})$ & 6 & 0.003 & 0.103 & 0.032 & 0.036 & $\mathrm{LN}$ & -5.843 & -2.276 & -3.957 & 1.166 & & & 0.056 & 0.926 \\
\hline$n$ & 6 & 1.256 & 1.629 & 1.4 & 0.131 & NO & & & & & & & 0.136 & 0.960 \\
\hline $\mathrm{K}_{\mathrm{s}}(\mathrm{cm} / \mathrm{s})$ & 6 & 0.0000276 & 0.068 & 0.015 & 0.027 & LR & -10.854 & 2.995 & -5.262 & 5.499 & & & & \\
\hline Longitudinal & & & & & & & & & & & & & & \\
\hline $\begin{array}{l}\text { Dispersivity }{ }^{1} \\
(\mathrm{~m})\end{array}$ & NA & 2.70E-02 & 0.178 & 0.09 & NA & UN & - & - & - & & & & & \\
\hline$\%$ Gravel & & & & & & & & & & & & & & \\
\hline Bulk Density $^{2}$ & NA & - & - & 1.94 & & $\mathrm{CO}$ & - & - & - & & & & & \\
\hline
\end{tabular}

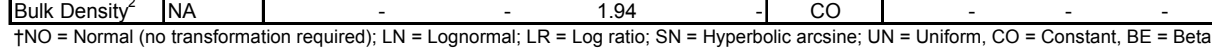

${ }^{1}$ Taken from Ho, et. al., 1999 [Stochastic Parameter Development for PORFLOW Simulations of the Hanford AX Tank Farm]

${ }^{2}$ Taken from Khaleel, et. al. 2000 (Modeling Data Package for S-SX Field Investigation Report (FIR) [DRAFT])

Table 2. Approximation for the distribution function for soil type "Hss" (Hanford silty fine sand) based on Khaleel and Freeman (1995) soil category SS (sand mixed with finer

\begin{tabular}{|c|c|c|c|c|c|c|c|c|c|c|c|c|c|c|}
\hline Hss & \multirow{2}{*}{\begin{tabular}{|c|}
$\begin{array}{c}\text { Number } \\
\text { of } \\
\text { samples }\end{array}$ \\
\end{tabular}} & \multicolumn{4}{|c|}{ Raw } & \multirow[b]{2}{*}{ Transform† } & \multicolumn{4}{|c|}{ Transformed (normal distribution) } & \multicolumn{2}{|c|}{ Beta Distribution } & \multicolumn{2}{|c|}{ Truncation Limits } \\
\hline Parameter & & Low & High & Mean & $\begin{array}{l}\text { Standard } \\
\text { Deviation }\end{array}$ & & $\begin{array}{l}\text { Upper } \\
\text { Limit }\end{array}$ & $\begin{array}{c}\text { Lower } \\
\text { Limit }\end{array}$ & Mean & $\begin{array}{l}\text { Standard } \\
\text { Deviation }\end{array}$ & A & B & Lower & Upper \\
\hline as & 38 & 0.321 & 0.587 & 0.445 & 0.060 & $\mathrm{NO}$ & & & & & & & 0.019 & 0.991 \\
\hline$R_{R}$ & 38 & 0.019 & 0.181 & 0.072 & 0.033 & NO & & & & & & & 0.053 & 1.000 \\
\hline$s_{r}$ & 38 & 0.047 & 0.339 & 0.159 & 0.059 & NO & & & & & 5.9070 & 31.3000 & 0.030 & 0.999 \\
\hline$\square(1 / \mathrm{cm})$ & 38 & 0.001 & $\begin{array}{l}0.387 \\
3\end{array}$ & 0.008 & $\begin{array}{l}0.076 \\
0.461\end{array}$ & LN & -0.949 & -7.131 & -4.866 & 1.212 & & & 0.031 & 0.999 \\
\hline$n$ & 38 & 1.262 & 3.265 & 1.915 & 0.461 & NO & & & & & & & 0.078 & 0.998 \\
\hline $\mathrm{K}_{\mathrm{s}}(\mathrm{cm} / \mathrm{s})$ & 30 & $3.20 \mathrm{E}-07$ & 8.88E-04 & 8.58E-05 & 2.66E-04 & LN & -7.027 & -14.955 & -9.363 & 1.885 & & & 0.002 & 0.892 \\
\hline $\begin{array}{l}\text { Longitudinal } \\
\text { Dispersivity }{ }^{1} \\
\text { (m) }\end{array}$ & INA & 0.0279 & 0.0341 & 0.031 & NA & UN & - & - & - & & - & & & \\
\hline \% Gravel & 38 & 0 & $\begin{array}{r}0.004 \\
\end{array}$ & 0.18 & 0.51 & & & & & & & & & \\
\hline $\begin{array}{l}\text { Bulk Density }{ }^{3} \\
\left(\mathrm{~g} / \mathrm{cm}^{3}\right)\end{array}$ & 35 & 1.28 & 2.13 & 1.61 & 0.17 & NO & - & - & - & & - & & & \\
\hline $\begin{array}{l}\text { Particle } \\
\text { Density } \\
\left(\mathrm{g} / \mathrm{cm}^{3}\right) \\
\end{array}$ & & & & & & NO & & & & & & & & \\
\hline
\end{tabular}

†NO = Normal (no transformation required); $\mathrm{LN}=$ Lognormal; $\mathrm{LR}=\mathrm{Log}$ ratio; $\mathrm{SN}=$ Hyperbolic arcsine; UN = Uniform, CO = Constant, $\mathrm{BE}=$ Beta

1 Taken from Ho, et. al., 1999 [Stochastic Parameter Development for PORFLOW Simulations of the Hanford AX Tank Farm].

${ }^{2}$ Taken from Khaleel, et. al. 2000 (Modeling Data Package for S-SX Field Investigation Report (FIR) [DRAFT]).

3 Taken from Freeman's e-mail to George Last, dated 12/27/01 (finetex1a.doc and HStex1.doc).

Table 3. Approximation for the distribution function for soil type "Hss_2W" (Hanford silty fine sand - 200 West Area) based on Khaleel and Freeman (1995) soil category SS

\begin{tabular}{|c|c|c|c|c|c|c|c|c|c|c|c|c|c|c|}
\hline Hss_2W & \multirow{2}{*}{\begin{tabular}{|c|}
$\begin{array}{c}\text { Number } \\
\text { of } \\
\text { samples }\end{array}$ \\
\end{tabular}} & \multicolumn{4}{|c|}{ Raw } & \multirow[b]{2}{*}{ Transformt } & \multicolumn{4}{|c|}{ Transformed (normal distribution) } & \multicolumn{2}{|c|}{ Beta Distribution } & \multicolumn{2}{|c|}{ Truncation Limits } \\
\hline Parameter & & Low & High & Mean & $\begin{array}{l}\text { Standard } \\
\text { Deviation }\end{array}$ & & $\begin{array}{l}\text { Upper } \\
\text { Limit }\end{array}$ & $\begin{array}{l}\text { Lower } \\
\text { Limit }\end{array}$ & Mean & $\begin{array}{l}\text { Standard } \\
\text { Deviation }\end{array}$ & A & B & Lower & Upper \\
\hline s & 11 & 0.321 & 0.566 & 0.398 & 0.076 & $\mathrm{NO}$ & & & & & & & 0.155 & 0.987 \\
\hline$\square_{R}$ & 11 & 0.019 & 0.102 & 0.057 & 0.027 & NO & & & & & & & 0.077 & 0.952 \\
\hline$s_{r}$ & 11 & 0.054 & 0.211 & 0.141 & 0.052 & NO & & & & & 6.2710 & 38.2750 & 0.046 & 0.914 \\
\hline$\square(1 / \mathrm{cm})$ & 11 & 0.001 & 0.017 & 0.005 & 0.004 & LN & -4.080 & -7.131 & -5.397 & 0.804 & & & 0.015 & 0.949 \\
\hline$n$ & 11 & 1.527 & 3.265 & 2.116 & 0.528 & NO & & & & & & & 0.132 & 0.985 \\
\hline $\mathrm{K}_{\mathrm{s}}(\mathrm{cm} / \mathrm{s})$ & 5 & $4.90 \mathrm{E}-06$ & $1.27 \mathrm{E}-04$ & $1.91 \mathrm{E}-05$ & $5.10 \mathrm{E}-05$ & LN & -8.971 & -12.226 & -10.865 & 1.312 & & & 0.150 & 0.926 \\
\hline Longitudinal & & & & & & & & & & & & & & \\
\hline $\begin{array}{l}\text { Dispersivity }{ }^{1} \\
\text { (m) }\end{array}$ & NA & 0.0279 & 0.0341 & 0.031 & NA & UN & - & - & - & & - & & & \\
\hline$\%$ Gravel & 11 & 0.000 & 0.000 & 0.000 & 0.000 & & & & & & & & & \\
\hline $\begin{array}{l}\text { Bulk Density } \\
\left(\mathrm{g} / \mathrm{cm}^{3}\right)\end{array}$ & 10 & 1.400 & 1.900 & 1.668 & 0.167 & NO & - & - & - & & - & & & \\
\hline $\begin{array}{l}\text { Particle } \\
\text { Density } \\
\left(\mathrm{g} / \mathrm{cm}^{3}\right)\end{array}$ & & & & & & NO & & & & & & & & \\
\hline
\end{tabular}

†NO = Normal (no transformation required); $\mathrm{LN}=$ Lognormal; $\mathrm{LR}=\mathrm{Log}$ ratio; $\mathrm{SN}=$ Hyperbolic arcsine; UN = Uniform, CO = Constant, $\mathrm{BE}=\mathrm{Bet}$

1 Taken from Ho, et. al., 1999 [Stochastic Parameter Development for PORFLOW Simulations of the Hanford AX Tank Farm].

${ }^{2}$ Taken from Khaleel, et. al. 2000 (Modeling Data Package for S-SX Field Investigation Report (FIR) [DRAFT]).

${ }^{3}$ Taken from Freeman's e-mail to George Last, dated 12/27/01 (finetex1a.doc and HStex1.doc). 
Table 4. Approximation for the distribution function for soil type "Hss_U" (Hanford silty fine sand - 200-UP-1) based on Khaleel and Freeman (1995) soil category SS (sand

\begin{tabular}{|c|c|c|c|c|c|c|c|c|c|c|c|c|c|c|}
\hline Hss_U & \multirow{2}{*}{\begin{tabular}{|c|}
$\begin{array}{c}\text { Number } \\
\text { of } \\
\text { samples }\end{array}$ \\
\end{tabular}} & \multicolumn{4}{|c|}{ Raw } & \multirow[b]{2}{*}{ Transform $†$} & \multicolumn{4}{|c|}{ Transformed (normal distribution) } & \multicolumn{2}{|c|}{ Beta Distribution } & \multicolumn{2}{|c|}{ Truncation Limits } \\
\hline & & Low & High & Mean & $\begin{array}{l}\text { Standard } \\
\text { Deviation }\end{array}$ & & $\begin{array}{c}\text { Upper } \\
\text { Limit }\end{array}$ & $\begin{array}{c}\text { Lower } \\
\text { Limit }\end{array}$ & Mean & $\begin{array}{l}\text { Standard } \\
\text { Deviation }\end{array}$ & A & B & Lower & Upper \\
\hline$\square_{s}$ & 6 & 0.353 & 0.566 & 0.437 & 0.078 & $\mathrm{NO}$ & & & & & & & 0.140 & 0.952 \\
\hline$R_{R}$ & 6 & 0.019 & 0.102 & 0.066 & 0.033 & NO & & & & & & & 0.074 & 0.866 \\
\hline$s_{r}$ & 6 & 0.054 & 0.211 & 0.147 & 0.064 & NO & & & & & 4.4347 & 25.6347 & 0.071 & 0.841 \\
\hline$\square(1 / \mathrm{cm})$ & 6 & 0.003 & 0.017 & 0.007 & 0.005 & LN & -4.080 & -5.843 & -4.994 & 0.596 & & & 0.077 & 0.937 \\
\hline$n$ & 6 & 1.527 & 3.265 & 2.347 & 0.597 & NO & & & & & & & 0.085 & 0.938 \\
\hline $\mathrm{K}_{\mathrm{s}}(\mathrm{cm} / \mathrm{s})$ & 2 & $4.90 \mathrm{E}-06$ & 1.27E-04 & $2.49 \mathrm{E}-05$ & 8.63E-05 & LN & -8.971 & -12.226 & -10.599 & 2.302 & & & 0.240 & 0.760 \\
\hline Longitudinal & & & & & & & & & & & & & & \\
\hline $\begin{array}{l}\text { Dispersivity }{ }^{1} \\
(\mathrm{~m})\end{array}$ & NA & 0.0279 & 0.0341 & 0.031 & NA & UN & - & - & - & - & - & & & \\
\hline$\%$ Gravel & 6 & 0 & 0 & 0 & 0 & & & & & & & & & \\
\hline $\begin{array}{l}\text { Bulk Density } \\
\left(\mathrm{g} / \mathrm{cm}^{3}\right)\end{array}$ & 6 & 1.4 & 1.72 & 1.58 & 0.13 & NO & - & - & - & & - & & & \\
\hline $\begin{array}{l}\text { Particle } \\
\text { Density }{ }^{3} \\
\left(\mathrm{~g} / \mathrm{cm}^{3}\right)\end{array}$ & & & & & & NO & & & & & & & & \\
\hline
\end{tabular}

TNO = Normal (no transformation required); $\mathrm{LN}=$ Lognormal; $\mathrm{LR}=\mathrm{Log}$ ratio; $\mathrm{SN}=$ Hyperbolic arcsine; $\mathrm{UN}=$ Uniform, $\mathrm{CO}=$ Constant, $\mathrm{BE}=\mathrm{Beta}$

Taken from Ho, et. al., 1999 [Stochastic Parameter Development for PORFLOW Simulations of the Hanford AX Tank Farm].

${ }^{2}$ Taken from Khaleel, et. al. 2000 (Modeling Data Package for S-SX Field Investigation Report (FIR) [DRAFT]).

3 Taken from Freeman's e-mail to George Last, dated 12/27/01 (finetex1a.doc and HStex1.doc).

Table 5. Approximation for the distribution function for soil type "Hss_Z" (Hanford silty fine sand - 200-ZP-1) based on Khaleel and Freeman (1995) soil category SS (sand

\begin{tabular}{|c|c|c|c|c|c|c|c|c|c|c|c|c|c|c|}
\hline Hss_Z & \multirow{2}{*}{$\begin{array}{c}\begin{array}{c}\text { Number } \\
\text { of } \\
\text { samples }\end{array} \\
\end{array}$} & \multicolumn{4}{|c|}{ Raw } & \multirow[b]{2}{*}{ Transform } & \multicolumn{4}{|c|}{ Transformed (normal distribution) } & \multicolumn{2}{|c|}{ Beta Distribution } & \multicolumn{2}{|c|}{ Truncation Limits } \\
\hline & & Low & High & Mean & $\begin{array}{l}\text { Standard } \\
\text { Deviation }\end{array}$ & & $\begin{array}{l}\text { Upper } \\
\text { Limit }\end{array}$ & $\begin{array}{l}\text { Lower } \\
\text { Limit }\end{array}$ & Mean & $\begin{array}{l}\text { Standard } \\
\text { Deviation } \\
\end{array}$ & A & $\mathrm{B}$ & Lower & Upper \\
\hline as & 5 & 0.3208 & 0.4134 & 0.35058 & 0.0401409 & NO & & & & & & & 0.229 & 0.941 \\
\hline$\nabla_{R}$ & 5 & 0.03 & 0.06 & 0.047 & 0.01548031 & NO & & & & & & & 0.136 & 0.799 \\
\hline$s_{r}$ & 5 & 0.09349845 & 0.17837508 & 0.13273273 & 0.0378506 & NO & & & & & 10.5323 & 68.8176 & 0.150 & 0.886 \\
\hline$\square(1 / \mathrm{cm})$ & 5 & 0.0008 & 0.0064 & 0.00279414 & 0.00211376 & LN & -5.05146 & -7.1309 & -5.88023 & 0.79664 & & & 0.058 & 0.851 \\
\hline$n$ & 5 & 1.63766 & 2.2593 & 1.839872 & 0.27356881 & NO & & & & & & & 0.230 & 0.937 \\
\hline $\mathrm{K}_{\mathrm{s}}(\mathrm{cm} / \mathrm{s})$ & 1 & $6.55 \mathrm{E}-06$ & $6.55 \mathrm{E}-06$ & $6.55 \mathrm{E}-06$ & $0.00 \mathrm{E}+00$ & LN & -11.936 & -11.936 & -11.936 & 1 & & & 0.000 & 1.000 \\
\hline Longitudinal & & & & & & & & & & & & & & \\
\hline $\begin{array}{l}\text { Dispersivity }{ }^{1} \\
(\mathrm{~m})\end{array}$ & NA & 0.0279 & 0.0341 & 0.031 & NA & UN & - & - & - & - & - & & & \\
\hline$\%$ Gravel & 5 & 0 & 0 & 0 & 0 & & & & & & & & & \\
\hline $\begin{array}{l}\text { Bulk Density }{ }^{3} \\
\left(\mathrm{~g} / \mathrm{cm}^{3}\right)\end{array}$ & 4 & 1.61 & 1.9 & 1.8 & 0.12987173 & NO & - & - & - & & - & & & \\
\hline $\begin{array}{l}\text { Particle } \\
\text { Density }{ }^{3} \\
\left(\mathrm{~g} / \mathrm{cm}^{3}\right)\end{array}$ & & & & & & NO & & & & & & & & \\
\hline
\end{tabular}

†NO = Normal (no transformation required); $\mathrm{LN}=$ Lognormal; $\mathrm{LR}=\mathrm{Log}$ ratio; $\mathrm{SN}=$ Hyperbolic arcsine; UN = Uniform, CO = Constant, $\mathrm{BE}=\mathrm{Bet}$

1 Taken from Ho, et. al., 1999 [Stochastic Parameter Development for PORFLOW Simulations of the Hanford AX Tank Farm].

${ }^{2}$ Taken from Khaleel, et. al. 2000 (Modeling Data Package for S-SX Field Investigation Report (FIR) [DRAFT])

${ }^{3}$ Taken from Freeman's e-mail to George Last, dated 12/27/01 (finetex1a.doc and HStex1.doc).

${ }^{3}$ Revised by Nichols (unacceptable to truncate both the lower $50 \%$ and the upper $50 \%$ )

Table 6. Approximation for the distribution function for soil type "Hfs" (Hanford fine sand) based on Khaleel and Freeman (1995) soil category S (sand). As modified by

\begin{tabular}{|c|c|c|c|c|c|c|c|c|c|c|c|c|c|c|}
\hline Hfs & \multirow{2}{*}{$\begin{array}{c}\begin{array}{c}\text { Number } \\
\text { of } \\
\text { samples }\end{array} \\
\end{array}$} & \multicolumn{4}{|c|}{ Raw } & \multirow[b]{2}{*}{ Transform } & \multicolumn{4}{|c|}{ Transformed (normal distribution) } & \multicolumn{2}{|c|}{ Beta Distribution } & \multicolumn{2}{|c|}{ Truncation Limits } \\
\hline Parameter & & Low & High & Mean & $\begin{array}{l}\text { Standard } \\
\text { Deviation }\end{array}$ & & $\begin{array}{c}\text { Upper } \\
\text { Limit }\end{array}$ & $\begin{array}{l}\text { Lower } \\
\text { Limit }\end{array}$ & Mean & $\begin{array}{l}\text { Standard } \\
\text { Deviation }\end{array}$ & A & B & Lower & Upper \\
\hline ss & 40 & 0.266 & 0.657 & 0.397 & 0.076 & NO & & & & & & & 0.042 & 1.000 \\
\hline$\nabla_{R}$ & 40 & 0.000 & 0.426 & 0.049 & 0.076 & NO & & & & & & & 0.261 & 1.000 \\
\hline$s_{r}$ & 40 & 0.000 & 0.648 & 0.110 & 0.122 & NO & & & & & 0.6183 & 4.9937 & 0.183 & 1.000 \\
\hline$\square(1 / \mathrm{cm})$ & 40 & 0.002 & 0.742 & 0.025 & 0.135 & $\mathrm{LN}$ & -0.299 & -6.032 & -3.694 & 1.337 & & & 0.040 & 0.994 \\
\hline$n$ & 40 & 1.193 & 4.914 & 2.107 & 0.859 & NO & & & & & & & 0.143 & 0.999 \\
\hline $\mathrm{K}_{\mathrm{s}}(\mathrm{cm} / \mathrm{s})$ & 40 & $6.72 \mathrm{E}-08$ & 4.42E-02 & 2.87E-04 & 7.84E-03 & $\mathrm{LN}$ & -3.119 & -16.516 & -8.158 & 2.975 & & & 0.002 & 0.955 \\
\hline Longitudinal & & & & & & & & & & & & & & \\
\hline $\begin{array}{l}\text { Dispersivity }{ }^{1} \\
(\mathrm{~m})\end{array}$ & NA & 0.183 & 0.223 & 0.203 & $\mathrm{NA}$ & UN & - & - & - & - & - & & & \\
\hline$\%$ Gravel & 40 & 0 & 10 & 0.57 & 1.63 & & & & & & & & & \\
\hline $\begin{array}{l}\text { Bulk Density }{ }^{3} \\
\left(\mathrm{~g} / \mathrm{cm}^{3}\right)\end{array}$ & 30 & 1.33 & 2.16 & 1.60 & 0.18 & NO & - & - & - & . & - & & & \\
\hline $\begin{array}{l}\text { Particle } \\
\text { Density }{ }^{3} \\
\left(\mathrm{~g} / \mathrm{cm}^{3}\right)\end{array}$ & & & & & & NO & & & & & & & & \\
\hline
\end{tabular}

†NO = Normal (no transformation required); $\mathrm{LN}=$ Lognormal; $\mathrm{LR}=\mathrm{Log}$ ratio; $\mathrm{SN}=$ Hyperbolic arcsine; UN = Uniform, CO = Constant, $\mathrm{BE}=$ Beta

${ }^{1}$ Taken from Ho, et. al., 1999 [Stochastic Parameter Development for PORFLOW Simulations of the Hanford AX Tank Farm]

${ }^{2}$ Taken from Khaleel, et. al. 2000 (Modeling Data Package for S-SX Field Investigation Report (FIR) [DRAFT])

${ }^{3}$ Taken from Freeman's e-mail to George Last, dated 12/27/01 (finetex1a.doc and HStex1.doc). 
Table 7. Approximation for the distribution function for soil type "Hfs_BC" (Hanford fine sand - BC Cribs and Trenches) based on Khaleel and Freeman (1995) soil category

\begin{tabular}{|c|c|c|c|c|c|c|c|c|c|c|c|c|c|c|}
\hline Hfs_BC & \multirow{2}{*}{\begin{tabular}{|c|}
$\begin{array}{c}\text { Number } \\
\text { of } \\
\text { samples }\end{array}$ \\
\end{tabular}} & \multicolumn{4}{|c|}{ Raw } & \multirow[b]{2}{*}{ Transform +} & \multicolumn{4}{|c|}{ Transformed (normal distribution) } & \multicolumn{2}{|c|}{ Beta Distribution } & \multicolumn{2}{|c|}{ Truncation Limits } \\
\hline & & Low & High & Mean & $\begin{array}{l}\text { Standard } \\
\text { Deviation }\end{array}$ & & $\begin{array}{l}\text { Upper } \\
\text { Limit }\end{array}$ & $\begin{array}{l}\text { Lower } \\
\text { Limit }\end{array}$ & Mean & $\begin{array}{l}\text { Standard } \\
\text { Deviation }\end{array}$ & A & B & Lower & Upper \\
\hline$\square_{s}$ & 18 & 0.323 & 0.444 & 0.380 & 0.040 & $\mathrm{NO}$ & & & & & & & 0.081 & 0.945 \\
\hline$\square_{R}$ & 18 & 0.016 & 0.061 & 0.033 & 0.011 & NO & & & & & & & 0.065 & 0.992 \\
\hline$s_{r}$ & 18 & 0.045 & 0.184 & 0.089 & 0.035 & NO & & & & & 5.8391 & 59.8393 & 0.102 & 0.997 \\
\hline$\square(1 / \mathrm{cm})$ & 18 & 0.005 & 0.201 & 0.021 & 0.045 & LN & -1.604 & -5.279 & -3.874 & 0.889 & & & 0.057 & 0.995 \\
\hline$n$ & 18 & 1.542 & 4.914 & 2.507 & 1.036 & NO & & & & & & & 0.176 & 0.990 \\
\hline $\mathrm{K}_{\mathrm{s}}(\mathrm{cm} / \mathrm{s})$ & 18 & $1.40 \mathrm{E}-04$ & 4.42E-02 & 2.25E-03 & 1.09E-02 & $\mathrm{LN}$ & -3.119 & -8.874 & -6.097 & 1.563 & & & 0.038 & 0.972 \\
\hline Longitudinal & & & & & & & & & & & & & & \\
\hline $\begin{array}{l}\text { Dispersivity }{ }^{1} \\
\text { (m) }\end{array}$ & NA & 0.183 & 0.223 & 0.203 & NA & UN & - & - & - & & - & & & \\
\hline$\%$ Gravel & 18 & 0 & 2 & 0.38 & 0.57 & & & & & & & & & \\
\hline $\begin{array}{l}\text { Bulk Density } \\
\left(\mathrm{g} / \mathrm{cm}^{3}\right)\end{array}$ & 8 & 1.52 & 1.79 & 1.65 & 0.10 & NO & - & - & - & & - & - & & \\
\hline $\begin{array}{l}\text { Particle } \\
\text { Density }{ }^{3} \\
\left(\mathrm{~g} / \mathrm{cm}^{3}\right)\end{array}$ & & & & & & NO & & & & & & & & \\
\hline
\end{tabular}

NO = Normal (no transformation required); $\mathrm{LN}=$ Lognormal; $\mathrm{LR}=\mathrm{Log}$ ratio; $\mathrm{SN}=$ Hyperbolic arcsine; $\mathrm{UN}=$ Uniform, $\mathrm{CO}=$ Constant, $\mathrm{BE}=$ Beta

${ }^{1}$ Taken from Ho, et. al., 1999 [Stochastic Parameter Development for PORFLOW Simulations of the Hanford AX Tank Farm]

${ }^{2}$ Taken from Khaleel, et. al. 2000 (Modeling Data Package for S-SX Field Investigation Report (FIR) [DRAFT])

${ }^{3}$ Taken from Freeman's e-mail to George Last, dated 12/27/01 (finetex1a.doc and HStex1.doc).

Table 8. Approximation for the distribution function for soil type "Hfs_2W" (Hanford fine sand-200 West Area) based on Khaleel and Freeman (1995) soil category S (sand).

\begin{tabular}{|c|c|c|c|c|c|c|c|c|c|c|c|c|c|c|}
\hline Hfs_2W & \multirow{2}{*}{\begin{tabular}{|c|}
$\begin{array}{c}\text { Number } \\
\text { of } \\
\text { samples }\end{array}$ \\
\end{tabular}} & \multicolumn{4}{|c|}{ Raw } & \multirow[b]{2}{*}{ Transformt } & \multicolumn{4}{|c|}{ Transformed (normal distribution) } & \multicolumn{2}{|c|}{ Beta Distribution } & \multicolumn{2}{|c|}{ Truncation Limits } \\
\hline & & Low & High & Mean & $\begin{array}{l}\text { Standard } \\
\text { Deviation } \\
\end{array}$ & & $\begin{array}{c}\text { Upper } \\
\text { Limit }\end{array}$ & $\begin{array}{c}\text { Lower } \\
\text { Limit }\end{array}$ & Mean & $\begin{array}{l}\text { Standard } \\
\text { Deviation } \\
\end{array}$ & A & $\mathrm{B}$ & Lower & Upper \\
\hline ss & 8 & 0.325 & 0.433 & 0.356 & 0.035 & NO & & & & & & & 0.188 & 0.986 \\
\hline$R_{R}$ & 8 & 0.027 & 0.058 & 0.042 & 0.014 & NO & & & & & & & 0.143 & 0.869 \\
\hline$s_{r}$ & 8 & 0.074 & 0.167 & 0.118 & 0.040 & NO & & & & & 7.3390 & 55.0938 & 0.142 & 0.889 \\
\hline$\square(1 / \mathrm{cm})$ & 8 & 0.004 & 0.026 & 0.010 & 0.008 & LN & -3.646 & -5.613 & -4.584 & 0.704 & & & 0.072 & 0.909 \\
\hline$n$ & 8 & 1.574 & 3.294 & 2.177 & 0.546 & NO & & & & & & & 0.135 & 0.980 \\
\hline $\mathrm{K}_{\mathrm{s}}(\mathrm{cm} / \mathrm{s})$ & 8 & $6.72 \mathrm{E}-08$ & 4.62E-04 & 3.67E-05 & $1.76 \mathrm{E}-04$ & LN & -7.680 & -16.516 & -10.212 & 2.808 & & & 0.012 & 0.816 \\
\hline Longitudinal & & & & & & & & & & & & & & \\
\hline $\begin{array}{l}\text { Dispersivity }{ }^{1} \\
\text { (m) }\end{array}$ & NA & 0.183 & 0.223 & 0.203 & NA & UN & - & - & - & & - & & & \\
\hline$\%$ Gravel & 8 & 0 & 2 & 0.38 & 0.74 & & & & & & & & & \\
\hline $\begin{array}{l}\text { Bulk Density } \\
\left(\mathrm{g} / \mathrm{cm}^{3}\right)\end{array}$ & 7 & 1.58 & 1.82 & 1.70 & 0.10 & NO & - & - & - & & - & & & \\
\hline $\begin{array}{l}\text { Particle } \\
\text { Density } \\
\left(\mathrm{g} / \mathrm{cm}^{3}\right)\end{array}$ & & & & & & NO & & & & & & & & \\
\hline
\end{tabular}

†NO = Normal (no transformation required); $\mathrm{LN}=$ Lognormal; $\mathrm{LR}=\mathrm{Log}$ ratio; $\mathrm{SN}=$ Hyperbolic arcsine; UN = Uniform, CO = Constant, $\mathrm{BE}=\mathrm{Bet}$

1 Taken from Ho, et. al., 1999 [Stochastic Parameter Development for PORFLOW Simulations of the Hanford AX Tank Farm]

${ }^{2}$ Taken from Khaleel, et. al. 2000 (Modeling Data Package for S-SX Field Investigation Report (FIR) [DRAFT])

${ }^{3}$ Taken from Freeman's e-mail to George Last, dated 12/27/01 (finetex1a.doc and HStex1.doc)

Table 9. Approximation for the distribution function for soil type "Hfs_U" (Hanford fine sand - 200-UP-1) based on Khaleel and Freeman (1995) soil category S (sand). As

\begin{tabular}{|c|c|c|c|c|c|c|c|c|c|c|c|c|c|c|}
\hline Hfs_U & \multirow{2}{*}{$\begin{array}{c}\text { Number } \\
\text { of } \\
\text { samples }\end{array}$} & \multicolumn{4}{|c|}{ Raw } & \multirow[b]{2}{*}{ Transform } & \multicolumn{4}{|c|}{ Transformed (normal distribution) } & \multicolumn{2}{|c|}{ Beta Distribution } & \multicolumn{2}{|c|}{ Truncation Limits } \\
\hline Parameter & & Low & High & Mean & $\begin{array}{l}\text { Standard } \\
\text { Deviation }\end{array}$ & & $\begin{array}{l}\text { Upper } \\
\text { Limit }\end{array}$ & $\begin{array}{c}\text { Lower } \\
\text { Limit }\end{array}$ & Mean & $\begin{array}{c}\text { Standard } \\
\text { Deviation }\end{array}$ & A & B & Lower & Upper \\
\hline s & 4 & 0.325 & 0.374 & 0.347 & 0.021 & NO & & & & & & & 0.150 & 0.902 \\
\hline$R_{R}$ & 4 & 0.028 & 0.057 & 0.042 & 0.015 & NO & & & & & & & 0.173 & 0.837 \\
\hline$s_{r}$ & 4 & 0.074 & 0.163 & 0.122 & 0.047 & NO & & & & & 5.9087 & 42.5209 & 0.153 & 0.809 \\
\hline$\square(1 / \mathrm{cm})$ & $\begin{array}{l}4 \\
4\end{array}$ & $\begin{array}{l}0.004 \\
1.673\end{array}$ & $\begin{array}{l}0.026 \\
3.294\end{array}$ & $\begin{array}{l}0.013 \\
2.451\end{array}$ & $\begin{array}{l}0.010 \\
0.663\end{array}$ & $\begin{array}{l}\text { LN } \\
\text { NO }\end{array}$ & -3.646 & -5.613 & -4.380 & 0.888 & & & $\frac{0.082}{0.120}$ & $\frac{0.796}{0.898}$ \\
\hline $\mathrm{K}_{\mathrm{s}}(\mathrm{cm} / \mathrm{s})$ & 4 & $6.72 \mathrm{E}-08$ & 4.62E-04 & $1.71 \mathrm{E}-05$ & 2.15E-04 & $\mathrm{LN}$ & -7.680 & -16.516 & -10.975 & 3.841 & & & 0.075 & 0.805 \\
\hline $\begin{array}{l}\text { Longitudinal } \\
\text { Dispersivity } \\
\end{array}$ & INA & 0183 & 0223 & 0203 & NA & UN & - & - & . & & - & & & \\
\hline$\%$ Gravel & 4 & $\frac{0.100}{0}$ & $\frac{0.223}{0}$ & $\frac{0.203}{0}$ & 0 & UIN & & & & & & & & \\
\hline $\begin{array}{l}\text { Bulk Density } \\
\left(\mathrm{g} / \mathrm{cm}^{3}\right)\end{array}$ & 4 & 1.58 & 1.82 & 1.72 & 0.12 & NO & - & - & - & & - & & & \\
\hline $\begin{array}{l}\text { Particle } \\
\text { Density } \\
\left(\mathrm{g} / \mathrm{cm}^{3}\right)\end{array}$ & & & & & & NO & & & & & & & & \\
\hline
\end{tabular}

†NO = Normal (no transformation required); $\mathrm{LN}=$ Lognormal; $\mathrm{LR}=\mathrm{Log}$ ratio; $\mathrm{SN}=$ Hyperbolic arcsine; $\mathrm{UN}=$ Uniform, $\mathrm{CO}=$ Constant, $\mathrm{BE}=$ Beta

Taken from Ho, et. al., 1999 [Stochastic Parameter Development for PORFLOW Simulations of the Hanford AX Tank Farm]

${ }^{2}$ Taken from Khaleel, et. al. 2000 (Modeling Data Package for S-SX Field Investigation Report (FIR) [DRAFT])

3 Taken from Freeman's e-mail to George Last, dated 12/27/01 (finetex1a.doc and HStex1.doc). 
Table 10. Approximation for the distribution function for soil type "Hfs_Z" (Hanford fine sand - 200-ZP-1) based on Khaleel and Freeman (1995) soil category S (sand). As

\begin{tabular}{|c|c|c|c|c|c|c|c|c|c|c|c|c|c|c|}
\hline Hfs_Z & \multirow{2}{*}{$\begin{array}{c}\begin{array}{c}\text { Number } \\
\text { of } \\
\text { samples }\end{array} \\
\end{array}$} & \multicolumn{4}{|c|}{ Raw } & \multirow[b]{2}{*}{ Transform† } & \multicolumn{4}{|c|}{ Transformed (normal distribution) } & \multicolumn{2}{|c|}{ Beta Distribution } & \multicolumn{2}{|c|}{ Truncation Limits } \\
\hline Parameter & & Low & High & Mean & $\begin{array}{l}\text { Standard } \\
\text { Deviation }\end{array}$ & & $\begin{array}{l}\text { Upper } \\
\text { Limit }\end{array}$ & $\begin{array}{c}\text { Lower } \\
\text { Limit }\end{array}$ & Mean & $\begin{array}{c}\text { Standard } \\
\text { Deviation }\end{array}$ & A & B & Lower & Upper \\
\hline ss & 4 & 0.326 & 0.433 & 0.366 & 0.047 & NO & & & & & & & 0.199 & 0.925 \\
\hline$\square_{R}$ & 4 & 0.027 & 0.058 & 0.042 & 0.015 & NO & & & & & & & 0.169 & 0.850 \\
\hline$s_{r}$ & 4 & 0.082 & 0.167 & 0.113 & 0.040 & NO & & & & & 6.9964 & 54.8679 & 0.218 & 0.911 \\
\hline $\begin{array}{l}\square(1 / \mathrm{cm}) \\
n\end{array}$ & $\begin{array}{l}4 \\
4\end{array}$ & $\begin{array}{l}0.004 \\
1.574\end{array}$ & $\begin{array}{l}0.013 \\
2.086\end{array}$ & $\begin{array}{l}0.008 \\
1.903\end{array}$ & $\begin{array}{l}0.004 \\
0.238\end{array}$ & $\begin{array}{l}\mathrm{LN} \\
\mathrm{NO}\end{array}$ & -4.358 & -5.521 & -4.788 & 0.508 & & & $\begin{array}{l}0.074 \\
0.083\end{array}$ & $\frac{0.802}{0.779}$ \\
\hline $\mathrm{K}_{\mathrm{s}}(\mathrm{cm} / \mathrm{s})$ & 4 & $1.38 \mathrm{E}-05$ & 3.70E-04 & $7.88 \mathrm{E}-05$ & $1.61 \mathrm{E}-04$ & $\mathrm{LN}$ & -7.902 & -11.191 & -9.449 & 1.446 & & & 0.114 & 0.858 \\
\hline $\begin{array}{l}\text { Longitudinal } \\
\text { Dispersivity }{ }^{1} \\
\text { (m) }\end{array}$ & NA & 0.183 & 0.223 & 0.203 & $N A$ & UN & - & 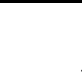 & & - & - & & & \\
\hline$\%$ Gravel & 4 & 0 & 2 & 0.75 & 0.95742711 & NO & & & & & & & & \\
\hline $\begin{array}{l}\text { Bulk Density } \\
\left(\mathrm{g} / \mathrm{cm}^{3}\right)\end{array}$ & 4 & 1.59 & 1.76 & 1.68 & 0.08544004 & NO & - & - & & - & - & & & \\
\hline $\begin{array}{l}\text { Particle } \\
\text { Density } \\
\left(\mathrm{g} / \mathrm{cm}^{3}\right)\end{array}$ & & & & & & NO & & & & & & & & \\
\hline
\end{tabular}

TNO = Normal (no transformation required); $L N=$ Lognormal; $L R=L$ og ratio; $S N=$ Hyperbolic arcsine; $U N=$ Uniform, $C O=$ Constant, $B E=B e t a$

${ }^{1}$ Taken from Ho, et. al., 1999 [Stochastic Parameter Development for PORFLOW Simulations of the Hanford AX Tank Farm]

${ }^{2}$ Taken from Khaleel, et. al. 2000 (Modeling Data Package for S-SX Field Investigation Report (FIR) [DRAFT])

${ }^{3}$ Taken from Freeman's e-mail to George Last, dated 12/27/01 (finetex1a.doc and HStex1.doc).

\begin{tabular}{|c|c|c|c|c|c|c|c|c|c|c|c|c|c|c|}
\hline Hcs & \multirow{2}{*}{\begin{tabular}{|c|}
$\begin{array}{c}\text { Number } \\
\text { of } \\
\text { samples }\end{array}$ \\
\end{tabular}} & \multicolumn{4}{|c|}{ Raw } & \multirow[b]{2}{*}{ Transform } & \multicolumn{4}{|c|}{ Transformed (normal distribution) } & \multicolumn{2}{|c|}{ Beta Distribution } & \multicolumn{2}{|c|}{ Truncation Limits } \\
\hline Parameter & & Low & High & Mean & $\begin{array}{l}\text { Standard } \\
\text { Deviation } \\
\end{array}$ & & $\begin{array}{l}\text { Upper } \\
\text { Limit }\end{array}$ & $\begin{array}{c}\text { Lower } \\
\text { Limit }\end{array}$ & Mean & $\begin{array}{l}\text { Standard } \\
\text { Deviation }\end{array}$ & A & $\mathrm{B}$ & Lower & Upper \\
\hline as & 82 & 0.197 & 0.651 & 0.353 & 0.077 & NO & & & & & & & 0.022 & 1.000 \\
\hline$R_{R}$ & 82 & 0.000 & 0.370 & 0.031 & 0.041 & NO & & & & & & & 0.225 & 1.000 \\
\hline$s_{r}$ & 82 & 0.000 & 0.569 & 0.084 & 0.069 & NO & & & & & 1.2795 & 13.8715 & 0.111 & 1.000 \\
\hline$\square(1 / \mathrm{cm})$ & 82 & 0.002 & 0.861 & 0.059 & 0.133 & $\mathrm{LN}$ & -0.149 & -6.119 & -2.838 & 1.052 & & & 0.001 & 0.995 \\
\hline$n$ & 82 & 1.266 & 5.000 & 2.020 & 0.680 & NO & & & & & & & 0.134 & 1.000 \\
\hline $\mathrm{K}_{\mathrm{s}}(\mathrm{cm} / \mathrm{s})$ & 81 & 2.100E-05 & $5.800 \mathrm{E}-02$ & 2.188E-03 & 1.197E-02 & $\mathrm{LN}$ & -2.847 & -10.771 & -6.125 & 1.741 & & & 0.004 & 0.970 \\
\hline Longitudinal & & & & & & & & & & & & & & \\
\hline $\begin{array}{l}\text { Dispersivity }{ }^{1} \\
(\mathrm{~m})\end{array}$ & NA & 1.83E-01 & 0.223 & 0.203 & NA & UN & - & - & & - & - & & & \\
\hline$\%$ Gravel & 82 & 0.00 & 31.90 & 2.55 & 4.56 & & & & & & & & & \\
\hline $\begin{array}{l}\text { Bulk Density } \\
\left(\mathrm{g} / \mathrm{cm}^{3}\right)\end{array}$ & 69 & 1.51 & 2.02 & 1.66 & 0.10 & NO & - & - & & - & - & & & \\
\hline \begin{tabular}{|l|} 
Particle \\
Density \\
$\left(\mathrm{g} / \mathrm{cm}^{3}\right)$ \\
\end{tabular} & & & & & & NO & & & & & & & & \\
\hline
\end{tabular}

†NO = Normal (no transformation required); $\mathrm{LN}=$ Lognormal; $\mathrm{LR}=\mathrm{Log}$ ratio; $\mathrm{SN}=$ Hyperbolic arcsine; UN = Uniform, CO = Constant, BE = Beta

${ }^{1}$ Taken from Ho, et. al., 1999 [Stochastic Parameter Development for PORFLOW Simulations of the Hanford AX Tank Farm]

${ }^{2}$ Taken from Khaleel, et. al. 2000 (Modeling Data Package for S-SX Field Investigation Report (FIR) [DRAFT])

3 Taken from Freeman's e-mail to George Last, dated 12/27/01 (finetex1a.doc and HStex1.doc).

Table 12. Approximation for the distribution function for soil type "Hcs_BC" (Hanford coarse sand - BC crib and trench area) based on Khaleel and Freeman (1995) soil

\begin{tabular}{|c|c|c|c|c|c|c|c|c|c|c|c|c|c|c|}
\hline Hcs_BC & \multirow{2}{*}{$\begin{array}{c}\text { Number } \\
\text { of } \\
\text { samples }\end{array}$} & \multicolumn{4}{|c|}{ Raw } & \multirow[b]{2}{*}{ Transform $\dagger$} & \multicolumn{4}{|c|}{ Transformed (normal distribution) } & \multicolumn{2}{|c|}{ Beta Distribution } & \multicolumn{2}{|c|}{ Truncation Limits } \\
\hline & & Low & High & Mean & $\begin{array}{l}\text { Standard } \\
\text { Deviation }\end{array}$ & & $\begin{array}{c}\text { Upper } \\
\text { Limit }\end{array}$ & $\begin{array}{c}\text { Lower } \\
\text { Limit }\end{array}$ & Mean & $\begin{array}{l}\text { Standard } \\
\text { Deviation }\end{array}$ & A & $\mathrm{B}$ & Lower & Upper \\
\hline 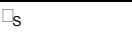 & 46 & 0.245 & 0.453 & 0.357 & 0.052 & NO & & & & & & & 0.016 & 0.968 \\
\hline$R_{R}$ & 46 & 0.000 & 0.045 & 0.026 & 0.011 & NO & & & & & & & 0.007 & 0.964 \\
\hline$s_{r}$ & 46 & 0.000 & 0.129 & 0.074 & 0.031 & NO & & & & & 5.1305 & 64.6175 & 0.009 & 0.964 \\
\hline$\square(1 / \mathrm{cm})$ & $\begin{array}{l}46 \\
46\end{array}$ & $\begin{array}{l}0.013 \\
1337\end{array}$ & $\begin{array}{l}0.861 \\
4.170\end{array}$ & $\begin{array}{l}0.072 \\
2.047\end{array}$ & $\begin{array}{l}0.146 \\
0.581\end{array}$ & LN & -0.149 & -4.343 & -2.632 & 0.800 & & & $\frac{0.016}{0.111}$ & $\frac{0.999}{1.000}$ \\
\hline $\mathrm{K}_{\mathrm{s}}(\mathrm{cm} / \mathrm{s})$ & $\begin{array}{l}40 \\
46\end{array}$ & 5.16E-04 & 4.93E-02 & $5.32 \mathrm{E}-03$ & $1.18 \mathrm{E}-02$ & $\mathrm{LN}$ & -3.010 & -7.569 & -5.235 & 1.173 & & & 0.023 & 0.971 \\
\hline \begin{tabular}{|l|} 
Longitudinal \\
Dispersivity \\
(m)
\end{tabular} & NA & 1.83E-01 & 0.223 & 0.203 & NA & UN & - & - & - & - & - & & & \\
\hline$\%$ Gravel & 46 & 0 & 31.9 & 2.68 & 5.34 & & & & & & & & & \\
\hline $\begin{array}{l}\text { Bulk Density }{ }^{3} \\
\left(\mathrm{~g} / \mathrm{cm}^{3}\right)\end{array}$ & 37 & 1.51 & 1.92 & 1.67 & 0.10 & NO & - & - & - & - & - & & & \\
\hline $\begin{array}{l}\text { Particle } \\
\text { Density }{ }^{3} \\
\left(\mathrm{~g} / \mathrm{cm}^{3}\right)\end{array}$ & & & & & & $\mathrm{NO}$ & & & & & & & & \\
\hline
\end{tabular}

$\dagger \mathrm{NO}=$ Normal (no transformation required); $\mathrm{LN}=$ Lognormal; $\mathrm{LR}=\mathrm{Log}$ ratio; $\mathrm{SN}=$ Hyperbolic arcsine; $\mathrm{UN}=$ Uniform, $\mathrm{CO}=$ Constant, $\mathrm{BE}=\mathrm{Beta}$

${ }_{1}^{1}$ Taken from Ho, et. al., 1999 [Stochastic Parameter Development for PORFLOW Simulations of the Hanford AX Tank Farm]

${ }^{2}$ Taken from Khaleel, et. al. 2000 (Modeling Data Package for S-SX Field Investigation Report (FIR) [DRAFT])

${ }^{3}$ Taken from Freeman's e-mail to George Last, dated 12/27/01 (finetex1a.doc and HStex1.doc). 
Table 13. Approximation for the distribution function for soil type "Hcs_2W" (Hanford coarse sand - 200 West Area) based on Khaleel and Freeman (1995) soil category S

\begin{tabular}{|c|c|c|c|c|c|c|c|c|c|c|c|c|c|c|}
\hline Hcs_2W & \multirow{2}{*}{$\begin{array}{c}\begin{array}{c}\text { Number } \\
\text { of } \\
\text { samples }\end{array} \\
\end{array}$} & \multicolumn{4}{|c|}{ Raw } & \multirow[b]{2}{*}{ Transformt } & \multicolumn{4}{|c|}{ Transformed (normal distribution) } & \multicolumn{2}{|c|}{ Beta Distribution } & \multicolumn{2}{|c|}{ Truncation Limits } \\
\hline Parameter & & Low & High & Mean & $\begin{array}{l}\text { Standard } \\
\text { Deviation }\end{array}$ & & $\begin{array}{l}\text { Upper } \\
\text { Limit }\end{array}$ & $\begin{array}{l}\text { Lower } \\
\text { Limit }\end{array}$ & Mean & \begin{tabular}{l|} 
Standard \\
Deviation
\end{tabular} & A & B & Lower & Upper \\
\hline s & 7 & 0.208 & 0.427 & 0.318 & 0.085 & $\mathrm{NO}$ & & & & & & & 0.098 & 0.900 \\
\hline$\square_{R}$ & 7 & 0.000 & 0.050 & 0.026 & 0.016 & NO & & & & & & & 0.048 & 0.936 \\
\hline$s_{r}$ & 7 & 0.000 & 0.117 & 0.077 & 0.039 & NO & & & & & 3.4657 & 41.3731 & 0.025 & 0.843 \\
\hline$\square(1 / \mathrm{cm})$ & 7 & 0.007 & 0.131 & 0.041 & 0.042 & LN & -2.034 & -4.978 & -3.183 & 0.970 & & & 0.032 & 0.882 \\
\hline$n$ & 7 & 1.311 & 2.096 & 1.759 & 0.301 & NO & & & & & & & 0.068 & 0.868 \\
\hline $\mathrm{K}_{\mathrm{s}}(\mathrm{cm} / \mathrm{s})$ & 7 & $1.80 \mathrm{E}-04$ & $5.80 \mathrm{E}-02$ & $1.09 \mathrm{E}-03$ & 2.16E-02 & LN & -2.847 & -8.623 & -6.822 & 2.002 & & & 0.184 & 0.976 \\
\hline $\begin{array}{l}\text { Longitudinal } \\
\text { Dispersivity }{ }^{1} \\
\text { (m) }\end{array}$ & NA & 1.83E-01 & 0.223 & 0.203 & NA & UN & - & - & - & & - & & & \\
\hline$\%$ Gravel & 7 & 0.000 & 15.000 & 2.143 & 5.669 & & & & & & & & & \\
\hline $\begin{array}{l}\text { Bulk Density } \\
\left(\mathrm{g} / \mathrm{cm}^{3}\right)\end{array}$ & 5 & 1.490 & 1.860 & 1.650 & 0.143 & NO & - & - & - & & - & & & \\
\hline \begin{tabular}{|l} 
Particle \\
Density \\
$\left(\mathrm{g} / \mathrm{cm}^{3}\right)$ \\
\end{tabular} & & & & & & NO & & & & & & & & \\
\hline
\end{tabular}

$+\mathrm{NO}=$ Normal (no transformation required); $\mathrm{LN}=$ Lognormal; $\mathrm{LR}=\mathrm{Log}$ ratio; $\mathrm{SN}=$ Hyperbolic arcsine; UN = Uniform, $\mathrm{CO}=$ Constant, $\mathrm{BE}=\mathrm{Beta}$

${ }^{1}$ Taken from Ho, et. al., 1999 [Stochastic Parameter Development for PORFLOW Simulations of the Hanford AX Tank Farm]

${ }^{2}$ Taken from Khaleel, et. al. 2000 (Modeling Data Package for S-SX Field Investigation Report (FIR) [DRAFT])

${ }^{3}$ Taken from Freeman's e-mail to George Last, dated 12/27/01 (finetex1a.doc and HStex1.doc)

Table 14. Approximation for the distribution function for soil type "Hcs_Z" (Hanford coarse sand - 200-ZP-1) based on Khaleel and Freeman (1995) soil category S (sand).

\begin{tabular}{|c|c|c|c|c|c|c|c|c|c|c|c|c|c|c|}
\hline Hcs_z & \multirow{2}{*}{\begin{tabular}{|c}
$\begin{array}{c}\text { Number } \\
\text { of } \\
\text { samples }\end{array}$ \\
\end{tabular}} & \multicolumn{4}{|c|}{ Raw } & \multirow[b]{2}{*}{ Transform† } & \multicolumn{4}{|c|}{ Transformed (normal distribution) } & \multicolumn{2}{|c|}{ Beta Distribution } & \multicolumn{2}{|c|}{ Truncation Limits } \\
\hline Parameter & & Low & High & Mean & $\begin{array}{l}\text { Standard } \\
\text { Deviation }\end{array}$ & & $\begin{array}{l}\text { Upper } \\
\text { Limit }\end{array}$ & $\begin{array}{l}\text { Lower } \\
\text { Limit }\end{array}$ & Mean & $\begin{array}{l}\text { Standard } \\
\text { Deviation }\end{array}$ & A & $\mathrm{B}$ & Lower & Upper \\
\hline s & 5 & 0.208 & 0.392 & 0.292 & 0.083 & NO & & & & & & & 0.157 & 0.886 \\
\hline$R$ & 5 & 0.000 & 0.040 & 0.021 & 0.014 & NO & & & & & & & 0.065 & 0.903 \\
\hline$s_{r}$ & 5 & 0.000 & 0.110 & 0.069 & 0.043 & NO & & & & & 2.3367 & 31.3462 & 0.054 & 0.824 \\
\hline$\square(1 / \mathrm{cm})$ & 5 & 0.041 & 0.131 & 0.067 & 0.037 & LN & -2.034 & -3.199 & -2.710 & 0.496 & & & 0.162 & 0.914 \\
\hline$n$ & 5 & 1.311 & 2.067 & 1.692 & 0.319 & NO & & & & & & & 0.116 & 0.880 \\
\hline $\mathrm{K}_{\mathrm{s}}(\mathrm{cm} / \mathrm{s})$ & 5 & $1.80 \mathrm{E}-04$ & $5.80 \mathrm{E}-02$ & $1.49 \mathrm{E}-03$ & $2.55 \mathrm{E}-02$ & LN & -2.847 & -8.623 & -6.512 & 2.361 & & & 0.186 & 0.940 \\
\hline Longitudinal & & & & & & & & & & & & & & \\
\hline $\begin{array}{l}\text { Dispersivity }{ }^{1} \\
\text { (m) }\end{array}$ & NA & 1.83E-01 & 0.223 & 0.203 & NA & UN & - & - & & - & - & & & \\
\hline$\%$ Gravel & 5 & 0 & 0 & 0 & 0 & & & & & & & & & \\
\hline $\begin{array}{l}\text { Bulk Density }{ }^{3} \\
\left(\mathrm{~g} / \mathrm{cm}^{3}\right)\end{array}$ & 3 & 1.49 & 1.65 & 1.56 & 0.08 & $\mathrm{NO}$ & - & - & & - & - & & & \\
\hline \begin{tabular}{|l} 
Particle \\
Density \\
$\left(\mathrm{g} / \mathrm{cm}^{3}\right)$ \\
\end{tabular} & & & & & & NO & & & & & & & & \\
\hline
\end{tabular}

$\dagger \mathrm{NO}=$ Normal (no transformation required); $\mathrm{LN}=$ Lognormal; $\mathrm{LR}=\mathrm{Log}$ ratio; $\mathrm{SN}=$ Hyperbolic arcsine; $\mathrm{UN}=$ Uniform, $\mathrm{CO}=$ Constant, $\mathrm{BE}=\mathrm{Beta}$

${ }^{1}$ Taken from Ho, et. al., 1999 [Stochastic Parameter Development for PORFLOW Simulations of the Hanford AX Tank Farm]

${ }^{2}$ Taken from Khaleel, et. al. 2000 (Modeling Data Package for S-SX Field Investigation Report (FIR) [DRAFT])

${ }^{3}$ Taken from Freeman's e-mail to George Last, dated 12/27/01 (finetex1a.doc and HStex1.doc).

Table 15. Approximation for the distribution function for soil type "Hgs" (Hanford gravelly sand) based on Khaleel and Freeman (1995) soil category GS

\begin{tabular}{|c|c|c|c|c|c|c|c|c|c|c|c|c|c|c|}
\hline Hgs & \multirow{2}{*}{\begin{tabular}{|c|}
$\begin{array}{c}\text { Number } \\
\text { of } \\
\text { samples }\end{array}$ \\
\end{tabular}} & \multicolumn{4}{|c|}{ Raw } & \multirow[b]{2}{*}{ Transform $†$} & \multicolumn{4}{|c|}{ Transformed (normal distribution) } & \multicolumn{2}{|c|}{ Beta Distribution } & \multicolumn{2}{|c|}{ Truncation Limits } \\
\hline Parameter & & Low & High & Mean & $\begin{array}{l}\text { Standard } \\
\text { Deviation }\end{array}$ & & $\begin{array}{c}\text { Upper } \\
\text { Limit }\end{array}$ & $\begin{array}{c}\text { Lower } \\
\text { Limit }\end{array}$ & Mean & $\begin{array}{l}\text { Standard } \\
\text { Deviation }\end{array}$ & A & $\mathrm{B}$ & Lower & Upper \\
\hline$\sigma_{s}$ & 17 & 0.180 & 0.436 & 0.250 & 0.071 & $\mathrm{NO}$ & - & - & - & 4 & - & . & 0.164 & 0.995 \\
\hline$G_{R}$ & 17 & 0.010 & 0.248 & 0.046 & 0.055 & NO & - & - & - & - & - & - & 0.258 & 1.000 \\
\hline$s_{r}$ & 17 & 0.030 & 0.569 & 0.165 & 0.122 & NO & & & & & 1.3622 & 6.8814 & 0.134 & 1.000 \\
\hline$\square(1 / \mathrm{cm})$ & 17 & 0.004 & 0.090 & 0.013 & 0.023 & LN & -2.411 & -5.655 & -4.313 & 1.033 & - & - & 0.330 & 1.000 \\
\hline$n$ & 17 & 1.529 & 4.148 & 2.111 & 0.681 & NO & & & & & - & & 0.197 & 0.999 \\
\hline $\mathrm{K}_{\mathrm{s}}(\mathrm{cm} / \mathrm{s})$ & 17 & 2.00E-06 & $9.00 \mathrm{E}-02$ & 4.73E-04 & $2.16 \mathrm{E}-02$ & LR & -2.408 & -13.122 & -7.657 & 2.626 & - & - & 0 & 1 \\
\hline \begin{tabular}{|l} 
Longitudinal \\
Dispersivity ${ }^{1}$ \\
(m)
\end{tabular} & NA & $4.68 \mathrm{E}-02$ & 0.134 & 0.088 & NA & UN & - & - & - & & - & & & \\
\hline$\%$ Gravel & 17 & 10 & 40.00 & 25.78 & 9.65 & $\mathrm{NO}$ & & & & & & & & \\
\hline Bulk Density ${ }^{2}$ & 15 & 1.68 & 2.16 & 1.92 & 0.16 & NO & - & - & - & & - & & & \\
\hline
\end{tabular}

†NO = Normal (no transformation required); $\mathrm{LN}=$ Lognormal; $\mathrm{LR}=\mathrm{Log}$ ratio; SN = Hyperbolic arcsine; UN = Uniform, CO = Constant, BE = Beta

${ }^{1}$ Taken from Ho, et. al., 1999 [Stochastic Parameter Development for PORFLOW Simulations of the Hanford AX Tank Farm]

${ }^{2}$ Taken from Khaleel, et. al. 2000 (Modeling Data Package for S-SX Field Investigation Report (FIR) [DRAFT]). Same as SG1. 
Table 16. Approximation for the distribution function for soil type "Hgs_2W" (Hanford gravelly sand - 200 West Area) based on Khaleel and Freeman (1995) soil category

\begin{tabular}{|c|c|c|c|c|c|c|c|c|c|c|c|c|c|c|}
\hline Hgs_2W & \multirow{2}{*}{\begin{tabular}{|c|}
$\begin{array}{c}\text { Number } \\
\text { of } \\
\text { samples }\end{array}$ \\
\end{tabular}} & \multicolumn{4}{|c|}{ Raw } & \multirow[b]{2}{*}{ Transformt } & \multicolumn{4}{|c|}{ Transformed (normal distribution) } & \multicolumn{2}{|c|}{ Beta Distribution } & \multicolumn{2}{|c|}{ Truncation Limits } \\
\hline Parameter & & Low & High & Mean & $\begin{array}{l}\text { Standard } \\
\text { Deviation } \\
\end{array}$ & & $\begin{array}{c}\text { Upper } \\
\text { Limit }\end{array}$ & $\begin{array}{c}\text { Lower } \\
\text { Limit } \\
\end{array}$ & Mean & $\begin{array}{l}\text { Standard } \\
\text { Deviation }\end{array}$ & A & $\mathrm{B}$ & Lower & Upper \\
\hline 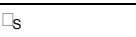 & 2 & 0.208 & 0.337 & 0.273 & 0.091 & $\mathrm{NO}$ & - & - & - & 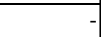 & - & & 0.240 & 0.760 \\
\hline$R_{R}$ & 2 & 0.010 & 0.049 & 0.030 & 0.028 & NO & - & - & - & & - & & 0.240 & 0.760 \\
\hline$s_{r}$ & 2 & 0.030 & 0.237 & 0.133 & 0.147 & $\mathrm{BE}$ & & & & & 0.5829 & 3.7866 & 0.049 & 0.103 \\
\hline$\square(1 / \mathrm{cm})$ & 2 & 0.004 & 0.016 & 0.008 & 0.008 & $\mathrm{LN}$ & -4.160 & -5.521 & -4.841 & 0.962 & - & - & 0.317 & 0.826 \\
\hline$n$ & 2 & 2.023 & 2.423 & 2.223 & 0.283 & NO & - & - & - & & - & & 0.240 & 0.760 \\
\hline $\mathrm{K}_{\mathrm{s}}(\mathrm{cm} / \mathrm{s})$ & 2 & 5.43E-05 & $1.02 \mathrm{E}-03$ & 2.35E-04 & 6.83E-04 & LR & -6.888 & -9.821 & -8.354 & 2.074 & - & & 0 & \\
\hline Longitudinal & & & & & & & & & & & & & & \\
\hline $\begin{array}{l}\text { Dispersivity }{ }^{1} \\
(\mathrm{~m})\end{array}$ & NA & 4.68E-02 & 0.134 & 0.088 & NA & UN & - & - & - & & - & & & \\
\hline$\%$ Gravel & 2 & 17.00 & 31.00 & 24.00 & 9.90 & $\mathrm{NO}$ & & & & & & & & \\
\hline Bulk Density ${ }^{2}$ & 2 & 1.73 & 1.89 & 1.81 & 0.11 & NO & - & - & - & - & - & & & \\
\hline
\end{tabular}

†NO = Normal (no transformation required); $\mathrm{LN}=\mathrm{Lognormal}$; $\mathrm{LR}=\mathrm{Log}$ ratio; $\mathrm{SN}=$ Hyperbolic arcsine; UN = Uniform, CO = Constant, $\mathrm{BE}=\mathrm{Beta}$

1 Taken from Ho, et. al., 1999 [Stochastic Parameter Development for PORFLOW Simulations of the Hanford AX Tank Farm]

${ }^{2}$ Taken from Khaleel, et. al. 2000 (Modeling Data Package for S-SX Field Investigation Report (FIR) [DRAFT]). Same as SG1.

Table 17. Approximation for the distribution function for soil type "Hg" (Hanford sandy gravel) based on Khaleel and Freeman (1995) soil category SG1 (sandy gravel with

\begin{tabular}{|c|c|c|c|c|c|c|c|c|c|c|c|c|c|c|}
\hline $\mathrm{Hg}$ & \multirow{2}{*}{\begin{tabular}{|c|}
$\begin{array}{c}\text { Number } \\
\text { of } \\
\text { samples }\end{array}$ \\
\end{tabular}} & \multicolumn{4}{|c|}{ Raw } & \multirow[b]{2}{*}{ Transformt } & \multicolumn{4}{|c|}{ Transformed (normal distribution) } & \multicolumn{2}{|c|}{ Beta Distribution } & \multicolumn{2}{|c|}{ Truncation Limits } \\
\hline Parameter & & Low & High & Mean & $\begin{array}{l}\text { Standard } \\
\text { Deviation }\end{array}$ & & $\begin{array}{c}\text { Upper } \\
\text { Limit }\end{array}$ & $\begin{array}{c}\text { Lower } \\
\text { Limit }\end{array}$ & Mean & $\begin{array}{c}\text { Standard } \\
\text { Deviation }\end{array}$ & A & B & Lower & Upper \\
\hline$a_{s}$ & 29 & 0.072 & 0.307 & 0.167 & 0.047 & NO & - & - & - & - & - & & 0.022 & 0.999 \\
\hline$R_{R}$ & 29 & 0.000 & 0.062 & 0.023 & 0.014 & NO & - & - & - & . & - & & 0.046 & 0.997 \\
\hline$s_{r}$ & 29 & 0.000 & 0.387 & 0.143 & 0.084 & NO & & & & & 2.3024 & 13.8393 & 0.046 & 0.998 \\
\hline$\square(1 / \mathrm{cm})$ & 29 & 0.002 & 0.919 & 0.018 & 0.190 & $\mathrm{LN}$ & -0.084 & -6.075 & -4.024 & 1.481 & - & & 0.083 & 0.996 \\
\hline$n$ & 29 & 1.347 & 2.947 & 1.727 & 0.360 & NO & & & & & - & & 0.146 & 1.000 \\
\hline $\mathrm{K}_{\mathrm{s}}(\mathrm{cm} / \mathrm{s})$ & 28 & $1.90 \mathrm{E}-07$ & $3.70 \mathrm{E}-02$ & 3.56E-04 & 8.72E-03 & $\mathrm{LN}$ & -3.297 & -15.476 & -7.941 & 3.228 & - & & 0.010 & 0.925 \\
\hline \begin{tabular}{|l} 
Longitudinal \\
\end{tabular} & & & & & & & & & & & & & & \\
\hline $\begin{array}{l}\text { Dispersivity }{ }^{1} \\
\text { (m) }\end{array}$ & NA & 0.027 & 0.178 & 0.09 & NA & UN & - & - & - & - & - & & & \\
\hline$\%$ Gravel & 29 & 22 & 80 & 51.42 & 12.81 & $\mathrm{NO}$ & & & & & & & & \\
\hline Bulk Density $^{2}$ & 26 & 1.6 & 2.3 & 1.91 & 0.21 & NO & - & - & - & - & - & & & \\
\hline
\end{tabular}

†NO = Normal (no transformation required); $L N=$ Lognormal; $L R=$ Log ratio; SN = Hyperbolic arcsine; UN = Uniform, CO = Constant, BE = Beta

${ }_{1}^{1}$ Taken from Ho, et. al., 1999 [Stochastic Parameter Development for PORFLOW Simulations of the Hanford AX Tank Farm]. Same as SSG

${ }^{2}$ Taken from Khaleel, et. al. 2000 (Modeling Data Package for S-SX Field Investigation Report (FIR) [DRAFT]). Same as SG-1.

Table 18. Approximation for the distribution function for soil type "Hg_2W" (Hanford sandy gravel -200 West Area) based on Khaleel and Freeman (1995) soil category SG1

\begin{tabular}{|c|c|c|c|c|c|c|c|c|c|c|c|c|c|c|}
\hline Hg_2W & \multirow{2}{*}{$\begin{array}{c}\begin{array}{c}\text { Number } \\
\text { of } \\
\text { samples }\end{array} \\
\end{array}$} & \multicolumn{4}{|c|}{ Raw } & \multirow[b]{2}{*}{ Transform† } & \multicolumn{4}{|c|}{ Transformed (normal distribution) } & \multicolumn{2}{|c|}{ Beta Distribution } & \multicolumn{2}{|c|}{ Truncation Limits } \\
\hline Parameter & & Low & High & Mean & $\begin{array}{l}\text { Standard } \\
\text { Deviation }\end{array}$ & & $\begin{array}{l}\text { Upper } \\
\text { Limit }\end{array}$ & $\begin{array}{c}\text { Lower } \\
\text { Limit }\end{array}$ & Mean & $\begin{array}{l}\text { Standard } \\
\text { Deviation } \\
\end{array}$ & A & $\mathrm{B}$ & Lower & Upper \\
\hline$\square_{s}$ & 12 & 0.072 & 0.217 & 0.154 & 0.040 & NO & - & - & - & & - & & 0.020 & 0.940 \\
\hline$R_{R}$ & 12 & 0.000 & 0.062 & 0.027 & 0.017 & NO & 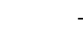 & - & - & - & - & & 0.054 & 0.980 \\
\hline$s_{r}$ & 12 & 0.000 & 0.387 & 0.172 & 0.106 & $\mathrm{BE}$ & & & & & 2.0011 & 9.6331 & 0 & 0.087 \\
\hline$\square(1 / \mathrm{cm})$ & 12 & 0.002 & 0.276 & 0.016 & 0.077 & LN & -1.288 & -6.075 & -4.106 & 1.318 & - & & 0.068 & 0.984 \\
\hline$n$ & 12 & 1.347 & 2.269 & 1.745 & 0.324 & NO & & & & & - & & 0.109 & 0.948 \\
\hline $\mathrm{K}_{\mathrm{s}}(\mathrm{cm} / \mathrm{s})$ & 12 & 3.30E-06 & 3.70E-02 & $1.48 \mathrm{E}-03$ & $1.21 \mathrm{E}-02$ & LN & -3.297 & -12.622 & -6.515 & 2.829 & - & & 0.015 & 0.872 \\
\hline Longitudinal & & & & & & & & & & & & & & \\
\hline $\begin{array}{l}\text { Dispersivity }{ }^{1} \\
(\mathrm{~m})\end{array}$ & NA & 0.027 & 0.178 & 0.09 & NA & UN & - & - & - & & - & & & \\
\hline$\%$ Gravel & 12 & 39.000 & 80.000 & 54.358 & 12.380 & $\mathrm{NO}$ & & & & & & & & \\
\hline Bulk Density ${ }^{2}$ & 9 & 1.630 & 2.300 & 1.891 & 0.225 & $\mathrm{NO}$ & - & - & - & - & - & & & \\
\hline
\end{tabular}

$\mathrm{TNO}=$ Normal (no transformation required); $\mathrm{LN}=$ Lognormal; $\mathrm{LR}=\mathrm{Log}$ ratio; $\mathrm{SN}=$ Hyperbolic arcsine; UN = Uniform, CO = Constant, $\mathrm{BE}=$ Beta

${ }^{1}$ Taken from Ho, et. al., 1999 [Stochastic Parameter Development for PORFLOW Simulations of the Hanford AX Tank Farm]. Same as SSG

${ }^{2}$ Taken from Khaleel, et. al. 2000 (Modeling Data Package for S-SX Field Investigation Report (FIR) [DRAFT]). Same as SG-1. 
Table 19. Approximation for the distribution function for soil type "Hg_U" (Hanford sandy gravel - 200-UP-1) based on Khaleel and Freeman (1995) soil category SG1 (sandy

\begin{tabular}{|c|c|c|c|c|c|c|c|c|c|c|c|c|c|c|}
\hline Hg_U & \multirow{2}{*}{\begin{tabular}{|c|}
$\begin{array}{c}\text { Number } \\
\text { of } \\
\text { samples }\end{array}$ \\
\end{tabular}} & \multicolumn{4}{|c|}{ Raw } & \multirow[b]{2}{*}{ Transformt } & \multicolumn{4}{|c|}{ Transformed (normal distribution) } & \multicolumn{2}{|c|}{ Beta Distribution } & \multicolumn{2}{|c|}{ Truncation Limits } \\
\hline Parameter & & Low & High & Mean & $\begin{array}{l}\text { Standard } \\
\text { Deviation }\end{array}$ & & $\begin{array}{l}\text { Upper } \\
\text { Limit }\end{array}$ & $\begin{array}{c}\text { Lower } \\
\text { Limit } \\
\end{array}$ & Mean & $\begin{array}{l}\text { Standard } \\
\text { Deviation }\end{array}$ & A & $\mathrm{B}$ & Lower & Upper \\
\hline 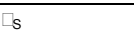 & 3 & 0.124 & 0.194 & 0.150 & 0.039 & $\mathrm{NO}$ & - & - & - & - & - & & 0.249 & 0.875 \\
\hline$R_{R}$ & 3 & 0.028 & 0.030 & 0.029 & 0.001 & NO & - & - & - & & - & & 0.136 & 0.805 \\
\hline$s_{r}$ & 3 & 0.144 & 0.239 & 0.204 & 0.052 & $\mathrm{BE}$ & & & & & 12.0545 & 46.9891 & 0 & 0.087 \\
\hline$\square(1 / \mathrm{cm})$ & 3 & 0.006 & 0.033 & 0.011 & 0.015 & $\mathrm{LN}$ & -3.417 & -5.083 & -4.473 & 0.918 & - & & 0.253 & 0.875 \\
\hline$n$ & 3 & 1.660 & 2.205 & 1.845 & 0.312 & NO & & & & & - & & 0.277 & 0.876 \\
\hline $\mathrm{K}_{\mathrm{s}}(\mathrm{cm} / \mathrm{s})$ & 3 & 3.300E-06 & $5.590 \mathrm{E}-03$ & $2.884 \mathrm{E}-04$ & $2.924 \mathrm{E}-03$ & LN & -5.187 & -12.622 & -8.151 & 3.940 & - & & 0.128 & 0.774 \\
\hline Longitudinal & & & & & & & & & & & & & & \\
\hline $\begin{array}{l}\text { Dispersivity }{ }^{1} \\
\text { (m) }\end{array}$ & NA & 0.027 & 0.178 & 0.09 & NA & UN & - & - & - & & - & & & \\
\hline$\%$ Gravel & 3 & 43.3 & 65 & 57.10 & 11.99 & NO & & & & & & & & \\
\hline Bulk Density ${ }^{2}$ & 3 & 1.8 & 2.3 & 2.09 & 0.26 & NO & - & - & - & - & - & & & \\
\hline
\end{tabular}

†NO = Normal (no transformation required); $\mathrm{LN}=$ Lognormal; $\mathrm{LR}=\mathrm{Log}$ ratio; $\mathrm{SN}=$ Hyperbolic arcsine; UN = Uniform, CO = Constant, BE = Beta

Taken from Ho, et. al., 1999 [Stochastic Parameter Development for PORFLOW Simulations of the Hanford AX Tank Farm]. Same as SSG

${ }^{2}$ Taken from Khaleel, et. al. 2000 (Modeling Data Package for S-SX Field Investigation Report (FIR) [DRAFT]). Same as SG-1.

Table 20. Approximation for the distribution function for soil type "Hg_Z" (Hanford sandy gravel - 200-ZP-1) based on Khaleel and Freeman (1995) soil category SG1 (sandy

\begin{tabular}{|c|c|c|c|c|c|c|c|c|c|c|c|c|c|c|}
\hline $\mathrm{Hg}_{2} \mathrm{Z}$ & \multirow{2}{*}{$\begin{array}{c}\begin{array}{c}\text { Number } \\
\text { of } \\
\text { samples }\end{array} \\
\end{array}$} & \multicolumn{4}{|c|}{ Raw } & \multirow[b]{2}{*}{ Transform $\dagger$} & \multicolumn{4}{|c|}{ Transformed (normal distribution) } & \multicolumn{2}{|c|}{ Beta Distribution } & \multicolumn{2}{|c|}{ Truncation Limits } \\
\hline Parameter & & Low & High & Mean & $\begin{array}{l}\text { Standard } \\
\text { Deviation }\end{array}$ & & $\begin{array}{c}\text { Upper } \\
\text { Limit }\end{array}$ & $\begin{array}{c}\text { Lower } \\
\text { Limit }\end{array}$ & Mean & $\begin{array}{l}\text { Standard } \\
\text { Deviation }\end{array}$ & A & B & Lower & Upper \\
\hline$\square$ & 9 & 0.072 & 0.217 & 0.156 & 0.043 & $\mathrm{NO}$ & - & - & - & - & - & & 0.025 & 0.922 \\
\hline$R$ & 9 & 0.000 & 0.062 & 0.026 & 0.020 & NO & - & - & - & . & - & & 0.090 & 0.964 \\
\hline$s_{r}$ & 9 & 0.000 & 0.387 & 0.161 & 0.120 & NO & & & & & 1.3637 & 7.0918 & 0.089 & 0.970 \\
\hline$\square(1 / \mathrm{cm})$ & 9 & 0.002 & 0.276 & 0.019 & 0.088 & LN & -1.288 & -6.075 & -3.983 & 1.453 & - & & 0.075 & 0.968 \\
\hline$n$ & 9 & 1.347 & 2.269 & 1.711 & 0.339 & NO & & & & & - & & 0.141 & 0.950 \\
\hline $\mathrm{K}_{\mathrm{s}}(\mathrm{cm} / \mathrm{s})$ & 8 & 2.83E-05 & 3.70E-02 & $3.51 \mathrm{E}-03$ & 1.37E-02 & LN & -3.297 & -10.473 & -5.651 & 2.359 & - & & 0.020 & 0.841 \\
\hline Longitudinal & & & & & & & & & & & & & & \\
\hline $\begin{array}{l}\text { Dispersivity }{ }^{1} \\
\text { (m) }\end{array}$ & NA & 0.027 & 0.178 & 0.09 & NA & UN & - & - & - & - & - & & & \\
\hline$\%$ Gravel & 9 & 39 & 80 & 53.44 & 13.08 & $\mathrm{NO}$ & & & & & & & & \\
\hline \begin{tabular}{|l} 
Bulk Density \\
\end{tabular} & 6 & 1.63 & 1.92 & 1.79 & 0.13 & $\mathrm{NO}$ & - & - & - & - & - & & & \\
\hline
\end{tabular}

†NO = Normal (no transformation required); $L N=$ Lognormal; $L R=$ Log ratio; SN = Hyperbolic arcsine; UN = Uniform, CO = Constant, BE = Beta

${ }^{1}$ Taken from Ho, et. al., 1999 [Stochastic Parameter Development for PORFLOW Simulations of the Hanford AX Tank Farm]. Same as SSG

${ }^{2}$ Taken from Khaleel, et. al. 2000 (Modeling Data Package for S-SX Field Investigation Report (FIR) [DRAFT]). Same as SG-1.

Table 21. Approximation for the distribution function for soil type "Hrg" (Hanford River Gravel) based on Khaleel and Freeman (1995) soil category SG2 (sandy gravel with

\begin{tabular}{|c|c|c|c|c|c|c|c|c|c|c|c|c|c|c|}
\hline $\mathrm{Hrg}$ & & & $\mathrm{Ra}$ & & & & Transf & rmed (no & nal distrik & bution) & Beta Di & tribution & Truncati & n Limits \\
\hline Parameter & $\begin{array}{c}\text { of } \\
\text { samples }\end{array}$ & Low & High & Mean & $\begin{array}{l}\text { Standard } \\
\text { Deviation }\end{array}$ & Transform $\dagger$ & $\begin{array}{c}\text { Upper } \\
\text { Limit }\end{array}$ & $\begin{array}{c}\text { Lower } \\
\text { Limit }\end{array}$ & Mean & $\begin{array}{l}\text { Standard } \\
\text { Deviation }\end{array}$ & A & B & Lower & Upper \\
\hline $\mathrm{s}$ & 40 & 0.051 & 0.191 & 0.102 & 0.031 & NO & & & & & - & & 0.048 & 0.998 \\
\hline$R$ & 40 & 0.007 & 0.036 & 0.020 & 0.007 & NO & & & & & - & & 0.045 & 0.987 \\
\hline$s_{r}$ & 40 & 0.082 & 0.359 & 0.197 & 0.066 & $\mathrm{BE}$ & & & & & 6.8937 & 28.1745 & 0 & 0.079 \\
\hline$\square(1 / \mathrm{cm})$ & 40 & 0.002 & 0.048 & 0.007 & 0.010 & LN & -3.047 & -6.119 & -4.907 & 0.763 & - & & 0.056 & 0.993 \\
\hline$n$ & 40 & 1.449 & 2.315 & 1.831 & 0.197 & NO & & & & & - & & 0.026 & 0.993 \\
\hline $\mathrm{K}_{\mathrm{s}}(\mathrm{cm} / \mathrm{s})$ & 40 & $3.70 \mathrm{E}-05$ & $3.90 \mathrm{E}-01$ & $1.46 \mathrm{E}-03$ & $6.26 \mathrm{E}-02$ & LN & -0.942 & -10.205 & -6.532 & 2.062 & - & & 0.037 & 0.997 \\
\hline 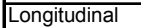 & & & & & & & & & & & & & & \\
\hline $\begin{array}{l}\text { Dispersivity }{ }^{1} \\
(\mathrm{~m})\end{array}$ & NA & 0.027 & 0.178 & 0.09 & $\mathrm{NA}$ & UN & - & - & - & - & - & & & \\
\hline \% Gravel & 40 & 50 & 85 & 67.63 & 8.83 & $\mathrm{NO}$ & & & & & & & & \\
\hline Bulk Density $^{2}$ & 40 & 1.56 & 2.42 & 1.97 & 0.16 & $\mathrm{NO}$ & - & & & & - & & & \\
\hline
\end{tabular}

$\mathrm{NO}=$ Normal (no transformation required); $\mathrm{LN}=\mathrm{Lognormal}$; $\mathrm{LR}=\mathrm{Log}$ ratio; SN = Hyperbolic arcsine; UN = Uniform, CO = Constant, BE = Beta

${ }_{1}^{1}$ Taken from Ho, et. al., 1999 [Stochastic Parameter Development for PORFLOW Simulations of the Hanford AX Tank Farm]. Same as SSG.

${ }^{2}$ Taken from Khaleel, et. al. 2000 (Modeling Data Package for S-SX Field Investigation Report (FIR) [DRAFT]). Same as SG-1. 
Table 22. Approximation for the distribution function for soil type "PPIz" (Plio-Pleistocene-silt) based on Khaleel and Freeman (1995) soil category SS (sand mixed with finer

\begin{tabular}{|c|c|c|c|c|c|c|c|c|c|c|c|c|c|c|}
\hline PPIz & \multirow{2}{*}{$\begin{array}{c}\text { Number } \\
\text { of } \\
\text { samples }\end{array}$} & \multicolumn{4}{|c|}{ Raw } & \multirow[b]{2}{*}{ Transform $†$} & \multicolumn{4}{|c|}{ Transformed (normal distribution) } & \multicolumn{2}{|c|}{ Beta Distribution } & \multicolumn{2}{|c|}{ Truncation Limits } \\
\hline & & Low & High & Mean & $\begin{array}{l}\text { Standard } \\
\text { Deviation }\end{array}$ & & $\begin{array}{c}\text { Upper } \\
\text { Limit }\end{array}$ & $\begin{array}{c}\text { Lower } \\
\text { Limit }\end{array}$ & Mean & $\begin{array}{c}\text { Standard } \\
\text { Deviation }\end{array}$ & A & B & Lower & Upper \\
\hline$\square_{s}$ & 9 & 0.293 & 0.533 & 0.420 & 0.092 & $\mathrm{NO}$ & & & & & & & 0.082 & 0.891 \\
\hline$R_{R}$ & 9 & 0.010 & 0.060 & 0.034 & 0.016 & NO & & & & & & & 0.073 & 0.946 \\
\hline$s_{r}$ & 9 & 0.020 & 0.113 & 0.080 & 0.029 & NO & & & & & 6.8296 & 78.7949 & 0.020 & 0.870 \\
\hline$\square(1 / \mathrm{cm})$ & 9 & 0.001 & 0.019 & 0.006 & 0.005 & LN & -3.988 & -6.522 & -5.200 & 0.702 & & & 0.030 & 0.958 \\
\hline$n$ & 9 & 1.522 & 2.815 & 2.101 & 0.464 & NO & & & & & & & 0.106 & 0.938 \\
\hline $\mathrm{K}_{\mathrm{s}}(\mathrm{cm} / \mathrm{s})$ & 9 & 4.12E-07 & 1.36E-01 & $5.57 \mathrm{E}-05$ & 4.53E-02 & LN & -1.995 & -14.702 & -9.795 & 3.805 & & & 0.099 & 0.980 \\
\hline Longitudinal & & & & & & & & & & & & & & \\
\hline $\begin{array}{l}\text { Dispersivity }{ }^{1} \\
\text { (m) }\end{array}$ & NA & 0.0279 & 0.0341 & 0.031 & NA & UN & - & - & - & - & - & & & \\
\hline$\%$ Gravel & 9 & 0 & 4 & 0.44 & 1.33 & & & & & & & & & \\
\hline $\begin{array}{l}\text { Bulk Density }{ }^{3} \\
\left(\mathrm{~g} / \mathrm{cm}^{3}\right)\end{array}$ & 9 & 1.55 & 1.8 & 1.68 & 0.08 & NO & - & - & - & - & - & & & \\
\hline $\begin{array}{l}\text { Particle } \\
\text { Density }{ }^{3} \\
\left(\mathrm{~g} / \mathrm{cm}^{3}\right)\end{array}$ & & & & & & NO & & & & & & & & \\
\hline
\end{tabular}

NO = Normal (no transformation required); $\mathrm{LN}=$ Lognormal; $\mathrm{LR}=\mathrm{Log}$ ratio; $\mathrm{SN}=$ Hyperbolic arcsine; UN = Uniform, CO = Constant, $\mathrm{BE}=\mathrm{Beta}$

Taken from Ho, et. al., 1999 [Stochastic Parameter Development for PORFLOW Simulations of the Hanford AX Tank Farm].

${ }^{2}$ Taken from Khaleel, et. al. 2000 (Modeling Data Package for S-SX Field Investigation Report (FIR) [DRAFT]).

${ }^{3}$ Taken from Freeman's e-mail to George Last, dated 12/27/01 (finetex1a.doc and HStex1.doc).

Table 23. Approximation for the distribution function for soil type "PPIz_U" (Plio-Pleistocene-silt - 200-UP-1) based on Khaleel and Freeman (1995) soil category SS (sand

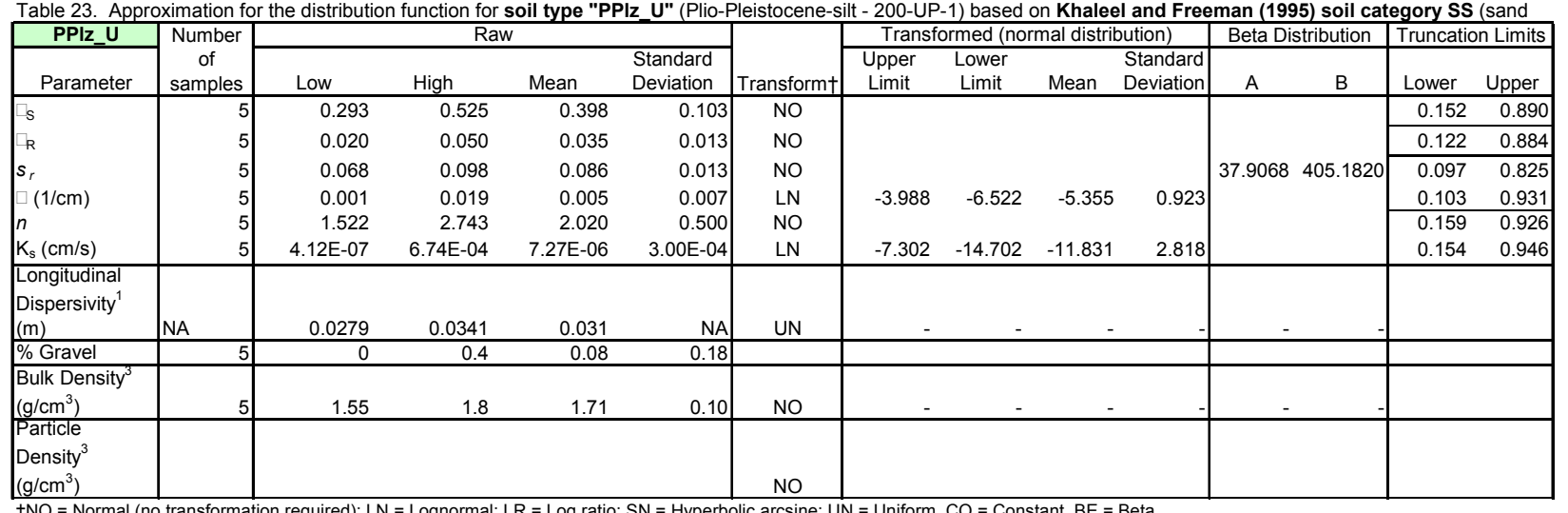

†NO = Normal (no transformation required); $\mathrm{LN}=$ Lognormal; $\mathrm{LR}=\mathrm{Log}$ ratio; $\mathrm{SN}=$ Hyperbolic arcsine; $\mathrm{UN}=$ Uniform, $\mathrm{CO}=$ Constant, $\mathrm{BE}=$ Beta

${ }^{1}$ Taken from Ho, et. al., 1999 [Stochastic Parameter Development for PORFLOW Simulations of the Hanford AX Tank Farm].

${ }^{2}$ Taken from Khaleel, et. al. 2000 (Modeling Data Package for S-SX Field Investigation Report (FIR) [DRAFT]).

${ }^{3}$ Taken from Freeman's e-mail to George Last, dated 12/27/01 (finetex1a.doc and HStex1.doc).

Table 24. Approximation for the distribution function for soil type "PPIz Z" (Plio-Pleistocene-silt - 200-ZP-1) based on Khaleel and Freeman (1995) soil category SS (sand

\begin{tabular}{|c|c|c|c|c|c|c|c|c|c|c|c|c|c|c|}
\hline PPIz_Z & \multirow{2}{*}{$\begin{array}{c}\text { Number } \\
\text { of } \\
\text { samples }\end{array}$} & \multicolumn{4}{|c|}{ Raw } & \multirow[b]{2}{*}{ Transform } & \multicolumn{4}{|c|}{ Transformed (normal distribution) } & \multicolumn{2}{|c|}{ Beta Distribution } & \multicolumn{2}{|c|}{ Truncation Limits } \\
\hline Parameter & & Low & High & Mean & $\begin{array}{l}\text { Standard } \\
\text { Deviation }\end{array}$ & & $\begin{array}{c}\text { Upper } \\
\text { Limit }\end{array}$ & $\begin{array}{c}\text { Lower } \\
\text { Limit }\end{array}$ & Mean & $\begin{array}{l}\text { Standard } \\
\text { Deviation }\end{array}$ & A & B & Lower & Upper \\
\hline ss & 4 & 0.373 & 0.533 & 0.448 & 0.081 & NO & & & & & & & 0.177 & 0.855 \\
\hline$R_{R}$ & 4 & 0.010 & 0.060 & 0.033 & 0.022 & NO & & & & & & & 0.155 & 0.893 \\
\hline$s_{r}$ & 4 & 0.020 & 0.113 & 0.073 & 0.044 & NO & & & & & 2.4964 & 31.9252 & 0.114 & 0.821 \\
\hline$\square(1 / \mathrm{cm})$ & $\begin{array}{l}4 \\
4\end{array}$ & $\begin{array}{l}0.005 \\
1.702\end{array}$ & $\begin{array}{l}0.010 \\
2.815\end{array}$ & $\begin{array}{l}0.007 \\
2.203\end{array}$ & $\begin{array}{l}0.002 \\
0.465\end{array}$ & $\begin{array}{l}\text { LN } \\
\text { NO }\end{array}$ & -4.605 & -5.279 & -5.007 & 0.295 & & & $\frac{0.179}{0.141}$ & $\frac{0.913}{0.906}$ \\
\hline $\mathrm{K}_{\mathrm{s}}(\mathrm{cm} / \mathrm{s})$ & 4 & $6.70 \mathrm{E}-05$ & 1.36E-01 & 7.11E-04 & $6.79 \mathrm{E}-02$ & LN & -1.995 & -9.611 & -7.249 & 3.532 & & & 0.252 & 0.932 \\
\hline $\begin{array}{l}\text { Longitudinal } \\
\text { Dispersivity }{ }^{1} \\
(m)\end{array}$ & & & & & & & & & & & & & & \\
\hline$\frac{(\mathrm{m})}{\% \text { Gravel }}$ & NA & $\begin{array}{r}0.0279 \\
0\end{array}$ & $\begin{array}{r}0.0341 \\
4\end{array}$ & $\begin{array}{r}0.031 \\
1\end{array}$ & $\begin{array}{r}\text { NA } \\
2\end{array}$ & UN & - & - & - & & - & & & \\
\hline $\begin{array}{l}\text { Bulk Density }{ }^{3} \\
\left(\mathrm{~g} / \mathrm{cm}^{3}\right)\end{array}$ & 3 & 1.49 & 1.66 & 1.58 & 0.09 & NO & - & - & - & & - & & & \\
\hline $\begin{array}{l}\text { Particle } \\
\text { Density }{ }^{3} \\
\left(\mathrm{~g} / \mathrm{cm}^{3}\right)\end{array}$ & & & & & & NO & & & & & & & & \\
\hline
\end{tabular}

$\dagger \mathrm{NO}=$ Normal (no transformation required); $\mathrm{LN}=$ Lognormal; $\mathrm{LR}=\mathrm{Log}$ ratio; $\mathrm{SN}=$ Hyperbolic arcsine; $\mathrm{UN}=$ Uniform, $\mathrm{CO}=$ Constant, $\mathrm{BE}=\mathrm{Beta}$

Taken from Ho, et. al., 1999 [Stochastic Parameter Development for PORFLOW Simulations of the Hanford AX Tank Farm].

${ }^{2}$ Taken from Khaleel, et. al. 2000 (Modeling Data Package for S-SX Field Investigation Report (FIR) [DRAFT])

${ }^{3}$ Taken from Freeman's e-mail to George Last, dated 12/27/01 (finetex1a.doc and HStex1.doc). 
Table 25. Approximation for the distribution function for soil type "PPIc" (Plio-Pleistocene-carbonate) based on Khaleel and Freeman (1995) soil category SS (sand mixed

\begin{tabular}{|c|c|c|c|c|c|c|c|c|c|c|c|c|c|c|}
\hline PPIc & \multirow{2}{*}{\begin{tabular}{|c|}
$\begin{array}{c}\text { Number } \\
\text { of } \\
\text { samples }\end{array}$ \\
som
\end{tabular}} & \multicolumn{4}{|c|}{ Raw } & \multirow[b]{2}{*}{ Transform } & \multicolumn{4}{|c|}{ Transformed (normal distribution) } & \multicolumn{2}{|c|}{ Beta Distribution } & \multicolumn{2}{|c|}{ Truncation Limits } \\
\hline Parameter & & Low & High & Mean & $\begin{array}{l}\text { Standard } \\
\text { Deviation } \\
\end{array}$ & & $\begin{array}{c}\text { Upper } \\
\text { Limit } \\
\end{array}$ & $\begin{array}{l}\text { Lower } \\
\text { Limit }\end{array}$ & Mean & $\begin{array}{l}\text { Standard } \\
\text { Deviation }\end{array}$ & A & $\mathrm{B}$ & Lower & Upper \\
\hline 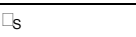 & 16 & 0.193 & 0.631 & 0.306 & 0.111 & $\mathrm{NO}$ & & & & & & & 0.155 & 0.998 \\
\hline$R_{R}$ & 16 & 0.019 & 0.241 & 0.072 & 0.057 & NO & & & & & & & 0.175 & 0.999 \\
\hline$s_{r}$ & 16 & 0.097 & 0.445 & 0.214 & 0.096 & NO & & & & & 3.6651 & 13.4934 & 0.113 & 0.992 \\
\hline$\square(1 / \mathrm{cm})$ & 16 & 0.003 & 0.073 & 0.011 & 0.017 & $\mathrm{LN}$ & -2.620 & -5.843 & -4.525 & 0.847 & & & 0.060 & 0.988 \\
\hline$n$ & 16 & 1.262 & 2.537 & 1.727 & 0.332 & NO & & & & & & & 0.081 & 0.993 \\
\hline $\mathrm{K}_{\mathrm{s}}(\mathrm{cm} / \mathrm{s})$ & 16 & 2.60E-07 & $6.80 \mathrm{E}-02$ & $5.00 \mathrm{E}-04$ & 1.73E-02 & $\mathrm{LN}$ & -2.688 & -15.163 & -7.600 & 3.280 & & & 0.011 & 0.933 \\
\hline Longitudinal & & & & & & & & & & & & & & \\
\hline $\begin{array}{l}\text { Dispersivity }{ }^{1} \\
(\mathrm{~m})\end{array}$ & NA & 0.0279 & 0.0341 & 0.031 & NA & UN & - & - & - & & - & & & \\
\hline$\%$ Gravel & 15 & 0 & 59 & 16.73 & 19.21 & $\mathrm{NO}$ & & & & & & & & \\
\hline $\begin{array}{l}\text { Bulk Density } \\
\left(\mathrm{g} / \mathrm{cm}^{3}\right)\end{array}$ & 16 & 1.48 & 2.13 & 1.71 & 0.18 & NO & - & - & - & . & - & & & \\
\hline $\begin{array}{l}\text { Particle } \\
\text { Density } \\
\left(\mathrm{g} / \mathrm{cm}^{3}\right)\end{array}$ & & & & & & NO & & & & & & & & \\
\hline
\end{tabular}

+NO = Normal (no transformation required); $\mathrm{LN}=$ Lognormal; $\mathrm{LR}=\mathrm{Log}$ ratio; $\mathrm{SN}=$ Hyperbolic arcsine; UN = Uniform, CO = Constant, $\mathrm{BE}=\mathrm{Beta}$

1 Taken from Ho, et. al., 1999 [Stochastic Parameter Development for PORFLOW Simulations of the Hanford AX Tank Farm].

${ }^{2}$ Taken from Khaleel, et. al. 2000 (Modeling Data Package for S-SX Field Investigation Report (FIR) [DRAFT]).

${ }^{3}$ Taken from Freeman's e-mail to George Last, dated 12/27/01 (finetex1a.doc and HStex1.doc).

Table 26. Approximation for the distribution function for soil type "PPIc_Z" (Plio-Pleistocene-carbonate - 200-ZP-1) based on Khaleel and Freeman (1995) soil category SS

\begin{tabular}{|c|c|c|c|c|c|c|c|c|c|c|c|c|c|c|}
\hline PPIc_Z & \multirow{2}{*}{\begin{tabular}{|c|}
$\begin{array}{c}\text { Number } \\
\text { of } \\
\text { samples }\end{array}$ \\
\cline { 2 - 2 }
\end{tabular}} & \multicolumn{4}{|c|}{ Raw } & \multirow[b]{2}{*}{ Transform } & \multicolumn{4}{|c|}{ Transformed (normal distribution) } & \multicolumn{2}{|c|}{ Beta Distribution } & \multicolumn{2}{|c|}{ Truncation Limits } \\
\hline Parameter & & Low & High & Mean & $\begin{array}{l}\text { Standard } \\
\text { Deviation }\end{array}$ & & $\begin{array}{l}\text { Upper } \\
\text { Limit }\end{array}$ & $\begin{array}{l}\text { Lower } \\
\text { Limit } \\
\end{array}$ & Mean & \begin{tabular}{l|} 
Standard \\
Deviation
\end{tabular} & A & B & Lower & Upper \\
\hline s & 15 & 0.193 & 0.631 & 0.312 & 0.112 & NO & & & & & & & 0.146 & 0.998 \\
\hline$R$ & 15 & 0.019 & 0.241 & 0.075 & 0.057 & NO & & & & & & & 0.164 & 0.998 \\
\hline$s_{r}$ & 15 & 0.097 & 0.445 & 0.220 & 0.096 & NO & & & & & 3.8823 & 13.7626 & 0.100 & 0.990 \\
\hline$\square(1 / \mathrm{cm})$ & 15 & 0.003 & 0.073 & 0.011 & 0.018 & LN & -2.620 & -5.843 & -4.518 & 0.876 & & & 0.065 & 0.985 \\
\hline$n$ & 15 & 1.262 & 2.537 & 1.734 & 0.343 & NO & & & & & & & 0.084 & 0.990 \\
\hline $\mathrm{K}_{\mathrm{s}}(\mathrm{cm} / \mathrm{s})$ & 15 & 0.00000026 & 0.068 & 0.00057392 & 0.01771766 & LN & -2.688 & -15.163 & -7.463 & 3.348 & & & 0.011 & 0.923 \\
\hline Longitudinal & & & & & & & & & & & & & & \\
\hline $\begin{array}{l}\text { Dispersivity }{ }^{1} \\
\text { (m) }\end{array}$ & NA & 0.0279 & 0.0341 & 0.031 & NA & UN & - & - & - & & - & & & \\
\hline$\%$ Gravel & 14 & 0.00 & 59.00 & 15.07 & 18.79 & NO & & & & & & & & \\
\hline $\begin{array}{l}\text { Bulk Density }{ }^{3} \\
\left(\mathrm{~g} / \mathrm{cm}^{3}\right)\end{array}$ & 14 & 1.48 & 1.94 & 1.68 & 0.16 & NO & - & - & - & & - & & & \\
\hline $\begin{array}{l}\text { Particle } \\
\text { Density } \\
\left(\mathrm{g} / \mathrm{cm}^{3}\right)\end{array}$ & & & & & & NO & & & & & & & & \\
\hline
\end{tabular}

$\left(\mathrm{g} / \mathrm{cm}^{3}\right)$

†NO = Normal (no transformation required); $\mathrm{LN}=$ Lognormal; $\mathrm{LR}=\mathrm{Log}$ ratio; $\mathrm{SN}=$ Hyperbolic arcsine; $\mathrm{UN}=$ Uniform, $\mathrm{CO}=$ Constant, $\mathrm{BE}=\mathrm{Beta}$

${ }^{1}$ Taken from Ho, et. al., 1999 [Stochastic Parameter Development for PORFLOW Simulations of the Hanford AX Tank Farm].

${ }^{2}$ Taken from Khaleel, et. al. 2000 (Modeling Data Package for S-SX Field Investigation Report (FIR) [DRAFT])

${ }^{3}$ Taken from Freeman's e-mail to George Last, dated 12/27/01 (finetex1a.doc and HStex1.doc).

Table 27. Approximation for the distribution function for soil type "Rg" (Ringold sandy gravel) based on Khaleel and Freeman (1995) soil category SG2 (sandy gravel with

\begin{tabular}{|c|c|c|c|c|c|c|c|c|c|c|c|c|c|c|}
\hline \multirow{2}{*}{\begin{tabular}{|c|}
$\mathbf{R g}$ \\
\\
Parameter \\
\end{tabular}} & \multirow{2}{*}{$\begin{array}{c}\text { Number } \\
\text { of } \\
\text { samples }\end{array}$} & \multicolumn{4}{|c|}{ Raw } & \multirow[b]{2}{*}{ Transform } & \multicolumn{4}{|c|}{ Transformed (normal distribution) } & \multicolumn{2}{|c|}{ Beta Distribution } & \multicolumn{2}{|c|}{ Truncation Limits } \\
\hline & & Low & High & Mean & $\begin{array}{l}\text { Standard } \\
\text { Deviation }\end{array}$ & & $\begin{array}{c}\text { Upper } \\
\text { Limit }\end{array}$ & $\begin{array}{c}\text { Lower } \\
\text { Limit }\end{array}$ & Mean & $\begin{array}{l}\text { Standard } \\
\text { Deviation }\end{array}$ & A & $\mathrm{B}$ & Lower & Upper \\
\hline$a_{s}$ & 18 & 0.056 & 0.433 & 0.178 & 0.139 & NO & & & & & - & & 0.189 & 0.967 \\
\hline$R_{R}$ & 18 & 0.000 & 0.780 & 0.063 & 0.180 & NO & & & & & - & & 0.363 & 1.000 \\
\hline$s_{r}$ & 18 & 0.000 & 1.952 & 0.230 & 0.437 & NO & & & & & 2.1112 & 14.3331 & 0.299 & 1.000 \\
\hline$\square(1 / \mathrm{cm})$ & 18 & 0.003 & 0.059 & 0.008 & 0.014 & LN & -2.827 & -5.952 & -4.853 & 0.893 & - & & 0.109 & 0.988 \\
\hline$n$ & 18 & 1.297 & 2.357 & 1.697 & 0.231 & NO & & & & & - & & 0.042 & 0.998 \\
\hline $\mathrm{K}_{\mathrm{s}}(\mathrm{cm} / \mathrm{s})$ & 18 & $6.20 \mathrm{E}-06$ & $1.30 \mathrm{E}-01$ & 4.13E-04 & 3.04E-02 & $\mathrm{LN}$ & -2.040 & -11.991 & -7.791 & 2.572 & - & & 0.051 & 0.987 \\
\hline \multicolumn{15}{|l|}{ Longitudinal } \\
\hline $\begin{array}{l}\text { Dispersivity }{ }^{1} \\
\text { (m) }\end{array}$ & NA & 0.027 & 0.178 & 0.09 & NA & UN & - & - & - & & - & & & \\
\hline$\%$ Gravel & 18 & 0 & 82 & 46.08 & 30.71 & $\mathrm{NO}$ & & & & & & & & \\
\hline Bulk Density² & 18 & 1.63 & 2.17 & 1.90 & 0.15 & $\mathrm{NO}$ & - & - & - & - & - & & & \\
\hline
\end{tabular}

†NO = Normal (no transformation required); LN = Lognormal; LR = Log ratio; SN = Hyperbolic arcsine; UN = Uniform, CO = Constant, BE = Beta

1 Taken from Ho, et. al., 1999 [Stochastic Parameter Development for PORFLOW Simulations of the Hanford AX Tank Farm]. Same as SSG.

${ }^{2}$ Taken from Khaleel, et. al. 2000 (Modeling Data Package for S-SX Field Investigation Report (FIR) [DRAFT]). Same as SG-1. 
Table 28. Approximation for the distribution function for soil type "Rg_2W" (Ringold sandy gravel - 200 West Area) based on Khaleel and Freeman (1995) soil category SG2

\begin{tabular}{|c|c|c|c|c|c|c|c|c|c|c|c|c|c|c|}
\hline Rg_2W & \multirow{2}{*}{$\begin{array}{c}\text { Number } \\
\text { of } \\
\text { samples }\end{array}$} & \multicolumn{4}{|c|}{ Raw } & \multirow[b]{2}{*}{ Transform $\dagger$} & \multicolumn{4}{|c|}{ Transformed (normal distribution) } & \multicolumn{2}{|c|}{ Beta Distribution } & \multicolumn{2}{|c|}{ Truncation Limits } \\
\hline Parameter & & Low & High & Mean & $\begin{array}{l}\text { Standard } \\
\text { Deviation }\end{array}$ & & $\begin{array}{c}\text { Upper } \\
\text { Limit }\end{array}$ & $\begin{array}{c}\text { Lower } \\
\text { Limit }\end{array}$ & Mean & $\begin{array}{l}\text { Standard } \\
\text { Deviation }\end{array}$ & A & B & Lower & Upper \\
\hline s & 8 & 0.08 & 0.43 & 0.30 & 0.13 & NO & & & & & - & & 0.051 & 0.852 \\
\hline$R$ & 8 & 0.00 & 0.78 & 0.13 & 0.27 & NO & & & & & - & & 0.318 & 0.993 \\
\hline$s_{r}$ & 8 & 0.00 & 1.95 & 0.33 & 0.66 & $\mathrm{BE}$ & & & & & 1.7377 & 15.2226 & 0 & 0.079 \\
\hline$\square(1 / \mathrm{cm})$ & 8 & 0.00 & 0.06 & 0.01 & 0.02 & $\mathrm{LN}$ & -2.827 & -5.547 & -4.329 & 0.879 & - & - & 0.083 & 0.956 \\
\hline$n$ & 8 & 1.30 & 2.36 & 1.75 & 0.30 & NO & & & & & - & 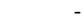 & 0.063 & 0.978 \\
\hline $\mathrm{K}_{\mathrm{s}}(\mathrm{cm} / \mathrm{s})$ & 8 & $7.80 \mathrm{E}-06$ & $8.70 \mathrm{E}-03$ & 1.06E-04 & $3.02 \mathrm{E}-03$ & LN & -4.744 & -11.761 & -9.155 & 2.564 & - & - & 0.155 & 0.957 \\
\hline Longitudinal & & & & & & & & & & & & & & \\
\hline $\begin{array}{l}\text { Dispersivity }{ }^{1} \\
\text { (m) }\end{array}$ & NA & 0.027 & 0.178 & 0.09 & $\mathrm{NA}$ & UN & - & - & - & & - & & & \\
\hline$\%$ Gravel & 8 & 0 & 70 & 22.175 & 28.788 & $\mathrm{NO}$ & & & & & & & & \\
\hline Bulk Density $^{2}$ & 8 & 1.630 & 2.118 & 1.838 & 0.167 & NO & - & - & - & & - & & & \\
\hline
\end{tabular}

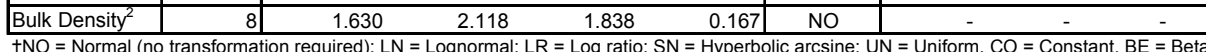

${ }^{1}$ Taken from Ho, et. al., 1999 [Stochastic Parameter Development for PORFLOW Simulations of the Hanford AX Tank Farm]. Same as SSG.

${ }^{2}$ Taken from Khaleel, et. al. 2000 (Modeling Data Package for S-SX Field Investigation Report (FIR) [DRAFT]). Same as SG-1.

Table 29. Approximation for the distribution function for soil type "Rg_U" (Ringold sandy gravel - 200-UP-1) based on Khaleel and Freeman (1995) soil category SG2 (sandy

\begin{tabular}{|c|c|c|c|c|c|c|c|c|c|c|c|c|c|c|}
\hline Rg_U & \multirow{2}{*}{$\begin{array}{c}\text { Number } \\
\text { of } \\
\text { samples }\end{array}$} & \multicolumn{4}{|c|}{ Raw } & \multirow[b]{2}{*}{ Transform } & \multicolumn{4}{|c|}{ Transformed (normal distribution) } & \multicolumn{2}{|c|}{ Beta Distribution } & \multicolumn{2}{|c|}{ Truncation Limits } \\
\hline Parameter & & Low & High & Mean & $\begin{array}{l}\text { Standard } \\
\text { Deviation }\end{array}$ & & $\begin{array}{c}\text { Upper } \\
\text { Limit }\end{array}$ & $\begin{array}{c}\text { Lower } \\
\text { Limit }\end{array}$ & Mean & $\begin{array}{l}\text { Standard } \\
\text { Deviation }\end{array}$ & A & B & Lower & Upper \\
\hline$\sigma_{\mathrm{s}}$ & 7 & 0.083 & 0.433 & 0.318 & 0.125 & $\mathrm{NO}$ & & & & & - & - & 0.030 & 0.821 \\
\hline$R_{R}$ & 7 & 0.009 & 0.780 & 0.144 & 0.282 & NO & & & & & - & & 0.316 & 0.988 \\
\hline$s_{r}$ & 7 & 0.060 & 1.952 & 0.381 & 0.695 & $\mathrm{BE}$ & & & & & 3.2853 & 24.1993 & 0 & 0.079 \\
\hline$\square(1 / \mathrm{cm})$ & 7 & 0.004 & 0.059 & 0.013 & 0.019 & LN & -2.827 & -5.547 & -4.320 & 0.949 & - & . & 0.098 & 0.942 \\
\hline$n$ & 7 & 1.297 & 2.357 & 1.768 & 0.319 & NO & & & & & - & 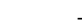 & 0.070 & 0.967 \\
\hline $\mathrm{K}_{\mathrm{s}}(\mathrm{cm} / \mathrm{s})$ & 6 & $8.90 \mathrm{E}-06$ & $1.75 \mathrm{E}-03$ & 7.83E-05 & $6.87 \mathrm{E}-04$ & LN & -6.348 & -11.629 & -9.455 & 1.961 & - & . & 0.134 & 0.943 \\
\hline Longitudinal & & & & & & & & & & & & & & \\
\hline $\begin{array}{l}\text { Dispersivity }{ }^{1} \\
\text { (m) }\end{array}$ & NA & 0.027 & 0.178 & 0.09 & NA & UN & - & - & - & & - & & & \\
\hline$\%$ Gravel & 7 & 0 & 70.00 & 16.49 & 25.78 & $\mathrm{NO}$ & & & & & & & & \\
\hline Bulk Density $^{2}$ & 7 & 1.63 & 2.12 & 1.82 & 0.17 & $\mathrm{NO}$ & - & - & - & & - & & & \\
\hline
\end{tabular}

\begin{tabular}{|l|rrrr|rcc}
\hline Bulk Density & \\
\hline
\end{tabular}

${ }_{1}^{1}$ Taken from Ho, et. al., 1999 [Stochastic Parameter Development for PORFLOW Simulations of the Hanford AX Tank Farm]. Same as SSG.

${ }^{2}$ Taken from Khaleel, et. al. 2000 (Modeling Data Package for S-SX Field Investigation Report (FIR) [DRAFT]). Same as SG-1. 


\section{Appendix C}

Resolution of Discrepancies in the System Assessment Capability Vadose Zone Model for the BC Cribs and Trenches 


\title{
Appendix C
}

\section{Resolution of Discrepancies in the System Assessment Capability Vadose Zone Model for the BC Cribs and Trenches}

\author{
W. E. Nichols
}

The System Assessment Capability (SAC) Initial Assessment (Bryce et al. 2002) exhibited large, early releases of technetium-99. In all cases, the releases from the vadose zone to groundwater were nearly instant, following disposal to ground by only a year or two. To date, no groundwater monitoring data show evidence of any technetium-99 plume from the area of these sites consistent with such large releases.

Because of the large predicted impact of technetium-99 from the $\mathrm{BC}$ cribs and trenches and inconsistency between predictions and groundwater monitoring data, resolution of the vadose zone model at these sites is required.

\section{C.1 Approach}

The SAC vadose zone modeling uses a one-dimensional approach for computational speed. It is recognized that the multidimensional aspects of the vadose zone are highly important, but multidimensional modeling of the hundreds of waste disposal sites addressed in the SAC in a stochastic framework is computationally untenable. For vadose zone sites with liquid discharges, this is compensated by applying $\mathrm{a} \mathrm{K}_{\mathrm{s}}$-dependent wetted area adjustment, wherein the area of the vadose zone area represented in the onedimensional model is scaled so that a unit gradient is attained in the layer with the lowest saturated hydraulic conductivity for the period with the highest liquid discharge rate.

However, for the $\mathrm{BC}$ cribs and trenches, the Ks-depended wetted area adjustment method does not yield an area larger than the site area, so the SAC model defaults to using the Waste Information Data System (WIDS) area. This is equivalent to declaring there is no lateral movement of liquid associated with the liquid discharges at these sites.

I propose that lateral spreading would still occur for the short-duration (less than one year) discharges that occurred at the $\mathrm{BC}$ cribs and trenches, and that two-dimensional modeling of each crib and trench for median input values can be used to quantify the extent of lateral spreading. Lateral spreading of fluid will tend to delay arrival of technetium-99 at the aquifer. If enough delay occurs, then the disposal inventory could still be consistent with the groundwater monitoring data that does not indicate a substantial technetium-99 plume in the vicinity of the BC cribs and trenches before calendar year 2000. 


\section{C.2 Multidimensional Modeling of BC Trenches}

The $\mathrm{BC}$ trenches and their respective areas and discharge volumes are listed in Table C.1. The BC trenches are long relative to their width and were, therefore, idealized as a two-dimensional feature symmetric about the length axis of the trench. An idealized two-dimensional model was constructed that assumes the trench is infinite in length, and that lateral spreading is strictly perpendicular to the trench length axis.

The SAC one-dimensional model for each BC trench with a substantial inventory of technetium-99 (trenches below 216-B-34 in Table C.1 did not have a large disposal of technetium-99) was expanded into a two-dimensional axial-symmetric model (half the trench represented, with results scalable to represent the whole trench). The vertical resolution (580 0.15-meter grid cells) was retained, and the x-axis was resolve into 96, 0.15-meter grid cells. This yielded a model grid of 55,680 grid nodes. The liquid and analyte discharges were converted to density-type sources and assigned to the topmost nodes in the grid index range from 1 to 10 (inner 1.5 meters), representing half the source term (again, consistent with the axial-symmetric treatment).

Hanford soils are anisotropic, considered about 10 times more conductive in the horizontal dimension than in the vertical. To consider this feature, each trench was modeled twice, once with isotropic properties and once with 10:1 anisotropy in saturated hydraulic conductivity.

Table C.1. BC Trenches (data from Maxfield 1979)

\begin{tabular}{||c|c|c||}
\hline \hline WIDS Identification & Area (square meters) & Discharge Volume (liters) \\
\hline \hline $216-\mathrm{B}-20$ & $152.4 \times 3.0=457.2$ & $4.68 \times 10^{6}$ \\
\hline $216-\mathrm{B}-21$ & $152.4 \times 3.0=457.2$ & $4.67 \times 10^{6}$ \\
\hline $216-\mathrm{B}-22$ & $152.4 \times 3.0=457.2$ & $4.74 \times 10^{6}$ \\
\hline $216-\mathrm{B}-23$ & $152.4 \times 3.0=457.2$ & $4.52 \times 10^{6}$ \\
\hline $216-\mathrm{B}-24$ & $152.4 \times 3.0=457.2$ & $4.7 \times 10^{6}$ \\
\hline $216-\mathrm{B}-25$ & $152.4 \times 3.0=457.2$ & $3.76 \times 10^{6}$ \\
\hline $216-\mathrm{B}-26$ & $152.4 \times 3.0=457.2$ & $5.88 \times 10^{6}$ \\
\hline $216-\mathrm{B}-27$ & $152.4 \times 3.0=457.2$ & $4.42 \times 10^{6}$ \\
\hline $216-\mathrm{B}-28$ & $152.4 \times 3.0=457.2$ & $5.05 \times 10^{6}$ \\
\hline $216-\mathrm{B}-29$ & $152.4 \times 3.0=457.2$ & $4.84 \times 10^{6}$ \\
\hline $216-\mathrm{B}-30$ & $152.4 \times 3.0=457.2$ & $4.78 \times 10^{6}$ \\
\hline $216-\mathrm{B}-31$ & $152.4 \times 3.0=457.2$ & $4.74 \times 10^{6}$ \\
\hline $216-\mathrm{B}-32$ & $152.4 \times 3.0=457.2$ & $4.77 \times 10^{6}$ \\
\hline $216-\mathrm{B}-33$ & $152.4 \times 3.0=457.2$ & $4.74 \times 10^{6}$ \\
\hline $216-\mathrm{B}-34$ & $152.4 \times 3.0=457.2$ & $4.87 \times 10^{6}$ \\
\hline $216-\mathrm{B}-52$ & $176.8 \times 3.0=530.4$ & $8.53 \times 10^{6}$ \\
\hline $216-\mathrm{B}-53 \mathrm{~A}$ & $18.3 \times 3.0=54.9$ & $5.49 \times 10^{5}$ \\
\hline $216-\mathrm{B}-53 \mathrm{~B}$ & $45.7 \times 3.0=137.2$ & $1.51 \times 10^{4}$ \\
\hline $216-\mathrm{B}-54$ & $61.0 \times 3.0=182.9$ & $9.99 \times 10^{5}$ \\
\hline $216-\mathrm{B}-58$ & $61.0 \times 3.0=182.9$ & $4.13 \times 10^{5}$ \\
\hline WIDS - Waste Information Data System & \\
\hline \multicolumn{2}{|l}{} \\
\hline
\end{tabular}


Once the release histories for the multidimensional model runs were available, the one-dimensional model was rerun with several AreaX (area scaling parameter) values. By trial-and-error, an AreaX scaling factor that would cause the one-dimensional model to produce releases similar to the twodimensional model (with explicit treatment of lateral flow) was determined. For all BC trenches, the value $\mathrm{AreaX}=3.0$ provided the best match for isotropic conductivity and AreaX $=6.5$ provided the best match for anisotropic (10:1 ratio) conductivity.

Figures C.1 through C.15 provide the modeling results for the $\mathrm{BC}$ trenches with substantial technetium-99 inventory (216-B-20 through 216-B-34, inclusive). Each figure depicts the release from the VADER vadose zone release model (i.e., the "input signal"), the release from the various Subsurface Transport Over Multiple Phases (STOMP) one-dimensional models (with variable AreaX factor values), and from the STOMP two-dimensional models (with isotropic and anisotropic conductivity).

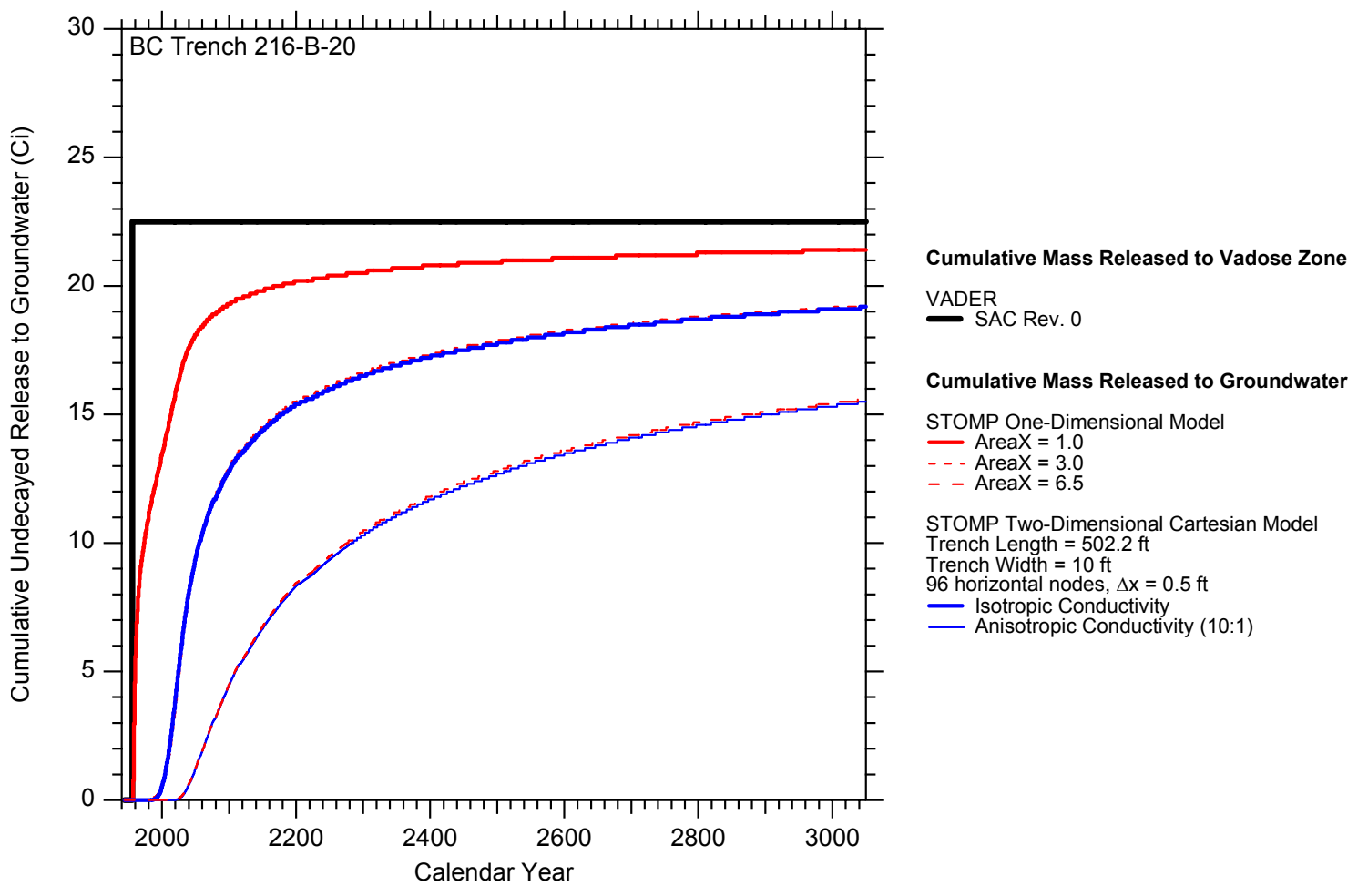

Figure C.1. Vadose Zone Cumulative Release to Groundwater Modeled for Trench 216-B-20 


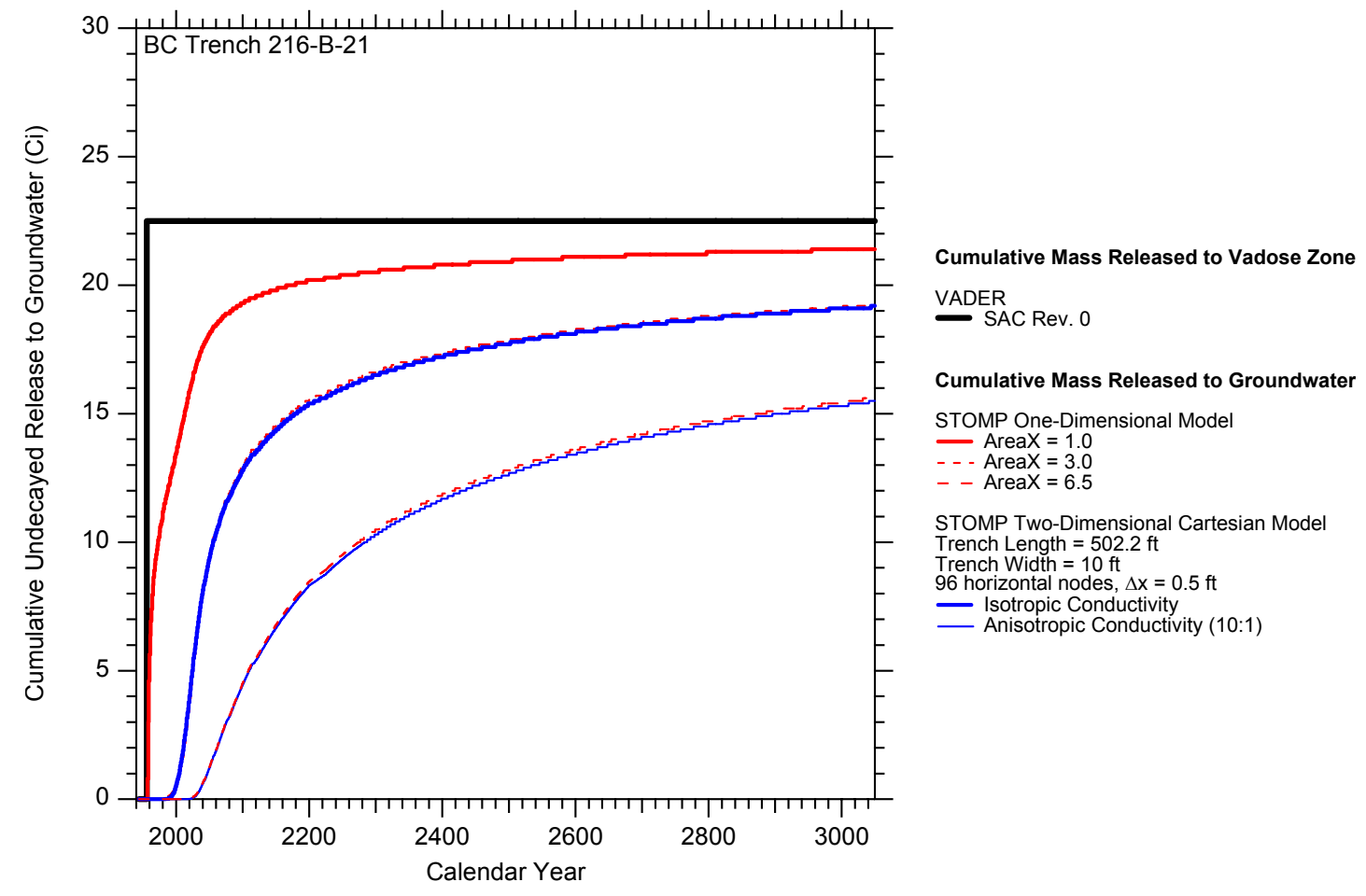

Figure C.2. Vadose Zone Cumulative Release to Groundwater Modeled for Trench 216-B-21

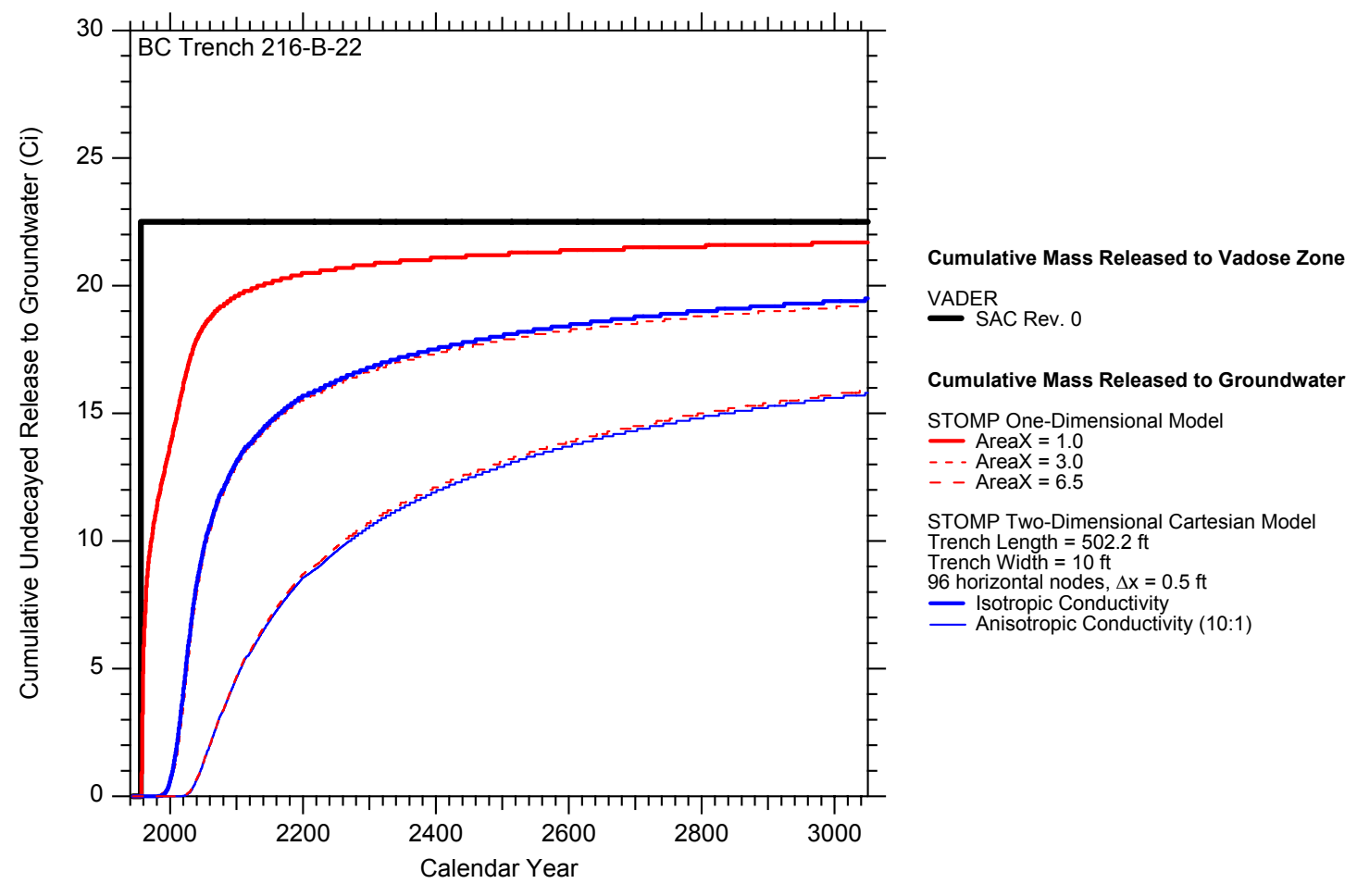

Figure C.3. Vadose Zone Cumulative Release to Groundwater Modeled for Trench 216-B-22 


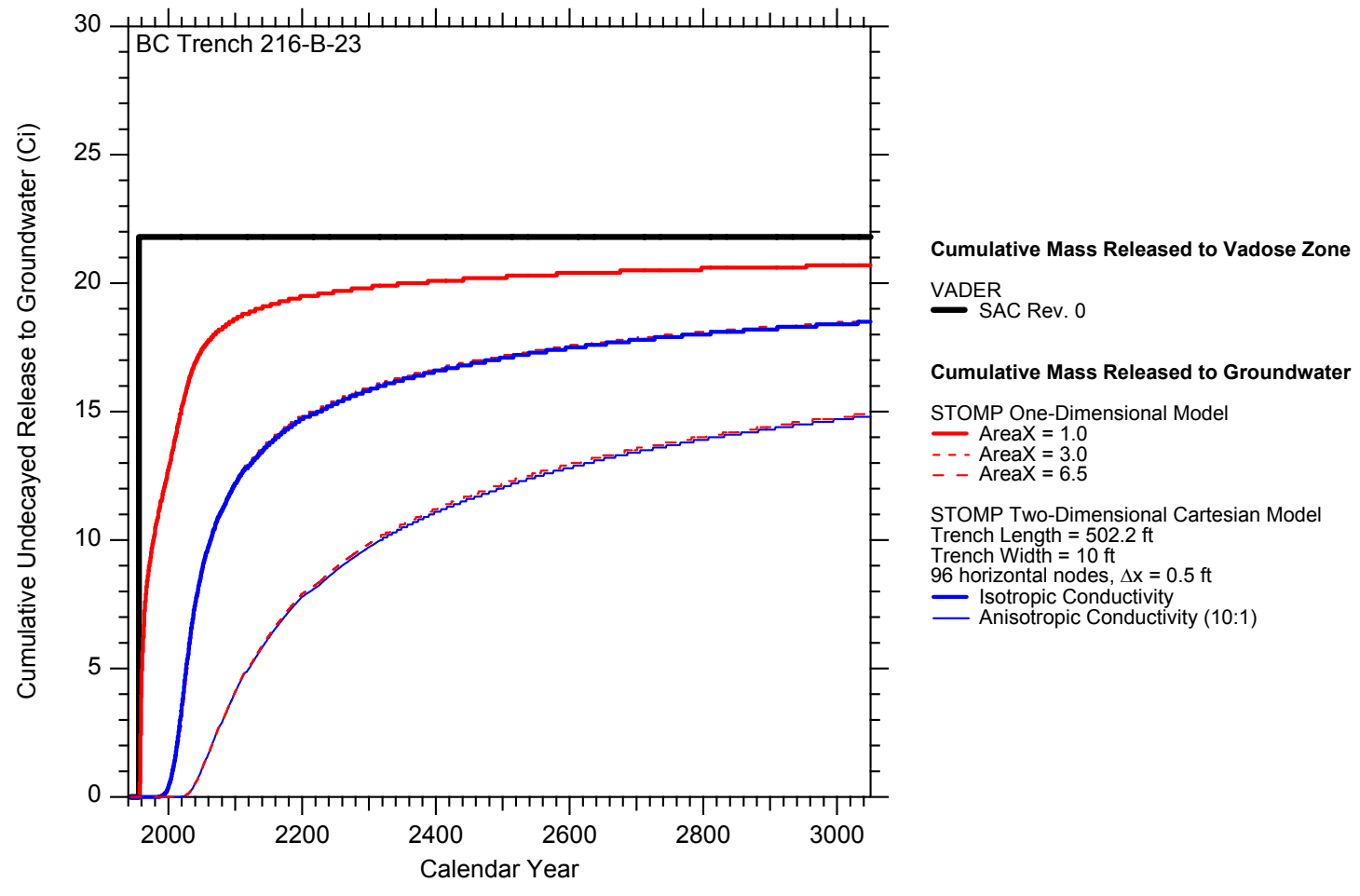

Figure C.4. Vadose Zone Cumulative Release to Groundwater Modeled for Trench 216-B-23

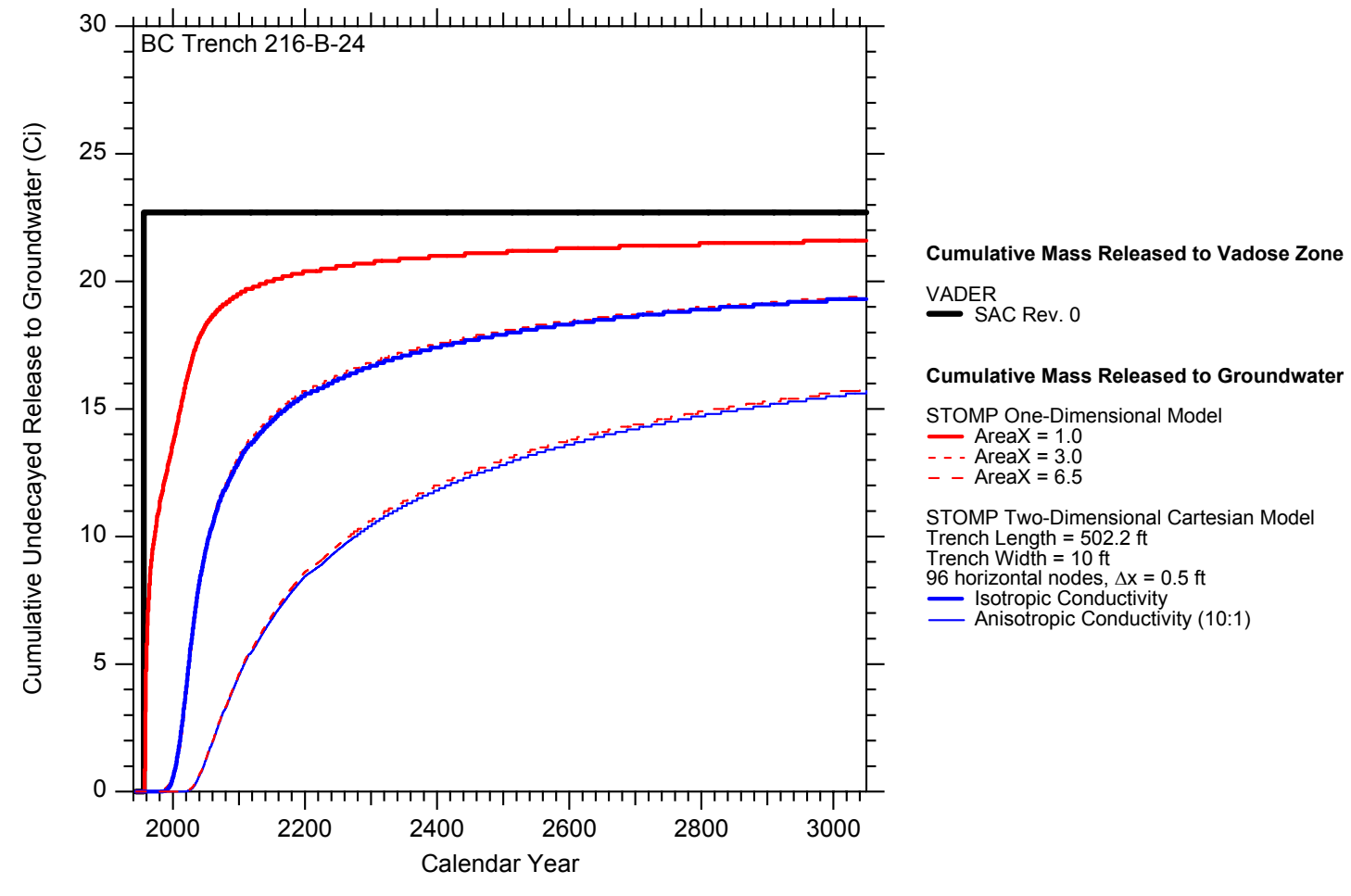

Figure C.5. Vadose Zone Cumulative Release to Groundwater Modeled for Trench 216-B-24 


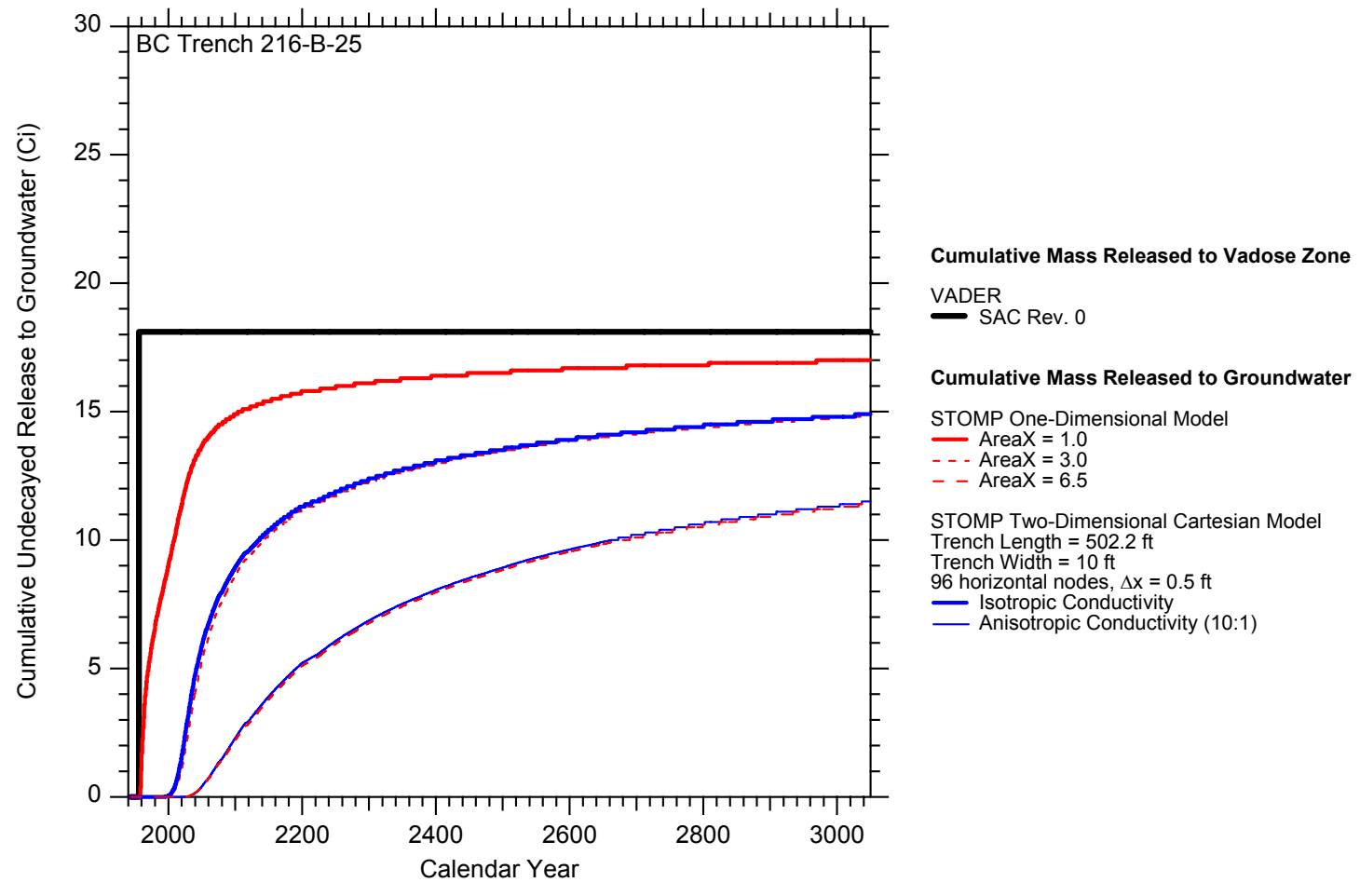

Figure C.6. Vadose Zone Cumulative Release to Groundwater Modeled for Trench 216-B-25

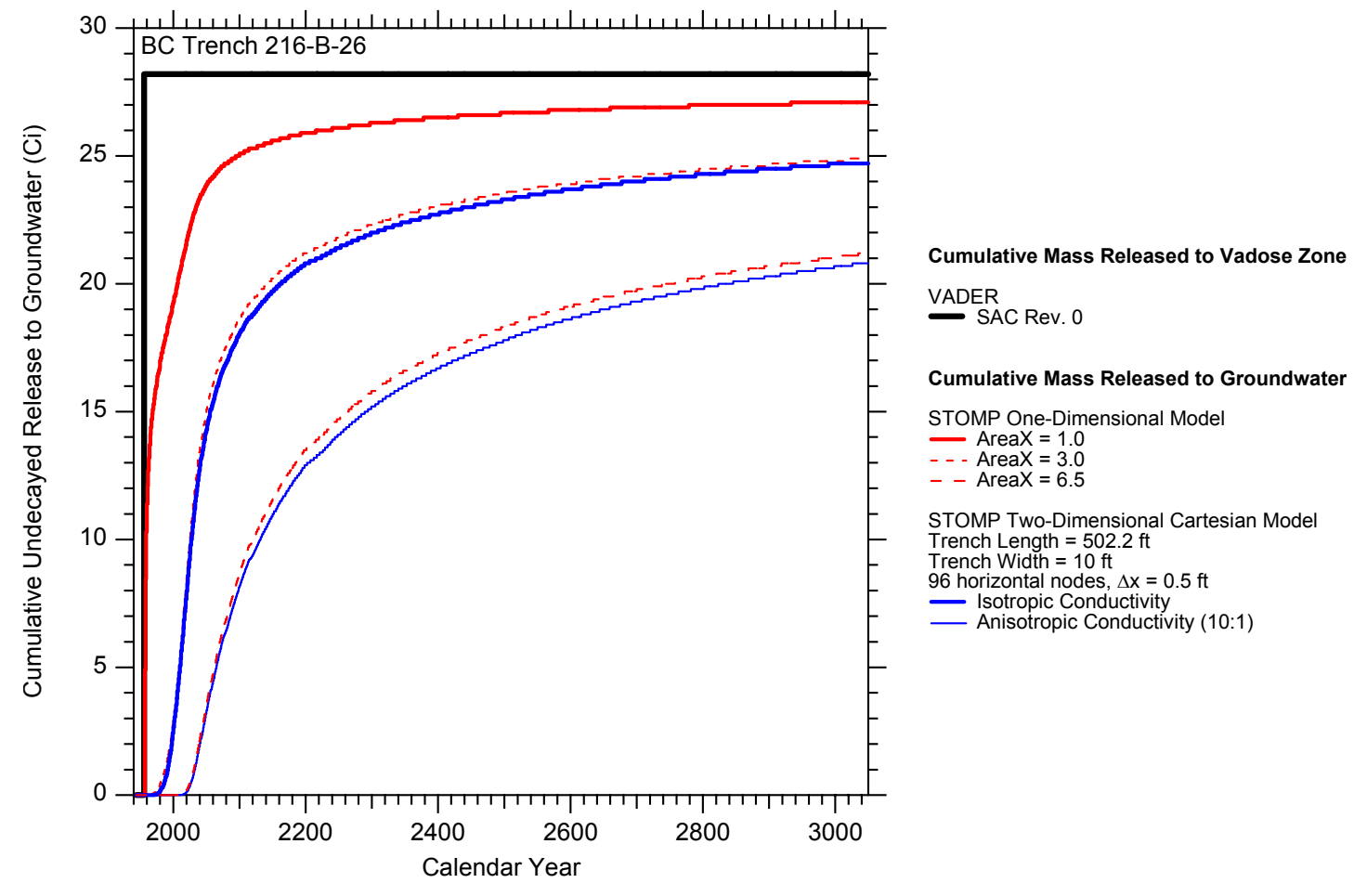

Figure C.7. Vadose Zone Cumulative Release to Groundwater Modeled for Trench 216-B-26

C.6 


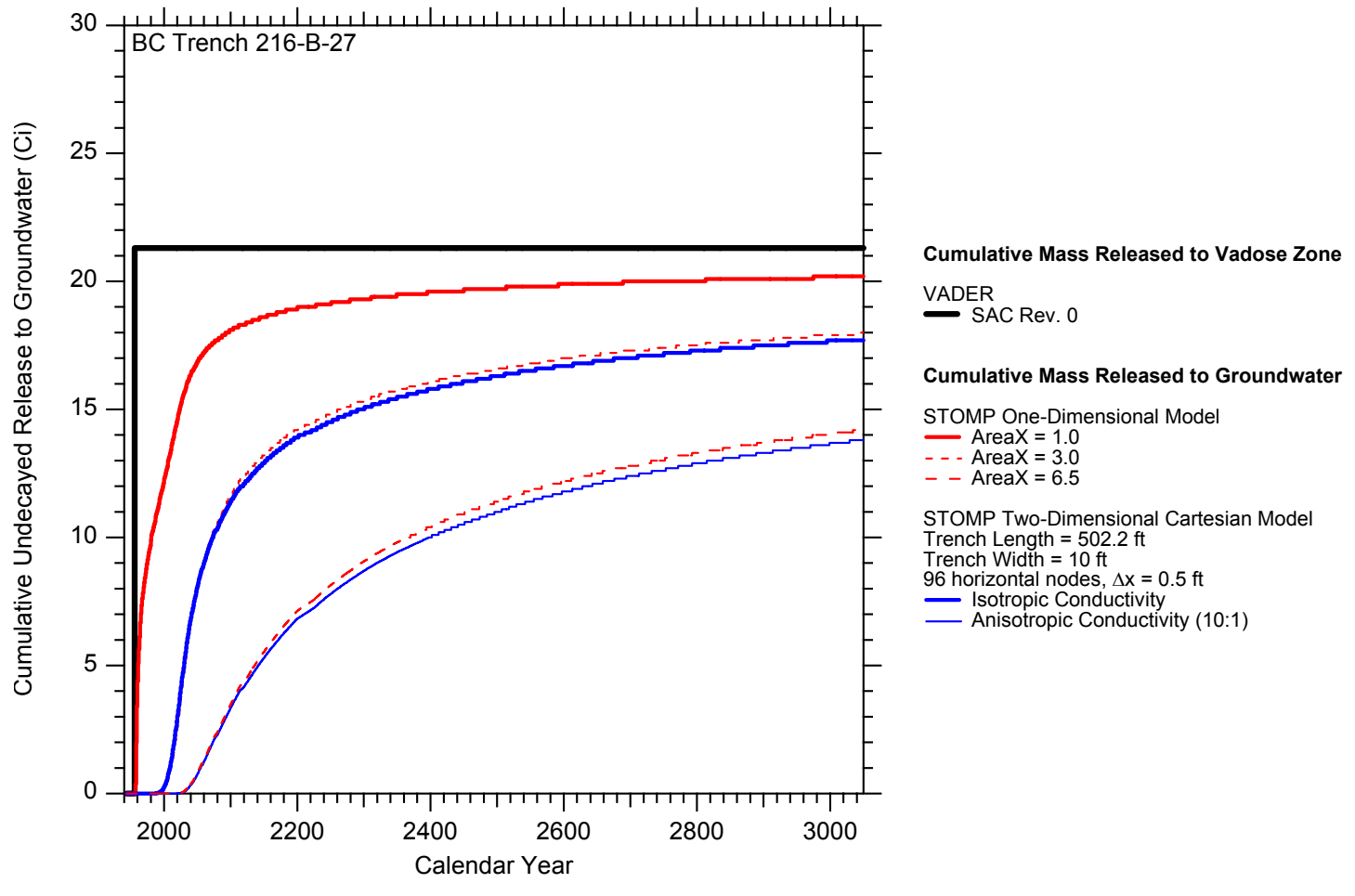

Figure C.8. Vadose Zone Cumulative Release to Groundwater Modeled for Trench 216-B-27

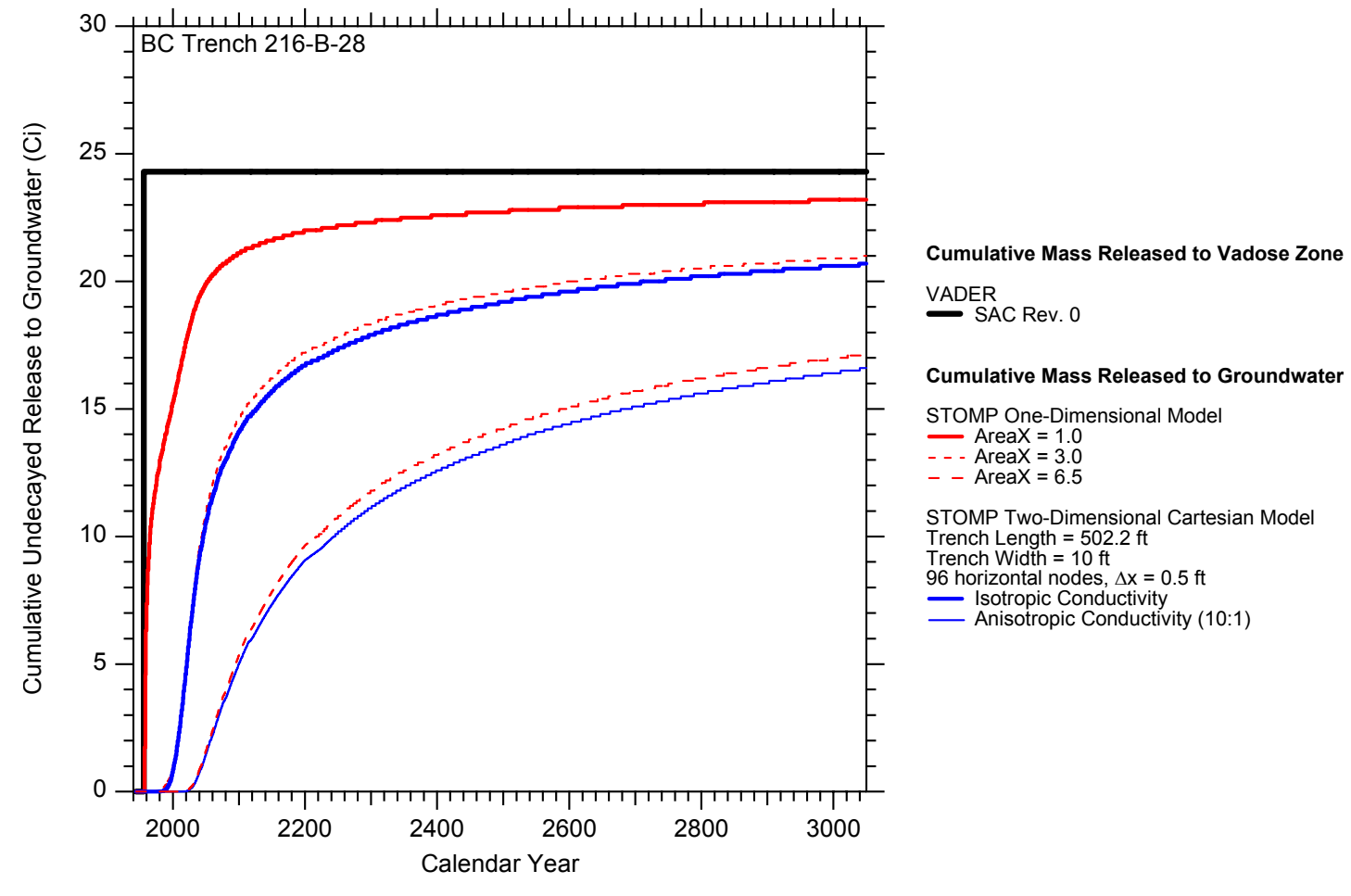

Figure C.9. Vadose Zone Cumulative Release to Groundwater Modeled for Trench 216-B-28

C.7 


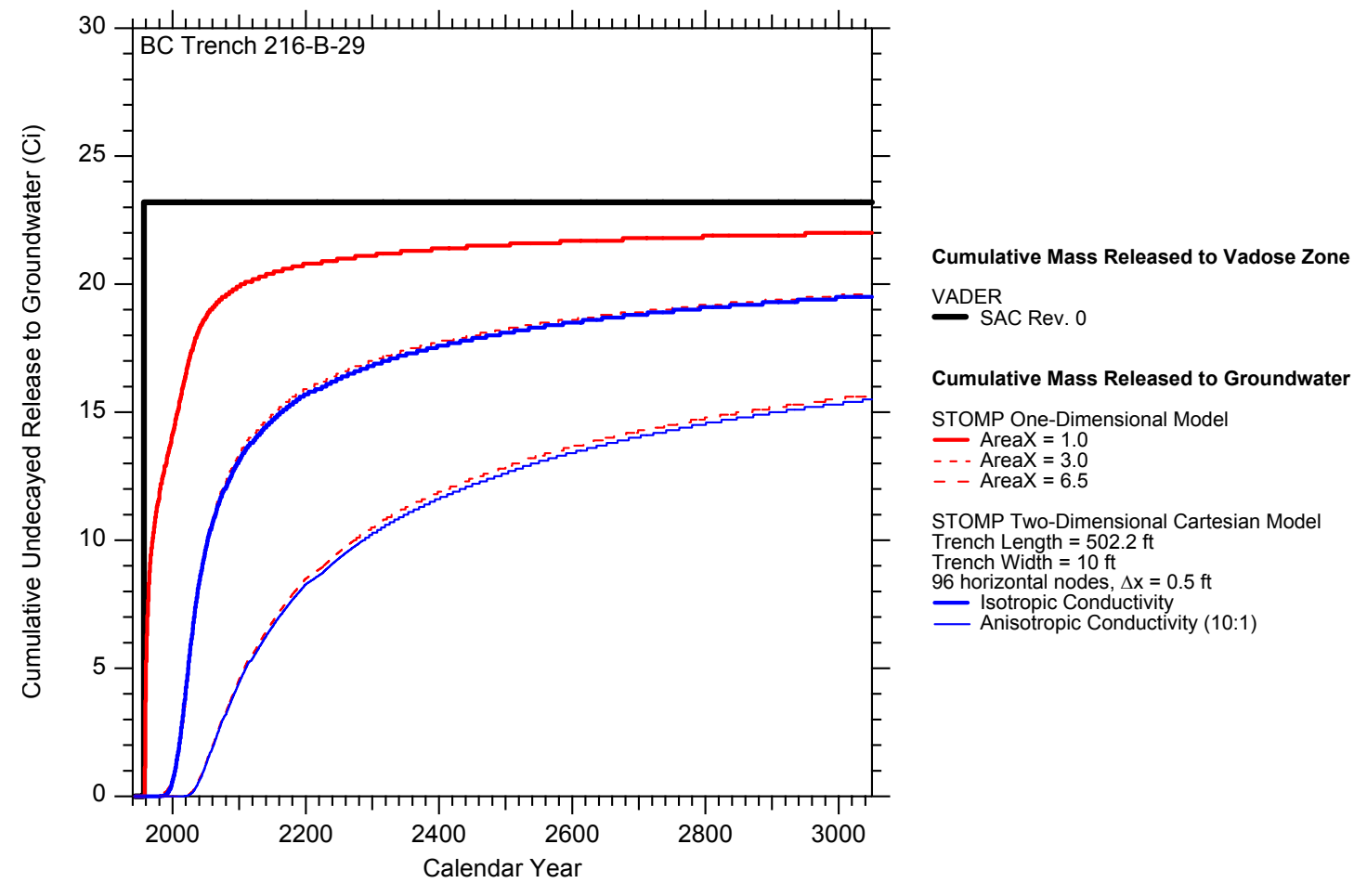

Figure C.10. Vadose Zone Cumulative Release to Groundwater Modeled for Trench 216-B-29

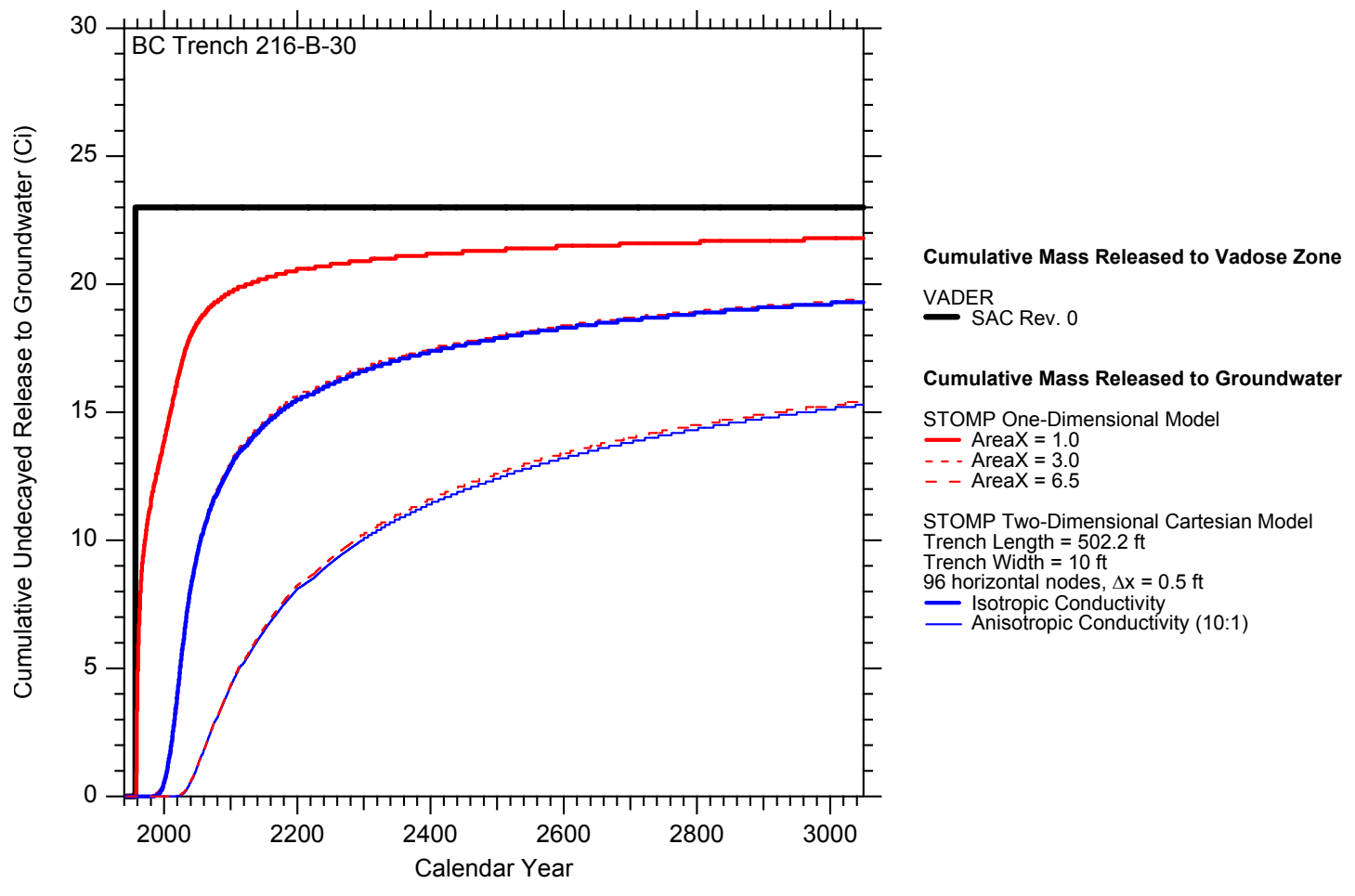

Figure C.11. Vadose Zone Cumulative Release to Groundwater Modeled for Trench 216-B-30 


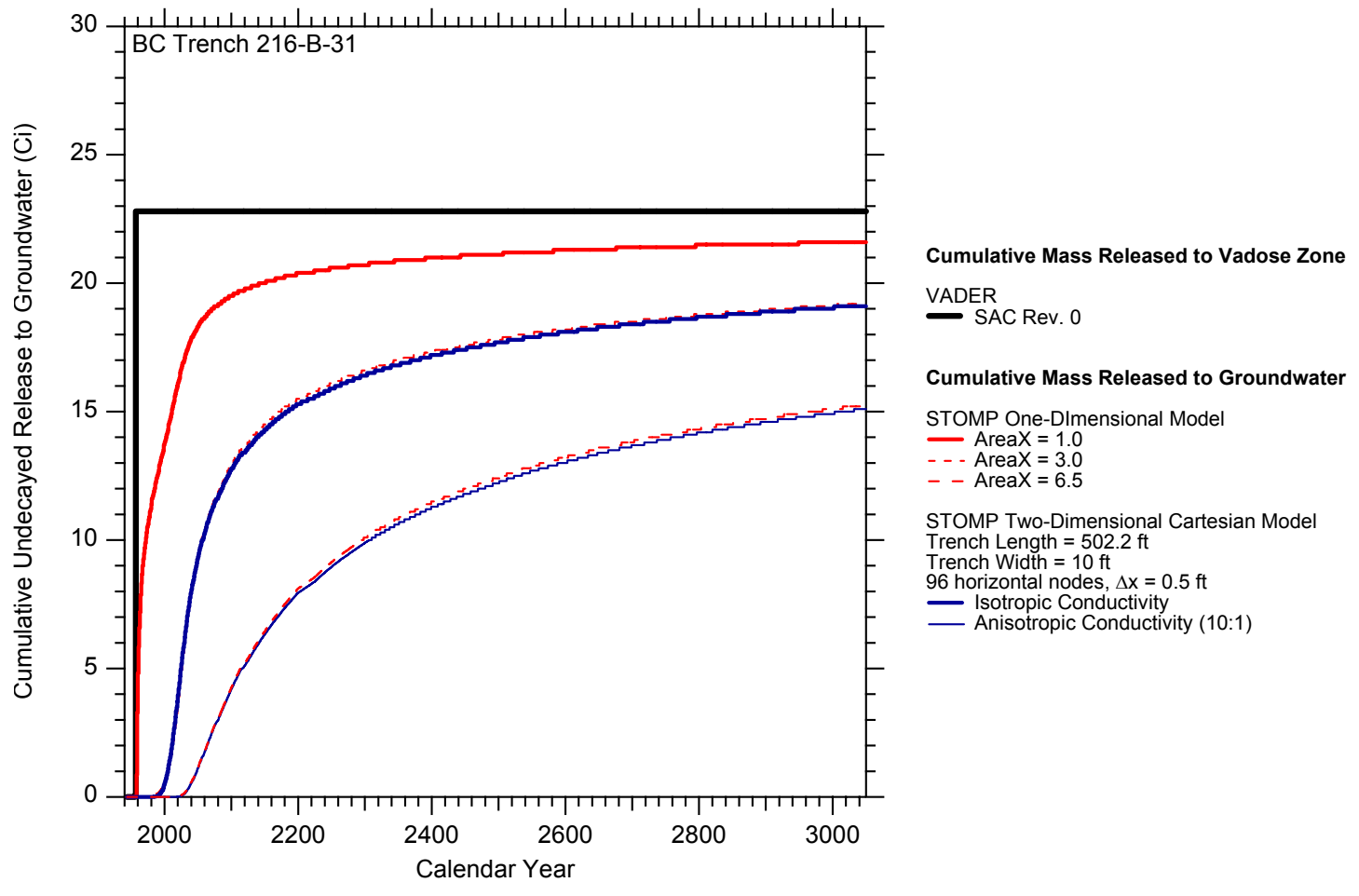

Figure C.12. Vadose Zone Cumulative Release to Groundwater Modeled for Trench 216-B-31

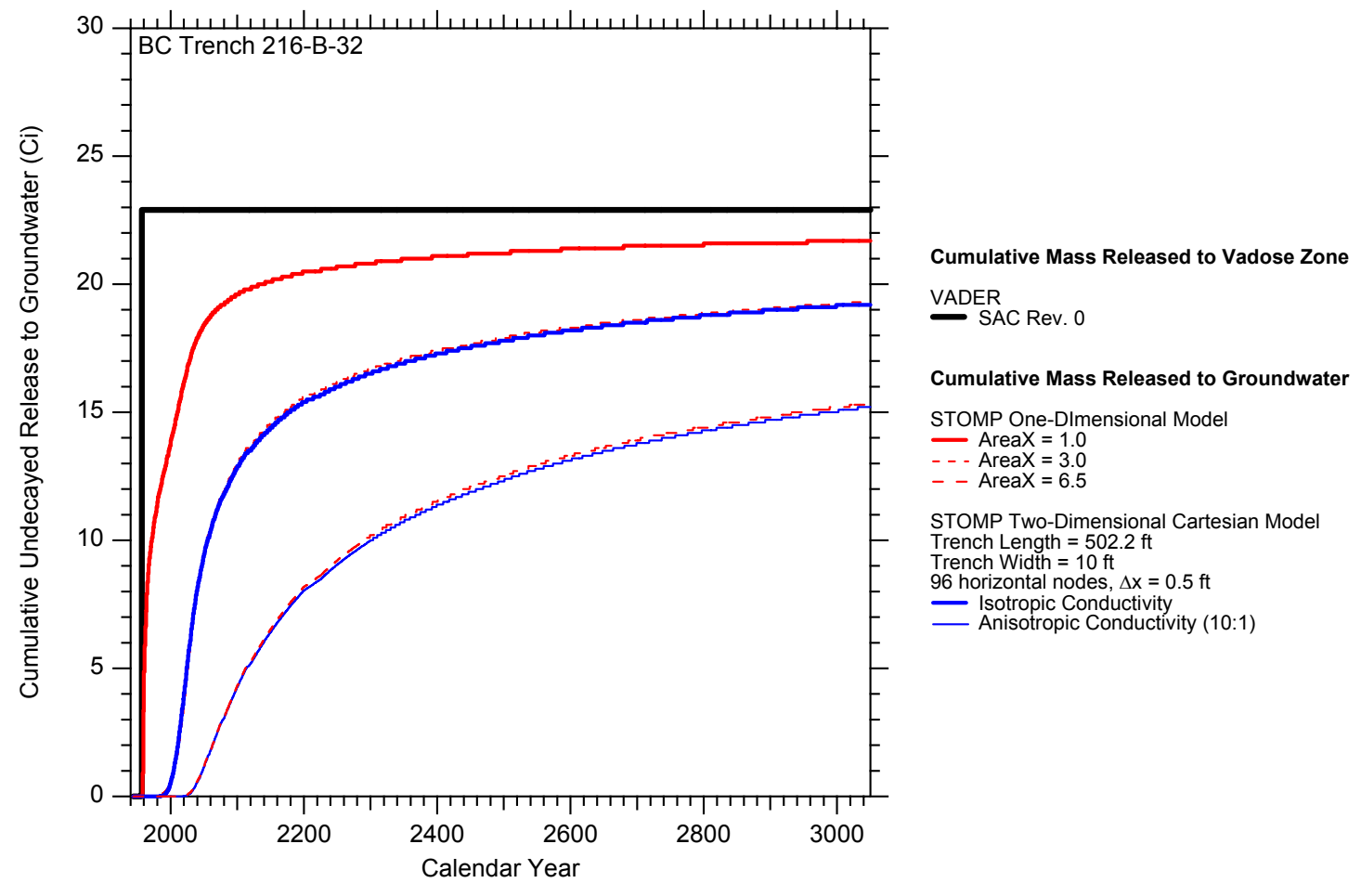

Figure C.13. Vadose Zone Cumulative Release to Groundwater Modeled for Trench 216-B-32 


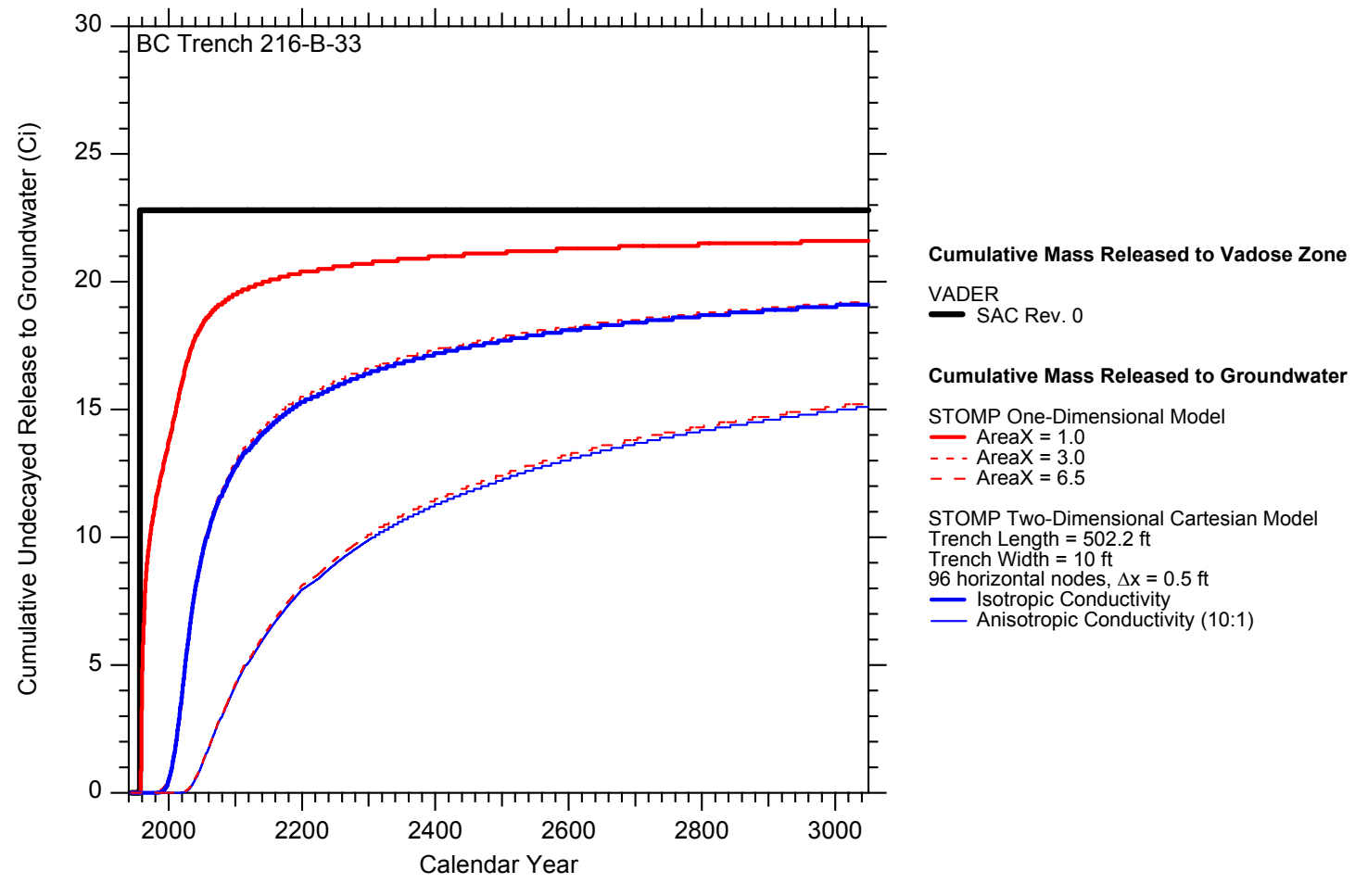

Figure C.14. Vadose Zone Cumulative Release to Groundwater Modeled for Trench 216-B-33

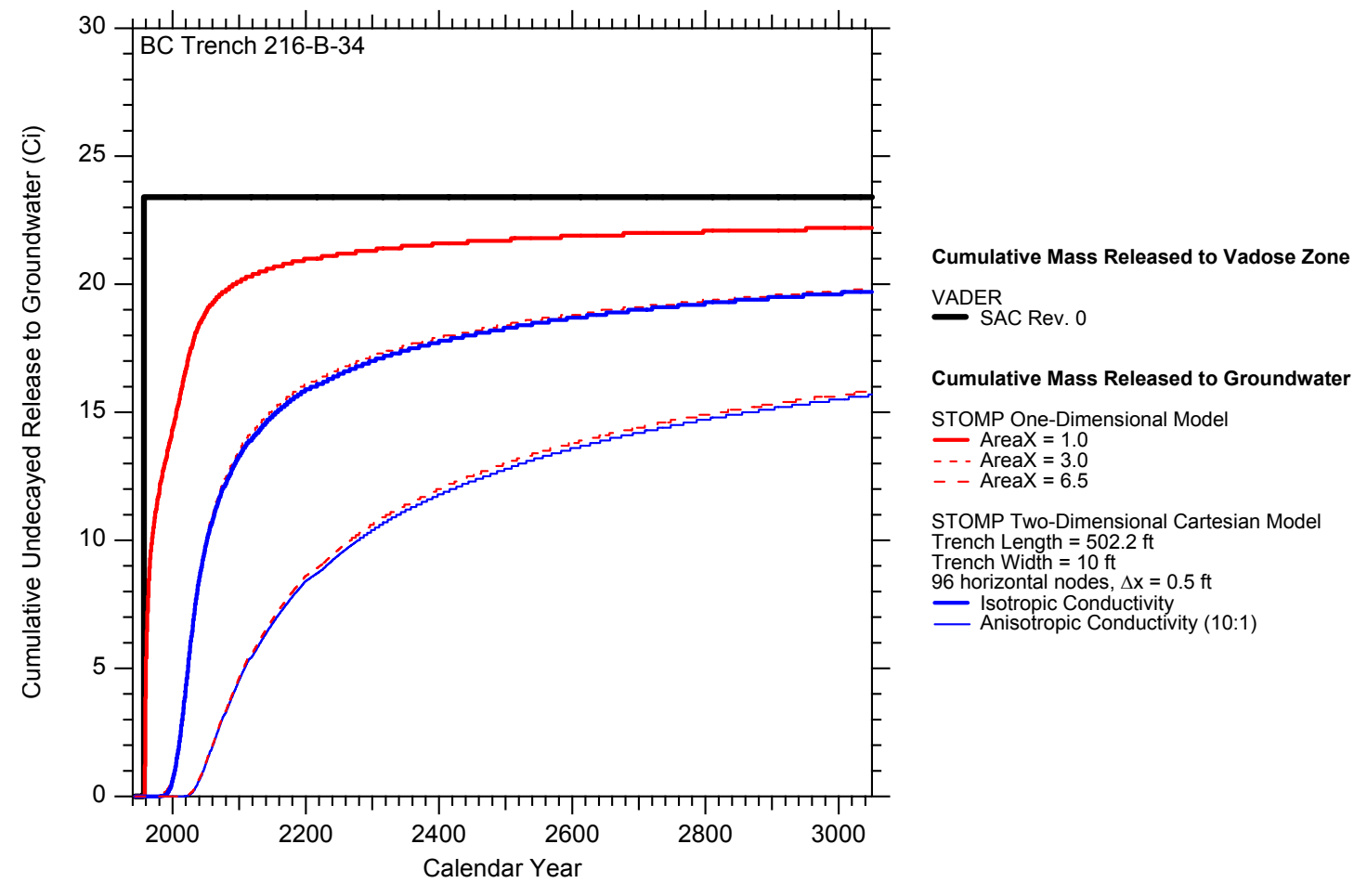

Figure C.15. Vadose Zone Cumulative Release to Groundwater Modeled for Trench 216-B-34 


\section{C.3 Multidimensional Modeling of BC Cribs}

The BC cribs and their respective areas and discharge volumes are listed in Table C.2. The BC cribs are essentially square and were idealized as a two-dimensional circular feature symmetric about the diameter. An idealized two-dimensional cylindrical model was constructed that assumes lateral spreading will be strictly radial outward.

The SAC one-dimensional model for each BC crib was expanded into a two-dimensional axialsymmetric cylindrical model (a 180-degree arc, or half the crib, represented with results scalable to represent the whole crib). The vertical resolution (580, 0.15-meter-grid cells) was retained, and the x-axis was resolved several ways. Ideally, the model should be resolved to the same degree horizontally ( 0.15 meter) as vertical to avoid numerical dispersion, but for the high volume (relative to disposal area) the number of nodes necessary to accomplish this leads to a model too large to solve practically with available computer systems. Instead, several successively finer resolutions were simulated for the first crib (216-B-14) to demonstrate convergence in the release history with finer resolution. It is notable that lower resolution leads to greater lateral flow (due to numerical dispersion in the horizontal dimension), which in turn leads to lower release predictions. This indicates the need to use full resolution in twodimensional models if release is not to be systematically under-predicted in SAC analyses.

Liquid and analyte discharges were converted to density-type sources and assigned to the topmost nodes in the grid index range covering the inner 13.7 meters (the radius of a circle with the same area as a typical BC crib), representing half the source term (again, consistent with the axial-symmetric treatment). Note that the area given in Table C.2 does not match the area declared in WIDS and the SAC database; often the WIDS area is larger than the true footprint.

Hanford soil is anisotropic, considered about 10 times more conductive in the horizontal dimension than in the vertical. To consider this feature, each crib was modeled twice, once with isotropic properties and once with 10:1 anisotropy in saturated hydraulic conductivity.

Once the release histories for the multidimensional model runs were available, the one-dimensional model was rerun with several AreaX (area scaling parameter) values. By trial-and-error, an AreaX scaling factor that would cause the one-dimensional model to produce releases similar to the

Table C.2. BC Cribs (data from Maxfield 1979)

\begin{tabular}{||c|c|c||}
\hline \hline WIDS Identification & Area (square feet) & Discharge Volume (liters) \\
\hline \hline $216-\mathrm{B}-14$ & $40 \times 40=1600$ & $8.71 \times 10^{6}$ \\
\hline $216-\mathrm{B}-15$ & $40 \times 40=1600$ & $6.32 \times 10^{6}$ \\
\hline $216-\mathrm{B}-16$ & $40 \times 50=2000$ & $5.6 \times 10^{6}$ \\
\hline $216-\mathrm{B}-17$ & $40 \times 40=1600$ & $3.41 \times 10^{6}$ \\
\hline $216-\mathrm{B}-18$ & $40 \times 40=1600$ & $8.52 \times 10^{6}$ \\
\hline $216-\mathrm{B}-19$ & $40 \times 40=1600$ & $6.4 \times 10^{6}$ \\
\hline \multicolumn{2}{|l}{} \\
\hline \multicolumn{2}{|l}{ WIDS $=$ Waste Information Data System } \\
\hline
\end{tabular}


two-dimensional model (with explicit treatment of lateral flow) was determined. For all BC cribs, the value $\mathrm{AreaX}=1.5$ provided the best match for isotropic conductivity and AreaX $=3.0$ provided the best match for anisotropic (10:1 ratio) conductivity.

Figures C.16 through C.24 shows simulated vadose zone release to groundwater results for $\mathrm{BC}$ crib 216-B-14 for various horizontal resolutions of the two-dimensional cylindrical model for the early years 1944 to 2000 for both isotropic and anisotropic (10:1) conductivity. Note that increasing release with increasing resolution, showing the need for a highly resolved two-dimensional model to preclude substantially under predicting release. The highest model resolution simulated was 580 vertical ( 0.15 meter) by 192 horizontal ( 0.43 meter) nodes, for a total model grid of 111,360 nodes. Ideally, the horizontal should be resolved to 0.15 -meter nodes also, but this would yield a model domain of more than 300,000 nodes, too large to simulate with available equipment in a reasonable time. As it was, the final resolution (111,360 nodes) could only be simulated on the analysis stations (paper.pnl.gov or plastic.pnl.gov) and not on any RANSAC compute node due to the memory demands of such a large domain. Hence, the release for the highest resolution should be seen as close, but not quite as high as the release that would be predicted for the fully resolved ( 0.15 -meter grid) model if it were run.

Also displayed in Figure C.16 are the release results for the one-dimensional model for AreaX $=1.0$ (SAC Rev. 0 default) and for AreaX $=1.5$, which approximates the isotropic release history, and AreaX $=$ 3.0, which approximates the anisotropic (10:1) release history. The one-dimensional model is shown to slightly under predict annual releases from the crib in early years (up to about 1980) and slightly over predict annual releases thereafter.

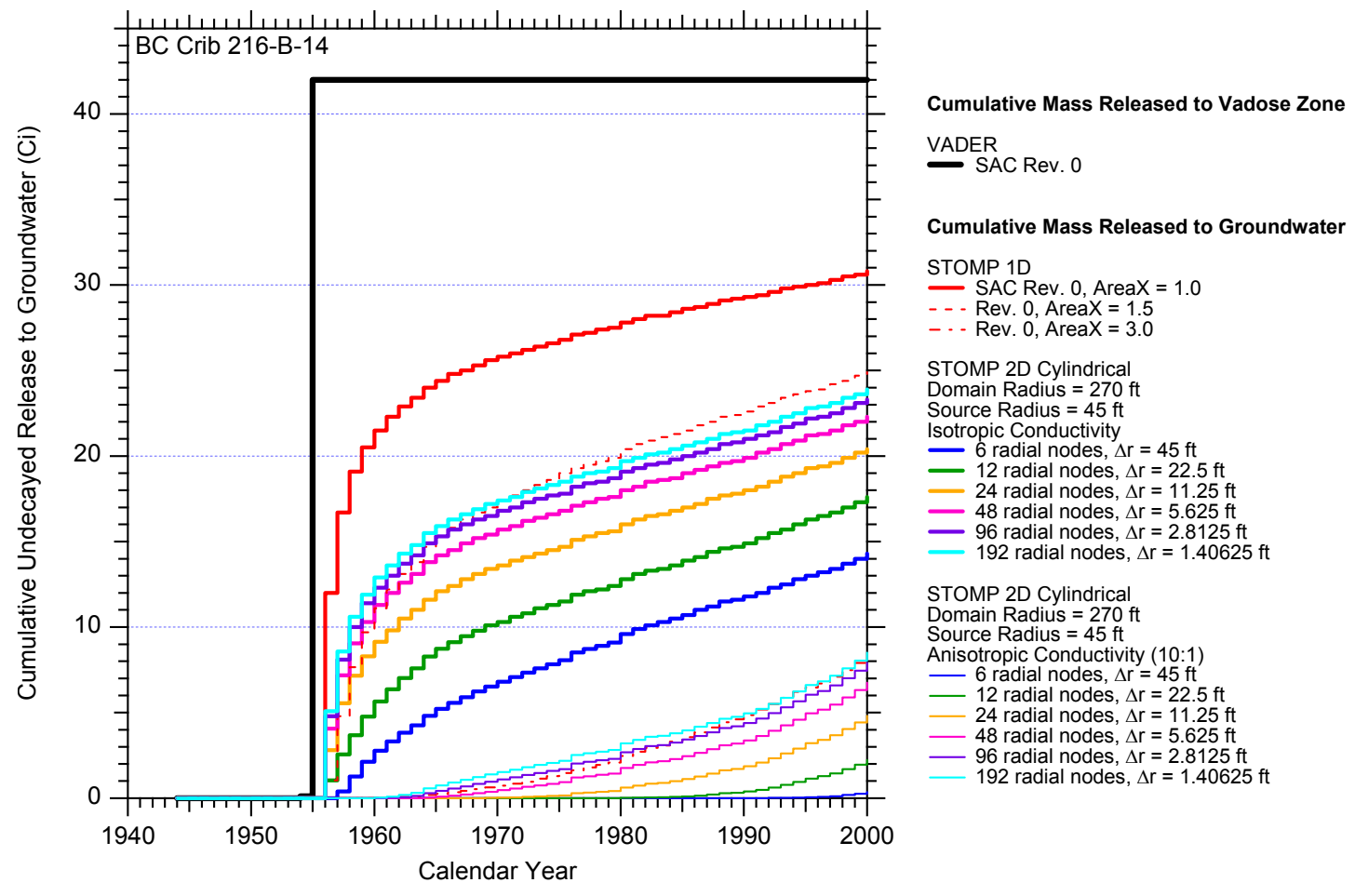

Figure C.16. Vadose Zone Cumulative Release to Groundwater Modeled for Crib 216-B-14 (1944 to 2000) 


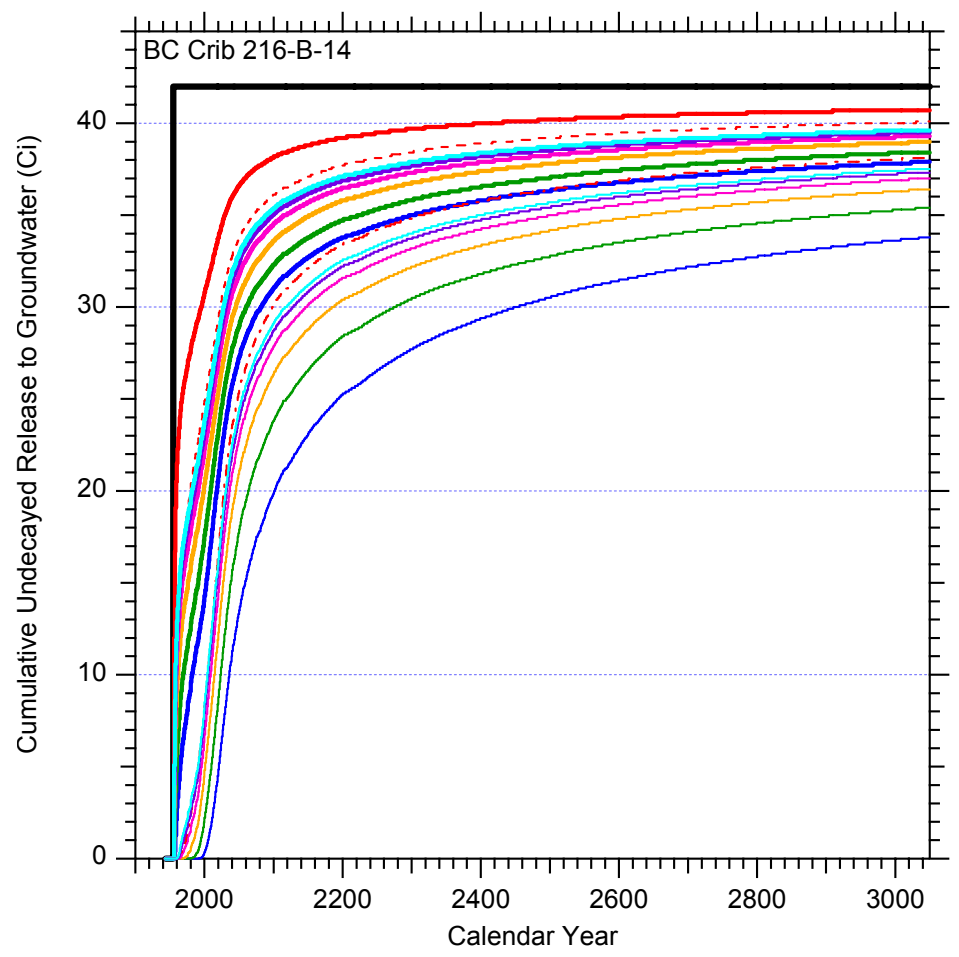

Cumulative Mass Released to Vadose Zone VADER

- SAC Rev. 0

Cumulative Mass Released to Groundwater STOMP 1D

- SAC Rev. 0, AreaX $=1.0$

- - Rev. 0, AreaX = 1.5

- - Rev. 0, AreaX $=3.0$

STOMP 2D Cylindrical

Domain Radius $=270 \mathrm{ft}$

Source Radius $=45 \mathrm{ft}$

Isotropic Conductivity $6 \mathrm{radial}$ nodes, $\Delta \mathrm{r}=45 \mathrm{ft}$

- 12 radial nodes, $\Delta r=22.5 \mathrm{ft}$

24 radial nodes, $\Delta r=11.25 \mathrm{ft}$

- 48 radial nodes, $\Delta r=5.625 \mathrm{ft}$

- 96 radial nodes, $\Delta r=2.8125 \mathrm{ft}$

192 radial nodes, $\Delta \mathrm{r}=1.40625 \mathrm{ft}$

STOMP 2D Cylindrical

Domain Radius $=270 \mathrm{ft}$

Source Radius $=45 \mathrm{ft}$

Anisotropic Conductivity (10:1)

6 radial nodes, $\Delta \mathrm{r}=45 \mathrm{ft}$

12 radial nodes, $\Delta r=22.5 \mathrm{ft}$

24 radial nodes, $\Delta r=11.25 \mathrm{ft}$

48 radial nodes, $\Delta r=5.625 \mathrm{ft}$

96 radial nodes, $\Delta r=2.8125 \mathrm{ft}$
192 radial nodes, $\Delta r=1.40625 \mathrm{ft}$

Figure C.17. Vadose Zone Cumulative Release to Groundwater Modeled for Crib 216-B-14

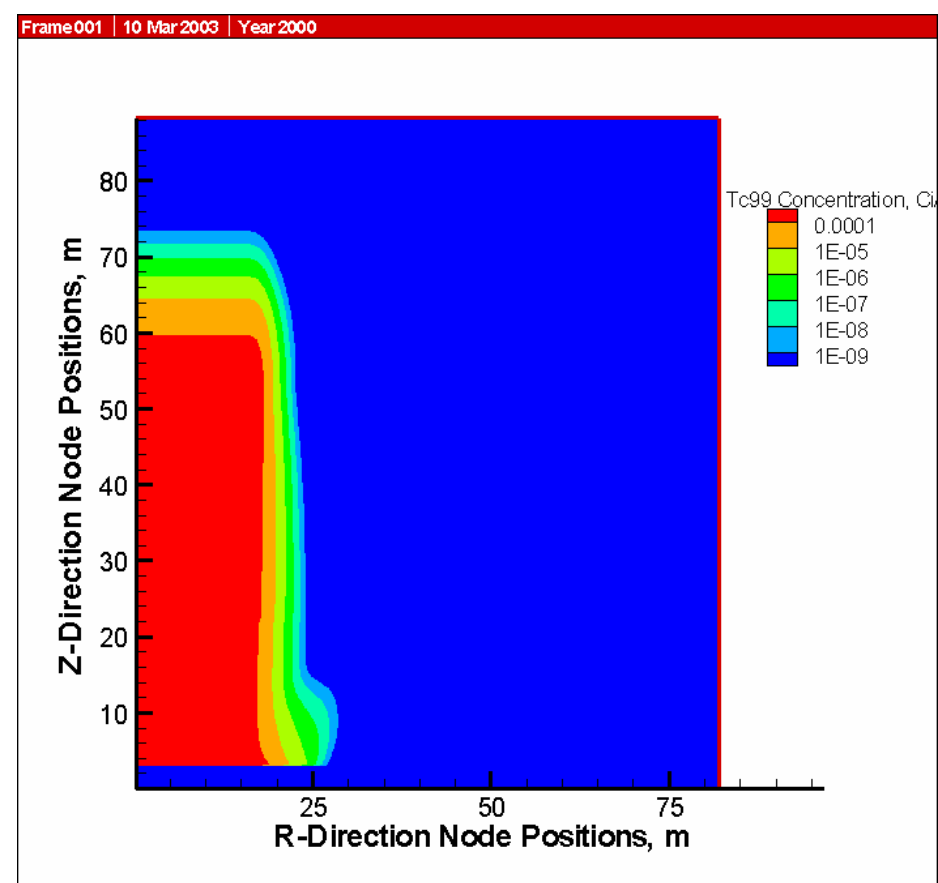

Figure C.18. Tc-99 Concentration $\left(\mathrm{Ci} / \mathrm{m}^{3}\right)$ of Two-Dimensional Axial-Symmetric (192 radial nodes) Isotropic Model of Crib 216-B-14 (center of crib is the left-hand side and the water table is the bottom of the domain) 


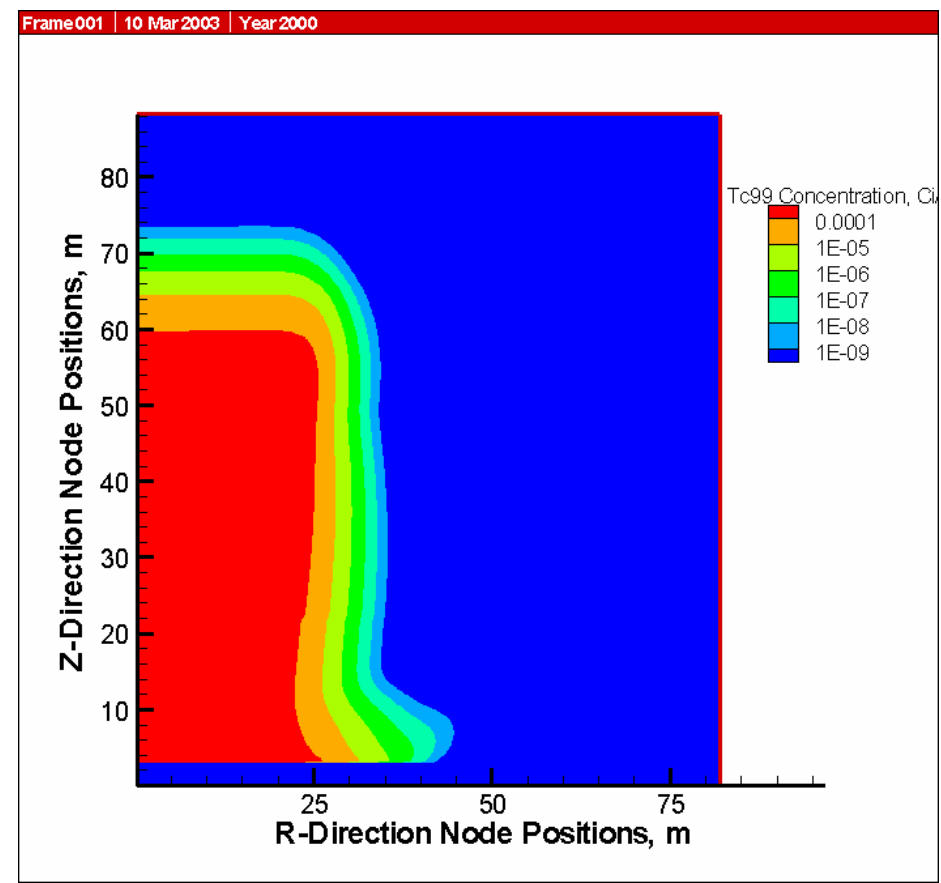

Figure C.19. Tc-99 Concentration $\left(\mathrm{Ci} / \mathrm{m}^{3}\right)$ of Two-Dimensional Axial-Symmetric (192 radial nodes) Anisotropic (10:1 conductivity ratio) Model of Crib 216-B-14 (center of crib is the left-hand side and the water table is the bottom of the domain).

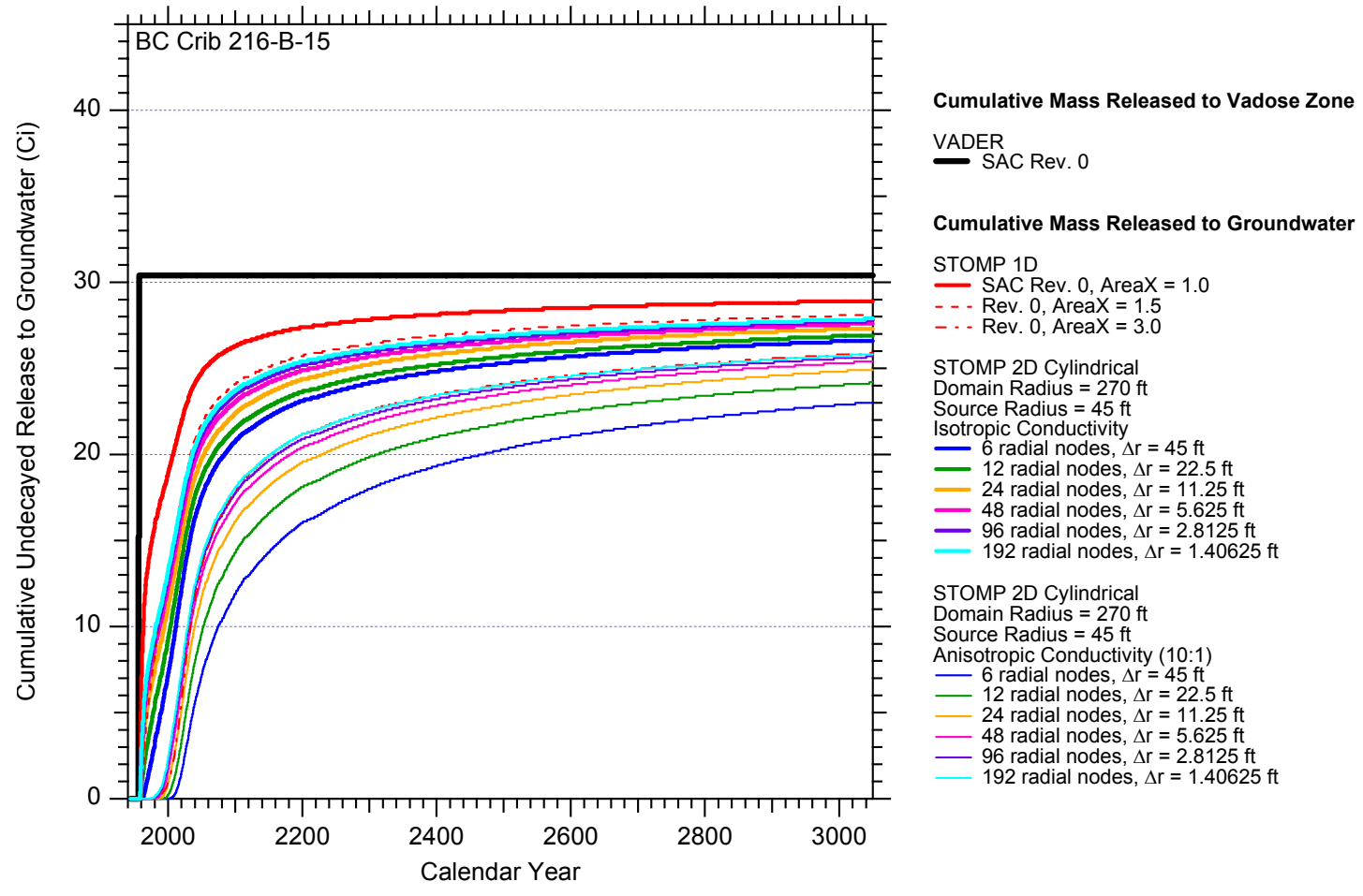

Figure C.20. Vadose Zone Cumulative Release to Groundwater Modeled for Crib 216-B-15 


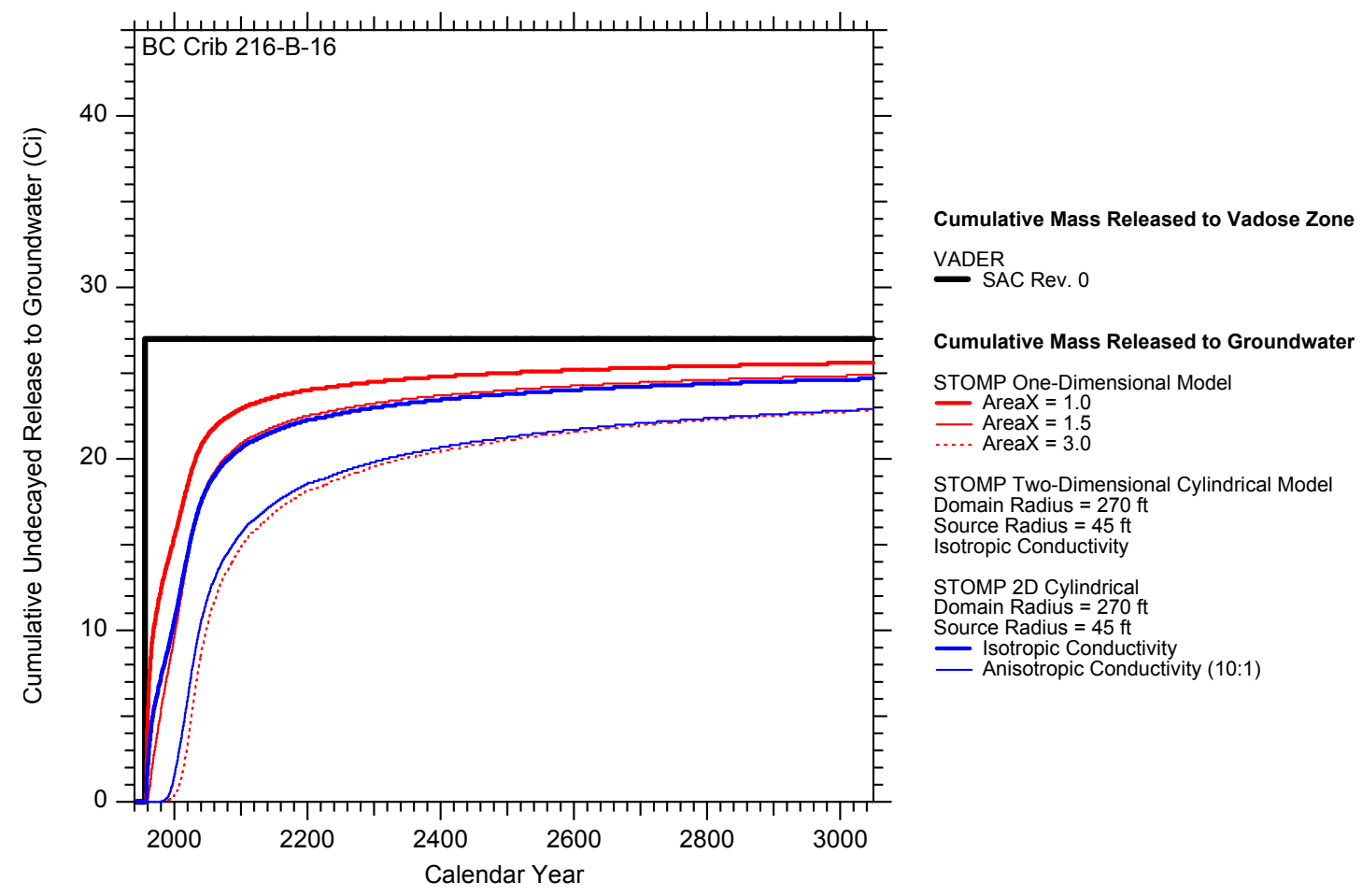

Figure C.21. Vadose Zone Cumulative Release to Groundwater Modeled for Crib 216-B-16

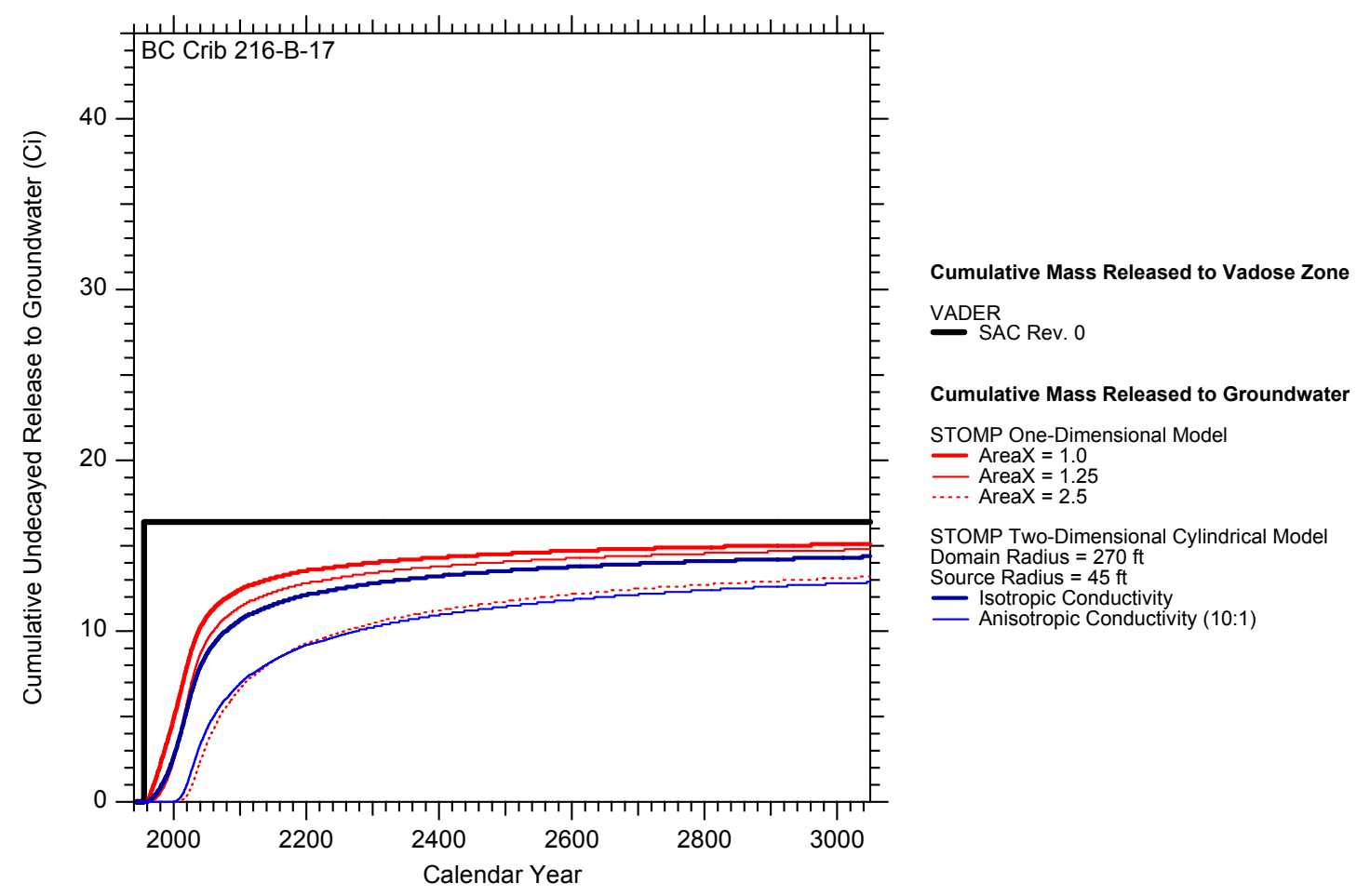

Figure C.22. Vadose Zone Cumulative Release to Groundwater Modeled for Crib 216-B-17 


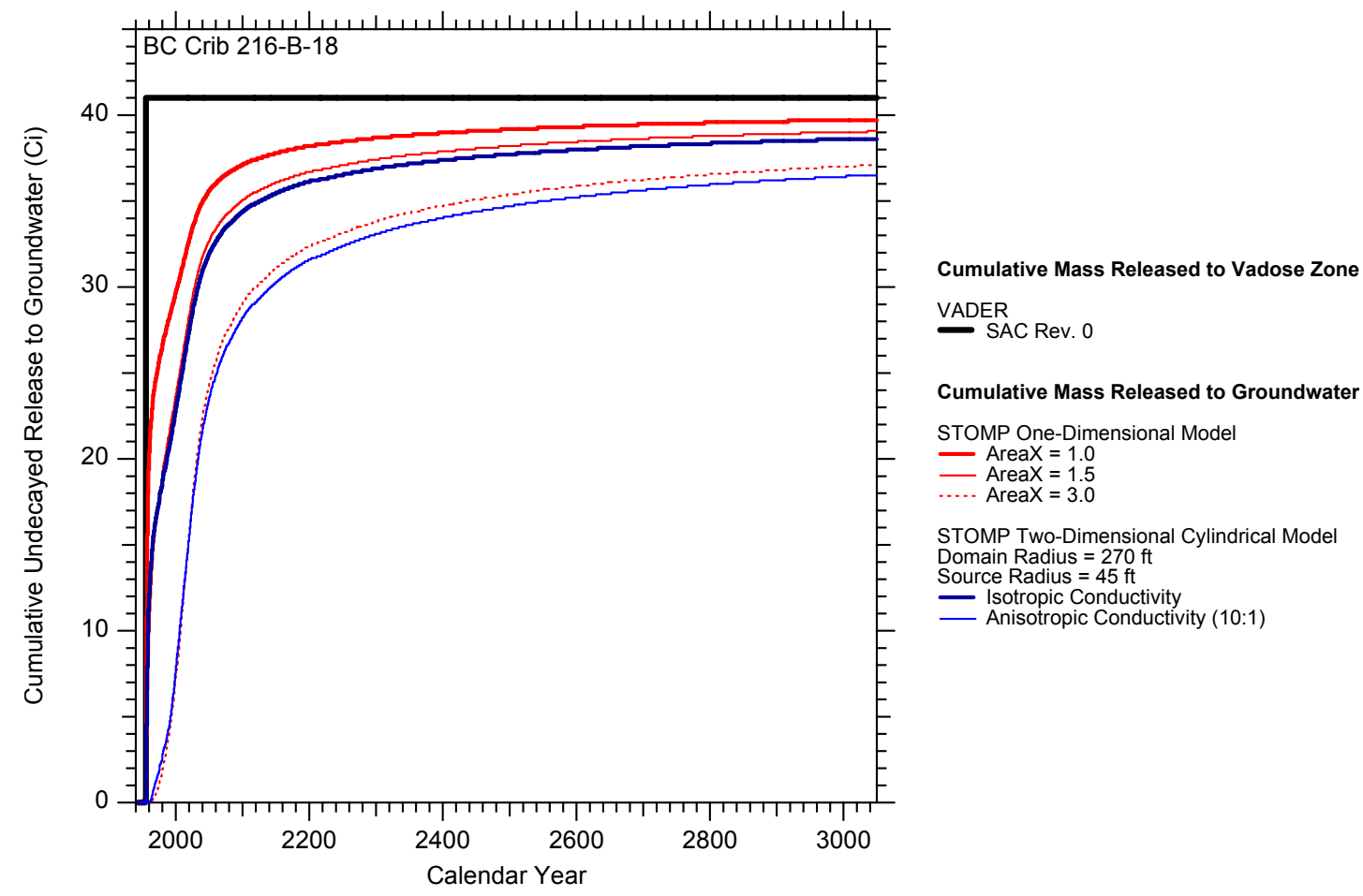

Figure C.23. Vadose Zone Cumulative Release to Groundwater Modeled for Crib 216-B-18

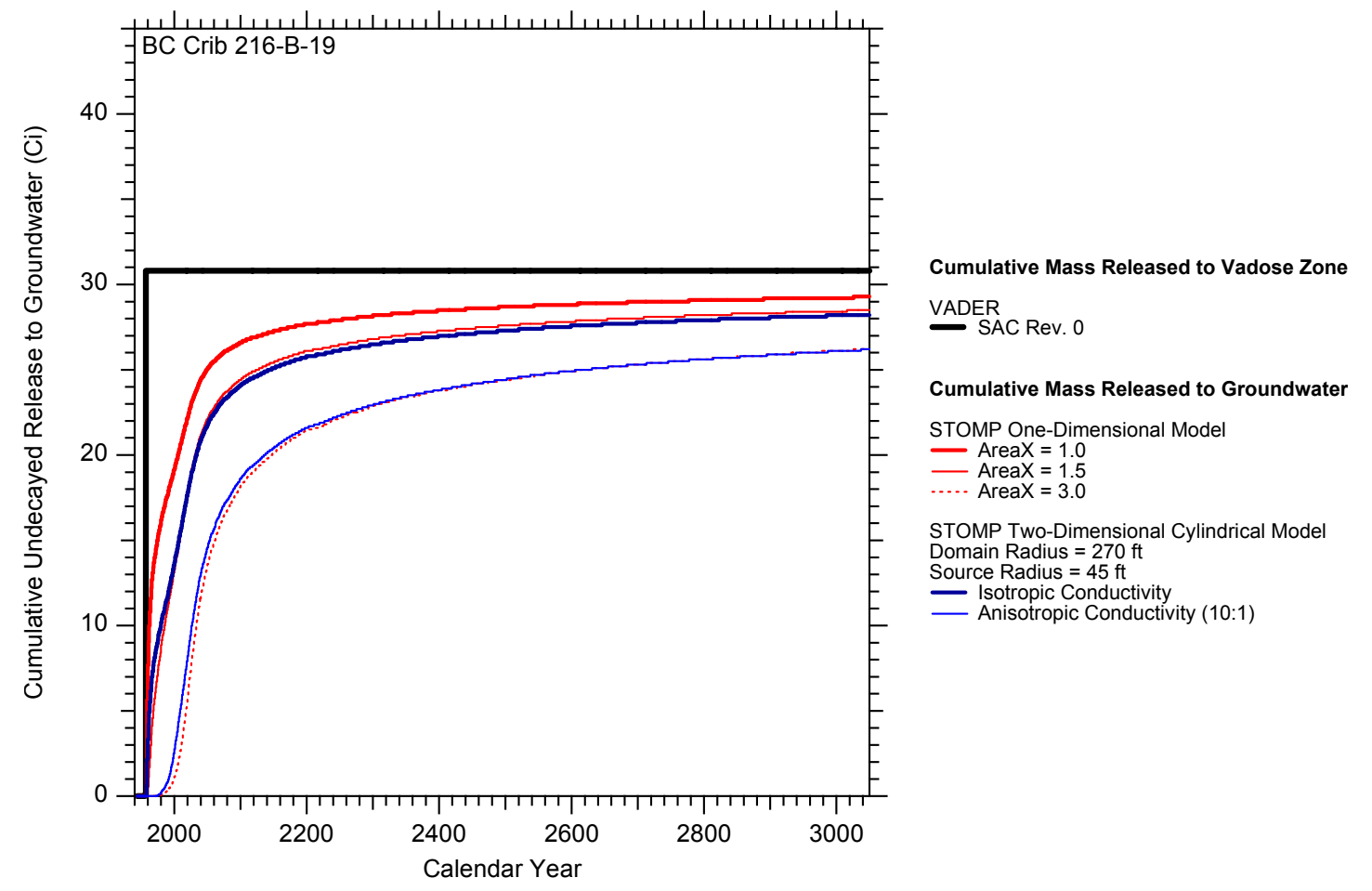

Figure C.24. Vadose Zone Cumulative Release to Groundwater Modeled for Crib 216-B-19 


\section{C.4 Computer Simulation Time}

An important implication of two-dimensional simulation in the SAC context is the simulation time required to solve for vadose zone transport of analytes. As a stochastic simulator, SAC will invoke a STOMP model of a vadose zone site for a number of cases equal to the number of realizations times the number of analytes. Ideally, locations with liquid discharges (such as the BC cribs and trenches) would be modeled as two-dimensional features. However, if the computer time required to perform the number of two-dimensional cases required is too great, a problem of feasibility arises.

The times required to solve the various one- and two-dimensional simulations of the crib 216-B-14 provides a basis for consideration. Table C.3 provides the timing results. Note all time are for simulations on a Pentium 4 processor, except the highest resolution grid which had to be run on a SAC analysis node due to the high RAM requirements of this resolution grid. The highest resolution twodimensional model, with 111,360 nodes, was too large to run on any RANSAC compute node as it required more RAM than any of the compute nodes are equipped with. The high memory demand of this size model has important implications for inclusion in SAC of a two-dimensional model of the BC cribs. Moreover, this model still wasn't sufficiently resolved (that would require a model with more than 300,000 nodes).

\section{C.5 Summary}

Based on the simulation times in Table C.3 and the simulation results shown earlier, several points can be made with respect to SAC Rev. 1 implementation:

1. If a two-dimensional capability is desired, the SPLIB solver is substantially faster for grid domains over 20,000 nodes and should be made standard for STOMP in SAC.

Table C.3. Computer Simulation Time for Various One- and Two-Dimensional STOMP Models of 216-B-14 Crib (Pentium 4, 2.2-GHz processor running under Linux)

\begin{tabular}{|c|c|c|c|c|c|}
\hline \multicolumn{3}{|c|}{ "Number of Nodes in Direction } & \multirow[b]{2}{*}{$\begin{array}{c}\text { Total Number of } \\
\text { Nodes }\end{array}$} & \multicolumn{2}{|c|}{ Polution Time(s) } \\
\hline$r$ & $\theta$ & $Z$ & & $\begin{array}{c}\text { Banded Matrix } \\
\text { Solver }\end{array}$ & SPLIB Solver \\
\hline 1 & $\overline{1}$ & 580 & 580 & 137 & 129 \\
\hline 6 & 1 & 580 & 3,480 & 960 & 955 \\
\hline 12 & 1 & 580 & 6,960 & 2,081 & 2,055 \\
\hline 24 & 1 & 580 & 13,920 & 4,910 & 4,501 \\
\hline 48 & 1 & 580 & 27,840 & 21,835 & 9,522 \\
\hline 96 & 1 & 580 & 55,680 & & 20,588 \\
\hline 192 & 1 & 580 & 111,360 & & $55,748^{(\mathrm{a})}$ \\
\hline
\end{tabular}

(a) Simulated on Pentium III, 1.3-GHz processor instead because RAM was insufficient on any RANSAC compute node for this large of grid domain. 
2. If a two-dimensional model were to be used directly in SAC, the time required to solve the vadose zone segment of SAC would increase starkly. For crib 216-B-14, more than 15 hours were required at a grid resolution that was nearly sufficient. In a production run with 25 realizations and 10 analytes, this would imply 3,750 hours of computer time for just one crib, or 22,500 hours for the six $\mathrm{BC}$ cribs. Spread over 132 compute nodes (assuming these were equipped with enough RAM to carry the problem), it would take 170 hours, or about one week, just to solve for the six BC cribs. Worse, these time estimates were based on runs on 2.2-GHz processors; 128 of the 132 compute nodes on RANSAC are 1.0-GHz processors (about three times slower). And this only for the BC cribs; there are many other liquid-discharge sites that make good candidates for two-dimensional simulation in SAC. It is clear that direct two-dimensional treatment of liquid discharge waste sites remains impractical, requiring at least RAM upgrades to the entire SAC cluster and unacceptably long simulation times to solve.

3. However, the results also demonstrate that the one-dimensional model can be made to approximate the direct two-dimensional model by selecting an appropriate value of the vadose zone wetted area based on detailed two-dimensional modeling.

It is recommended that for the $\mathrm{BC}$ cribs and trenches the one-dimensional model continue to be used in SAC Rev. 1, but with vadose zone wetted area scaling factors derived from the simulations performed in this report.

\section{C.6 Projected Impact on Initial Assessment}

To demonstrate the change from following these calibration factors, the total technetium-99 release from all BC cribs and trenches was simulated both using the SAC Rev. 0 approach (effectively AreaX = 1.0) and with the vadose zone wetted area scaling parameters derived in this study. The results are shown in Figure C.25. Note the difference predicted by year 2000; 449 curies released to the aquifer in the initial assessment model (one-dimensional model, AreaX $=1.0$ ) compared to only 18.2 curies released in the one-dimensional model with scaling factors drawn from the detailed two-dimensional models. Based on the more detailed modeling, the absence of a detected technetium plume in groundwater monitoring data for this area, the much lower release is considered much more realistic.

\section{C.7 References}

Bryce RW, CT Kincaid, PW Eslinger, and LF Morasch (eds.). 2002. An Initial Assessment of Hanford Impact Performed with the System Assessment Capability. PNNL-14027, Pacific Northwest National Laboratory, Richland, Washington.

Maxfield HL. 1979. Handbook - 200 Areas Waste Sites. RHO-CD-673, Volumes I and II, Rockwell Hanford Company, Richland, Washington. 


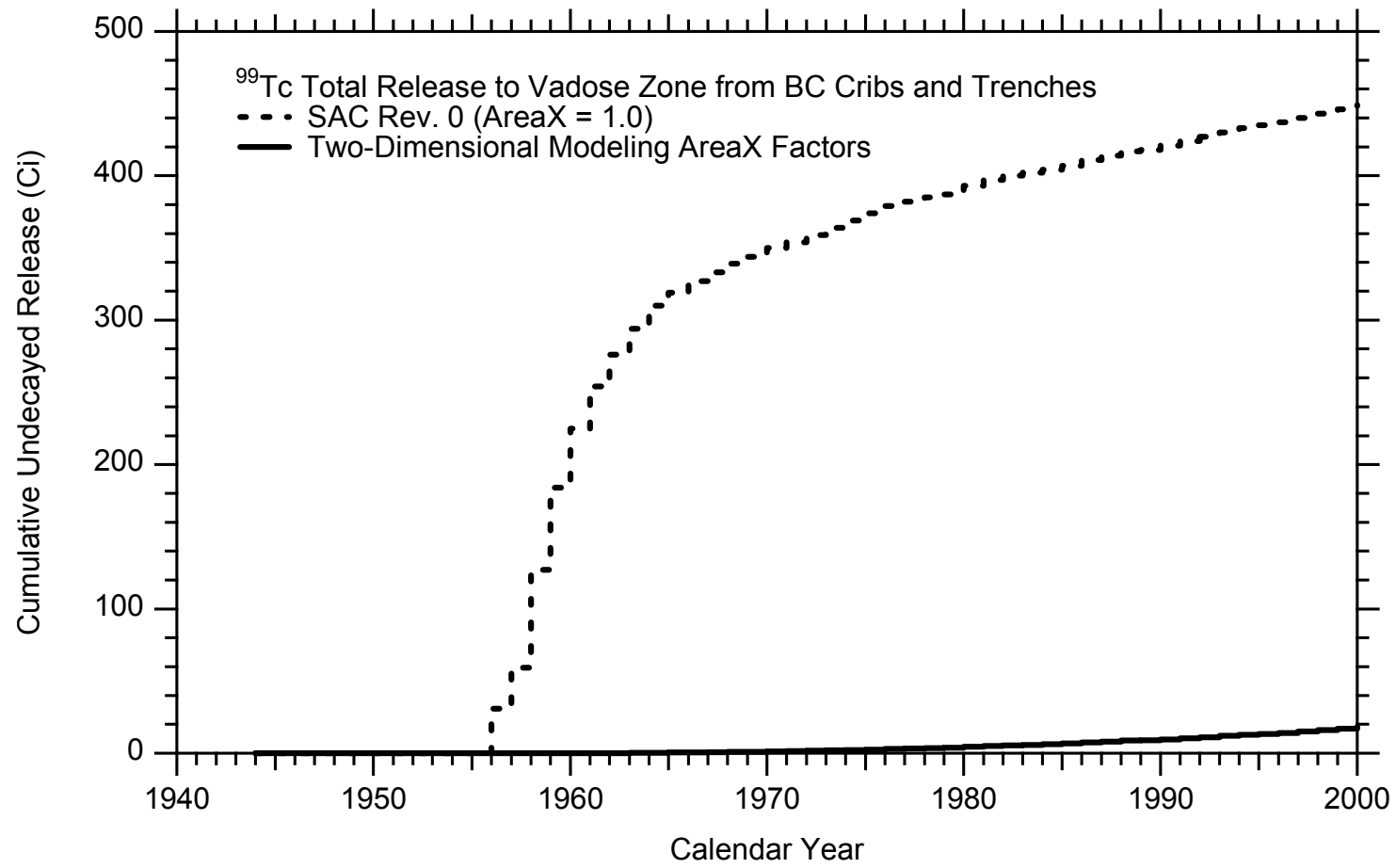

Figure C.25. Total Annual Release from all BC Cribs and Trenches Simulated in SAC Rev. 0 Initial Assessment and with Vadose Zone Wetted Area Scaling Parameters Conditioned to Direct Two-Dimensional Simulations 


\section{Appendix D}

\section{Surface Barrier Degradation}




\title{
Appendix D
}

\section{Surface Barrier Degradation}

\author{
G. W. Gee and A. L. Ward
}

Surface barriers, consisting of vegetated soil and assorted sublayers, will be constructed and placed over as many as 200 waste sites at Hanford. These surface barriers, if effective, will isolate the general public from buried waste and limit surface erosion and minimize water and biotic intrusion into the waste. Over time, it is assumed that numerous forces, including wind, water, fire, drought, and seismic activity will act to degrade the barrier surface. This appendix describes key potential failure mechanisms and outlines several scenarios that could be used to simulate barrier degradation in long term assessments. The most probable failure mechanism is wind erosion resulting in sand dune formation, which can change surface texture and vegetation and result in increased recharge rates. In terms of recharge control, a surface barrier at Hanford may change from a very low recharge rate $(<0.1$ millimeter per year) to something more representative of a stabilized sand dune at the Hanford Site (e.g., 4 millimeters per year or greater).

\section{D.1 Introduction}

In the mid 1980s the U.S. Department of Energy initiated a Barrier Development Program at the Hanford Site (see Attachment 1). The purpose of the program was to develop a long-term barrier, capable of isolating waste for more than 1,000 years. The barrier development program included 12 elements designed to address all aspects of barrier design and construction:

- biointrusion

- water intrusion

- wind and water erosion

- physical stability

- material quality and quantity

- monitoring
- modeling

- prototype design and construction

- natural analogs

- climate change

- regulatory issues

- technical exchange

Field tests were initiated to test selected aspects of the long-term barrier and culminated in the design and construction of a prototype surface barrier (PSB), placed over the B-57 crib in the 200 BP-1 Operable Unit, adjacent to the BY Tank Farm in the 200 East Area at the Hanford Site. Over 130 reports and papers have been published to date, documenting various aspects of the PSB, construction, and performance (see Attachment 1). Figure D.1 shows the general features of PSB designed for long-term (1,000 year) protection.

Testing of PSB has successfully demonstrated that above-grade vegetated covers at Hanford act as a sponge, storing incident precipitation during wet (winter) periods and subsequently losing water by evapotranspiration (ET) during dry (summer) periods, thus minimizing water intrusion into underlying 


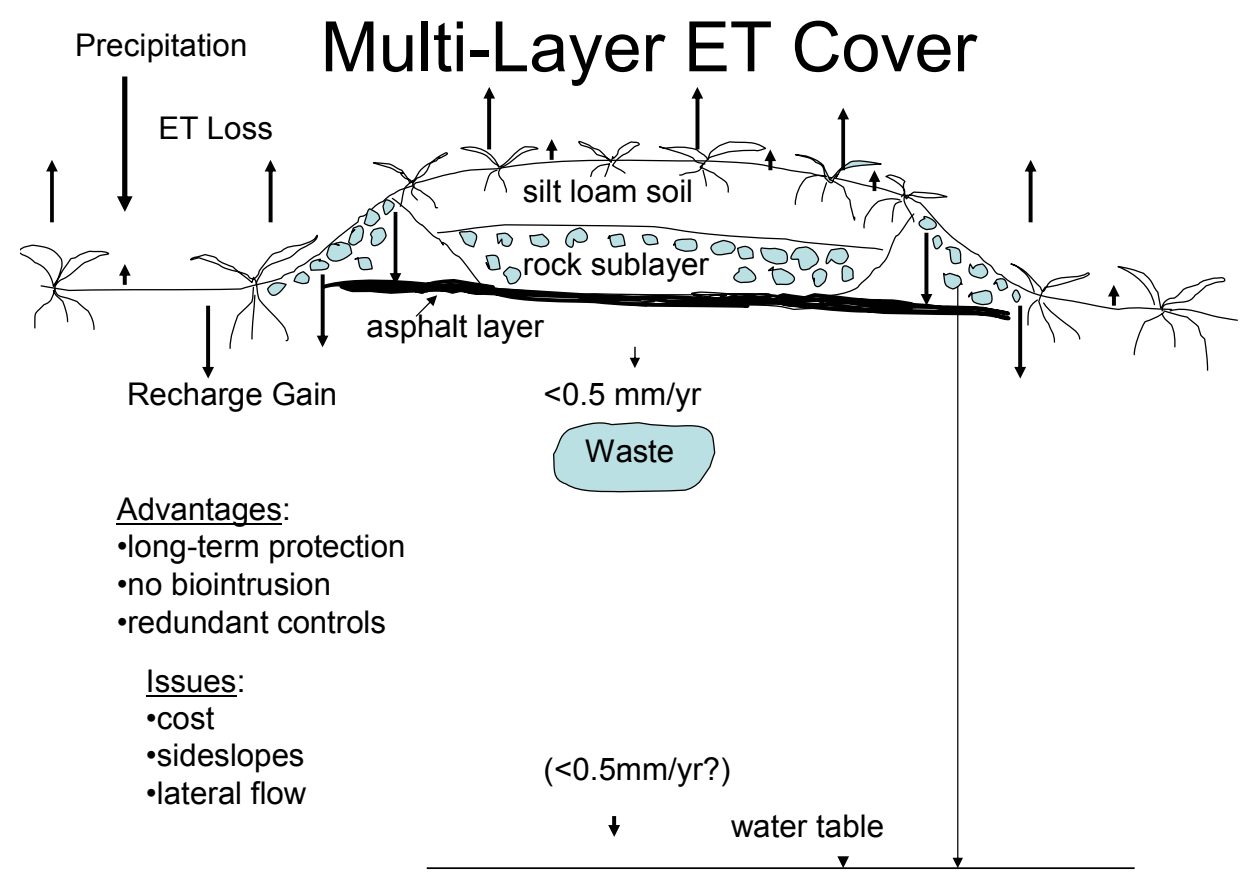

Figure D.1. Hanford Prototype Surface Barrier (PSB) Designed for Long-Term (1,000 year) Protection of Hanford Waste Sites

waste. In contrast, the side slopes, built to engineering specifications (DOE 1994), are designed to stabilize the barrier against wind and water erosion. Because they are coarse and mostly barren they allow significant water to infiltrate into subsurface sediments surrounding the waste (Ward and Gee 1997; Gee et al. 2002; Wittreich et al. 2003). The results from the PSB studies indicate that the complete barrier system, soil cover and side slopes, must be understood to evaluate total barrier performance. In the final design of long-term barriers there may be tradeoffs between erosion control and water intrusion protection, as illustrated by the side slope drainage measurements which have shown that coarse side slopes, used for erosion protection, can drain up to $20 \%$ or more of the annual precipitation (Wittreich et al. 2003).

\section{D.2 Alternative Designs}

In addition to PSB (Figure D.1), other barrier designs have been proposed for Hanford (DOE 1997). Only PSB has been tested in full-scale prototype. However, some alternative covers have been tested in small lysimeters (Fayer et al. 1999). These include the so-called modified RCRA C cover. The modified RCRA C cover incorporates the low permeability (asphalt layer) layer of PSB but does not use the biointrusion layer; thus, the total thickness is less than PSB and construction costs are correspondingly reduced. Monofill ET covers have also been proposed for use at Hanford. Figure D.2 shows the general features of a monofill ET cover, which consists simply of a soil layer placed above the waste and vegetated with native plants. Side slope issues that exist for all above-grade surface barriers will affect both the modified RCRA C and the monofill ET cover. An alternative cover that has not been considered yet but has great potential for Hanford is what can be called the Shallow Liner ET Cover (Figure D.3). 


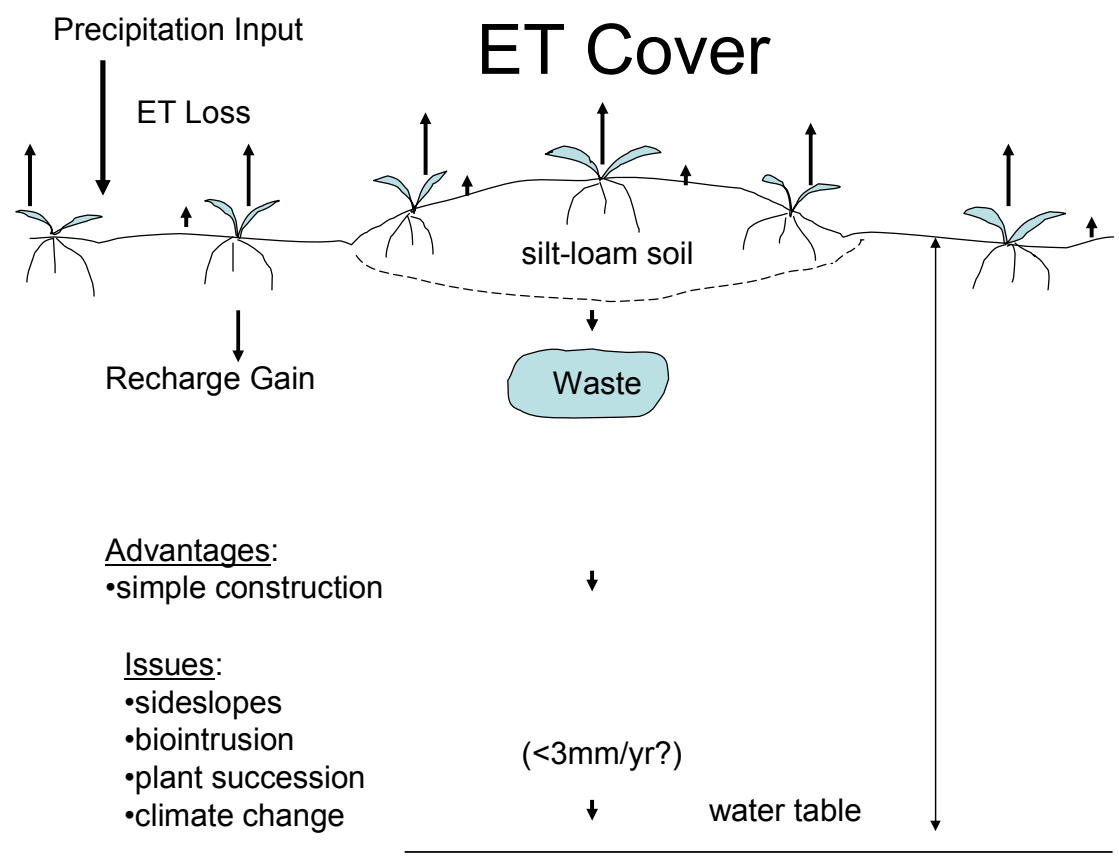

Figure D.2. Simple Evapotranspiration (ET) Cover, with Silt Loam Soil (for optimal water storage) and Native Vegetation (shrub steppe) to Enhance Surface Water Loss

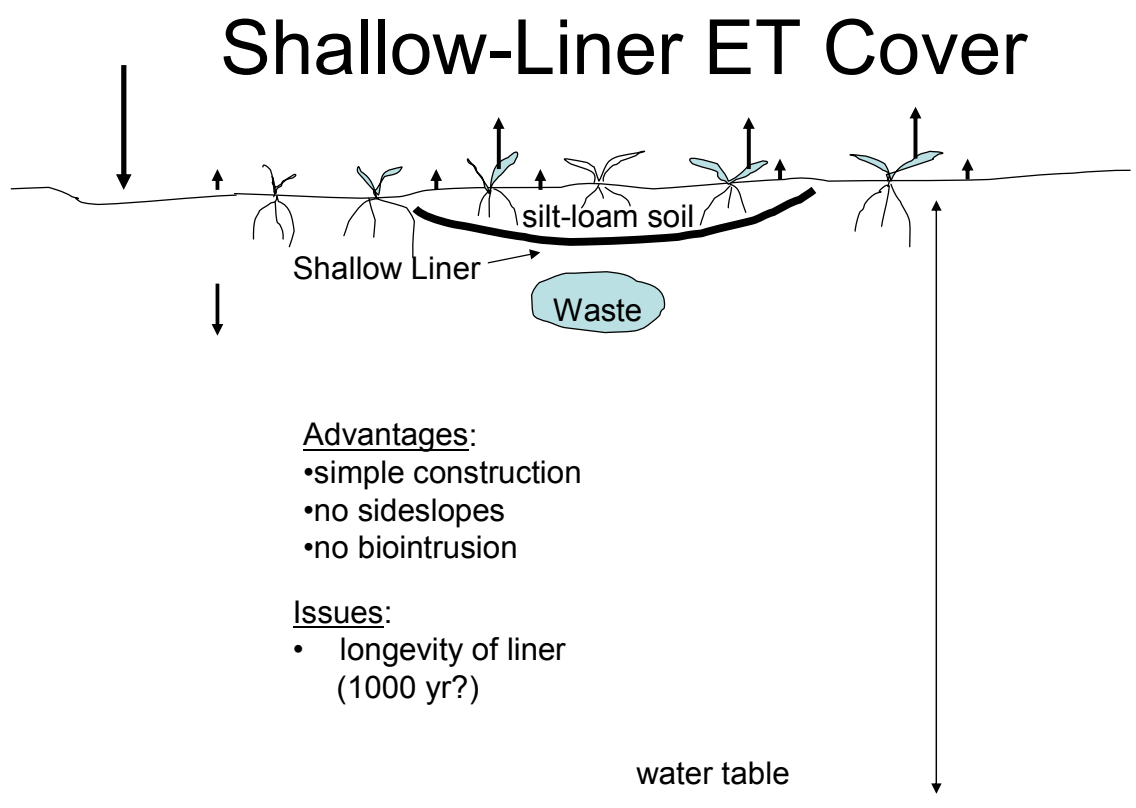

Figure D.3. Shallow Liner Evapotranspiration (ET) Cover. Includes a low permeability (Geomembrane) below a silt loam surface to provide redundant drainage control, minimize biointrusion and eliminate side slopes. 
This design eliminates side slopes and biointrusion and because these are two mechanisms that can aid to the degradation of surface covers, such design features should be seriously considered for placement at Hanford waste sites.

No systematic study of all surface barrier degradation mechanisms has been made to date. For example, the impact of side slopes on net water infiltration into the waste has not been addressed in current designs of above grade surface barriers, nor previously factored into discussions of barrier degradation. The interaction of side slope recharge, erosion control, depositional processes and impacts from fire, disease, etc. have not been systematically incorporated into a final design. In the following sections we attempt to describe the most reasonable and expected degradation (or failure) mechanisms for surface barriers at Hanford, including effect of wind erosion, biointrusion protection, and the impact of side slopes on degradation on final barrier performance. We offer some alternative designs for improved side slope performance, and provide several timelines for expected barrier degradation including estimates of overall net infiltration or recharge associated with final barrier performance as a consequence of a specific design.

\section{D.3 Barrier Degradation Assumptions}

In recent numerical assessments, (such as the initial assessment performed with the System Assessment Capability (SAC) (Bryce et al. 2002) it was assumed that there were two kinds of barriers: 1) a long-term (1,000 year) barrier used primarily for tank farms and transuranic waste sites and 2) a 500-year barrier used for solid waste landfills and other low-level waste sites at Hanford. There have been no specific degradation mechanisms specified but for the initial assessment performed with SAC, the following assumptions were made about performance and recharge rates.

\section{D.3.1 The 1,000-Year Barrier}

This barrier was assumed to perform optimally ( 0.1 millimeter per year) for 1,000 years. After 1,000 years, the barrier was assumed to degrade (by a combination of unspecified failure mechanisms) to a pre-operations recharge level specified by the soil type that existed prior to the waste-site construction. The degradation was assumed to take place in 5 equal steps of 200 years over the next 1,000 years. For example, if the pre-operations recharge level was 2 millimeters per year, the following scenario was assumed:

- Year 0 to 1000 - recharge $=0.1$ millimeter per year

- Year 1001 to 1200 - recharge $=0.4$ millimeter per year

- Year 1201 to 1400 - recharge $=0.8$ millimeter per year

- Year 1401 to 1600 - recharge $=1.2$ millimeters per year

- Year 1601 to 1800 - recharge $=1.6$ millimeters per year

- Year 1801 to 2000 - recharge $=2.0$ millimeters per year 


\section{D.3.2 The 500-Year Barrier}

This barrier was assumed to perform optimally ( 0.1 millimeter per year) for 500 years. After 500 years, the barrier was assumed to degrade (by a combination of unspecified failure mechanisms) to a pre-operations recharge level specified by the soil type that existed prior to the waste-site construction. The degradation was assumed to take place in 5 equal steps of 100 years over the next 500 years. For example, if the pre-operations recharge level was 2 millimeters per year, the following scenario was assumed:

- Year 0 to 500 - recharge $=0.1$ millimeter per year

- Year 501 to 600 - recharge $=0.4$ millimeter per year

- Year 601 to 700 - recharge $=0.8$ millimeter per year

- Year 701 to 800 - recharge $=1.2$ millimeters per year

- Year 801 to 900 - recharge $=1.6$ millimeters per year

- Year 901 to 1000 - recharge $=2.0$ millimeters per year

These degradation assumptions were made purely to simplify the modeling and do not represent any actual degradation responses. They are considered conservative assumptions, in that degradation processes are generally slow, though some catastrophic events such as floods, drought, and related climate change events can cause rapid alteration of the landscape. In fact, extreme dynamics are responsible for much of the geologic setting for Hanford (Baker et al. 1991; Bjornstad and Teel 1993; Gaylord and Stetler 1994; Peterson et al. 1993). Prediction of the exact timing of degradation is virtually impossible, so the stepwise degradation assumptions are as reasonable as any other alternatives.

Other recent assessments (such as the ILAW performance assessment [reference]) have assumed that the barrier disappears at the end of its design life.

\section{D.4 Potential Degradation Mechanisms}

This section describes degradation mechanisms that could affect surface barriers placed over Hanford waste sites.

\section{D.4.1 Wind Deposition}

The most likely mechanism for long-term degradation of a barrier at Hanford is wind induced sanddune formation (sand deposition). Studies by Gaylord et al. (1993); Gaylord and Stetler (1994) demonstrate that most of the surficial soil at Hanford is eolian (wind blown) in nature, with about half of the Hanford Site exposed to or covered by stabilized or active dunes. Active and stabilized dunes have their highest densities in areas to the south and east of the 200 Areas, while some stabilized dunes are located in the 200 East Area. All soil in the 200 Areas is covered with a mantle of windblown sand material (Gaylord and Stetler 1994). For long-term considerations, all surface covers are assumed to be affected in some way by wind action. When vegetated, the soil surface is generally stabilized against wind erosion. However, there are local changes to microrelief because of wind action that can affect water storage and other surface properties. Coppice dunes are found extensively at the Hanford Site. 
These miniature dunes consist of fine sands deposited around shrubs, creating small mounds (hummocks) elevated 0.5 meter or more above surroundings. The intermound (or swale) is a depression that is often sparsely vegetated and has different water-storage capacity than that found on the hummock. At one coppice dune site near the Yakima Barricade, west of the 200 Areas at Hanford, Link et al. (1994) found that water storage was strongly associated with vegetation patterns and that actual water storage was inversely correlated with vegetation, suggesting the greater the plant density the lower the available water in the soil profile, consistent with our ET cover concepts. An irrigation treatment demonstrated that all of the rainfall and irrigation water was consumed (transpired) by plants at this coppice dune site. Soil texture was coarser in the top 0.5 meter of the hummock than in the swale but vegetation density was greatest on the hummock. It is entirely possible that as coarser soils accumulate, that water storage capacities will actually decrease, with corresponding decreases in vegetation density and conversion from deep-rooted vegetation to shallow rooted vegetation. Coppice dunes are complex systems and illustrate the dynamic nature of the soil surface in the Hanford environment. It is most likely that changes similar to coppice dune features will develop on even the most stable cover under the present Hanford climatic regime. Initially, this change may not directly impact barrier drainage rates, but features like coppice dunes are a precursor to larger accumulation of sands over time and the subsequent change from shrub vegetation to sparse grasses as observed on a significant portion of the Hanford Site (Gaylord and Stetler 1994). Based on these observations, it is likely that engineered surface barriers will change from wellcontoured surfaces to surfaces with significant microrelief (hummocks and swales) and finally to more extensive stabilized dunes in the next 1,000 years or more.

A possible scenario for wind action on the surface barrier is as follows:

1. Year 1 (barrier placement) to year 500. Barrier performance as specified $(<0.1$ millimeter per year)

2. Year 501 to year 1000 . Development of stabilized dunes - linearly degrades to 4 millimeters per year of average recharge. This rate is based on recharge estimates of stabilized dunes obtained from chloride mass balance data of Murphy et al. (1996).

3. Year 1001 and beyond. Surface barrier is assumed to behave like a stabilized sand dune. (Recharge assumed to be 4 millimeters per year). It should be noted that the chloride mass balance method apparently predicts recharge reliably in the very low $(<1$ millimeter per year) range but there is less certainty when the recharge is above a few $\mathrm{mm} / \mathrm{yr}$ (Prych 1995; Tyler et al. 1999), so a sand-dune recharge rate of 4 millimeters per year may not be conservative and likely will have to be updated in the future, as more reliable results are obtained.

\section{D.4.2 Water Erosion}

Studies conducted at PSB have demonstrated that little if any runoff or surface erosion has occurred over the 9 years of monitoring of the surface barrier (Gee et al. 2002; Wittreich et al. 2003). The low grade on slopes for the soil cover plus the well-established vegetation has minimized any water erosion on PSB. There is no evidence that water erosion would cause any significant barrier degradation at the Hanford site. Runoff occurs primarily in winter or early spring when soils are frozen and when snowmelt occurs rapidly due to warm (e.g., Chinook) winds (Skaggs and Walters 1981; Gee and Hillel 1988). For soil on gentle slopes with well established vegetation, runoff is accompanied by little or no sediment loss. 
The lack of evidence for water erosion allows us to assume that there will be no changes in recharge rate due to any plausible water erosion scenario.

\section{D.4.3 Biotic Intrusion}

There is ample evidence that biotic (plant and animal) intrusion has occurred at waste sites at Hanford in the past (Dabrowski 1973; O'Farrell and Gilbert 1975, Landeen and Mitchell 1982; Marshall 1987). Deep-rooted tumbleweed (Salsoa kali) has a tap root that can penetrate to depths of 5 meters or more in the sandy soil and backfill sediment at Hanford. Dabrowski (1973) describes waste sites near the Columbia River in the 100 Areas where tumbleweeds intruded in to wastes containing cesium-137 and strontium-90. Uptake of strontium-90 caused the plants to become radioactive. The radioactive tumbleweeds created problems, because as they aged, some were blown off the waste site, thus becoming an undesirable biotic vector. Ants and burrowing insects, small (pocket mice and gophers) and large mammals (badgers) also have been observed to intrude into waste and bring contaminants to the surface where they have been scattered to locations some distance from the waste sites (O'Farrell and Gilbert 1975; Cline et al. 1980; Landeen and Mitchell 1982, Kennedy et al. 1985). A waste site, called the BC cribs, located to the south of the 200 East Area, has documented widespread surface contamination, attributed to biotic intrusion. In the 1950s, a badger hole was found at one of the BC cribs, which contained near-surface contamination (strontium-90 and cesium-137). The badger likely foraged for mice in contaminated soil. Jackrabbits then used the burrow and became contaminated (O'Farrell and Gilbert 1975). Coyotes and raptors subsequently ate the jackrabbits and spread the contamination over a wide area (more than several hundred hectares). Similar situations have been observed at the Idaho National Laboratory, near Arco, Idaho (Arthur and Markum 1983; Arthur et al. 1987).

While such intrusion is possible, particularly at waste sites with surface spills or with otherwise nearsurface contamination, a properly designed surface cover will limit biotic intrusion. Features to prevent biotic intrusion were incorporated into the design of the Hanford surface barrier. These features included a sublayer of coarse rock designed to discourage digging (see Cline and Rogers 1982) and an asphalt layer that is impervious to water, small mammals and burrowing insects (Myers and Duranceau 1993; Wing and Gee 1994). An asphalt layer is placed below the rock layer, providing a redundancy that limits not only biotic intrusion (including both plant root and animal intrusion into underlying wastes) but prevents water intrusion as well. For ET cover systems with no rock or asphalt sublayers, the possibility of biointrusion remains. However, in the final barrier design for all waste sites at Hanford, we assume that some kind of biotic intrusion protection will exist and that borrowing animals will be confined to the near surface (top meter of soil) and their presence does not create pathways for water intrusion. This assumption is supported by the work of Landeen (1994) who demonstrated that pocket mice burrows acted much like vent tubes, allowing for advective drying of the near surface soils thus reducing the actual water content in the profile during the summer months and subsequently increasing the actual storage capacity of the soil. Based on past biointrusion studies we conclude that biotic transport can be minimized with a properly designed surface barrier and that water intrusion will not be enhanced. The most probable scenario for biotic intrusion then is to assume that it is minimal and that water intrusion is not affected by biotic vectors, so the recharge impact is zero from biotic intrusion. 


\section{D.4.4 Fire, Plant Succession and Associated Wind Erosion}

A concern about relying on ET for water removal is the dynamic nature of the vegetation. At Hanford, a key component of any reliable surface barrier will be a vegetated surface. Periodic fires can remove the vegetation in dramatic and often catastrophic fashion. Wildfires have occurred periodically at Hanford. Two of them, one in 1984 and one in 2000, each burned over 64,749 hectares leaving large portions of the landscape temporarily barren (Link et al. 1990; Gee et al. 1992a). The 2000 fire occurred in late June, when understory vegetation (primarily cheatgrass) had senesced (died) and was tinder dry. The fire, started by an auto accident on Highway 24, quickly spread to the Hanford Site, jumping Highways 24 and 240 and burning most of Rattlesnake Mountain and part of Benton City, in addition to spreading onto and around the 200 Areas. The removal of almost all vegetation from the western perimeter of the 200 West Area on to the top of Rattlesnake Mountain left the land surface in that area vulnerable to wind erosion, which did occur. The surface soil in this area has a fine sand texture, which is highly susceptible to wind erosion. It was enough of a problem that tank farm operations were periodically curtailed because of blowing dust. Subsequently, a windbreak, consisting of a double row of 1,500 trees (Australian willow), was placed along the western boarder of the 200 West Area to protect buildings, vehicles, and personnel from sand blasting and dust inhalation. Irrigation of the windbreak was initiated in the summer of 2001 and is continuing because trees do not survive in the Hanford environment without supplemental irrigation (Gee et al. 2002).

In addition to the tree placement and irrigation, other measures, including straw mulching were implemented to lessen the impact of bare surface exposures or wind erosion. By the spring of 2003, the surface has stabilized by natural revegetation, so that little erosion, if any, has occurred for the past two years. This is consistent with the observations made by Link et al. (1990), who demonstrated that after the 1984 fire that plants on the Fitzner/Eberhartdt Arid Land Ecology (ALE) Reserve recovered sufficiently to actively remove stored water from the soil profile in a fashion similar to pre-fire conditions. The effectiveness of the plant water uptake was such that after two years there were no marked differences between unburned and burned sites. The data of Link et al. (1990) clearly demonstrate that for silt loam soil, the effect of fire is temporary and recovery is rapid. For most, if not all of the Hanford Site, it would be expected that the no significant impact should occur, particularly when the soil is fine-textured with significantly large storage capacities. Wind erosion occurs from silt loam soil, only if it is very dry and highly disturbed. Vegetation tends to anchor the finer (silt loams) soil so that is it far less susceptible to wind erosion than coarse soil (e.g., fine sands). Based on these observations, we conclude that fire may have a temporary impact on surface barriers, but with fine soil (silt loam) dominating the surfaces, that recovery of vegetation is rapid and the impacts from fire can be considered negligible.

\section{D.4.5 Drought and Plant Succession}

Another concern with surface barriers is the potential for extended drought followed by elevated precipitation (wet climate) conditions. In such a scenario, the excess (or elevated) precipitation would either be incident on the soil surface and runoff or be infiltrated into the soil. For coarse soils the lack of vegetation would allow drainage while for fine soil drainage would be contained in the soil for subsequent use by plants (ET). Drought in the current shrub-steppe environment often leads to fire, so much of the 
discussion on fire and plant succession hold for this case of drought. There are no data to show performance of a cover under an extreme drought or extended period (multiple years) of dryness. Clearly vegetation would be affected. While much of the shrub-steppe has been altered by fire, the most dramatic thing is the potential conversion of the shrub-steppe vegetation, where deep-rooted shrubs dominate the vegetation type, to cool-season, shallow-rooted grasses (e.g., bromus tectorum or cheatgrass), thus, reducing the water storage capacity of the soil by virtue of the change in both rooting depth and plant phenology (life cycle), such that less water can be lost from the soil by transpiration over time. The famous ecologist, Leopold (1966), described the process of converting the western U.S. native shrubsteppe vegetation to cheatgrass prairie through a succession of fires. Invasion of cheatgrass perpetuates itself. After senescence, cheatgrass stalks and heads acts like dry tinder. When a fire starts (via lightning strike or man) the fuel is the dead cheatgrass, which burns rapidly, destroying the shrubs. Regeneration of the shrubs requires a seed source and the seeds in turn must compete with cheatgrass for a limited water supply in fall and winter. The cheatgrass acts much like winter wheat, germinating in the fall, going dormant in winter, then sprouting in full vigor in early spring. It generally out-competes its rivals for water so that many shrub seedlings do not survive, and the cheatgrass becomes the dominant plant species in a fire-swept steppe country. The process repeats itself until the cheatgrass dominates the entire landscape. It is entirely possible that over time much of the Hanford Site landscape could become cheatgrass dominated. The impact on coarse soil sites would be dramatic since water storage will change and more drainage and recharge will result. Increased recharge has been observed at Hanford where the coarse soil shrub-steppe landscape has been converted from shrub-steppe to grassland (Prych 1995; Fayer and Walter 1995). A fire-affected site near the 300 Area, with a fine sand over coarse (Burbank loamy sand) soil, transitioned from shrub-steppe to grassland (bluegrass and cheatgrass). The estimated recharge rate was 25 millimeters per year, as obtained from neutron-probe monitoring (Fayer and Walter 1995) while at this same site (Prych 1995) used chlorine-36 analysis to estimate a recharge rate of about 5 millimeters per year. This compares to shrub-steppe recharge rate estimates that are generally much less than 1 millimeter per year (Prych 1995; Murphy et al. 1996).

In contrast, where soil is fine textured (e.g., silt loams), there appears to be little impact on the recharge with this vegetation change, since the soil water storage is sufficient to contain the water, hold it near the surface long enough that both soil evaporation and plant transpiration act to remove it. Studies at the Field Lysimeter Test Facility near the Hanford Meteorological Station have demonstrated that 1-meter-thick silt loam soil, void of any vegetation, is entirely capable of losing all of the annual precipitation via evaporation. Data collected for over a period of 12 years (Fayer et al. 1999) indicated that there has been no drainage from bare, silt loam soil data, suggesting that fire and subsequent vegetation changes, will have little or no effect on the drainage from a silt-loam surface-barrier. Based on these observations we assume that fire will not adversely impact the barrier performance but may impact the surroundings by increasing the recharge in surrounding areas where there are coarse soils dominated by cheatgrass or similar shallow-rooted plants.

\section{D.4.6 Other Mechanisms}

Other mechanisms for barrier degradation include subsidence, human intrusion and climate change. These mechanisms were considered in the Hanford barrier development program. 


\section{D.4.6.1 Subsidence}

Subsidence or surface collapse is associated with consolidation of waste (e.g., collapse of waste containers, general settlement of surficial materials after backfilling operations or response to seismic events). While subsidence can affect the integrity of a capillary barrier and the impermeable asphalt by differential settlement, the assumption was made that stabilization of the waste with grout injection, dynamic compaction, or other means could minimize effects of consolidation at most waste sites. The PSB has been studied for nearly 10 years and tested for consolidation and surface stability. Civil surveys indicate that the surfaces have remained stable for the first decade after construction (Wittreich et al. 2003) with little indication of settlement even on the 2:1 rock side slopes. Based on these findings, it is assumed that stable surfaces can be achieved and that subsidence will not be a major degradation mechanism for most of the Hanford waste sites. Where there are buried objects such as empty metal tanks, wooden boxes, and building with large void spaces, special consideration will have to be given to address consolidation effects on barrier performance. In principle, technologies such as dynamic compaction and grout injection can be used to minimize subsidence effects.

\section{D.4.6.2 Inadvertent Human Intrusion}

Inadvertent human intrusion is a possible scenario but warning markers identifying no-dig zones at the wastes sites have been proposed for the Hanford waste sites (Adams and Wing 1986) and if such markers were used it would lessen the chance for inadvertent intrusion. It could be envisioned that after loss of institutional control, that deliberate removal of an entire surface barrier is possible since the surface cover is always exposed and vulnerable. However, the likelihood of such a scenario of cover removal appears remote, particularly if the warning and marker systems are used.

\section{D.4.6.3 Climate Change}

Climate change, on the other hand, is entirely possible and was considered in the barrier development program. One scenario would be for Hanford to experience a wetter, cooler climate, which could increase the chance for water storage to be exceeded. Paleoclimate studies suggest that if the past were a indicator of the future that change to a wetter and cooler environment would produce at most a $30 \%$ increase in the precipitation over the long-term (Wing et al. 1995). In the design of PSB, a doubling of precipitation was assumed to be the upper limit of precipitation for 1,000-year performance (Myers and Duranceau 1994). Studies of PSB indicated that applications of 1,000-year-storm events and precipitation elevated to 3 times the annual average value caused less than 0.2 millimeter of drainage in 3 years of testing at rates of 480 millimeters per year or three times the annual average rate (Gee et al. 2002a; Wittreich et al. 2003). Based on these observations, we assume that the human intrusion and climate change scenarios will not significantly impact the recharge rates for surface barriers at Hanford.

\section{D.5 Side Slope Impacts on Degradation}

Side slopes can have a huge impact on surface barrier performance. As demonstrated by the Hanford surface barrier tests, sparsely covered gravel and rock side slopes, while effective in eliminating wind and water erosion, add drainage water to the areas surrounding the soil cover. Side slope drainage can be as much as $20 \%$ or more of the annual precipitation (Gee et al. 2002a; Wittreich et al. 2003). While 
advective drying reduces the drainage rates, particularly on steep rock side slopes, they still contribute a large portion of the total recharge, particularly when the waste areas are small and the ratio of the side slope area to the total area is large. For sites with dimensions less than 100 meters on a side the side slope area can be $40 \%$ or more of the total area when the side slopes have 5:1 (horizontal:vertical) dimensions or less. The contribution of the total recharge then becomes dramatically weighed toward the recharge rate of the side slopes.

For many of the proposed waste sites in the 200 Areas at Hanford, which have deep underlying water tables, the added water from the side slopes can percolate into the subsurface and carry contaminants to groundwater. Degradation of stabilized, armored side slopes is not expected under any of the probable scenarios, except in the case of sand-dune formation. Under such a scenario, the side slope drainage would be reduced to the drainage rate of the sand dune material and attendant vegetative cover.

Improvements over present side slope design might include terracing and additions of fine materials trenched into the side slopes to improve water holding capacity and provide adequate rooting media for native plants. If such schemes were employed it is possible that recharge rates could be reduced to values comparable to the soil cover but such schemes have not yet been demonstrated.

\section{D.6 Timelines for Barrier Degradation}

Timelines for drainage from 500-year and 1,000-year barriers are listed in Table D.1. The tables assume that sand dune formation is responsible for barrier degradation and increases the recharge over time. It is assumed that the dune develops sooner on the 500-year barrier but ends at the final recharge rate at the same time as the 1,000-year barrier. This assumption is tied solely to differences in climate effects that cause the sand dune formation (for the 500-year barrier scenario the sand dune forms sooner and expresses its full impact sooner than on the 1,000-year barrier). The final rate for both barriers in 2,000 years is assumed to be 4 millimeters per year, a rate observed by Murphy et al. (1996) on a stabilized sand dune at Hanford. This rate may not be conservative because it was estimated from chloride mass balance techniques, which become insensitive at rates much above a few millimeters per year (Tyler et al. 1999). Also, higher recharge rates have been observed on stabilized soil that are vegetated (Fayer and Walters 1995). Selected barrier performance is illustrated in Table D.2, where the final drainage rates for various covers are listed along with the probabilities of a number of degradation factors.

\section{D.7 Summary and Conclusions}

Wind and water erosion, biointrusion, fire, drought, subsidence, human intrusion, and climate change were considered as possible barrier degradation mechanisms. In addition, side slope water intrusion was considered in light of its potential effects on overall barrier performance. The most plausible degradation mechanism for the Hanford Site is wind erosion, causing sand dune formation. Timelines of degradation were developed which assumed that the final barrier will be covered with a dune that drains at the rate of 4 millimeters per year. It is possible that higher rates may develop on barriers covered with sand dunes but such rates have yet to be documented. 
Table D.1. Drainage Rates for 500-Year and 1,000-Year Surface Barriers (assumes an initial recharge rate of $0.1 \mathrm{~mm} / \mathrm{yr}$ and a final recharge rate of $4 \mathrm{~mm} / \mathrm{yr}$ after 2000 years)

\begin{tabular}{||c|c|c||}
\hline $\begin{array}{c}\text { Time } \\
(\mathrm{yrs})\end{array}$ & $\begin{array}{c}500-\text { Year Barrier } \\
(\mathrm{mm} / \mathrm{yr})\end{array}$ & $\begin{array}{c}1,000-\text { Year Barrier } \\
(\mathrm{mm} / \mathrm{yr})\end{array}$ \\
\hline \hline Present & 0.1 & 0.1 \\
\hline+500 & 0.1 & 0.1 \\
\hline+600 & 0.4 & 0.1 \\
\hline+700 & 0.8 & 0.1 \\
\hline+800 & 1.2 & 0.1 \\
\hline+900 & 1.6 & 0.1 \\
\hline+1000 & 2.0 & 0.1 \\
\hline+1200 & 2.4 & 1.5 \\
\hline+1400 & 2.8 & 2.5 \\
\hline+1600 & 3.2 & 3.0 \\
\hline+1800 & 3.6 & 3.5 \\
\hline+2000 & 4.0 & 4.0 \\
\hline
\end{tabular}

Table D.2. Degradation Factor Probabilities for Selected Landfill Covers at the Hanford Site

\begin{tabular}{|c|c|c|c|c|}
\hline Factors & $\begin{array}{l}\text { Multilayer } \\
\text { Hanford }\end{array}$ & Modified RCRA C & $\begin{array}{l}\text { Monofill } \\
\text { ET }\end{array}$ & $\begin{array}{c}\text { Shallow Liner } \\
\text { ET }\end{array}$ \\
\hline Wind deposition & $\mathrm{H}$ & $\overline{\mathrm{H}}$ & $\overline{\mathrm{H}}$ & $\overline{\mathrm{H}}$ \\
\hline Water erosion & $\mathrm{L}$ & $\mathrm{L}$ & $\mathrm{M}$ & $\mathrm{L}$ \\
\hline Biointrusion & $\mathrm{L}$ & $\mathrm{L}$ & $\mathrm{H}$ & $\mathrm{L}$ \\
\hline Human intrusion & $\mathrm{L}$ & $\mathrm{M}$ & $\mathrm{H}$ & $\mathrm{L}$ \\
\hline Subsidence & $\mathrm{L}$ & $\mathrm{L}$ & M & $\mathrm{L}$ \\
\hline Fire & $\mathrm{L}$ & $\mathrm{L}$ & $\mathrm{M}$ & $\mathrm{L}$ \\
\hline Drought & $\mathrm{L}$ & $\mathrm{L}$ & $\mathrm{M}$ & $\mathrm{L}$ \\
\hline Side slope impact & $\mathrm{H}$ & $\mathrm{H}$ & $\mathrm{H}$ & $\mathrm{L}$ \\
\hline Climate change & $\mathrm{M}$ & $\mathrm{M}$ & $\mathrm{H}$ & $\mathrm{M}$ \\
\hline Final Recharge (mm/yr) & 4 & 4 & $>4$ & $<4$ \\
\hline \multicolumn{5}{|l|}{$\begin{array}{l}\mathrm{H}=\text { High } \\
\mathrm{L}=\text { Low. } \\
\mathrm{M}=\text { Medium. }\end{array}$} \\
\hline
\end{tabular}

\section{D.8 References}

Adams MR and NR Wing. 1986. Protective Barrier and Warning Marker System Development Plan. RHO-RE-OL-35P, Rockwell Hanford Operations, Richland, Washington.

Arthur WJ III and OD Markham. 1983. "Small Mammal Soil Burrowing as a Radionuclide Transport Vector at a Radioactive Waste Disposal Area in Southeastern Idaho.” J. Environ. Qual. 12:112-122.

Arthur WJ III, OD Markham, CR Groves, and BL Keller. 1987. "Radionuclide Export by Deer Mice at a Solid Radioactive Waste Disposal Area in Southeastern Idaho." Health Physics 52:45-53. 
Baker VR, BN Bjornstad, AJ Busacca, KR Fecht, EP Kiner, UL Moody, JG Rigby, DF Stradling, and AM Tallman. 1991. "Quaternary Geology of the Columbia Plateau." In R. B. Morrison (ed.) Quaternary Nonglacial Geology: Conterminous U.S.: The Geology of North America. v. K-2. Geological Society of America, Boulder, Colorado.

Bjornstad BN and SS Teel. 1993. Natural Analog Study of Engineered Barriers at the Hanford Site. PNL-8840, Pacific Northwest Laboratory, Richland, Washington.

Brunner DR and DJ Keller. 1972. Sanitary Landfill Design and Operation. SW-65ts, U.S. Environmental Protection Agency, Washington, D.C.

Cline JF and VA Uresk. 1979. "Revegetation of Disturbed Grounds in the Semi-Arid Climate of Southcentral Washington." Health Physics 36:289-294.

Cline JF, KA Gano, and LE Rogers. 1980. "Lose Rock as Biobarriers in Shallow Land Burial.” Health Physics 39:497-504.

Dabrowski TE. 1973. Radioactive Tumbleweed in the 100 Areas. UNI-65, United Nuclear Industries, Inc., Richland, Washington.

Fayer MJ and TB Walters. 1995. Estimated Recharge Rates at the Hanford Site. PNL-10285, Pacific Northwest National Laboratory, Richland, Washington.

Fayer MJ, EM Murphy, JL Downs, FO Khan, CW Lindenmeier, and BN Bjornstad. 1999. Recharge Data Package for the Immobilized Low-Activity Waste 2001 Performance Assessment. PNNL-13033, Pacific Northwest National Laboratory, Richland, Washington.

Gee GW, MJ Fayer, ML Rockhold, and MD Campbell. 1992. "Variations in Recharge at the Hanford Site." Northwest Sci. 66:237-250.

Gee GW, AL Ward, BG Gilmore, SO Link, GW Dennis, and TK O’Neil. 1996. Hanford PrototypeBarrier Status Report: FY 1996. PNNL-11367, Pacific Northwest National Laboratory, Richland, Washington.

Gee GW, AL Ward, and CD Wittreich. 2002a. The Hanford Site 1000-Year Cap Design Test. PNNL 14143, Pacific Northwest National Laboratory, Richland, Washington.

Gee GW, JS Carr, JO Goreham, and CE Strickland. 2002b. Water Monitoring Report for the $200 \mathrm{~W}$ Area Shelter Belt, Hanford Site, Richland, Washington. PNNL-14074, Pacific Northwest National Laboratory, Richland, Washington.

Kennedy WE, Jr, LL Cadwell, and DH McKenzie. 1985. "Biotic Transport from a Low-Level Radioactive Waste Site." Health Physics 47:723-728.

Landeen DS. 1994. The Influence of Small Mammal Burrowing Activities on Water Storage at the Hanford Site. WHC-EP-0730, Westinghouse Hanford Company, Richland, Washington. 
Landeen DS and RM Mitchell. 1982. Intrusion of Radioactive Waste Burial Sites by the Great Basin Pocket Mouse (Perognathus parvus). RHO-SA-211, Rockwell Hanford Company, Richland, Washington.

Leopold A. 1966. A Sand County Almanac. Oxford University Press, New York, pp. 154-157.

Link SO, GW Gee, ME Thiede, and PA Beedlow. 1990. "Response of a Shrub-Steppe Ecosystem to Fire: Soil Water and Vegetational Change." Arid Soil Research and Rehabilitation 4:163-172.

Lutton RJ, GL Regan, and LW Jones. 1979. Design and Construction of Covers for Solid Waste Landfills. USEPA Report 600/2-79-165, U.S. Environmental Protection Agency, Cincinnati, Ohio.

Marshall E. 1987. “Hanford's Radioactive Tumbleweed.” Science 236:1616-1620.

Murphy EM, TR Ginn, and JL Phillips. 1996. "Geochemical Estimates of Recharge in the Pasco Basin: Evaluation of the Chloride Mass Balance Technique." Water Resource Research 32:2853-2869.

Myers DR and DA Duranceau (eds.). 1994. Prototype Hanford Surface Barrier: Design Basis Document. BHI-00007, Bechtel Hanford, Inc., Richland, Washington.

O'Farrell TP and RO Gilbert. 1975. "Transport of Radioactive Materials by Jackrabbit on the Hanford Reservation." Health Physics 29:9-15.

Petersen KL, JC Chatters, and WJ Waugh. 1993. Long-Term Climate Change Assessment Study Plan for the Hanford Site Permanent Isolation Barrier Development Program. WHC-EP-0569 Rev. 1, Westinghouse Hanford Company, Richland, Washington.

Suter GW II, RJ Luxmoore, and ED Smith. 1993. "Compacted Soil Barriers at Abandoned Landfill Sites are Likely to Fail in the Long Term.” J. Environ. Qual. 22:217-226.

Tyler SW, BR Scanlon, GW Gee, and GB Allison. 1999. "Water and Solute Transport in Arid Vadose Zones: Innovations in Measurement and Analysis." In Vadose Zone Hydrology, pp. 334-373, J Hopmans and MB Parlange (eds.), Oxford Press, New York.

Ward AL and GW Gee. 1997. "Performance Evaluation of a Field-Scale Surface Barrier." J. Environ. Qual. 26:694-705.

Wing NR and GW Gee. 1994. “Quest for the Perfect Cap.” Civil Engr. 64(10):38-41.

Wing NR, KL Petersen, C Whitlock, and RL Burk. 1995. Long-Term Climate Change Effects Task for the Hanford Site Permanent Isolation Barrier Development Program: Final Report. BHI-00144, Bechtel Hanford, Inc., Richland, Washington.

Wittreich CD, JK Linville, GW Gee, and AL Ward. 2003. 200-BP-1 Prototype Hanford Barrier Annual Monitoring Report for Fiscal Year 2002. CP-14873, Rev. 0, Fluor Hanford, Inc., Richland, Washington. 


\section{Attachment 1: Surface Barrier Publications from the Hanford Site}

1. Phillips, S. J., M. R. Adams, T. W. Gilbert, C. C. Meinhardt, R. M. Mitchell, and W. J. Waugh. 1985. Engineered Barrier Test Facility Status Report: 1984. RHO-WM-SR-3P, Rockwell Hanford Operations, Richland, Washington.

2. Phillips, S. J., T. W. Gilbert, and M. R. Adams. 1985. Preliminary Engineering Specifications for a Test Demonstration Multilayer Protective Barrier Cover System. RHO-WM-EV-8 P, Rockwell Hanford Operations, Richland, Washington.

3. Fayer, M. J., W. Conbere, P. R. Heller, and G. W. Gee. 1985. Model Assessment of Protective Barrier Designs. PNL-5604, Pacific Northwest Laboratory, Richland, Washington.

4. Myers, D. R. 1985. Disposal Materials Study. RHO-WP-EV-12P, Rockwell Hanford Operations, Richland, Washington.

5. Adams, M. R., and M. F. Kaplan. 1986. "Marker Development for Hanford Waste Site Disposal." In Waste Management '86, (Vol. 1), pp. 425-431, RG Post (ed.). University of Arizona, College of Engineering and Mines, Tucson, Arizona.

6. Phillips, S. J., and J. N. Hartley. 1986. "Protective Barrier Systems for Final Disposal of Hanford Waste Sites.” In Waste Management '86, (Vol. 1), pp. 433-437, RG Post (ed.). University of Arizona, College of Engineering and Mines, Tucson, Arizona.

7. Kaplan, M. F., and M. R. Adams. 1986. "Using the Past to Protect the Future: Marking Nuclear Waste Disposal Sites.” Archeology 39(5):51-54.

8. Adams, M. R., and N. R. Wing. 1986. Protective Barrier and Warning Marker System Development Plan. RHO-RE-OL-35P, Rockwell Hanford Operations, Richland, Washington.

9. Fayer, M. J. 1987. Model Assessment of Protective Barrier Designs: Part II. PNL-6297, Pacific Northwest Laboratory, Richland, Washington.

10. Last, G. V., M. A. Glennon, M. A. Young, and G. W. Gee. 1987. Protective Barrier Materials Analysis: Fine Soil Site Characterization. PNL-6314, Pacific Northwest Laboratory, Richland, Washington.

11. Gee, G. W. 1987. "Preliminary Analysis of the Performance of the Protective Barrier and Marker System.” Appendix M, in Final Environmental Impact Statement, Disposal of Hanford Defense High-Level, Transuranic and Tank Wastes. DOE/EIS-0113, U.S. Department of Energy, Richland, Washington.

12. Kirkham, R. R., G. W. Gee, and J. L. Downs. 1987. Field Lysimeter Test Facility for Protective Barriers: Experimental Plan. PNL-6351, Pacific Northwest Laboratory, Richland, Washington. 
13. Waugh, W. J., and S. O. Link. 1988. Barrier Erosion Control Test Plan: Gravel Mulch, Vegetation, and Soil Water Interactions. WHC-EP-0067, Westinghouse Hanford Company, Richland, Washington.

14. Wing, N. R., M. D. Campbell, J. L. Downs, G. W. Gee, R. R. Kirkham, and S. J. Phillips. 1988. "Protective Barrier Development: The Field Lysimeter Test Facility." In Proceedings of the International Topical Meeting on Nuclear and Hazardous Waste Management Spectrum '88, pp. 196-198. American Nuclear Society, Inc., La Grange Park, Illinois, WHC-SA-0203-FP, Westinghouse Hanford Company, Richland, Washington.

15. Phillips, S. J., M. S. Ruben, and R. R. Kirkham. 1988. "Engineered Surface Barriers for Waste Disposal Sites: Lysimeter Facility Design and Construction." In DOE Model Conference Proceedings, pp. 1229-1238. CONF-881054, October 3-7, Martin Marietta, Oak Ridge, Tennessee.

16. Ligotke, M. W. 1988. Soil Erosion Rates from Mixed Soil and Gravel Surfaces in a Wind Tunnel: A Preliminary Report. PNL-6677, Pacific Northwest Laboratory, Richland, Washington.

17. Waugh, W. J., and M. G. Foley. 1988. Protective Barrier Climate-Change Impacts: Technical Workshop Findings and Recommendations. PNL-6615, Pacific Northwest Laboratory, Richland, Washington.

18. Ligotke, M. W. 1989. Surface Stability Test Plan for Protective Barriers. PNL-6722, Pacific Northwest Laboratory, Richland, Washington.

19. Gee, G. W., R. R. Kirkham, J. L. Downs, and M. D. Campbell. 1989. The Field Lysimeter Test Facility (FLTF) at the Hanford Site: Installation and Initial Tests. PNL-6810, Pacific Northwest Laboratory, Richland, Washington.

20. Gee, G. W., M. D. Campbell, H. D. Freeman, and J. F. Cline. 1989. Assessment of Cover Systems at the Grand Junction, Colorado, Uranium Mill Tailings Pile: 1987 Field Measurements. PNL6762, Pacific Northwest Laboratory, Richland, Washington.

21. Petersen, K. L. 1989. The Long-Term Climate Change Assessment Task of the Hanford Site, Washington Protective Barrier Development Program. WHC-SA-0537-FP, Westinghouse Hanford Company, Richland, Washington.

22. Cadwell, L. L., L. E. Eberhardt, and M. A. Simmons. 1989. Animal Intrusion Studies for Protective Barriers: Status Report for FY 1988. PNL-6869, Pacific Northwest Laboratory, Richland, Washington.

23. Freeman, H. D., G. W. Gee, and J. F. Relyea. 1989. Field Study Plan for Alternate Barriers. PNL-6840, Pacific Northwest Laboratory, Richland, Washington.

24. Freeman, H. D., and G. W. Gee. 1989. Hanford Protective Barriers Program Asphalt Barrier Studies - FY 1988. PNL-6874, Pacific Northwest Laboratory, Richland, Washington. 
25. Waugh, W. J. 1989. Gravel Admix, Vegetation and Soil Water Interactions in Protective Barriers Experimental Design, Construction and Initial Conditions. PNL-6616, Pacific Northwest Laboratory, Richland, Washington.

26. Freeman, H. D., and G. W. Gee. 1989. Hanford Protective Barriers Program: Status of Asphalt Barrier Study - FY 1989. PNL-7513, Pacific Northwest Laboratory, Richland, Washington.

27. Link, S. O., and W. J. Waugh. 1989. Evapotranspiration Studies for Protective Barriers: Experimental Plans. PNL-6899, Pacific Northwest Laboratory, Richland, Washington.

28. Petersen, K. L. 1990. "The Long-Term Climate Change Assessment Task of the Protective Barrier Development Program for Low-Level Waste Site Remediation at the Hanford Site, Washington." In High Level Radioactive Waste Management. Vol 2, pp. 1235-1239. Proceeding of an International Topical Meeting. American Nuclear Society, La Grange Park, Illinois. WHC-SA0808-FP, Westinghouse Hanford Company, Richland, Washington.

29. Fayer, M. J. 1990. Test Plan for Hydrologic Modeling of Protective Barriers. PNL-7152, Pacific Northwest Laboratory, Richland, Washington.

30. Wing, N. R., and G. W. Gee (eds.). 1990. Hanford Site Protective Barrier Development Program: Fiscal Year 1989 Highlights. WHC-EP-0318, Westinghouse Hanford Company, Richland, Washington.

31. Campbell, M. D., G. W. Gee, M. J. Kanyid, and M. L. Rockhold. 1990. Field Lysimeter Test Facility: Second Year (FY 1989) Test Results. PNL-7209, Pacific Northwest Laboratory, Richland, Washington.

32. Landeen, D. S., L. L. Cadwell, L. E. Eberhardt, R. E. Fitzner, and M. A. Simmons. 1990. Animal Intrusion Field Test Plan. WHC-EP-0253, Westinghouse Hanford Company, Richland, Washington.

33. Link, S. O., M. E. Thiede, R. D. Evans, J. L. Downs, and W. J. Waugh. 1990. Evapotranspiration Studies for Protective Barriers: FY 1988 Status Report. PNL-6985, Pacific Northwest Laboratory, Richland, Washington.

34. Relyea, J. F., M. R. Sackschewsky, and W. J. Waugh. 1989. Small-Tube Lysimeter Facility Status Report for Fiscal Year 1989. WHC-EP-0297, Westinghouse Hanford Company, Richland, Washington.

35. Walters, W. H., K. A. Hoover, and L. L. Cadwell. 1990. Project Test Plan for Runoff and Erosion on Fine-Soil Barrier Surfaces and Rock-Covered Side Slopes. PNL-6791, Pacific Northwest Laboratory, Richland, Washington.

36. Hoover, K. A., L. L. Cadwell, and W. H. Walters. 1990. Hanford Protective Barriers Program: Water Erosion Studies - FY 1989. PNL-7214, Pacific Northwest Laboratory, Richland, Washington. 
37. Landeen, D. S. 1990. Animal Intrusion Status Report for Fiscal Year 1989. WHC-EP-0299, Westinghouse Hanford Company, Richland, Washington.

38. Ligotke, M. W., and D. C. Klopfer. 1990. Soil Erosion Rates from Mixed Soil and Gravel Surfaces in a Wind Tunnel. PNL-7435, Pacific Northwest Laboratory, Richland, Washington.

39. Waugh, W. J., M. E. Thiede, C. J. Kemp, L. L. Cadwell, and S. O. Link. 1990. Field Study of Gravel Admix, Vegetation, and Soil Water Interactions: Protective Barrier Program Status Report - FY 1989. PNL-7440, Pacific Northwest Laboratory, Richland, Washington.

40. Hunter, C. R., A. J. Busacca, and W. J. Waugh. 1990. A Feasibility Study of Modeling Pedogenic Carbonates in Soils and Sediments at the U.S. Department of Energy's Hanford Site. PNL-7413, Pacific Northwest Laboratory, Richland, Washington.

41. Wing, N. R., and G. W. Gee. 1990. "Protective Barrier Development: Overview." In Proceedings of the Twenty-Eighth Hanford Symposium on Health and the Environment, Environmental Monitoring, Restoration, and Assessment: What Have We Learned?, pp. 147-151, RH Gray (ed.), Pacific Northwest Laboratory, Richland, Washington. WHC-SA-0619 FP, Westinghouse Hanford Company, Richland, Washington.

42. Wing, N. R., and G. W. Gee. 1990. "Protective Barrier Development: Overview." In Proceedings of the International Topical Meeting on Nuclear and Hazardous Waste Management Spectrum '90, pp. 335-337. American Nuclear Society, Inc., La Grange Park, Illinois. WHC-EP0380, Westinghouse Hanford Company, Richland, Washington.

43. Glantz, C. S., M. N. Schwartz, K. W. Burk, R. B. Kaspar, M. W. Ligotke, and D. J. Perrault. 1990. Climatological Summary of Wind and Temperature Data for the Hanford Meteorology Monitoring Network. PNL-7471, Pacific Northwest Laboratory, Richland, Washington.

44. Campbell, M. D., and G. W. Gee. 1990. Field Lysimeter Test Facility: Protective Barrier Test Results (FY 1990, The Third Year). PNL-7558, Pacific Northwest Laboratory, Richland, Washington.

45. Sackschewsky, M. R., J. C. Chatters, S. O. Link, and C. A. Brandt. 1991. Protective Barrier Program: Test Plan for Plant Community Dynamics. WHC-EP-0380. Westinghouse Hanford Company, Richland, Washington.

46. Nichols, W. E. 1991. Comparative Simulations of a Two-Layer Landfill Barrier Using the Help Version 2.0 and UNSAT-H Version 2.0 Computer Codes. PNL-7583, Pacific Northwest Laboratory, Richland, Washington.

47. Landeen, D. S. 1991. Animal Intrusion Status Report for Fiscal Year 1990. WHC-EP-0398, Westinghouse Hanford Company, Richland, Washington. 
48. Campbell, M. D., G. W. Gee, R. R. Kirkham, S. J. Phillips, and N. R. Wing. 1991. "Water Balance Lysimetry at a Nuclear Waste Site." in Proceedings of the International Symposium on Lysimetry, pp. 125-134, RG Allen (ed.), American Society of Civil Engineers, New York.

49. Kirkham, R. R., M. L. Rockhold, G. W. Gee, M. J. Fayer, M. D. Campbell, and L. J. Fritschen. 1991. "Lysimeters: Data acquisition and analysis." In Proceedings of the International Symposium on Lysimetry, pp. 362-370, RG Allen (ed.), American Society of Civil Engineers, New York.

50. Phillips, S. J., J. F. Relyea, C. J. Kemp, N. R. Wing, M. D. Campbell, G. W. Gee, M. J. Graham, R. R. Kirkham, and M. S. Rubin. 1991. "Development of Hanford Site Lysimeter Facilities." In Proceedings of the International Symposium on Lysimetry, pp. 19-27, RG Allen (ed.), American Society of Civil Engineers, New York.

51. Waugh, W. J., M. E. Thiede, L. L. Cadwell, G. W. Gee, H. D. Freeman, M. R. Sackschewsky, and J. F. Relyea. 1991. "Small Lysimeters for Documenting Arid Site Water Balance." In

Proceedings of the International Symposium on Lysimetry, pp. 151-159, RG Allen (ed.), American Society of Civil Engineers, New York.

52. Cadwell, L. L. (ed.). 1991. Hanford Site Protective Barrier Development Program: Fiscal Year 1990 Highlights. PNL-7831, Pacific Northwest Laboratory, Richland, Washington.

53. Petersen, K. L. 1991. Modern and Pleistocene Climatic Patterns in the West. WHC-EP-0523, Westinghouse Hanford Company, Richland, Washington.

54. Chatters, J. C., and H. A. Gard. 1991. Archaeological Mounds as Analogs of Engineered Covers for Waste Disposal Sites Literature Review and Progress Report. PNL-7718, Pacific Northwest Laboratory, Richland, Washington.

55. Sackschewsky, M. R., C. J. Kemp, L. L. Cadwell, M. E. Thiede, and W. J. Waugh. 1991. Status Report for the Small-Tube Lysimeter Facility Fiscal Year 1990. WHC-EP-0381, Westinghouse Hanford Company, Richland, Washington.

56. Fayer, M. J., M. L. Rockhold, and D. J. Holford. 1992. Model Assessment of Protective Barriers: Part III Status of FY 1990 Work. PNL-7975, Pacific Northwest Laboratory, Richland, Washington.

57. Petersen, K. L. 1992. A Warm and Wet Little Climate Optimum and a Cold and Dry Little Ice Age in the Southern Rocky Mountains, U.S.A. WHC-SA-1382-FP. Westinghouse Hanford Company, Richland, Washington.

58. Link, S. O., J. L. Downs, M. E. Thiede, D. J. Lettau, T. R. Twaddell, and R. A. Black. 1992. Evapotranspiration Studies for Protective Barriers: FY 1990 Status Report. PNL-8032, Pacific Northwest Laboratory, Richland, Washington. 
59. Link, S. O., M. E. Thiede, J. L. Downs, D. J. Lettau, and W. J. Waugh. 1992. "Evapotranspiration Studies for Protective Barriers: FY 1989 Status Report.” PNL-8033, Pacific Northwest Laboratory, Richland, Washington.

60. Fayer, M. J., M. L. Rockhold, and M. D. Campbell. 1992. "Hydrologic Modeling of Protective Barriers: Comparison of Field Data and Simulation Results.” Soil Sci. Soc. Am. J., 56:690-700.

61. Wing, N. R. 1992. A Peer Review of the Hanford Site Permanent Isolation Surface Barrier Development Program. WHC-MR-0392. Westinghouse Hanford Company, Richland, Washington.

62. Gee, G. W., M. J. Fayer, M. L. Rockhold, and M. D. Campbell. 1992. "Variations in Recharge at the Hanford Site." Northwest Sci., 66:237-250.

63. Gee, G. W., M. D. Campbell, G. S. Campbell, and J. H. Campbell. 1992. "Rapid Measurement of Low Soil Water Potentials Using a Water Activity Meter.” Soil Sci. Soc. Am. J., 56:1068-1070.

64. Ligotke, M. W. 1993. Soil Erosion Rates Caused by Wind and Saltating Sand Stresses in a Wind Tunnel. PNL-8478, Pacific Northwest Laboratory, Richland, Washington.

65. Fayer, M. J. 1993. Model Assessment of Protective Barriers: Part IV, Status of FY 1992 Work. PNL-8498, Pacific Northwest Laboratory, Richland, Washington.

66. Wing, N. R., and G. W. Gee. 1993. "The Development of Permanent Isolation Surface Barriers: Hanford Site, Richland, Washington, U.S.A.” in Proceedings of Geoconfine '93, pp. 357-362. June 8-11, 1993, Montpellier, France. WHC-SA-1799-FP, Westinghouse Hanford Company, Richland, Washington.

67. Petersen, K. L., J. C. Chatters, and W. J. Waugh. 1993. Long-Term Climate Change Assessment Study Plan for the Hanford Site Permanent Isolation Barrier Development Program. WHC-EP0569 Rev. 1, Westinghouse Hanford Company, Richland, Washington.

68. Wing, N. R. 1993. The Results of Laboratory Test to Determine the Physical Properties of Various Barrier Construction Materials. WHC-SD-ER-DP-006, Westinghouse Hanford Company, Richland, Washington.

69. Gee, G. W., L. L. Cadwell, H. D. Freeman, M. W. Ligotke, S. O. Link, R. A. Romine, and W. H. Walters, Jr. 1993. Testing and Monitoring Plan for the Permanent Isolation Surface Barrier Prototype. PNL-8391, Pacific Northwest Laboratory, Richland, Washington.

70. Cadwell, L. L., S. O. Link, and G. W. Gee. 1993. Hanford Site Permanent Isolation Surface Barrier Development Program: Fiscal Year 1992 and 1993 Highlights. PNL-8741, Pacific Northwest Laboratory, Richland, Washington. 
71. Link, S. O., R. N. Kickert, M. J. Fayer, and G. W. Gee. 1993. A Comparison of Simulation Models for Predicting Soil Water Dynamics in Bare and Vegetated Lysimeters. PNL-8675, Pacific Northwest Laboratory, Richland, Washington.

72. Sackschewsky, M. R., C. J. Kemp, and L. L. Cadwell. 1993. Status Report for the Small-Tube Lysimeter Facility Fiscal Year 1992. WHC-EP-0597, Westinghouse Hanford Company, Richland, Washington.

73. Petersen, K. L., and J. C. Chatters. 1993. Long-Term Climate Change Assessment Task for the Hanford Site Permanent Isolation Barrier Development Program: Status through FY 1992. WHC-EP-0644, Westinghouse Hanford Company, Richland, Washington.

74. Chamness, M. 1993. An Investigation of Bergmounds as Analogs to Erosion Control Factors on Protective Barriers. PNL-8841, Pacific Northwest Laboratory, Richland, Washington.

75. Bjornstad, B. N., and S. S. Teel. 1993. Natural Analog Study of Engineered Protective Barriers at the Hanford Site. PNL-8840, Pacific Northwest Laboratory, Richland, Washington.

76. U.S. Department of Energy (DOE). 1993. Treatability Test Plan for the 200-BP-1 Prototype Surface Barrier. DOE/RL-93-27, Department of Energy, Richland, Washington.

77. Gee, G. W., D. Felmy, J. C. Ritter, R. R. Kirkham, S. O. Link, J. L. Downs, and M. J. Fayer. 1993. Field Lysimeter Test Facility: Status Report IV. PNL-8911, Pacific Northwest Laboratory, Richland, Washington.

78. Gaylord, D. R., L. D. Stetler, G. D. Smith, and R. W. Mars. 1993. Summary of 1990 Eolian Characterization Studies, Hanford Site, Washington. PNL-8862, Pacific Northwest Laboratory, Richland, Washington.

79. Wing, N. R. 1993. Permanent Isolation Surface Barrier: Functional Performance. WHC-EP0650, Westinghouse Hanford Company, Richland, Washington.

80. Gilmore, B. G., and W. H. Walters. 1993. Water Erosion Field Tests for Hanford Protective Barriers: FY 1992 Status Report. PNL-8949, Pacific Northwest Laboratory, Richland, Washington.

81. Kirkham, R. R. 1993. Comparison of Surface Energy Fluxes with Satellite-Derived Surface Energy Flux Estimates from a Shrub-Steppe. PNL-9003, Pacific Northwest Laboratory, Richland, Washington.

82. U.S. Department of Energy (DOE) 1993. Report on Value Engineering Study of Permanent Isolation Surface Barrier and Warning Marker System Development Plan at the Hanford Site. DOE/RL/12074--8, Department of Energy, Richland, Washington.

83. Wing, N. R. 1994. Permanent Isolation Surface Barrier Development Plan. WHC-EP-0673, Westinghouse Hanford Company, Richland, Washington. 
84. Waugh, W. J., J. C. Chatters, G. V. Last, B. N. Bjornstad, S. O. Link, and C. R. Hunter. 1994. Barrier Analogs: Long-Term Performance Issues, Preliminary Studies, and Recommendations. PNL-9004, Pacific Northwest Laboratory, Richland, Washington.

85. Link, S. O., L. L. Cadwell, C. A. Brandt, J. L. Downs, R. E. Rossi, and G. W. Gee. 1994. Biointrusion Test Plan for the Permanent Isolation Surface Barrier Prototype. PNL-9411, Pacific Northwest Laboratory, Richland, Washington.

86. Kirkham, R. R., and G. W. Gee. 1994. Experimental Plan and Construction Guidance for Hanford Protective Barrier Test at Hill AFB, Utah. PNL-9412, Pacific Northwest Laboratory, Richland, Washington.

87. Freeman, H. D., and R. A. Romine. 1994. Hanford Permanent Isolation Barrier Program: Asphalt Technology Test Plan. PNL-9336, Pacific Northwest Laboratory, Richland, Washington.

88. Link, S. O., W. J. Waugh, J. L. Downs, M. E. Thiede, J. C. Chatters, and G. W. Gee. 1994. "Effects of Coppice Dune Topography and Vegetation on Soil Water Dynamics in a Cold-Desert Ecosystem." J. Arid Environ. 27:265-278.

89. Waugh, W. J., M. E. Thiede, D. J. Bates, L. L. Cadwell, G. W. Gee, and C. J. Kemp. 1994. "Plant Cover and Water Balance in Gravel Admixtures at an Arid Waste-Burial Site." J. Environ. Qual. 23:676-685.

90. Landeen, D. S. 1994. The Influence of Small Mammal Burrowing Activity on Water Storage at the Hanford Site. WHC-EP-0730, Westinghouse Hanford Company, Richland, Washington.

91. U.S. Department of Energy. 1994. Constructability Report for the 200-BP-1 Prototype Surface Barrier. DOE/RL-94-76, U.S. Department of Energy, Richland Operations Office, Richland, Washington.

92. Myers, D. R., and D. A. Duranceau (eds.). 1994. Prototype Hanford Surface Barrier: Design Basis Document." BHI-00007, Bechtel Hanford, Inc., Richland, Washington.

93. Wing, N. R., and G. W. Gee. 1994. "Quest for the Perfect Cap.” Civil Engineering 64(10):38-41.

94. Gee, G. W., and N. R. Wing (eds.). 1994. In-Situ Remediation: Scientific Basis for Current and Future Technologies, Parts 1-2. Thirty-Third Hanford Symposium on Health and the Environment. November 7-11, 1994, Pasco, Washington. Battelle Press, Columbus, Ohio.

95. Wing, N. R., and G. W. Gee. 1994. "The Development of Surface Barriers at the Hanford Site." In G. W. Gee and N. R. Wing (eds.) pp. 427-440. In-Situ Remediation: Scientific Basis for Current and Future Technologies, Parts 1-2. Thirty-Third Hanford Symposium on Health and the Environment. November 7-11, 1994, Pasco, Washington. Battelle Press, Columbus, Ohio. 
96. Waugh, W. J., K. L. Petersen, S. O. Link, B. N. Bjornstad, and G. W. Gee. 1994. "Natural Analogs of the Long-Term Performance of Engineered Covers." In G. W. Gee and N. R. Wing (eds.) pp. 379-410. In-Situ Remediation: Scientific Basis for Current and Future Technologies, Parts 1-2. Thirty-Third Hanford Symposium on Health and the Environment. November 7-11, 1994, Pasco, Washington. Battelle Press, Columbus, Ohio.

97. Freeman, H. D., and R. A. Romine. 1994. "Hanford Permanent Isolation Barrier Program: Asphalt Technology Development." In G. W. Gee and N. R. Wing (eds.) pp. 491-506. In-Situ Remediation: Scientific Basis for Current and Future Technologies, Parts 1-2. Thirty-Third Hanford Symposium on Health and the Environment. November 7-11, 1994, Pasco, Washington. Battelle Press, Columbus, Ohio.

98. Gilmore, B. G., and W. H. Walters. 1994. "Summary of Method Develop a Representative Equation for Soil Loss from the Hanford Permanent Isolation Barrier." In G. W. Gee and N. R. Wing (eds.) pp. 507-522. In-Situ Remediation: Scientific Basis for Current and Future Technologies, Parts 1-2. Thirty-Third Hanford Symposium on Health and the Environment. November 7-11, 1994, Pasco, Washington. Battelle Press, Columbus, Ohio.

99. Landeen, D. S. 1994. "The Influence of Small-Mammal Burrowing Activity on Water Storage at the Hanford Site." In G. W. Gee and N. R. Wing (eds.) pp. 523-544. In-Situ Remediation: Scientific Basis for Current and Future Technologies, Parts 1-2. Thirty-Third Hanford Symposium on Health and the Environment. November 7-11, 1994, Pasco, Washington. Battelle Press, Columbus, Ohio.

100. Ligotke, M. W. 1994. "Control of Eolian Soil Erosion from Waste-Site Surface Barriers." In G. W. Gee and N. R. Wing (eds.) pp. 545-560. In-Situ Remediation: Scientific Basis for Current and Future Technologies, Parts 1-2. Thirty-Third Hanford Symposium on Health and the Environment. November 7-11, 1994, Pasco, Washington. Battelle Press, Columbus, Ohio.

101. Link, S. O., W. J. Waugh, and J. L. Downs. 1994. "The Role of Plants in Isolation Barrier Systems." In G. W. Gee and N. R. Wing (eds.) pp. 561-592. In-Situ Remediation: Scientific Basis for Current and Future Technologies, Parts 1-2. Thirty-Third Hanford Symposium on Health and the Environment. November 7-11, 1994, Pasco, Washington. Battelle Press, Columbus, Ohio.

102. Myers, D. R., and N. R. Wing. 1994. "Hanford Site Protective Isolation Surface Barrier: Taking Research and Development to Engineered Application.” In G. W. Gee and N. R. Wing (eds.) pp. 613-624. In-Situ Remediation: Scientific Basis for Current and Future Technologies, Parts 12. Thirty-Third Hanford Symposium on Health and the Environment. November 7-11, 1994, Pasco, Washington. Battelle Press, Columbus, Ohio.

103. Petersen, K. L. 1994. "The Long-Term Climate Change Task of the Hanford Permanent Isolation Barrier Development Program.” In G. W. Gee and N. R. Wing (eds.) pp. 633-648. In-Situ Remediation: Scientific Basis for Current and Future Technologies, Parts 1-2. Thirty-Third Hanford Symposium on Health and the Environment. November 7-11, 1994, Pasco, Washington. Battelle Press, Columbus, Ohio. 
104. Gee, G. W., H. D. Freeman, W. H. Walters, M. W. Ligotke, M. D. Campbell, A. L. Ward, S. O. Link, S. K. Smith, B. G. Gilmore, and R. A. Romine. 1994. Hanford Prototype Surface Barrier Status Report: FY 1994. PNL-10275, Pacific Northwest Laboratory, Richland, Washington.

105. Gaylord, D. R., and L. D. Stetler. 1994. "Aeolian-Climate Thresholds and Sand Dunes at the Hanford Site, South-Central Washington, U.S.A.” J. Arid Environments 28:95-116.

106. Freeman, H. D., R. A. Romine, and A. H. Zacher. 1994. Hanford Permanent Isolation Barrier Program: Asphalt Technology Data and Status Report - FY 1994. PNL-10194, Pacific Northwest Laboratory, Richland, Washington.

107. Wing, N. R., G. W. Gee, and J. W. Bammann. 1995. "Program Management of a Multi-Year Technology Development Effort." PM Network 9(3):47-50.

108. Sackschewsky, M. R., C. J. Kemp, S. O. Link, and W. J. Waugh. 1995. "Soil Water Balance Changes in Engineered Soil Surfaces." J. Environ. Qual. 24:352-359.

109. Rockhold, M. L., M. J. Fayer, C. T. Kincaid, and G. W. Gee. 1995. Estimation of Natural Ground Water Recharge for the Performance Assessment of a Low-Level Waste Disposal Facility at the Hanford Site. PNL-10508, Pacific Northwest Laboratory, Richland, Washington.

110. Link, S. O., M. E. Thiede, R. D. Evans, J. L. Downs, and G. W. Gee. 1995. "Responses of Big Sagebrush and Spiny Hopsage to Increasing Water Stress.” In B. A. Roundy, E. D. McArthur, J. S. Haley, and D. K. Mann (eds.). In Proceedings of the Wildland Shrub and Arid Land Restoration Symposium, pp. 196-201. USDA-FS, Intermountain Research Station, Ogden, Utah.

111. Wing, N. R., F. M. Corpuz, K. L. Petersen, and A. M. Tallman. 1995. Physical Stability of LongTerm Surface Barriers-Assessment of Potentially Disruptive Natural Events. BHI-00145, Bechtel Hanford, Inc., Richland, Washington.

112. Wing, N. R., K. L. Petersen, C. Whitlock, R. L. Burk. 1995. Long-Term Climate Change Effects Task for the Hanford Site Permanent Isolation Barrier Development Program: Final Report. BHI-00144, Bechtel Hanford, Inc., Richland, Washington.

113. Duranceau, D. A. 1995. Site Evaluation Report for Candidate Basalt Quarry Sites. BHI-00005, Bechtel Hanford, Inc., Richland, Washington.

114. Fayer, M. J., and C. S. Simmons. 1995. "Modified Soil Water Retention Functions for All Matric Suctions." Water Resour. Res. 31:1233-1238.

115. Petersen, K. L., S. O. Link, and G. W. Gee. 1995. Hanford Site Long-Term Surface Barrier Development Program: Fiscal Year 1994 Highlights. PNL-10605, Pacific Northwest Laboratory, Richland, Washington.

116. Link, S. O., N. R. Wing, and G. W. Gee. 1995. "The Development of Permanent Isolation Barriers for Buried Wastes in Cold Deserts: Hanford, Washington.” J. Arid Land Studies 4:215-224. 
117. Link, S. O., L. L. Cadwell, K. L. Petersen, M. R. Sackshewsky, and D. S. Landeen. 1995. The Role of Plants and Animals in Isolation Barriers at Hanford, Washington. PNL-10788. Pacific Northwest National Laboratory, Richland, Washington.

118. Gee, G. W., A. L. Ward, B. G. Gilmore, M. W. Ligotke, and S. O. Link. 1995. Hanford Prototype-Barrier Status Report: FY 1995. PNL-10872. Pacific Northwest National Laboratory, Richland, Washington.

119. Gee, G. W., A. L. Ward, B. G. Gilmore, S. O. Link, G. W. Dennis, and T. K. O’Neil. 1996. Hanford Prototype-Barrier Status Report: FY 1996. PNNL-11367. Pacific Northwest National Laboratory, Richland, Washington.

120. U.S. Department of Energy (DOE). 1996. Focused Feasibility Study of Engineered Barriers for Waste Management Units in the 200 Areas. DOE/RL-93-33. Bechtel Hanford, Inc., Richland, Washington.

121. Ward, A. L., and G. W. Gee. 1997. "Performance Evaluation of a Field-Scale Surface Barrier." J. Environ. Qual. 26:694-705.

122. Gee, G. W., N. R. Wing, and A. L. Ward. 1997. "Development and Testing of Permanent Isolation Surface Barriers at the Hanford Site.” pp. D3-D22. In Barrier Technologies for Environmental Management. National Academy Press, Washington, D.C.

123. Gee, G. W., and A. L. Ward, 1997. "Still in Quest of the Perfect Cap." pp.145-164. In T. D. Reynolds and R. C. Morris (eds.). Landfill Capping in the Semi-Arid West,-Conference Proceedings. Jackson Lake, Wyoming, May, 1997, Environmental Science and Research Foundation, Idaho Falls, Idaho.

124. Fayer, M. J., and G. W. Gee. 1997. "Hydrologic Model Tests for Landfill Covers Using Field Data." pp.53-68. In T. D. Reynolds and R. C. Morris (eds.). Landfill Capping in the Semi-Arid West,-Conference Proceedings. Jackson Lake, Wyoming, May, 1997, Environmental Science and Research Foundation, Idaho Falls, Idaho.

125. Gee, G. W., A. L. Ward, and M. J. Fayer. 1997. "Surface Barrier Research at the Hanford Site." Land Contamination and Reclamation. 5(3):233-237.

126. Ward, A. L., G. W. Gee, and S. O. Link. 1997. Hanford Prototype-Barrier Status Report: FY 1997. PNNL-11789. Pacific Northwest National Laboratory, Richland, Washington.

127. Gee, G. W., A. L. Ward, and R. R. Kirkham. 1997. "Long-term Performance of Surface Covers Estimated with Short-term Testing." pp. 67-81. CONF-980652. Conference Proceedings of the Long-Term Stewardship Workshop. U.S. Department of Energy, Grand Junction, Colorado.

128. U.S. Department of Energy (DOE). 1999. 200-BP-1 Prototype Barrier Treatability Test Report. DOE/RL-99-11. U.S. Department of Energy, Richland, Washington. 
129. Ward, A. L., and G. W. Gee. 2000. "Hanford Site Surface Barrier Technology." pp. 1415-1423.

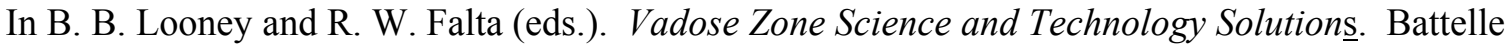
Press, Columbus, Ohio.

130. Gee, G. W., and A. L. Ward. 2000. Comment on paper 19209-HZ Moisture accumulating under asphalt cover at radioactive waste-burial site. J. Haz. and Toxic and Rad. Waste Mgt. 4(1):40-41.

131. Miller, C. W., and C. D. Wittreich. 2001. Alternative Fine-Grained Soil Borrow Source Study Work Plan. BHI-01478. Bechtel Hanford, Inc., Richland, Washington.

132. Galgoul, M. J., and C. Sump. 2002. Alternative Fine-Grained Soil Borrow Source Study Final Report. BHI-01551. Rev. 0. Bechtel Hanford, Inc. Richland, Washington.

133. Gee, G.W., A.L. Ward and C.D. Wittreich. 2002. The Hanford Site 1000-Year Cap Design Test. PNNL 14143, Pacific Northwest National Laboratory, Richland, Washington.

134. Wittreich, C. D., J. K. Linville, G. W. Gee, and A. L. Ward. 2003. 200-BP-1 Prototype Hanford Barrier Annual Monitoring Report for Fiscal Year 2002. CP-14873. Rev. 0. Flour Hanford, Richland, Washington. 


\section{Distribution}

No. of

Copies

\section{ONSITE}

2 DOE Office of River Protection

R. M. Yasek

R. W. Lober

9 DOE Richland Operations Office

B. L. Charboneau A6-33

B. L. Foley A6-38

J. P. Hanson A5-13

R. D. Hildebrand A6-38

J. G. Morse A6-38

K. M. Thompson A6-38

S. H. Wisness A3-04

DOE Public Reading Room (2) H2-53

5 Bechtel Hanford Inc.

P. G. Doctor

H9-01

K. R. Fecht

K. A. Gano

J. K. Linville

S. G. Weiss

9 CH2M HILL Hanford Group, Inc.
F. J. Anderson
A. J. Knepp
M. N. Jarayssi
F. M. Mann
W. J. McMahon
C. W. Miller
D. A. Myers
C. D. Wittreich
M. I. Wood

E6-35

H6-03

H6-03

E6-35

E6-35

H6-62

E6-35

H6-62

H8-44

\section{Fluor Federal Services}

R. Khaleel

R. J. Puigh
No. of

Copies

8 Fluor Hanford, Inc.

J. V. Borghese

E6-35

F. M. Coony

B. H. Ford

T. W. Fogwell

E6-35

R. Jackson

E6-35

V. J. Rohay

E6-35

L. C. Swanson

E6-35

E6-35

E6-35

M. E. Todd-Robertson

E6-35

Stoller

R. G. McCain

B2-62

51 Pacific Northwest National Laboratory

R. L. Aaberg

K3-54

C. Arimescu

K6-04

M. P. Bergeron

K9-36

B. N. Bjornstad

K6-81

R. W. Bryce

E6-35

A. L. Bunn

K6-85

K. J. Cantrell

K6-81

Y. J. Chien

K6-81

W. J. Deutsch

K6-81

R. L. Dirkes

K6-75

J. L. Downs

K6-85

D. W. Engle

K5-12

P. W. Eslinger

K6-04

M. J. Fayer

K9-33

E. J. Freeman

K9-36

M. D. Freshley

K9-33

G. W. Gee

K9-33

T. J. Gilmore

K6-81

D. G. Horton

K6-81

C. T. Kincaid

K9-33

G. V. Last (5)

K6-81

C. A. LoPresti

K5-12

W. J. Martin

K6-81

T. B. Miley

K6-04

C. J. Murray

K6-81 
No. of

Copies

B. A. Napier

W. E. Nichols

G. W. Patton

J. V. Ramsdell, Jr.

S. P. Reidel

M. C. Richmond

R. G. Riley

M. L. Rockhold

R. J. Serne
No. of

Copies

K3-54

K9-33

K6-75

K3-54

K6-81

K9-33

K6-96

K9-36

P7-22
D. L. Strenge

M. B. Triplett

P. D. Thorne (5)

A. L. Ward

M. D. White

M. D. Williams

S. K. Wurstner

S. B. Yabusaki

Hanford Technical Library (2)
K3-54

K6-04

K9-33

K9-33

K9-36

K9-36

K9-36

K9-36

$\mathrm{H} 2-53$

Distr.2 